\title{
Translocal Modes of Belonging
}

\section{Diasporic Identity and Digital Media}

\author{
Amongst \\ Migrant Women in London
}

Melis Mevsimler 


\title{
Translocal Modes of Belonging
}

Diasporic Identity and Digital Media Amongst Migrant Women in London

\section{Translokale Vormen van Verbondenheid}

\section{Diaspora Identiteit en Digitale Media Onder Migrantenvrouwen in Londen}

(met een samenvatting in het Nederlands)

\section{PROEFSCHRIFT}

ter verkrijging van de graad van doctor aan de

Universiteit Utrecht op gezag van de rector magnificus,

prof. dr. H.R.B.M. Kummeling,

ingevolge het besluit van het college voor promoties in het openbaar te verdedigen op

WOENSDAG 21 APRIL 2021

DES OCHTENDS TE 10.30 UUR

door

\author{
Melis Mevsimler \\ geboren op 29 maart 1992 \\ te Nicosia, Cyprus
}


Promotoren: Prof. dr. S. Ponzanesi

Prof. dr. M. Georgiou

Copromotor: Dr. K. Leurs 


\section{Table of Contents}

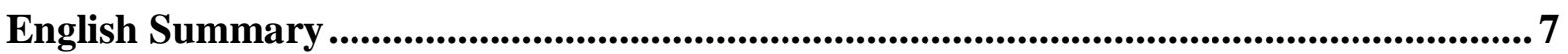

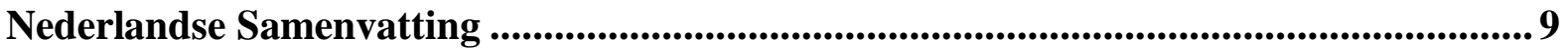

Acknowledgements.................................................................................................................. 11

Introduction......................................................................................................................................... 13

The Overarching Research Question............................................................................. 17

Media Research on Diaspora and Migration............................................................... 17

The Place: London as a "Global City" ......................................................................... 20

The People: Who Is This Thesis About? ........................................................................ 21

At the Crossroads of Urban and Digital Spaces: The Notion of "Translocality" ........ 23

Organisation of the Thesis................................................................................................ 27

Chapter 1: Theoretical Foundations .......................................................................................... 31

1.1 Digital Media Research on Diaspora and Migration: A Non-media-centric Approach .................................................................................................................. 32

1.2 The City, Everyday Conviviality, and Cosmopolitanism .................................. 36

1.3 Examining the City from Below: An Analysis of Everyday Life ...................... 42

1.4 Diaspora, Gender, and Cultural Identity.......................................................... 47

1.5 The Mediation of "Cultural Identity" in the Age of Digital Media .................. 51

1.6 Sub-research Questions .................................................................................... 55

Chapter 2: Methodology ...........................................................................................58

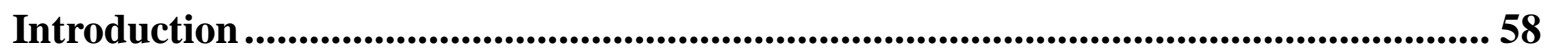

2.1 "Multi-sited" Media Ethnography ...............................................................61

2.1.1 Participant Recruitment ......................................................................................... 65

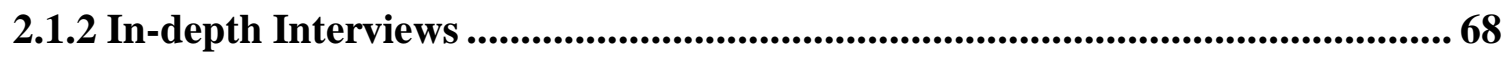

2.1.3 Observation ............................................................................................ 71

2.2 Digital Ethnography …....................................................................................................... 74

2.3 Online Data Collection and Visualisation ............................................................. 76

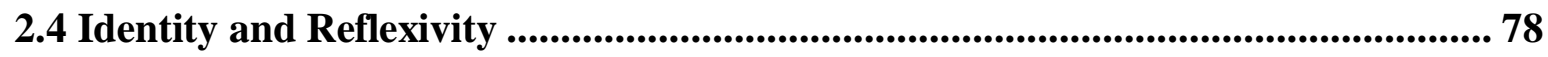

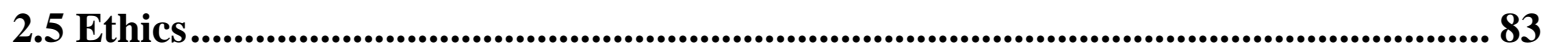

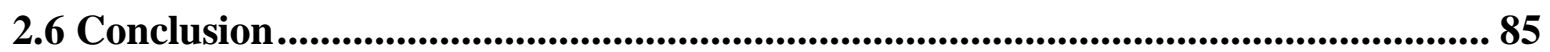

Chapter 3: Diasporic Nationalism and Digital Tactics: The Case of Turkey's Diaspora 88

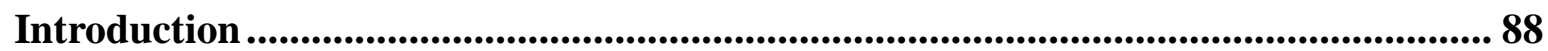

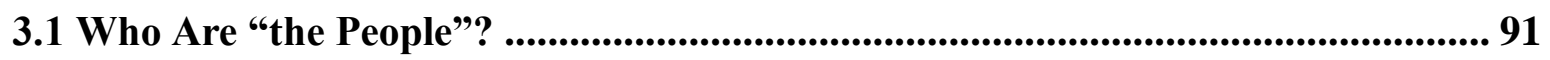


3.2 Diasporic Nationalism as a Translocal Phenomenon: Blocking and Unfriending 93

3.3 Politics, Social Class, and Exclusionary Social Networks in the City 100

3.4 Religion, Nationalism, and Cosmopolitanism: Digitally Embodied

Performances.. .106

3.5 Religion, Nationalism, and Cosmopolitanism: Super-private Online Spheres.... 114

3.5 Generation: Youth Identities and Affordances-in-practice .............................. 116

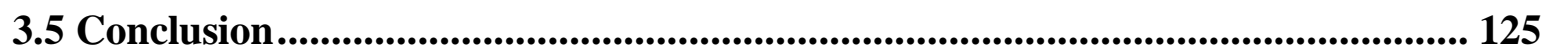

Chapter 4: Generation and Mediating the Diasporic Self: The Case of the Somali

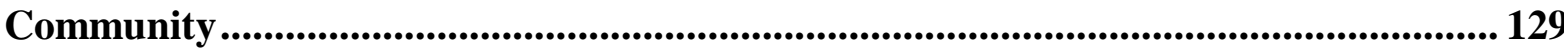

Introduction ......................................................................................................................... 129

4.1 Who Are "the People"? ......................................................................... 132

4.2 First-generation Somali Women and Diasporic Humanitarianism .................... 136

4.3 Second-generation Somali Women and Transnational Youth Culture ................ 145

4.4 Second-generation Somali Women in the City ................................................. 155

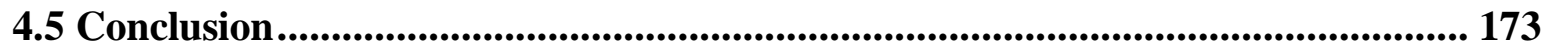

Chapter 5: Social Class and Digital Acts of Citizenship: The Case of the Romanian Community ............................................................................................................................ 177

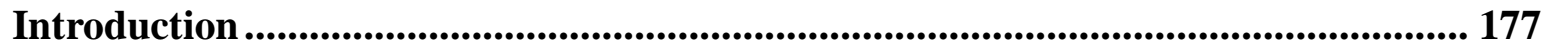

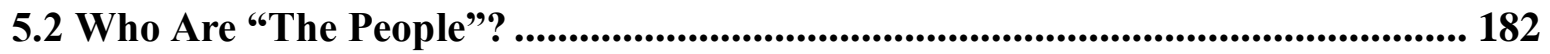

5.2 The Working Class: Cosmopolitanism and Britishness ...................................... 186

5.3 The Lower-middle Class: Neoliberal Cosmopolitanism and Whiteness .............. 194

5.4 The Middle Class: Occidental Cosmopolitanism and Europeanness................... 201

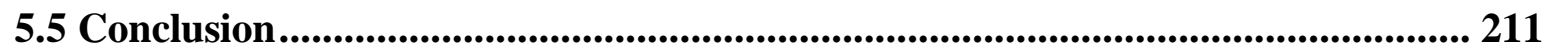

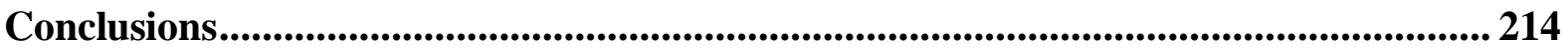

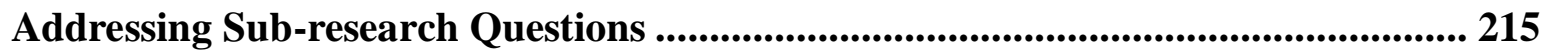

Ethnographic Return in the Field of Diaspora, Migration, and Digital Media......... 215

Cosmopolitanism, Identity, and Belonging in the City.................................................. 219

Identity, Agency, and Digital Media in the City ......................................................... 221

Intersectionality and Shifting Sites of Belonging....................................................... 223

Identity and Translocal Modes of Belonging................................................................. 225

Suggestions for Further Research ................................................................................... 228

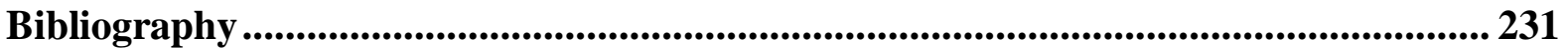

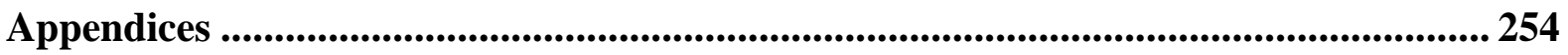

Appendix 1. Interviewees' Information (with Pseudonyms) ....................................... 254

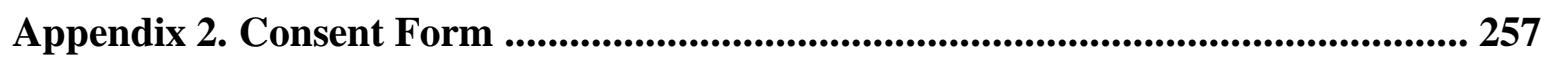


Appendix 3. Individual Semi-structured Interview Topic Guide

Appendix 4. Organisations that Helped with Participant Recruitment and Observation... 


\section{English Summary}

Over the last decade in Britain, dominant media narratives and populist representations have played a significant dual role representing migration as a crisis and reducing migrants' identities to racialised stereotypes. In response to these representational and discursive exlusions, I take a bottom-up approach by turning attention to how migrant women, as subjects of racialised and gendered marginalisation, use digital technologies for communication, representation, and recognition. Drawing upon an interdisciplinary framework that encompasses media studies, urban studies, diaspora studies, and migration studies, and by employing a rich ethnographic approach, I explore how migrant women originally from Turkey, Somalia, and Romania, now living in London, mediate their cultural identities at the intersections of urban and digital spaces. Driven by the voices and the experiences of such migrant women, my thesis contributes to the growing body of scholarly work that examines the relationships between diaspora, migration, and digital media, by further elaborating upon how the interplay of urban and technological dynamics coconstitutes gendered diasporic identities.

I argue that migrant women use digital media technologies as resources through which they position themselves and move across different spheres of belonging, simultaneously mediating their identities as urban, national, and transnational entities. Whilst identity and belonging mutually constitute a complex articulation of subjectivity, their actions of (self-) emplacement and mobility within multi-spatial geographies should be understood and contextualised in relation to the micro-politics of everyday life that materialise in the city. In line with this, I suggest that diasporic migrant women's mediation of cultural identities can be understood through the notion of translocal modes of belonging. This notion recognises how migrant women use digital media to invoke varying alliances, aesthetics, and identity performances for self-positioning and mobility in relation to the structured power geometries that exist within a multi-spatial framework.

The intervention I make in this thesis is three-fold. Empirically, I present an intersectional and contextualised account of the relationship between gendered diasporic experiences and digital technology, exploring how the interplay of ethnicity, race, religion, social class, and generation has concrete implications for the situated, everyday life-worlds of migrant women. Methodologically, I adopt a mixed-methods approach by combining 
qualitative and quantitative methodologies in order to examine diasporic cultural identity production in the context of an online-offline continuum that traverses the intersections between urban and digital spaces. In this context, I demonstrate a methodological trajectory that aims to uncover how this hybrid space - one that encompasses both material and digital streets - becomes reflexive of the gendered, racialised, religious, classed, and generational positions that migrant women adopt. Conceptually, I propose translocational modes of belonging as a means by which to understand how, on urban, national, and transnational scales, the social positionalities of migrant women vary due to shifting, complex power geometries, and how they use digital technologies to develop collective identities and relations of inclusion and exclusion accordingly in a reflexive manner. 


\section{Nederlandse Samenvatting}

In Groot-Brittannië hebben dominante mediaverhalen en populistische representaties van migranten de afgelopen tien jaar een belangrijke tweeledige rol gespeeld: Migratie wordt verbeeld als een crisis, terwijl de identiteit van migranten wordt gereduceerd tot een aantal racistische stereotypen. In deze thesis bestudeer ik de macht van de media door een bottomup benadering te hanteren. Ik richt de aandacht op de manier waarop vrouwelijke migranten - die vaak het onderwerp zijn van zowel raciale als op gender gebaseerde marginalisatie — gebruik maken van digitale technologieën voor communicatie, representatie en erkenning. Media, urbane, diaspora, en migratiestudies worden bij elkaar gebracht in mijn interdisciplinaire analysekader. Ik combineer dit kader met een grondige etnografische benadering. Ik onderzoek hoe vrouwelijke migranten die oorspronkelijk uit Turkije, Somalië en Roemenië komen en nu in Londen wonen hun culturele identiteit bemiddelen op het kruispunt van stedelijkheid en digitaliteit. Door verder uit te werken hoe het samenspel van stedelijke en technologische dynamieken inwerkt op specifieke uitdragingen van diasporische identiteiten draag ik bij aan onderzoek dat ingaat op de relatie tussen diaspora, migratie en digitale media.

Ik beargumenteer dat vrouwelijke migranten digitale praktijken inzetten om plekken te verwerven om hun stedelijke, nationale en transnationale identiteiten uit te dragen . Hoewel identiteit en het gevoel thuis te zijn in een bepaalde omgeving bijeenkomen in een complexe articulatie van subjectiviteit, moeten hun acties van (zelf)positionering en mobiliteit binnen verschillende ruimtelijke contexten begrepen en gecontextualiseerd worden in relatie tot de micropolitiek van het dagelijks leven dat zich in de stad materialiseert. Ik beargumenteer dat de manier waarop vrouwelijke migranten in de diaspora hun culturele identiteiten bemiddelen, kan worden begrepen middels de notie van translokale vormen van verbondenheid. Deze benadering erkent hoe vrouwelijke migranten digitale praktijken inzetten om vorm te geven aan zowel lokale, kosmopolitische als transnationale allianties, esthetische uitingen en identiteitspresentaties. Op deze manier eigenen zij zich plekken toe om zichzelf te positioneren in relatie tot de onevenwichtige machtsstructuren van de stad, de diaspora en online gemeenschappen.

De interventies die ik in deze thesis maak, zijn drievoudig. Gebaseerd op origineel empirisch veldwerk presenteer ik een intersectionele en gecontextualiseerde analyse van de 
wisselwerkingen tussen ervaringen van diaspora enerzijds en digitale technologie anderzijds. Op basis van feministische, intersectionele theorie onderzoek ik specifiek hoe het samenspel van etniciteit, religie en generatie concrete implicaties heeft voor de gesitueerde, alledaagse levenswereld van vrouwelijke migranten. Ten tweede hanteer ik een 'mixed-methods' benadering door kwalitatieve en kwantitatieve methodologieën te combineren in mijn onderzoek naar diasporische, culturele identiteitsvorming binnen een online-offline continuüm dat gevormd wordt op het grensvlak van stedelijke en digitale ruimtes. Dit methodologische traject is erop gericht te ontdekken hoe deze hybride (urbane-digitale) ruimte de positionering van vrouwelijke migranten kleurt, specifiek vanuit een perspectief met aandacht voor gender, etniciteit, religie en generatie. Tot slot stel ik voor om de sociale posities van vrouwelijke migranten op stedelijke, nationale en transnationale schaal te begrijpen middels het concept van translokale vormen van verbondenheid. Ik laat daarbij zien dat deze sociale posities variëren als gevolg van verschuivende, complexe machtsgeometrieën, en de manier waarop deze vrouwen op reflexieve wijze digitale technologieën gebruiken om collectieve identiteiten en relaties van inclusie en uitsluiting te ontwikkelen. 


\section{Acknowledgements}

Many thanks to my wonderful supervisors, Sandra Ponzanesi, Koen Leurs and Myria Georgiou. Sandra, thank you very much for believing in me and giving me the opportunity to be a member of the ERC Project ConnectingEurope. This was a life-changing experience! Koen, you were always there to guide me, even when I did not believe in myself. I cannot imagine getting this thesis done without your support and mentorship. Myria, I remember my first day in your class at LSE. I was very shy to speak-up because I feared that my ideas didn't matter at all. However, you are a passionate teacher who encourages her students to believe in themselves and always think beyond borders. Over the years, you nurtured my ideas and encouraged me to bring out the best of my ability. I am immensely grateful.

In Utrecht, I am so thankful to the members of the dream team: Claudia Minchilli, Donya Alinejad and Laura Candidatu. You were my main supporters over those four years. You are simply the smartest, funniest, and kindest. I cannot wait to re-unite in a Covid-free world. And, my dearest friend Zerrin Cengiz. Over the years, our nights sipping raki were the highlights of my week. Thank you for always being there for me. Additionally, thank you to my English language editors Nina and Sophie for their patience and amazing work.

In London, I would like to express my thanks to Hoden, Hayat, Veronica and Mohamed without whom I would not have been able to carry out this demanding research project. And of course, my eternal gratitude to all the women who have let me in their lives and helped me understand what it means to be an immigrant and a woman under politically difficult circumstances.

I am deeply thankful to the one and only Sergen Bahceci. Your love and support made the most difficult times of this journey much more bearable, if not easier. I cannot wait to start a new chapter in my post- $\mathrm{PhD}$ life with you.

Finally, a $\mathrm{PhD}$ would have remained a dream if it were not for the support of my wonderful family. Thank you to my aunts Senal and Yelda who have always encouraged me to dream big and work hard. Thank you to my grandmother Gokcen who has changed the fate of the women in our family with her vision and resilience. Thank you to my brother Mertkan, you are simply the best gift my parents have given to me. Above all, I am deeply grateful to my amazing parents Alsen and Muhabbet. No book could teach what you have taught me about love and resistance. Thank you for everything you have done for me. 


\section{Introduction}

no one leaves home unless

home is the mouth of a shark

you only run for the border

when you see the whole city running as well

—Warsan Shire, "Home"

"It was a moment that felt as [if] we were all going through similar experiences despite distances," one of the young British-Somali participants, Sahra said, showing me her tweets from 2016.

It was a moment like we were all together and talked about things that are very important in my opinion. We could see in her [Shire's] lines something we all share. This is what you can find on social media. It's all about experience, it's powerful to meet people when you don't even live in the same country, same continent and say "Yeah, I know what you mean, I've been there."

Sahra was talking about the time when the work of the young British-Somali poet, Warsan Shire, was picked up by American pop icon Beyoncé for her album Lemonade in 2016. Like many other diasporic Somali women, Sahra also tuned into the discussion on Twitter where Shire's poems about immigration, womanhood, and love were retweeted by thousands of followers who saw themselves reflected in the young poet's prolific lines. As Sahra states, it was a moment when young women from different parts of the world created an imaginary transnational space in which they felt connected through captions and hashtags that proved how they all had something in common. This kind of connectivity, between people situated in different locations and time zones, is something that has been a way of life for many of us who encountered migration, either as immigrants ourselves or the loved ones of immigrants - even before the introduction of the internet and social media.

Where I grew up, in Northern Cyprus, there were frequent power cuts because of the declining electric power infrastructure. During my childhood, they often caused me to miss my favourite Turkish TV series, which aired on Friday evenings. Luckily, I was not the only 
one looking forward to turning on the TV on Friday evenings. Far from Nicosia, my cousins in London also impatiently waited for Fridays. Despite thousands of kilometres and a twohour time difference, we grew up watching the same TV series, which were the major topic of conversation for us during our weekly telephone calls on Sunday. If there was a power cut on Friday, my cousins enthusiastically explained to me over the telephone what I had missed. I felt as if we really were spending our Sundays together in the same living room. Those conversations, in which they also talked about their neighbourhood or school, made me dream about London - a place gleaming with lights in contrast to the darkness of Cyprus. I imagined London as a place where the lights and the TV never went off.

When, at the age of twelve, I finally made it to London to visit my aunt and cousins, I was stunned by the city - its streets were always crowded, its buildings were so tall, and my cousins had so many friends from different places across the world. I had come from the last divided capital city in Europe, growing up nearby the UN's Green Line, which separated Turks from Greeks, Muslims from Christians, us from them. All I had ever known was that people who belonged to other places beyond "our" borders were just different from us, even though we inhabited the same small island. As a teenager, London's shiny streets, crowded with so many people from different ethnicities, races, and cultures captured my imagination. Like many other Turkish Cypriots, I became utterly convinced that London was the place where borders would no longer matter, since its inhabitants already crossed them through their everyday encounters with difference. During my two-months stay with my aunt, I also realised how the daily routines of the family members revolved around Turkish television: My aunty never missed the morning shows at 7 am ( 9 am Turkish time); my uncle never missed the news bulletin at $5 \mathrm{pm}$ (7 pm Turkish time); and my cousins never missed the prime time television series at $6 \mathrm{pm}$ (8 pm Turkish time). I remember how I felt that I was slowly adjusting to life between the two time zones of the United Kingdom and Cyprus-for my aunt already a natural way of living, evidenced for instance by the way she would say "it's 17.00 now which means 19.00 in Cyprus" when asked what the time was. This resembled the response she gave whenever she was asked about whether she feels like she belongs to England or Cyprus more: "I belong to both. I live here in London, but I also feel like a part of me still lives in Cyprus. I am both British and Turkish Cypriot."

My initial deep interest in Turkish television series and films gradually became a passion for websites and blogs, a passion that was encouraged when my parents indulged me by buying a broadband subscription when I was fifteen (helped by the fact that the electric power infrastructure had been reconstructed by then). Although my daily reality was indeed 
shaped by the adversities of living in Northern Cyprus, the internet allowed me to imagine differently, as I could cross borders and traverse great distances. This ability made me aware of how our everyday lives and the ways in which we perceive ourselves (and others) can be co-constituted, on the one hand by being situated in particular geographical locations, and mobility across mediated networks and spaces on the other.

Yet borders continued to follow me, even after I left Nicosia and moved to my dream city-London. I still remember when a classmate asked me whether I moved to London to claim social benefits instead of working like "other lazy Cypriots." Such experiences I had in London led to a sad realisation of how borders are not only physical, but also social and symbolic constructions that force people such as myself to always choose a side. I was born on the Northern side of a divided island and I did not have any other choice than to be a Turkish Cypriot. It was followed by many other positions I had to assume without really having a choice: being a woman, being a Muslim, being a migrant-being other. ${ }^{1}$ Wherever I had been, the word "identity" always echoed a reflexive yet burdensome process of negotiation that forced me to locate myself within a complex map of subjectivity and to accept my belonging to multiple groups and cultural sites within and across borders. Nonetheless, to this day, I still consider London as the only place where I can challenge all such imposed borders by in some way always imagining that I belong to its multicultural mosaic of people striving in a foreign land for themselves and their loved ones.

Drawing upon my personal experiences and reflections unfolded above, the city and the media have been long-term intellectual interests of mine. Both have allowed me to think critically about the social struggles faced by some who challenge borders, both in their physical and symbolic form, demanding communication, recognition, and representation. The city, as the physical site of the vast majority of everyday lives, determines our material realities and shapes how we perceive both ourselves and others within a particular urban context and culture. The media offer possibilities for us to travel across distances and time zones, and to move across multiple cultural worlds. Thus, whilst the juxtapositions of the city and the media open up novel avenues of imagination and belonging, they can also create fields of tension with regard to the simultaneity of situatedness and mobility, proximate and distant, and material and intangible.

\footnotetext{
${ }^{1}$ Here and throughout the thesis, I use the word "other" in a manner that acknowledges, and refers to, the social constructions of a collective 'other' that are different from, and even threatening to, the collective self (Balibar 2005, 25).
} 
Started in 2016, the ERC project ConnectingEurope ${ }^{2}$ based at Utrecht University, has allowed me the opportunity to combine my intellectual interests of identity, media, and the city for a research project to tell the stories of women such as Sahra, my aunt, and myselfwomen who cross borders and connect different locations and time zones on a day-to-day basis. Despite increasing scholarly engagement examining the so-called "feminisation of migration" (Madianou and Miller 2012; Marchetti and Salih 2017; Parreñas 2015), the ways in which digital media technologies impact migrant women's identities and sense of belonging remain inadequately researched. In this context, the project explores how migrant women from Turkey, Somalia, and Romania create digitally mediated networks that cross physical, social, and symbolic borders in three different European cities, namely: London, Amsterdam, and Rome. As part of the ConnectingEurope project, I was appointed as the doctoral researcher who focused on London between the years 2016 and 2021. My research project examines how diasporic migrant women mediate their cultural identities at the intersections of urban and digital spaces, and is based on fieldwork conducted between September 2017 and September 2018.

As was depicted by the result of the Brexit referendum and the subsequent political developments in the United Kingdom, my research marks a time characterised by the socalled "failure of multiculturalism" (Mathieu 2017; Shahi 2010; Werbner 2009) when migrants' identities and sense of belonging became increasingly questioned. In this thesis, I provide a rich ethnographic account that depicts how migrant women — at this very particular time in British and European history, and as the subjects of hegemonic discourses of alterity — challenge gendered, ethicised, and racialised forms of marginalisation. In this context, I would like to think of this thesis as an empirical and conceptual contribution towards gaining a better understanding of how the juncture of the city and the digital mediates the ways in which diasporic migrant women challenge power geometries and negotiate their identities by connecting different locations and cultural worlds on a day-to-day basis. In the remainder of this introduction to the thesis, I outline the overarching research question and elaborate upon the rationale of the thesis.

\footnotetext{
${ }^{2}$ The ConnectingEurope project is hosted by the department of Media and Culture Studies/Graduate Gender Programme at Utrecht University, the Netherlands (PI Prof. Sandra Ponzanesi). Detailed information about the project's research objectives and outcomes can be accessed via this link: $<$ http://connectingeuropeproject.eu/>.
} 


\section{The Overarching Research Question}

This thesis explores the everyday lives and cultures of diasporic migrant women in London, with a particular focus on their digital media use and the ways in which such technologies allow them to move between a range of cultural, imagined, and symbolic spaces. My research on migrant women from Turkey, Somalia, and Romania now living in London addresses the following overarching research question:

How do diasporic migrant women living in London mediate their cultural identities at the crossroads of digital and urban spaces?

This fundamental question guides my unpacking of the relationship between digital media, the city, and diaspora. My three-fold investigation demonstrates how such relationships with the media, and the ways in which they generate multiple attachments embedded in cultural identities, are far from straightforward. In this context, this overarching research question leads me to embark on an interdisciplinary literature review and pose several further questions. In the following sections, I briefly discuss how these elements relate to each other, with the aim of justifying the rationale of my research.

\section{Media Research on Diaspora and Migration}

The intersections of media, diaspora, and migration have received a considerable amount of scholarly attention across a wide range of fields, such as sociology, anthropology, and media and communications. This body of work has largely explored the role of media and communication technologies in consolidation of diasporic identities and cultures, uncovering "the interconnections between locations (past and present), and between spaces - physical and virtual" (Retis and Tsagarousianou 2019, 4). In this context, diasporas-which are often seen as deterritorialised communities - have begun to be understood as transnational cultural communities that establish networks of sociality and connectivity across spatially fluid sites and temporal contexts (Siapera 2010,96). From letters to television and mobile technologies, mediated communication has proven to cross the boundaries of time and space, and has become a significant part of the everyday reality of migrants who seek to connect distant and proximate places and maintain local and transnational networks, connections, and communities (Georgiou 2006; Hegde 2016). 
In this context, academic research on the ways in which diasporic migrant identities are mediated through traditional media such as newspapers, radio, cinema, and television demonstrate how diasporic media production and consumption serve myriad purposes. Whilst diasporic media can be produced and consumed by a migrant or ethnic community in the "host" nation to preserve identity and sustain culture, the mediated products of the homeland also help to maintain a sense of belonging to the "home" nation on a transnational level (for example, Iranian television in Los Angeles [Naficy 2003]; Turkish satellite television audiences [Aksoy and Robins 2003]; Turkish and Kurdish media production in Europe [Rigoni 2002]; and Greek Cypriot media production and consumption in London and New York [Georgiou 2006]).

However, the engagement of migrant groups with transnational mediascapes is not confined simply to a nexus between countries of origin and countries of settlement. As this body of research has also shown to us, diasporas often go well beyond the realm of the nation-state through the construction and experience of diverse territories, landscapes, and cultures. In this context, the media open up avenues "for complex negotiation and identity construction" (Siapera 2010, 109), bridging local, national, and transnational scales together in production and consumption of cultural products and commodities. By generating new avenues of identity formation, the media may lead to a greater level of understanding and reflexivity towards established identities and generate new sites of identification and belongingness. Therefore, the production and consumption of media by migrants problematises the notion that cultural identity and belonging are confined to one nation-state or cultural site, and demand further conceptualisation within a transnational framework (Aksoy and Robins 2003).

I draw upon the work of these scholars in my examination of media and diasporic identity production by uncovering a diversity of sites of cultural identity production within a transnational framework. Thus, following this body of research, I theorise diasporic identity as a multi-layered cultural formation that inhabits diverse political influences and imaginaries in an interconnected world, rather than a mere reflection of the singularity of the nation-state. Whilst this broad body of research examines traditional media forms in general, I focus on digital media in particular. Such largely internet-based media have intensified the level of connectivity across diverse spatial and temporal contexts, and generated new ways of establishing mediated cultural sites, connections, and communities online. This presents the need to understand the socio-cultural and emotional significance of these new technologies to 
migrants and examine how they are used for diasporic identity production in a digitally interconnected world.

The introduction of various forms of digital media has had wide ranging impacts on all of our lives in recent decades. Digital media - the so-called "new media" - in general refers to the web and encompasses a wide range of channels, platforms, apps, and media. As Shaw $(2017,593)$ describes, digital media "are often described as a constellation of technologies that are networked, computerized, social, mobile and interactive." These technologies challenge us to examine the plethora of ways in which they are used-socially, interactively, and connectively_-beyond basic processes of their production and consumption (also associated with more traditional media forms). In this regard, the introduction of digital media technologies has stirred an academic debate about how to approach this new communicative environment and how to develop new theoretical and methodological tools for research. Migrants were quick to adopt these new media technologies in order to establish information networks, communicate with their loved ones, as well as to produce and consume cultural commodities (Brinkerkhoff 2009, 12). However, despite their evident role in the facilitation of cross-border connectivity and interactivity, the specific ways in which digital technologies mediate diasporic migrant identities and communities remain a relatively undertheorised area of research. As will be demonstrated in the following chapters, the existing body of literature has, thus far, employed different theoretical and methodological tools. Three distinct phases of digital media and diaspora research can be discerned,

from media-centric (the advent of cyberspace and the belief in a separate space between online and offline worlds), to an ethnographic phase (linked to the embedding of technology in everydayness), and back to the media-centric approaches with digital methods and the rise of data studies that takes digital information as leading and self-explanatory. (Candidatu, Leurs and Ponzanesi 2019, 43)

According to this genealogy, my research project takes place at a time in which the field is dominated by "digital information," which is captured as digital data and analysed through predominantly web-oriented tools and perspectives. However, my research aims to situate the digital media practices of migrant women in the context of their daily lives and experiences in London, delving deep into the context of an online-offline continuum that connects urban and digital spaces. Hence, I focus on how digital media are embedded in situated sociocultural settings by going beyond the "online" realm, delving deep into everyday life in the 
city. In this context, I aim to employ a non-media centric, ethnographic approach to the use of digital technologies by migrant women within the context of "the everyday." In order to further this aim, I build a theoretical and methodological approach that synthesises both established notions in traditional media research, which focuses on the "everyday embeddedness" of the media in our lives (Moores 2006; Morley 1991, 2000, 2010; Silverstone 2005), and the recently emerging concepts and methodologies specific to the "digital" in media studies. In doing so, I demonstrate an analytical framework that builds upon the existing wealth of literature, uncovering the entanglements between the media and multi-layered diasporic identity in a manner that permits the capture of new forms of mediated engagements and social changes brought about by digital communication technologies.

\section{The Place: London as a "Global City"}

London is not merely a contextual backdrop to my study. Rather, it is central to understanding how digital media use becomes meaningful along with other socio-cultural dynamics in the everyday lives of migrant women. My research documents extensively how the city impacts upon the ways in which migrant women perceive themselves and others, and how they experience different spheres of belonging across situated urban contexts. London's urban environment is shaped by the many different ethnic, cultural, and social groups that inhabit it. The experience of moving across different spaces within the city demonstrates how its multi-cultural composition and ethnic and social distinctions have profound implications for the everyday realities of its inhabitants. Moreover, as a major media hub, London offers a range of ways via which its residents can connect socially through communication technologies. As Saskia Sassen (1991) describes, London (similar to New York and Tokyo) is a global city, characterised by its position as a major media and migration hub due to a massive influx of information, people, and capital. London's position as a global hub for media and migration adds a sense of urgency to my investigation of digital mediations of diasporic identity in a manner that accounts for how everyday lives and cultures are placed within the wider social context of the city.

As Keith $(2005,20)$ writes, "studying the city means studying power." The social hierarchies that are imposed upon marginalised groups through national schemes and a global world order materialise in cities. In other words, the city is not a spatially bounded unit, but rather is a fluid entity shaped by the interplay of urban, national, and transnational formations 
(Eade 1997; Georgiou 2013, 2017; Keith 2005). This challenges me to approach London as an urban milieu that is characterised by locally situated lives and experiences on the one hand, and broader national and transnational social formations on the other. As Georgiou (2013) argues, the complexity of urban life in London also manifests itself in its dynamic media environment. Giant media corporations and celebrities that serve local and global audiences mediate the branded image of the city from the top down. Yet, as Georgiou also reminds us, the city is also characterised by "synergies of power" in which we can observe the struggles between different social actors-how they produce and consume cultural products and modes of sociality. In this context, the city not only provides a fertile ground upon which its inhabitants can engage with diverse mediated cultural sites. Rather, the complex relationship between the city and the media also reveals how different social groups struggle for self-representation and recognition from the bottom up (Georgiou 2013, 22-24). Since I am particularly interested in the lives and experiences of migrant women who are members of ethnic, racial, religious, and cultural minority groups, I approach the city with an intersectional perspective that acknowledges their varying social positionings in the context of the social inequalities implicated in London's urban environment. In this context, my study operates in an analytical framework that elaborates upon how digital media becomes part of the way in which urban, national, and transnational workings of power play out for my participants in the city and how they develop actions and agencies in response.

\section{The People: Who Is This Thesis About?}

This thesis tells the stories of migrant women from Turkey, Somalia, and Romania who now live in London. These migrant women all belong to large groups of people dispersed from their original homelands - that is to say, they are part of diasporas. Therefore, my thesis is not only about migrant women but, more widely, about the female members of large diasporic migrant groups across the world - a situation that defines how they construct and live their identities in London and beyond. Although I will review the literature on diaspora extensively in the next chapter, it is relevant to briefly introduce my understanding of the concept here, since it is the unifying characteristic of the three communities under consideration, and is intimately connected to the overarching research question outlined in the introduction.

"Diaspora" derives from the Greek term diasperien, which means "to sow or scatter seeds" (Murray 2014). Historically, it has been used to refer to communities that have been dislocated from their homelands as a result of migration, immigration, or exile (Braziel and 
Mannur 2003, 1, 2). Today, the concept is used by scholars to refer to the movement of people for diverse reasons, as a result (amongst others) of slavery, labour, war, trade, and economic forces, who are defined through their shared historical, ethnonational, religious, or cultural characteristics (Cohen 2003, 1-4). In relation to this broad definition, the communities featured in this research, with their origins in Turkey, Somalia, and Romania, are diasporic migrant groups that are dispersed across different parts of the world, but maintain their own identities, consciousness, and memories through shared characteristics and experiences.

Cohen $(1996,12)$, an influential scholar of migration and diaspora studies, argues that diasporic groups that develop their own political and cultural sense of belonging challenge the ideals of uniform social and national identity of nation-states within their established territorial boundaries. In this context, majoritarian dominant narratives perpetuate anger and violence towards minorities by portraying immigrants and minorities as "outsiders" who invade the nation and disrupt its social cohesion and unity (Appadurai 2006, 52). Yet, the mass movement of people across the borders of nation-states is an inevitable consequence of a globalised capitalist economy, which demands the transnational movement of labour and capital to sustain itself. Thus, the concept of diaspora is of crucial importance for those who seek to examine the tension between nationalism and globalisation, and to understand how "difference" is articulated and politicised in contemporary societies. As Retis and Tsagarousianou $(2019,2)$ write, the concept of diaspora is associated with the notion of agency and involves "processes of making sense of this dispersion, of creating infrastructures for narration and action in transnational and translocal contexts, or to the meeting of roots and routes as Gilroy (1993) aptly suggests."

In the light of the above and for two, albeit interrelated reasons, I use the term "diaspora" as an overarching concept via which to address the shared characteristics of the three different migrant groups in my study. First, whilst these migrant women are members of ethnic, religious, and cultural minority groups in London (and the wider United Kingdom), they are also part of a larger population dispersed across different parts of the world. The significance of digital communication technologies in connecting members of diasporic communities in the contemporary global culture has been reflected in the notion of "digital diasporas" (Everett 2009). My study gives a rich account of the key role digital media have in the formation of diverse diasporic connections and affiliations on local and transnational levels. Via its ethnographic approach, it demonstrates how digitally mediated diasporic identities and cultures are simultaneously constituted through online and offline practices. In 
this regard, whilst contributing to the growing field of digital diasporas, crucially, it accounts for diversity within and across diasporas and explains the social and emotional significance of digital spaces and practices for their members - factors that have thus far been largely neglected in the literature (Ponzanesi 2020, 11).

Second, as the concept of diaspora suggests, we should critically engage with the issue of agency and broader questions of power and politics. Such migratory movements occurred under distinct circumstances and for distinct reasons, and all three groups, each in their own way, endure the social, political, and economic implications of hegemonic power structures. As Georgiou (2005, 4) argues, whilst diasporic media cultures encompass groups with particular ethnic, linguistic, and/or religious affiliations within and across nation-states, they are indeed constituted with universal claims of human rights, recognition, and representation. Thus, diasporic media cultures "inevitably depend on the universalismparticularism continuum" (Georgiou 2005, 4).

This universalism-particularism nexus, which shapes diasporic media cultures, also calls for an intersectional perspective. Indeed, current literature on diaspora argues extensively for an intersectional perspective that accounts for both the specificity and internal diversity of diasporic migrant communities (e.g., Anthias 2009a; Brah 2005; Clifford 1994). Although the researched communities in my study develop their own distinct "diasporic consciousness" through shared ethnic, linguistic, or religious characteristics (Safran 1991), the cultural identity production of their female members accounts for the interplay of different classed, gendered, and generational positionalities. In this context, I approach diasporic cultural identity from an intersectional perspective and acknowledge that the ways in which migrant women use digital media for communication and self-representation are reflexive of their classed, gendered, and generational positionalities as well as their particular ethnic, religious, and linguistic affiliations.

\section{At the Crossroads of Urban and Digital Spaces: The Notion of "Translocality"}

As I have made clear above, whilst the rationale behind this research project is to examine diasporic identity production through digital media use, my interest in "everydayness" and situated social and cultural lives highlights the need to approach the city itself as an equally important layer of analysis. This is why, whilst placing the mediation of diasporic identity at the centre of my research, I also aim to uncover how the city and digital media mutually (re)configure the everyday lives, contexts, and practices of migrant women. To this end, my 
ethnographic research project is theoretically and empirically designed to examine the cultural identities of diasporic migrant women at the crossroads of urban and digital spaces.

Even though my ethnographic research is empirically grounded in the analysis of everyday life in London, I acknowledge that the city is not a static, spatially bounded unit. As a global city, London's boundaries are porous and broader transnational formations are incorporated in the "locality" of its urban space, defining its environment, networks, and boundaries (Sassen 1991). Moreover, as explained above, the media plays a central role in the production of diasporic identities, with its ability to connect different cultural landscapes beyond the boundaries of time and space. This means that both the city and digital media challenge me to recognise how cultures and identities - no matter how (locally) situated my approach may be-are formed at the intersections of spatially fluid cultural sites and contexts. Therefore, in the context of my investigation of diasporic cultural identities, my main conceptual and empirical areas of focus - the urban and the digital - problematise the notion of "space." They both demand that I acknowledge how spatiality plays an important role in the production of identities and cultures in the context of "the everyday," but can no longer solely be "defined by physical location" (Jordan 2002, cited in Carpentier 2007, 4).

As Georgiou (2010) argues, it is in the city that the politics of identity and representation materialise. "The nation, we may say, is a space of identification and identity, whilst the city is an existential and experimental space' (Robins 2001, cited in Georgiou 2010, 15). However, as Georgiou (2010, 2) argues, even though we acknowledge the importance of the city as an everyday site in which self-identifications with certain positions materialise, we need to understand how diasporic media cultures consist of different spatial scales, namely "the home, the city, the nation and the transnational space." In this context, she proposes a "multi-spatial approach" to the theorisation of diasporic identity and culture. Such an approach suggests that, even when we take the city as the primary level of analysis (for the reason that it is where everyday lives and practices are constituted), we should be attentive to how diasporic identity "is lived as multi-positioned in symbolic and geographical spaces" of urban, national, and transnational belonging (Georgiou 2010, 30). Nonetheless, the notion of a "multi-spatial matrix" raises the question of how to design our empirical research at the intersections of the city and mediated cultural spaces of urban, national, and transnational belonging. In this context, I operationalise the concept of "translocality" in my empirical investigation, as it accounts for the ways in which national and transnational spaces become entangled in their co-constitution of situated everyday life-worlds that materialise in particular localities and urban contexts. 
The concept of translocality has been employed by researchers from fields as diverse as media and communications, migration studies, international development, urban studies, and geography (for an in-depth literature review, see Greiner and Sakdapolrak 2013). The concept emerged out of the need to understand how social fields increasingly transcend physical borders, and how identities and cultures are not territorially bounded (Greiner and Sakdapolrak 2013). Thus, although it follows an epistemological and methodological logic similar to transnational social fields (Basch, Schiller and Blanc 1994; Levitt and Schiller 2006), translocality diverges from, yet does not contradict, theories of transnationalism. Indeed, by theorising diasporic identities and cultures as de-territorialised and spatially unbounded (Anthias 2009a; Clifford 1994; Glick Schiller and Caglar 2013; Levitt and Schiller 2006; Tölölyan 1996; Vertovec 2001), such theories have yielded valuable insights into how communities are no longer confined within national boundaries. However, as Greiner and Sakdapolrak (2013,3) compellingly argue, transnationalism is still primarily concerned with the transgression of national borders and the de-terreritorialisation of communities by tending to neglect the continuing relation between identity and territory in localised contexts. In contrast, translocality acknowledges that identities and communities exist on border transgressions other than those of the nation-state (such as the borders of the neighbourhood, the city, and Europe) whilst recognising that they are primarily localised phenomena (Greiner and Sakdapolrak 2013).

In the field of media and communications, Murphy and Kraidy $(2003,299)$ argue that one of the greatest challenges facing ethnographic approaches is to establish theoretical and methodological frameworks that are able to create a nexus between local and transnational (and/or global) dynamics as they are manifested in people's "everydayness." In my research, articulations of the local-transnational nexus are fundamental to adequately capturing the concrete implications of being spatially bounded within particular urban space(s) whilst also being mobile across complex geographies with the facilitation of digital media. In this context, Carpentier's (2007) utilisation of the concept of translocality in his investigation of the relationship between the media and the city provides a key reference. He proposes that by taking the "local as a departure point," we can understand how, whilst the local (urban) has its own situated dynamics and organisation, the media articulate its context and community through broader national and transnational formations (Carpentier 2007, 7). As he writes, the translocal "is the moment where the local merges with a part of its outside context, without transforming itself into this context. It is the moment where the local simultaneously incorporates its context and transgresses into it" (Carpentier 2007, 6). Therefore, the prefix 
"trans-" in the notion of translocality enables both the empirical investigation of these transversal crossings, and an understanding of the constitution of cultures and social relations within a multi-spatial framework in the age of digital technologies.

In this context, the operationalisation of "translocality" as a concept and a research perspective in my study achieves two purposes. First, as Appadurai (1995) proposes, locality provides us with a socio-culturally situated context for an investigation of how different spatial scales and contexts are embedded in people's daily lives. Hence, translocality allows me to establish an analytical framework that investigates the "local" context and build upon it in the theorisation of how digitally mediated diasporic spaces, contexts, and practices are articulated within a multi-spatial framework. In my research, "locality" is shaped on the level of the city in which the everyday lives and cultures of migrant women are articulated. This is the reason why I take the "local" and the "urban" as parallel empirical units of analysis and elaborate upon how London's particular contexts and dynamics, as Appadurai (1995) amply explains, are always produced in relation to larger-scale formations.

Second, as Anthias $(2018,153)$ writes, "a translocational lens" allows for the conceptualisation of cultural identity with an intersectional perspective, since it "attends to the spatial, temporal and scalar aspects within which intersections of power are embedded as well as the broader social context." In this context, when applied with a bottom-up approach, the concept of translocality brings a new perspective to the conceptualisation of gendered diasporic identity. Not only does it acknowledge how diasporic women articulate their identities within entangled systems of power, but it also unpacks the ways in which they use digital media to negotiate urban, national, and transnational belonging and power geometries simultaneously.

In this context, by researching gendered diasporic identity from a translocal and intersectional perspective, my thesis uncovers the complex relationship between digital media, the city, and space. It recognises the implications of both "situatedness" in a particular urban context, and "mobility" across digitally mediated spaces. Furthermore, it demonstrates how diasporic migrant women in London use digital media technologies to position themselves within and traverse different spaces of belonging at various social locations and socio-spatial layers. Thus, it achieves a multi-spatial approach to diasporic identity production "at the crossroads of [the] urban and [the] digital" (McQuire 2008, viii). My thesis proposes that, in the era of digital media technologies, diasporic identities are "translocal" cultural formations, as they cannot be de-coupled from their "locality," whilst always merging with other scales in which such contexts are situated (Carpentier 2007, 6). 


\section{Organisation of the Thesis}

I have now introduced my personal interest in the study, and how it informed the direction I have taken within the broader framework of the ERC project ConnectingEurope. Then I presented the overarching research question of the thesis and discussed why (digital) media, the city, and diaspora constitute the main areas of my research. I ended by introducing the concept of translocality and outlining the rationale for employing it as an analytical lens via which to examine the cultural identities of diasporic migrant women at the juncture of urban and digital realms. In the following, I outline the overall organisation of the thesis.

In Chapter 1, I introduce the theoretical foundations of my study by reviewing the current literature on digital media, the city, and diaspora, explaining how I bring these into dialogue with each other through the concept of translocality. First, I highlight how I position my study within this exiting body of research by employing a non-media centric approach with the express purpose of examining digital media use in situated socio-cultural settings. Second, I discuss the diverse ways in which the city itself-in this case, London-impacts the identity construction of diasporic migrant women, and how I pursue my analysis of "everyday life" with regard to its specific urban dynamics and culture. Third, I proceed to a discussion of the concept of diaspora and highlight the importance of studying the identities of diasporic migrant women as an intersectional and dynamic cultural formation. In this context, I discuss how I adopt Hall's (1990) work on diasporic cultural identity and the media with the aim of understanding contemporary technological and socio-cultural changes in the age of digital media. Finally, the chapter ends by highlighting the theoretical aims of my study and introducing sub-research questions to help address the overarching research question.

Chapter 2 presents the methodological trajectory of my study. I begin by discussing the reasons for employing an ethnographic research design. Then, I present an account of the multiple online and offline methods used to achieve my research objectives by employing a multi-sited and mixed-methods approach to my ethnography. In this context, I discuss how I utilised in-depth interviews, observation, and online data collection and analysis, in such a manner as to enable an examination of the relation between digital media, the city, and diasporic identity construction along an online-offline continuum. Finally, I proceed to examine the ethical considerations raised, and how I tackle these at different stages of my project. 
The empirical discussion is organised into three chapters in which I present my findings on migrant communities from Turkey, Somalia, and Romania. Each chapter focuses on a different theme: diasporic nationalism; identity performativity; and citizenship, respectively. These different themes allow me to introduce and analyse different elements of my empirical study, each of which are particular to the female members of the three diasporic migrant communities under investigation. As such, these themes have emerged out of my fieldwork as frameworks with which to understand and contextualise the myriad ways in which migrant women use digital media technologies in line with their respective migratory trajectories, material realities, and ethnic, classed, and generational backgrounds. Nonetheless, as will be illustrated throughout the empirical discussion and the conclusions, I also draw parallels between each case and conceptualise gendered diasporic identity in a manner that accounts both for the particular characteristics of each community and overarching claims of communication, representation, and recognition.

Chapter 3 is the first empirical chapter. It focuses on diasporic migrant women from Turkey and engages with the topic of diasporic nationalism. Specifically, it investigates how migrant women use digital media as tactical interventions to both navigate and participate in diasporic nationalism. The findings are contextualised by presenting an elaborate account of how diasporic nationalism is an inherently translocal phenomenon that influences migrant women's experience of space, social relationships, and sense of community in London. In this context, the chapter explores the ways in which digital media have become central to the identity construction of these women as they juggle the political and social pressures of their "home" nation and the global city in which they now live.

Chapter 4 is the second empirical chapter, in which I investigate the case of Somali migrant women. It discusses how generation-specific experiences of the digital and the city co-constitute different diasporic identity performances for first- and second-generation Somali women. The analysis first unpacks the ways in which both first- and secondgeneration women use the internet to locate themselves as part of a global Somali diaspora. In this context, it illustrates how the second generation, who lack any vivid memory or lived experience of Somalia, engage with distinct symbolic spaces in which transnational diasporic youth culture flourishes. The analysis continues by further exploring how the urban context of London lead these young women to redefine their British-Somali identity and womanhood at the intersection of race and religion.

Chapter 5 is the third and final empirical chapter and focuses on Romanian migrant women. In this chapter, I engage with the subject of citizenship, as the main theme that 
emerged out of my fieldwork. I present an in-depth analysis of how the Romanian migrant women in my study use websites and social media platforms to achieve recognition and equality in a diasporic context. I present my findings with a class-specific analysis by demonstrating how the diasporic subjectivities of my participants are framed by socioeconomic realities and experiences they encounter in London. In a neoliberal and racialised socio-political context that denies them equal rights and recognition as citizens, I demonstrate the role of digital media in allowing them to combine urban, national, and European belonging in their production of diasporic identities.

In my conclusion, I first return to the sub-research questions and reflect upon the overall empirical findings of the study. Then, I address the overarching research question and present the notion of translocal modes of belonging. This notion argues that the diasporic identities of migrant women are digitally mediated through various modes of belonging that enable them to both self-position and traverse multiple socio-spatial formations and dynamics within the context of their everyday life-worlds. I conclude by making several suggestions for further research. 


\section{Chapter 1: Theoretical Foundations}

This study seeks to address how diasporic migrant women mediate their cultural identities at the intersections of urban and digital spaces. In formulating the main (and sub-) research questions and the conceptual framework of my thesis, three main aspects of my studydigital media, the city, and diaspora-guided my decision-making process with regard to which theories and studies to use as reference. In this context, I focused on the relevant academic literature in order to synthesise these three dimensions in line with the notion of translocality, a concept that recognises migrant women's situatedness and mobility in an online-offline continuum that traverses the intersections between urban and digital spaces.

I start this chapter by briefly recapping how each dimension guided my argumentation shaping the analytical framework of this thesis. First, as I aim to understand how the "digital" is integrated in everyday socio-cultural settings, I refer to non-media-centric approaches in my investigation to capture the full gamut of ways in which my participants use and relate to digital media within the context of "the everyday." Second, London, as the site of my fieldwork, is not merely incidental. Rather, as a hub for media and migration with distinct urban environment and dynamics, I believe it demands particular attention for contextualising the wider social context in which my participants live their everyday lives. Third, I do not take the category "migrant women" for granted. My participants are part of large diasporic populations dispersed across the world. This indeed shapes how they perceive their "home" and "host" nations; mediate relations of we-ness and otherness; and engage with networksboth social and connective - on local and transnational levels. Furthermore, the very concept of "diaspora" itself calls for an intersectional perspective that challenges us to bring out the internal diversity of the communities being researched at the intersections of gender, ethnicity, religion, social class, and generation. In relation to these aspects of my research, developing a conceptual framework is difficult, since it requires bringing together and balancing the dimensions of (digital) media, the city, and diaspora. As previously explained, I aim to achieve this by developing a conceptual framework based on the notion of translocality, allowing me to examine diasporic cultural identity formations as they are situated in everyday life-worlds at the intersections of urban and digital spaces.

This chapter aims to discuss the pre-existing theories and studies upon which I drew when developing the conceptual framework of my thesis. Section 1.1 reviews research on diaspora and digital media, and explains my rationale for choosing a non-media-centric, ethnographic approach grounded in the notion of "the everyday" with the purpose of 
positioning the contribution I make with my study. Moving forwards, sections 1.2 and 1.3 explain how an analysis of everyday life is employed in the city with regard to the cultural and social dynamics of the city. The former discusses how the implications of London's multicultural urban environment on identity construction are accounted for through the notions of "everyday conviviality" (Gilroy 2006), and "vernacular cosmopolitanism" (Bhabha 2000; Werbner 2006). The latter section discusses how my micro-scale analysis of everyday life is situated within a wider social context that acknowledges broader systems of power and how these implicate diasporic migrant women in particular. Section 1.4 explores the concept of diaspora with a particular focus on gender and explains the reasons for studying diasporic identity as intersectional, dynamic, cultural formations. Section 1.5 is dedicated to explaining how I examine the relationship between digital media and identity within the context of "the everyday" by building upon Hall's (1990) theorisation of diasporic cultural identities via cinematic representations. Finally, section 1.6 introduces overall theoretical aims and sub-research questions.

\subsection{Digital Media Research on Diaspora and Migration: A Non-media-centric Approach}

With the recent prominence of media-centric approaches, terms such as "digital diaspora" (Everett 2009), “e-diasporas" (Diminescu 2008), and "diaspora online” (Trandafoiu 2013) utilise a set of qualitative and quantitative methodologies to examine the "online" as a distinct domain of life and have become widespread. Diminescu (2008), for example, introduces the notion of the "connected migrant" in relation to role of the internet in overcoming physical distance and maintaining the homeland connections of migrants. Similarly, Brinkerhoff (2009) argues that "online" and "offline" are distinct spaces, and members of "digital diasporas" use the internet to "escape into cyberspace" (cited in Alinejad 2017, 36). Whilst this body of research provides useful insights into the ways in which the notion of physical space changes with digital media technologies (Alinejad 2017, 35), it is oriented towards an examination of the "online" as a distinct space with its own separate practices, beliefs, and value systems. In this context, it is largely occupied with the question of what is new about migrant identity and experiences in the context of new media technologies and the web's large-scale connectivity and interactivity. This approach tends to address such questions via an examination of migrants' web-based connections with their countries of 
origin. The predominant focus on the "home" nation leads this body of work to generally overemphasise the national, ethnic, and religious ties of migrants. However, as explained in the introduction, media research on traditional media forms reveals how migrant subjectivities and experiences operate across multiple cultural sites on a transnational level. In this context, research on digital media technologies in the field seems to neglect how diasporas enable multi-layered, hybrid identities by going beyond established national, ethnic, and religious attachments (Ponzanesi 2020, 2).

Furthermore, as this body of work tends to regard the online as a separate realm of life (from the offline), it largely attributes the spatio-temporal connections of diasporas (for example, with the country of origin) to the technological changes brought by the internet and digital media. However, the relationship between diasporas and the media, whether in its old or new forms, are not solely determined by technological dynamics, but rather are also coconstituted by broader political and socio-cultural dynamics that impact the practices, meanings, and values assigned to different communication technologies. Indeed, the reason why many media and communication scholars see media as social institutions (Lister et al. $2009,10,22)$ is because they argue for studying the social changes brought about by such technologies, rather than simply studying the technological change itself. In other words, they argue that media research should uncover the relationship between changing socio-cultural and technological dynamics in an open, non-deterministic way that acknowledges their mutual constitution of notable social change in our societies. As Livingstone $(2000,7)$ suggests, the field of media and communications "represents not a discipline but a diverse set of phenomena, informed by social theory, bounded by technology." In this context, and as Natale $(2016,593)$ argues, the media "should be regarded as a cultural construction through which people make sense of the impact of media change within their social and material environment." According to Natale, old and new media are relational concepts, and each entails a variety of meanings and practices that should be examined within their respective social and material settings.

Both theoretically and empirically, a digital-centric approach carries with it the danger of portraying an overly optimistic picture in which minorities are seen as having the tools and spaces to self-represent and voice their interests. However, we should be aware of the hegemonic power structures and socio-cultural dynamics that continue to hold back minorities and other marginalised groups from fully participating in the public sphere. This is even more apparent for the female members of such groups, who face multiple forms of marginalisation in their participation within the public sphere due to a plethora of gendered 
norms and regulations (Georgiou 2012, 4, 6). Such concerns dictate the need for an intersectional perspective in my investigation, so that I might unpack how migrant women's relationships with digital media technologies are co-constituted by the hegemonic workings of power that marginalise them at the intersections of gender, ethnicity, race, class, generation, and religion. As Anthias and Yuval-Davis (2005, 69-79) argue, at the empirical level, the category of "women" demands an intersectional perspective, enabling us to examine how nationalism, racism, and patriarchy interact in determining the specific social positions of female members of ethnic minority groups. This means that we should be attentive to how migrant women are situated in specific socio-cultural contexts in relation to broader structures of power, and acknowledge the urgency to understand digital media's political, social, and cultural significance to them from an intersectional perspective.

With the above considerations in mind, my research project is specifically not preoccupied with examining the "newness" of digital media solely in relation to their technological infrastructures (Lister et al. 2009, ii, iii). Although I do consider the technological properties of digital media technologies, I mainly draw upon the notion of affordance from a non-media-centric perspective. The notion of affordance refers both to physical properties of an artefact, and the social, cultural, or emotional values and meanings attached to it (Hutchby 2001). In this context, by gaining an in-depth understanding of how they are used by individuals within socio-culturally situated settings (Hutchby 2001), I examine how such media allow or restrict certain activities. Thus, I ask what is new about migration in the context of digitalisation, and what persists through time, given new modes of connectivity and sociality. Furthermore, how do migrant women themselves perceive the role of digital media technologies in their lives and cultures? I address these questions with a particular emphasis on the material settings, and the dynamic relationship between the media and broader cultural practices in a holistic framework.

As Costa (2016) argues, in order to understand the "sociality" of digital media, we need to examine the remarkable social impact they have had on individuals, with a particular focus on their daily lives and routines. Therefore, we need to go beyond the domain of the "online" and examine the dynamic relationship between the media and broader cultural settings and practices by elaborating upon "the everyday." Following this, I employ a nonmedia-centric approach in my investigation in order to study "online" and "offline" as existing on a continuum. This is done with the express purpose of understanding how migrant women experience sociality and connectivity through digital media technologies within their situated everyday life-worlds. 
The non-media-centric approach has been one of the most prominent approaches in media and communications studies from the very early stages of its establishment as an interdisciplinary field (Krajina, Moores and Morley 2014; Moores 2006; Morley 1991, 2000, 2010; Morley and Robins 1995). This body of work has contributed immensely to the field by generating an epistemological shift from technological determinism (technology-oriented research and theories) to a focus on the "sociality" surrounding such media, understanding the social uses and cultural and emotional significance of the media technologies within the context of "the everyday." Morley (2007) argues that "we need to 'de-centre' the media in our analytical framework, so as to understand better the ways in which the media-related processes and everyday life are interwoven with each other" (cited in Krajina, Moores and Morley 2014, 200). A non-media-centric approach can allow us to understand affective and socio-spatially situated nature of migrants' digital media practices, which has thus far been undertheorised (Alinejad and Ponzanesi 2020). It leads to an investigation of the broader everyday socio-cultural settings in which migrant women relate to and use digital media and communication technologies. In this context, I turn for inspiration to studies that operationalise the established notion of "mediation" with a non-media-centric approach.

In its broadest sense, the theory of mediation advocates a theorisation of the relationship between the media and social processes as dialectic and culturally dynamic (Barbero 1993; Couldry 2008; Madianou 2005; Silverstone 2005). Theoretically, the concept of mediation leads to an understanding of the media with regard to the historical, sociocultural, political, and economic contexts in which they "influence and shape institutions, structures, ideas, beliefs, and so on, are in turn influenced by these" (Siapera 2010, 10). Several researchers, such as Georgiou (2006), Nedelcu (2012), Madianou and Miller (2012), and Hegde (2016), draw on the theory of mediation to theorise how everyday practices and spaces of belonging amongst migrants are established and experienced through digital media technologies. For example, Madianou and Miller's (2012) influential research on transnational families demonstrates how migrant women attribute different social and emotional meanings to specific digital media forms according to their specific motivations and needs. By doing so, it reveals the complex relationship between the media and everyday realities of migrant women. In this context, they compellingly argue that individuals themselves appropriate and negotiate affordances of technologies in relation to broader

\footnotetext{
${ }^{3}$ Early research on media and communication tended to argue that technological changes determined societies' structure and culture - an approach referred as "technological determinism" (e.g., Adorno and Horkheimer [1947] 1997; Herman and Chomsky 1988; McLuhan 1964).
} 
cultural practices and power structures within the context of their everyday life-worlds (Madianou and Miller 2012). This body of work, therefore, does not approach the "digital" as "abstracted and distanced from local and embodied social relations" (Miller and Slater 2000, 7), but rather views it holistically, as a part of everyday culture. Thus, in contrast to mediacentric approaches, which see the "online" and "offline" as separate domains of life, they are seen as existing along a continuum-embedded in everyday lives and routines.

What can be gleaned from the above is the inspiration I draw in my empirical investigation from the body of research that operationalises the theory of mediation with a non-media-centric perspective. In this context, I diverge from media-centric scholarly work on diaspora, migration, and the digital media (e.g., Brinkerhoff 2009; Diminescu 2008; Kok and Rogers 2017) by approaching "online" and "offline" as mutually constituting everyday lives, rather than being distinct domains. In doing so, I hope to contribute to existing literature by exploring the ways in which, along with other social and cultural practices, for diasporic migrant populations, the digital becomes integrated in everyday lives and cultures. However, this raises the question of "which alternative analytical frames might best help to understand these socio-cultural and media technological dynamics together" (Alinejad 2017, 8). In this regard, my research focuses on the city, which for many constitutes the main site of everyday life. I demonstrate that its analysis yields an understanding of how socio-cultural and digital media-technological dynamics co-exist along an "online" and "offline" continuum.

\subsection{The City, Everyday Conviviality, and Cosmopolitanism}

As Appadurai (2006) articulates in the Fear of Small Numbers, dominant majoritarian narratives represent minorities as a danger to their societies, in which the nation-state seems to lose control and authority in the face of powerful forces of globalisation. In this context, as Brexit and the rise of right-wing ideologies in the rest of Europe show, multiculturalism is seen as the "menace" of an increasingly globalised world order by threatening the sovereignty of the nation and distorting its social unity and harmony. However, as Pollock et al. $(2002,2)$ write, three powerful contemporary forces_ - "nationalism", "globalisation," and "multiculturalism" - are intertwined and co-constitute each other. Nation-states — particularly the economically powerful nation-states of the West-rely on international labour and capital to sustain their economies and status in the world order. Whilst the nation-state benefits from the international movement of people and capital, its exercising of authority and control over 
its borders demonstrates its desire to contain and shape multiculturalism according to its needs and priorities (Pollock et al. 2002). In this context, as Hall (2000, 209) argues, "the multicultural question" ponders "how we are to envisage the futures of those many different societies now composed of peoples from very different backgrounds, cultures, contexts, experiences and positions in the ranking order of the world; societies where difference refuses to disappear." The people who drive the story of this study are members of diasporic migrant groups from Turkey, Somalia, and Romania and thus, their ethnic, religious, and cultural status as "minorities" implicate them in debates around the "multicultural question"-in this case, within the national context of the United Kingdom.

As for many other nation-states, the United Kingdom's relationship with cross-border mobility and resettlement began long before the phenomenon of globalisation as we know it today. As the capital of the former British Empire, London and some other large British cities were major metropolises due to the movement of people from the British Empire's overseas colonies. After the break-up of the British Empire, in the aftermath of the Second World War, immigration from these former colonies set the scene for the United Kingdom to become a multicultural, multi-ethnic nation-state. With the purpose of deciding who can belong to this "nation," laws and policies have historically defined and restricted multiculturalism through different border policies and modes of citizenship (Siapera 2010, 29).

The United Kingdom initially promoted a pluralistic model of integration based on a civic understanding of citizenship. Members of former colonies were entitled to a British passport until the Immigration Act of 1971, which introduced greater restrictions on new immigrants (Siapera 2010, 29). Despite these new regulations, as Joppke (1996) highlights, the British state introduced a wide range of policies aimed at integrating immigrants into society. Since colonial times, Great Britain favoured a decentralised form of organisation in which local governments were responsible for running and reporting to the colonial authorities. In this respect, when compared to other European colonial powers (for example, the French), the British did not aim to assimilate cultural difference. This approach continued even after its transition to a nation-state with the aim of maintaining cultural diversity whilst guaranteeing equal opportunity and anti-discrimination laws and policies (Siapera 2010, 31). Even though immigration has always been an important part of Great Britain's colonial and national history, a divergent set of policies and practices have shaped its present multicultural and multi-ethnic society. The experiences of the three different groups in my study, all of whom migrated to London at different times (and under different circumstances), have been highly affected by these divergent state policies. For instance, Romanian migrants who 
recently migrated to London following the country's accession to EU membership in 2007 found it very difficult to establish their own diasporic community organisations due to decreasing state funding. In this sense, their experiences of resettlement in London significantly differ from Turkish and Somali migrants, who were provided with at least some sort of support and guidance from the British state (such as public housing and financial aid). This disparity reveals how the increasingly more discriminatory political discourses and practices impact minority and migrant groups in contemporary British society.

The above raises the question of how things have evolved to the point of the recent resurgence of the exclusionary logic of British nationalism and the radical decision to break away from the EU. Critiques of multiculturalism largely highlight the lack of social cohesion and unity, depicting immigrants as a burden on the welfare state. The famous slogan of the "Leave Camp" in the Brexit referendum — "Let's take back control"- emphasised the idea that leaving the EU would mean the United Kingdom would be able to take back power from Brussels over its politics, economy, and borders. In order words, leaving the EU would mean that the country would be able to establish its own immigration system and decide who is "in" and who is "out" in order to "restore" social cohesion. What Brexit signals is the support of almost half of the nation for right-wing policies to strictly control the borders and "secure" the territory from "irregular" migrants, as well as for its dominant discourses, which contest the rights of many migrants already resident in the United Kingdom to stay. These dominant discourses reveal how the state's re-assertion of its borders should also be recognised for its de-territorialised dimensions, as much as for controlling territorial boundaries, since it seeks to contain multiculturalism and migration through a wide range of discourses and practices implicated in the fabric of everyday life that deny the protection, recognition, and human rights of racialised minorities (Yuval-Davis, Wemyss and Cassidy 2019). Therefore, for migrants - for those who cross borders physically - the border continues to be a social and symbolic "actor" that separates an "inside" from an "outside" (Bryant 2010, 144) long after the event. Thus, borders are also "mental spaces" that, in Bryant's words $(2010,144)$, create inclusions and exclusions by granting or refusing legitimacy to some of those who cross.

Nevertheless, despite the critiques of multiculturalism within the UK national context, London continues to successfully brand itself as a "melting pot" and sustains its status as an economic powerhouse thanks to its multi-ethnic and multicultural population. Today, as a global city, London relies on both low- and highly skilled migrants in order to sustain its post-industrial economy and prominent position in the global economic system (Sassen 1991, 14). Diasporic cultures are an inseparable aspect of London's "brand" as a city (Georgiou 
2013, 2017), and migrants constitute an important source of labour and capital (Sassen 1991). Despite years of Eurosceptic political and public discourse, around 60\% of Londoners chose to vote to remain in the EU. ${ }^{4}$ At the time of conducting this research project, London is still the only major European capital whose mayor, Sadiq Khan, has a Muslim background and identifies himself as a moderate, liberal Muslim (Georgiou 2017). Indeed, the mayor's campaign \#LondonIsOpen emphasised that the city would remain open to the world and continues to embrace diversity and difference even after leaving the EU. "Let's say together - me, you, and thousands of other Londoners - that despite Brexit, London will always be open to the world, proud of our diversity and inclusive to everyone."5 The words Khan's chose to describe the campaign surely reflects London's multi-ethnic and multicultural demographics. According to the Migration Observatory (2011) based at the University of Oxford, 37\% of Londoners were born outside the United Kingdom, and the percentage of white British people living in the city fell to around $45 \%$ in $2011 .{ }^{6}$ As Keith $(2005,8)$ articulates, multiculturalism is not only a state-controlled bureaucratic political and economic project, but also "a product of cultural globalisation that involves demographic movements of migration and cultural networks of transnational sentiment." This raises the question whether a multicultural city such as London possesses the possibility to open up new avenues for us to learn to live with our differences. Can cities such as London be archetypes of a multiculturalism that we can hope to achieve on a national level, even in the face of an increasingly divisive contemporary political climate across Europe?

Paul Gilroy $(2006,1-6)$ recognises a glimmer of hope in this respect. According to Gilroy, the "crisis of multiculturalism" is indeed embedded in a kind of "post-imperial melancholia" for former imperial powers such as Britain, which suffer from a sense of loss and grief due to the pressures of globalisation. In this context, he argues that everyday interactions and encounters in the city-the so-called "everyday conviviality of multiculture" - can remedy this "post-colonial melancholia" (Gilroy 2006, 1-6). However, Gilroy may well be criticised for drawing an overly optimistic picture. Critics draw attention to the fact that everyday encounters of difference do not necessarily render cultural differences obsolete (Amin 2012), and its inhabitants do not necessarily live in "culture of fusion and synthesis" (Ang 2003, 150). Yet Gilroy's notion of “conviviality" challenges us to

\footnotetext{
${ }^{4}$ Accessed via $<$ https://data.london.gov.uk/apps and analysis/eu-referendum-results-a-demographicbreakdown/>.

${ }^{5}$ Accessed via <https://www.london.gov.uk/what-we-do/arts-and-culture/london-open>.

${ }^{6}$ Accessed via $\langle$ https://migrationobservatory.ox.ac.uk/resources/briefings/london-census-profile/>.
} 
explore and theorise what is distinctive about urban lives and practices, and how everyday experiences of cultural difference shape people's understanding of themselves and others. Thus, despite the fact that multiculturalism is a polysemic and contested term (Hall 2000, 2, 3), Gilroy's notion of conviviality invites us not to take multiculturalism for granted and understand how ordinary interactions (around difference) in urban contexts shapes people's sense of identity and belonging.

I share Gilroy's optimism to an extent, perhaps based on my own experience as detailed in the introduction of this thesis. Despite its complexity and uncertainty, the coexistence of different groups in the same urban space, each with their own cultural characteristics, histories, beliefs, and practices, leads to new avenues of thinking about how we can accommodate and negotiate cultural difference in our societies. This is the reason why the cultural diversity of our cities is of immense significance to many scholars who research urban centres and their inhabitants. The city is a container of encounters and experiences around cultural diversity and difference. Therefore, they are the best places to address the question of whether Gilroy's "conviviality" can indeed lead to new avenues for understanding both the self and the other - avenues that go "beyond policy, beyond official, intellectual, or party-political responses to the so-called crisis of multiculturalism" (Siapera 2010,4). My intellectual interest in the city also stems from this question, with a particular focus on the implications of urban multiculturalism in the construction of cultural identity and a sense of belonging for diasporic migrant women. Therefore, as one of the analytical centrepieces in my thesis, the city leads me to foreground the role of cultural difference and diversity in determining how migrant women relate, both to themselves and to others, and how those relations influence their sense of togetherness and the social divisions they encounter. Whereas Sassen's (1991) Global City approaches the city as a politico-economic frame of reference, discussing its characteristics as a major node in neoliberal global economy, my approach emphasises the role of culture, focussing instead on how the city's multicultural context and dynamics determine the experiences and identities of its inhabitants.

Following this, alongside some prominent scholars from cultural studies, postcolonial theory, and anthropology (e.g., Bhabha 2000; Hall 2008; Werbner 2006), I turn to cosmopolitanism - a concept that allows me to recognise the role of culture in the identity formations of the citizens of the multicultural city (Keith 2005, 2). In particular, I operationalise the concept of "vernacular cosmopolitanism" (Bhabha 2000; Werbner 2006) in order to examine the implications of "everyday conviviality" (Gilroy 2006) on the cultural identities and experiences of diasporic migrant women. The critical theorist Homi Bhabha 
$(2000,139)$ refers to migrants and minorities in Britain as "vernacular cosmopolitans" who translate between different cultures and negotiate different traditions in their everyday lives and ordinary practices: "It is this double life of British minorities that makes them 'vernacular cosmopolitans,' translating between cultures, renegotiating traditions from a position where 'locality' insists on its own terms, while entering into larger national and societal conversations.” As Bhabha argues, whilst migrant and minority populations in Britain continuously (re-)negotiate different traditions in their vernacular practices and routines, they indeed shed light upon the concrete implications of multiculturalism. In this context, vernacular cosmopolitanism challenges us to recognise how cosmopolitanism is not a normative ideal embraced only by the elite and the privileged, but rather is a necessity and a way of life for minorities in Britain. Following this, in my study, I draw inspiration from the concept of vernacular cosmopolitanism with the purpose of acknowledging and mapping the ways in which complex relations of we-ness and otherness are negotiated and experienced by migrant women in London.

Vernacular cosmopolitanism aims to uncover cosmopolitan visions and practices in relation to the realities and experiences of people in situated socio-cultural contexts (Pollock et al. 2002, 13). Thus, it recognises the multiplicity of the cosmopolitan ethos and its coexistence with different cultural identifications and formations. In this regard, Pnina Werbner $(2006,7)$ refers to vernacular cosmopolitanism as an oxymoron, since it seeks to conceptualise "apparently contradictory opposites: cosmopolitan patriotism, rooted cosmopolitanism, cosmopolitan ethnicity, working class cosmopolitanism and discrepant cosmopolitanism" (emphasis in original). Therefore, the concept's pluralistic and ambivalent character suggests that cosmopolitanism becomes embedded in the identities and experiences of those who do not necessarily self-identify as cosmopolitan or imagine a "borderless cosmopolitan community" (Werbner 2006, 2). My research study provides strong evidence that confirms this point. For example, women from Turkey maintain their national identity and cultural sense of belonging to their "home" nation through their religious identity, whilst strongly promoting ideals of multiculturalism in their claims for recognition in the urban public space as Muslim women. In this context, although they do not explicitly claim (or aspire) to be cosmopolitan, their diasporic identities are articulated with an urban cosmopolitan ethos as much as nation-oriented, religious identifications (see chapter 3 in this thesis). In line with Werbner's (2006) observations, the concept of vernacular cosmopolitanism allows me to unpack how migrants and minorities construct such complex, hybrid identities by negotiating seemingly contradictory cultural affiliations. 
Furthermore, as Nava (2002) argues, how (and why) women articulate and normalise difference allows us to unpack the gender-specific experiences of women and understand their processes of identity production in multicultural cities accordingly. As members of a multicultural city, the migrant women in my study all translate different cultures and traditions. However, the ways in which they develop their cosmopolitan ethos depends upon their varying material realities and social positionings. In this context, I ask how London coconstitutes diasporic migrant women's cosmopolitan, hybrid identities at the interplay of race, religion, generation, and social class in tandem with gender. In this context, vernacular cosmopolitanism allows me to address this question in a manner that accounts for their diverse negotiations of difference and articulations of diasporic identities within the specific socio-cultural contexts in which these come into being.

\subsection{Examining the City from Below: An Analysis of Everyday Life}

As Scott $(2016,1)$ writes, since the 1990s, the terms "digital city," "smart city," "cyber city," and "intelligent city" have gained academic prominence, promoting "futuristic visions of cities as radically transformed by digital technologies." Yet recent literature on urban media and communication emphasises how physical and digital spaces co-constitute a hybrid milieu by drawing attention to the unequal power dynamics and social struggles embedded in urban infrastructure and culture (e.g., Aurigi 2016; Georgiou 2013; Krajina and Stevenson 2019; McQuire 2008, 2016; Scott 2016). In The Media City, McQuire (2008) argues that digital media technologies have led to the emergence of "public sphericules" in which different groups can join the public space. However, for marginalised groups, "the problem is less one of being able to speak than of being heard" (McQuire 2008, 205). He further elaborates on this point with his concept of "geomedia," which both recognises and questions the role played by digital technology in the "production of public space, impacting on how we conceive and exercise our incipient right the 'right to the city,' how we negotiate social encounters, and how we experience relations of proximity and distance, presence and absence" (McQuire 2016, 12, emphasis in original). However, as McQuire and Georgiou (2015) suggest, media studies and urban studies currently stand in isolation from each other, and there is still a need to bridge the gap between the two fields (cited in Leurs et al. 2015). This indicates the need for further investigation of how the dynamic relationship between broader power structures and digital technology impacts the capabilities of minorities and 
marginalised groups. In this context, I am particularly interested in the role of digital technology in the social struggles of migrant women for self-representation and recognition, as subjects who face multiple forms of marginalisation within gendered and racialised social hierarchies in urban contexts. In line with this, the question is: What are the roles of digital media technologies (if any) in the constitution of agency and action for migrant women in the city?

My thesis addresses this question empirically via a micro-scale analysis of the everyday lives of migrant women living in London. It does so with the purpose of conceptualising the relationship between digital media and agency from the bottom up. Yet, this "everydayness" is articulated within a multi-spatial framework that encompasses the locally situated lives and broader systems of power that intersect urban, national, and transnational scales. As Çağlar and Schiller (2018) argue, this socio-spatial interplay locates migrants within unequal networks of power by connecting their everyday lives and experiences in the city with regional, national, and transnational formations. In this context, my aim in this section is to explain how I develop a conceptual approach in my analysis of everyday life in the city with a translocational lens that acknowledges the intersections of the city with broader national and transnational workings of power, and how migrant women use digital technology to negotiate (or challenge) them.

As Eade $(1997,3)$ argues, an examination of everyday life in a city such as London gives us the opportunity to "investigate locales within one of the world cities where it is widely accepted that the interweaving of global and local developments is intense." Globalisation has been held accountable for issues of "power", "inequality", and "conflict" for a whilst now, however, an in-depth understanding of how these play out for people in their everyday lives demands particular attention be paid to the micro-level, local contexts in which those everyday lives are embedded (Eade 1997, 7, 9). In my study, the ways in which issues of power and politics impact my participants are often revealed in how they perceive themselves in relation to national, transnational and global social hierarchies. For example, as will be discussed in chapter 4 , the young Somali participants in my study demonstrate a remarkable level of reflexivity towards how Somalis are portrayed, not only in the British media, but also in international news coverage. Likewise, as will be demonstrated in chapter 5 , Romanian migrant women often construct their identity within a social imaginary that operates on a European level. They show a hyphenated reflexivity that they continue to be seen as "outsiders" in a European context according to Western Europe-centric political discourses and practices. Yet, the city, as the main site of their everyday lives, is where both 
groups create and experiment with counter-agencies and actions by creating and practicing urban identities that, according to them, have the potential to accommodate (their) differences and diversity.

In this context, my research provides rich evidence, suggesting that we can understand the concrete implications of power structures that operate across different scales through a micro-level examination of everyday urban lives and practices. Therefore, I agree with Eade (1997) that an investigation of locale allows us to understand how issues of power, inequality, and conflict truly play out for city dwellers. Eade refers to globalisation as both an overarching formation and a process with which to refer to political and socio-cultural dynamics that go beyond, yet still materialise in, the local context. In my study, my aim is to specifically identify how different urban, national, and transnational spaces interweave and materialise for migrant women. I achieve this by understanding how the materiality of the urban environment connects with digitally mediated urban, national, and transnational landscapes in the multi-layered identity formation of migrant women. In this context, through a translocational lens, I examine how physical spaces of the "local" (urban) intersect with national and transnational contexts and spaces in the constitution of individual and collective identities.

My focus on the materiality of lives and spaces in the city leads me to pay attention to the workings of urban and broader power relations, and the varying ways in which they impact migrant women's material realities. Acknowledging the diversity of material realities and lifestyles within the city, and how these are linked to urban and social inequalities, allows me to contextualise the different positionalities, experiences, and sense-making processes of its residents (Ellis 2009, cited in Eade and Eckardt 2011, 12). London is a vast city that offers a plethora of different avenues of life and opportunities to its inhabitants. However, simultaneously, it is known for the deeply structured classed, ethnic, and racial inequalities that exist within and across different neighbourhoods and boroughs. Therefore, an examination of everyday life-worlds in the city requires one to be sensitive towards microscale communities, contexts, and spatial inequalities whilst situating them within the wider social landscape of London.

For example, the Grenfell Tower fire on 14 June 2017 in the country's wealthiest borough, the Royal Borough of Kensington and Chelsea, once again drew attention to how the city was indeed an "astonishing landscape of inequality" (MacLeod 2018, 463). Estates such as that in which Grenfell Tower stands, house mostly poorer families and ethnic minorities who carry out working-class jobs in wealthy boroughs. The indifferent and 
undemocratic attitude of the Conservative-run municipal authority and the state towards Grenfell residents has been seen by many as a brutal example of how the neoliberal political assault on the British social welfare state comes at the expense of the physical and emotional well-being of vulnerable residents (MacLeod 2018, 464). This is one of the many examples that highlight the importance of paying attention to the micro-scale spaces and contexts in which my participants' daily lives and routines play out whilst situating them within the broader urban context of London.

Furthermore, whilst it is important to acknowledge that the city's micro-scale spatial contexts impact quality of life and reinforce political, social, and economic inequalities (Atkinson, Burrows and Rhodes 2016; Higgins, Campanera and Nobajas 2014; Oakley et al. 2017), we should also recognise how they create diverse networks of relations of, and around, cultural difference for their inhabitants. My research reveals how migrant women form relations of we-ness and otherness, not only in relation to the white majority in the national context, but also in relation to the other ethnic and cultural groups they encounter on a daily basis in the city. In this context, the different social and cultural groups migrant women encounter and interact with in their everyday lives affect how they construct both themselves and others with regard to issues of race, social class, religion, generation, and so on. Back's (1993) research on multi-racial adolescent communities in South London confirms this point. By unearthing how racialised constructions of identity dominate cross-racial struggles over notions of belonging, Back interestingly demonstrates fluid and fragile articulations of inclusions and exclusions in local youth cultures. Thus, encounters with others in the city always carry elements of power and antagonism regarding the struggle to determine who are included in (or indeed excluded from) a particular space (Ahmed 2000, 8, 9). Cities are containers of various opportunities, tensions, and ambiguities that underpin people's relations - both with themselves, and with others. Therefore, it is important to acknowledge how city spaces are not only articulated in relation to their material realities, but also in relation to the experiences and imaginaries of urban dwellers - their sense of togetherness and their divisions. As Massey (2007, 7-10) argues, although London's "place identity" is "framed within a geographical imagination of London as a world city," its internal political dynamics and socio-cultural power structures shape the way in which profound binaries of "us" versus "them" are perceived by its inhabitants.

In this context, I believe that a translocal lens enables me to focus on such micro-level contexts within the cities (streets, neighbourhoods, boroughs, regions, etc.) with its emphasis on locality (and its context and community), allowing me to uncover the political and socio- 
cultural dynamics deeply embedded in both the urban context, and its culture. Furthermore, as explained at the beginning of this section, it also leads to an understanding of how these dynamics relate to broader national and transnational systems and formations through digitally mediated networks and spaces. In this regard, Appadurai (1995) emphasises the value of translocality as a concept and research perspective, making a convincing argument for how global and national formations and dynamics are interweaved and (re-)configured in neighbourhoods. He argues that global "localities" mainly operate at the neighbourhood level, shaping its context and community, "which belong in one sense to nation-states, but are, from another point of view, what we might call translocalities" (Appadurai 1995, 216). However, at this point, it is also important for me to state that, whilst I also argue for focusing on micro-scale contexts and communities, my approach to "translocality" differs slightly from Appadurai in two, albeit interrelated ways.

Firstly, I do not confine the "local" (in its physical sense) necessarily to the context and community of the neighbourhood. The reasons for this are mainly methodological and thus will be discussed thoroughly in the next chapter. However, it is important for me to state here that the neighbourhood as a locale is certainly an important space in which contexts and communities are shaped. However, I define where the city starts and ends using the perspectives of my participants as depending on the spaces and networks they construct and experience in their everyday lives. Therefore, differently from Appadurai, I do not necessarily start with, and build upon, the context of neighbourhood, instead allowing my participants to define their sense of "locality" in relation to the urban spaces and contexts in which their everyday lives are embedded. Therefore, the localities within the city, in their physicality and sociality, depend not only on where my participants live, but also on how they live, which is itself closely linked to their interests in the city-and where those interests manifest (King 2007, 1-6).

Secondly, in his argument supporting the use of translocality as an analytical lens via which to understand the relations amongst community, media, and the city, Carpentier (2007, 6) argues that the concept may be most useful when we understand the local and its contexts regardless of the scales these contexts imply. I find Carpentier's approach useful in the sense that I do not neglect the organisational role played by (and the mediation of) the nation-state and globalisation. Rather, I aim to uncover these from the perspectives of my participants without presupposing their role or significance. This is the why I refer to transnationalism as an overarching framework rather than globalisation, as doing so enables greater flexibility to discuss how migrant women themselves recognise the impact of both national and supra- 
national scales in the formation of translocalities. Hence, the "trans-" in translocality signals the co-production of communities, cultures, and spaces in a non-deterministic manner that recognises how urban geographies are articulated in relation to a diverse set of social conditions and practices across varying socio-spatial layers.

What can be gleaned from the above is that an examination of the city should explain how the "institutional and general organization of social hierarchies along visible differences" (Eade and Eckardt 2011, 12) is embedded across different social fields and spaces in the urban context. If the question is about how these social hierarchies truly play out for people, the answer lies in how they live their lives and carry out their everyday practices and interactions in the city. The dialogical relationship between the city and its people means that, whilst the city shapes how we perceive ourselves, it is also shaped by us in return. As Lefebvre (1991) theorises, the city is a "lived space" that is constituted through the everyday experiences and understandings of people. Yet, as Lefebvre notes, we cannot see it as separate from the systems of power, such as government, bureaucracy, and capitalism, since the "lived space" is fundamentally a social field that comes into being via the political struggles that emerge between the powerful elite and general population.

As explained in the introduction, the digital and the city are the two main analytical lenses through which I examine the cultural identities of diasporic migrant women. Having now clarified how I approach and incorporate each in my thesis, in the next section, I proceed to discuss the concepts of diaspora and cultural identity in the context of this study.

\subsection{Diaspora, Gender, and Cultural Identity}

Whilst early research on migration primarily focused on migrant women's experiences as the wives and children of male migrants, since the beginning of 1980s, scholars have drawn attention to the unique experiences of women at each stage of the migration process (Boyd and Grieco 2003, 3). Boyd and Grieco $(2003,7)$ explain that gender is incorporated into international migration theory by understanding the ways in which "gender is deeply embedded in determining who moves, how those moves take place, and the resultant futures of migrant women and families." However, as Palmary et al. $(2013,2)$ attest, research on gender and migration tends to focus on "mobility" (in terms of movement from one place to another), and the experiences before and after resettlement consider gender as little more than a neutral category of identity. In this context, they argue that a feminist intervention would 
seek to unearth how "gender is not merely an additional (discretionary or supplementary) variable that qualifies an already existing gender-neutral category of 'migrant' but rather structures that category (as male or female) in the first place" (Palmary et al. 2013, 3, 4). Marchetti and Salih $(2017,6)$, for example, point towards the increasing number of migrant women in the last three decades - a phenomenon referred to as the "feminisation of migration"- either under family reunion schemes or as single migrants to study or to work, but also trafficked as sex workers or domestic workers with little or no social or legal protection. In this context, they highlight the need to understand the political and economic regimes of cross-border mobility, as well as social and cultural norms and regulations in order to understand the gendered nature of migration (Marchetti and Salih 2017, 9). Similarly, by studying the case of Filipino domestic workers, the work of Parreñas (2015) demonstrates how the experiences of migrant women reflect a gendered view of society, specifically in the ways in which the international division of labour reproduces historical gendered divisions and inequalities. As the aforementioned examples demonstrate, critically interrogating gender in our theoretical and empirical discussions reveals how migrant women become subjected to othering, not only as ethnic and cultural minorities, but also as women in national and transnational systems of power.

In this context, the gender-specific realities, experiences, and strategies of women demand particular attention, since they allow us to study their unique roles and responsibilities in the formation of diasporas (Marchetti and Salih 2017, 9, 10). Furthermore, they allow us to critically engage with issues of power and politics by examining the interlinked systems of domination over race, ethnicity, class, gender, and generation on a national and global level. In other words, as Anthias and Yuval-Davis (2005, 69-79) argue, the deconstruction of the category of women on an empirical level allows us to understand how dominant structures of nationalism, racism, and patriarchy-which are practiced in the construction of others - are intertwined across different societal, ethnic, and cultural contexts. Intersectionality, as an analytical concept, allows us to address these entangled power structures in our empirical research and deconstruct the category of women accordingly in a critical manner.

The notion of intersectionality, which emerged from black feminist thinking, recognises how multiple oppressions of sexism, racism, classism, and nationalism are not experienced in isolation, but rather as a single, compound form of marginalisation (e.g., Collins 2000; Crenshaw 1989; Davis 1981). In this context, scholars such as Clifford (1994), Brah (2005), and Anthias (2009a), who compellingly argue for a more nuanced 
understanding of diasporas in relation to structured power relations with an intersectional perspective, provide key references. For example, Clifford $(1994,313)$ argues that the everyday lived realities of diasporic subjects are constituted through cultural differences that are racialised, classed, and gendered. Brah $(2005,15)$ offers an intersectional approach with the purpose of identifying how nationality and ethnicity intersect with issues of race, class, and generation in her theorisation of diaspora as a gendered phenomenon. Similarly, Anthias (2009a, 6-10) criticises "methodological nationalism" when theorising diasporas solely in relation to the nation. She argues for the use of intersectionality as a "heuristic device" via which to understand the intersections of different social locations in shaping diasporic identities and experiences. In this context, she urges for a more situated theorisation of diasporic identities and experiences by being attentive to the diverse ways in which particular contexts, places, and times impact gendered diasporic subjectivities (Anthias 2009a). Overall, these scholars demonstrate the significance of understanding how diasporic identities cannot be reduced to ethnic and national identifications, since they intersect with other social and cultural categories within specific political and socio-cultural contexts.

The translocal lens employed in this study provides a vital component that contributes towards the project's intersectional analysis of diasporic cultural identity. For example, most women in my study state how they perceive themselves in an empowered position in diasporic spaces given their increased socio-economic and symbolic capital after moving to London. Turkish women experience this via their participation in Turkish politics (see chapter 3), and Somali women via their role as organisers and donors of fund-raising campaigns aimed at rebuilding Somalia (see chapter 4). Both experiences help women to maintain a sense of belonging to their countries of origin by becoming part of diasporic spaces that are, on a transnational level, facilitated by digitally mediated connections and interactions. Yet even though many women now living in London earn their own incomes and increase their socio-economic status, they still experience discrimination and marginalisation as a result of a specific interplay of their gender, race, and religion. For example, the positions and possessions of such women are never stable, and thus an intersectional approach enables us to recognise their fluidity across different scales. Anthias (2020) compellingly elaborates on this point in her book Translocational Belongings, in which she presents a rich account of how the processes relating to the establishment of collective identities and belongings operate in an intersectional system of power across place, scale, and time. Thus, the concept of translocality has the potential to enhance our understanding of how different spatialities and temporalities are relational and interconnected 
in shaping modalities of power. My study contributes to the further establishment of a translocational lens with a bottom-up approach that yields a contextualised understanding of how migrant women themselves experience, negotiate, and challenge this intertwined landscape of power and inequality, and connect (or disconnect) different spatialities and temporalities accordingly.

In the light of the theoretical discussions above, by employing an intersectional and translocal lens, I demonstrate how gender is not a neutral attribute, but an important identity position that explains how (and why) migrant women experience certain realities and everyday life-worlds across intertwined cultural sites. As I work with female members of three diasporic communities, I demonstrate how, despite their particularities and distinctions, gendered diasporic subjectivities are always intersectional, dynamic, and context dependent. As Clifford (1994) argues, we need more comparative studies of diasporas that avoid archetypical definitions in order to acknowledge how the diverse histories, experiences, and realities of both individuals and groups render diasporas heterogeneous formations despite their shared characteristics.

Furthermore, as explained in the introduction, in my investigation of the female members of diasporas, I draw particular inspiration from the notion of identity. The reasons for this can be broadly summarised in two points. The first reason is connected to the fact that, as clearly manifested by the Brexit "Leave Camp," the identities and sense of belonging of migrants have become a major source of political conflict in the United Kingdom. In political and public policy circles, migrant identities are often discussed in an unsophisticated and populist manner in relation to the question of whether migrants' sense of belonging, loyalty, and commitment lie in their "home" or "host" country. In academic circles, however, identity theory tends to focus on the examination of how it impacts upon the everyday lives of individuals and groups within specific settings through dialectic processes-how we perceive ourselves, how we perceive others, and how others perceive us (Vertovec 2001, 577). Here, identity becomes a useful heuristic device via which to study the relations that human beings have established with themselves and others as socially constructed in nature at the advent of structural control and objectification (Rose 1996, 130). In other words, conceptually, identity has analytical value as a means via which to understand how one's subjectivity has historically come into being in relation to political, social, and cultural forms of domination. This dialogical process between the self and other political, social and cultural groups renders identity a fluid notion suspended between the individual's self-formation and broader societal forces. As Hall $(1996,2)$ argues, although identity is an ambivalent concept, 
"its centrality to the question of agency and politics" underscores its significance and relevance with regard to the issues of cultural difference and diversity in contemporary Western societies. In this context, I believe that by approaching identity as an intersectional and dynamic cultural formation, in the context of migrant women, my academic research project both challenges the hegemonic narratives of the political elite, and refuses to reduce migrant women to their ethnic and national affiliations.

The second reason is connected to the theoretical and empirical gap that exists in the study of diaspora, migration, and digital media. As explained in the first section of this chapter, whilst digital media have attracted a substantial level of academic attention, thus far, research has primarily provided insights into the digitally mediated ethnic, religious, and national identities and connections of diasporas. However, as has been demonstrated above, influential scholars studying migration and diaspora draw attention to the fact that diasporic identities are situated, temporal, and heterogeneous formations. This means that there is still a need to "fill in the gap" in the literature, so that we might understand the identity production of diasporas in the age of digital media technologies in a manner that is attentive to gendered, classed, racialised, and generational nuances. In this context, I draw upon Stuart Hall's (1990) theorisation of diasporic cultural identity, allowing us to recognise the temporality of diasporic cultural formations, and to socio-culturally contextualise their media-related practices. In his work Cultural Identity and Diaspora, the prominent cultural studies scholar Stuart Hall (1990) demonstrated a seminal theoretical framework that encompassed media, culture, and identity three decades ago. His work encouraged a generation of scholars and researchers to examine how the media and cultural production and consumption are intertwined in the ways diasporas construct their cultural identities. In this regard, in the next section, I draw upon and adapt his work with the purpose of developing a conceptual approach via which to theorise diasporic identity in the age of digital media.

\subsection{The Mediation of "Cultural Identity" in the Age of Digital Media}

Hall has been highly influential in understanding identity as a socially constructed cultural formation via which diasporas continuously re-imagine themselves in their everyday lives and cultural practices. Hall's (1990) theorisation of cultural identity suggests that we should theorise diasporic subjectivities as articulated through continuous processes that unite people, not only through a common homeland, but also through shared life trajectories and 
experiences. Hall distinguishes between two possible theorisations of cultural identity: First, cultural identity can be referred to as fixed and unchangeable by distinguishing one group of people from others based on shared history and practices. Second, identity can be seen as unstable and fluid, as it is socially constructed in nature. Here, it is with the latter definition that Hall challenges us to see the complexity of cultural identity by understanding how diasporic subjectivities are never stable and always in a state of temporal "flux." Therefore, Hall challenges us to see identities from a cultural perspective as multi-layered and hybrid social constructions articulated through dynamic, temporal, and context-dependent formation processes. He argues that cultural identity is never an essence, but a process of positioning between shared cultural practices and similarities on the one hand, and ruptures and discontinuities on the other (Hall 1990, 226). Hall (1990, 229) elaborates on the role difference plays in the process with reference to Derrida's "différance," which "remains suspended between the two French verbs 'to differ' and 'to defer' (postpone)." Thus, whilst this sense of identity recognises relations of difference, he also emphasises how identity is never concluded in the process of continuous (re-)production. Hall's concept of cultural identity allows me to synthesise the elements of city, diaspora, and the media in my theorisation of gendered diasporic identity in three ways.

Following Hall, I examine how difference is articulated in the diasporic identity production of migrant women who encounter it and live with the presence of others on an everyday basis as the inhabitants of the multicultural city. In this sense, Hall's conceptualisation of identity is an exceptionally useful notion for my study, which operates within the context of London, where my participants construct and perform multiple articulations of the self (and others) with regard to many different ethnic and cultural groups who also inhabit the city. The multiplicity and temporality of different positions from which to develop relations of similarity and difference in relation to multiple groups highlight how, as Hall argues, cultural identity is a dynamic and context-dependent process of articulation and negotiation.

Second, by theorising cultural identity as a temporal and dynamic formation, I am better equipped to recognise how varying social positionalities and spatial contexts intertwine in diasporic identity production from a translocational and intersectional perspective. As Anthias $(2009 \mathrm{~b}, 15,16)$ argues, we should see identities as socially constructed "translocational positionalities," structured by the interplay of different social locations (such as gender, race, and class) and intersecting fluid spaces (such as local, national, and transnational belonging) by recognising the importance of context and the situated nature of 
identity claims. With these considerations in mind, following Hall, I aim to recognise how my participants actively and continuously (re-)produce their cultural identities and sense of belonging through articulations of difference at the intersections between multiple social locations and cultural spaces.

Third, Hall $(1990,225)$ invites us to recognise the power of the media in the production of cultural identity, always changing with regard to the "narratives of the past" and the "continuous 'play' of history, culture and power." Thus, cultural identity can never be understood within a past and present binary because any revisiting (or retelling) of the past is about making something of the present and future. In Hall's words, cultural identity "belongs to the future as much as to the past" (225) and entails both continuities and discontinuities as they are (re-)produced. In this constant (re-)production of identity, Hall refers to the central role of imagination. He argues that identity is produced in an open symbolic space, and thus, it gives prominence to imagination in the ways past, present, and future are continuously (re)constructed in relation to each other. In this context, he theorises the practices of representation in Caribbean cinema as the positions from which the members of diaspora speak or write from "the positions of enunciation" (222). Through these positions of enunciation, they continuously (re-)imagine their histories, cultures, and experiences (222). This is the reason, Hall argues, that identity is "always constituted within, not outside, representation" (236) in relation to the intertwined relationship between identity, representation, and the media.

Hall's theorisation of the relationship between the media and identity echoes Anderson's (1983) Imagined Communities, which demonstrates the power of the media in the establishment of cultural homogenisation on the level of the nation-state by encouraging its members to think of (or to imagine) themselves as having a shared past, present, and future. Therefore, the central power of the media lies with its ability to reinforce "social imaginaries" - that we think of ourselves in a collectivist way through knowledge, practices, myths, symbols, and so on (Taylor 2002). Following Hall, I investigate the mediation of diasporic cultural identities through the everyday digital media use of migrant women as "positions of enunciation" from which they construct, imagine, and represent their histories, cultures, and experiences.

However, with the advent of new media technologies, my investigation cannot solely focus on the consolidation of identity through representational practices by interpreting "the media-as-text" (Alinejad 2017, 41, 46; Livingstone 2003). This requires me to go beyond the semiotic production and consumption of culture and to also understand the relationship 
between the media and cultural identity with regard to contemporary technological and sociocultural changes. As explained in the first section of this chapter, I draw upon the theory of mediation in my ethnographic investigation of digital media use (Barbero 1993; Couldry 2008; Madianou 2005; Silverstone 2005). The notion of mediation suggests that we need to incorporate the social and cultural in our understanding of material infrastructures of technology by acknowledging the meaning-making processes and situated everyday settings in which individuals find themselves. This challenges us to understand processes of mediation as representing "how people not only interpret media texts, but also the meanings of material media devices. This interpretation happens when they are taken up in practices of use" (Alinejad 2017, 41). Thus, an examination of digital media through "practices of use" adapts Hall's theory of construction of cultural identity through the media by situating their role beyond representational and discursive texts and practices in the age of digital technologies (Alinejad 2017, 41).

Whilst I offer a comprehensive discussion of how I empirically study "practices of use" in my methodology chapter, it is important to state here that I examine digital media use as encompassing a wide range of practices - from its cultural production and consumption, to interpersonal communication, and large-scale connectivity and interactivity. Within the theoretical framework of my research, by examining the "online" and the "offline" simultaneously, I investigate how migrant women mediate their cultural identities and sense of belonging through their everyday digital media use. ${ }^{7}$ In doing so, I aim to understand how, following Hall, digital media use can be seen as "positions of enunciation" through which migrant women not only construct (and imagine), but also "live, practice and experience" their identities (Braziel and Mannur 2003, 9). These "positions of enunciation" are fundamentally translocational in nature: they are formed in complex and shifting spaces, and in relation to intersectional social locations. However, how they are articulated can be best contextualised through the situated everyday life-worlds that materialise in the city.

\footnotetext{
${ }^{7}$ Here, it is important to stress that I do not ignore significant media events that create a sense of occasion and bring people together (Couldry 2003a, 62). I examine these as they take place during my empirical investigation and explore why and how they matter to my participants within the broader social and cultural settings in which their everyday lived realities are embedded.
} 


\subsection{Sub-research Questions}

The empirical focus of my thesis, as outlined in the introduction, is to understand the relationship between cultural identity production and digital media with a particular focus on the female members of three different diasporic migrant groups in London. In this context, the overarching research question driving my study is: How do diasporic migrant women living in London mediate their cultural identities at the crossroads of urban and digital spaces? In framing the theoretical foundations of my thesis, I consider how the city and digital media are equally important in the constitution of everyday life-worlds, bringing these together via a translocational perspective. I aim to address the overarching research question through several sub-questions informed by the remaining questions and gaps in the literature as highlighted in this first chapter.

Firstly, as explained in the opening section of this chapter, a non-media-centric approach allows us to address the urgent question of how (and why) digital media become socially and emotionally meaningful to diasporic migrant women in their social and cultural lives - an area that has thus far been largely neglected in academic literature. Secondly, as discussed in the subsequent section, London's multiculturalism — "everyday conviviality," in Gilroy's (2006) words - plays a central role in shaping the urban environment and raises the question of how everyday encounters with difference influence formations of both self and other. In this context, the notion of "vernacular cosmopolitanism" is operationalised with the aim of examining and contextualising how urban multiculturalism influences the cosmopolitan visions and practices of migrant women in diverse ways. Thirdly, as discussed in the next section, a city such as London should also be held accountable for its deep inequalities and divisions, implicating its inhabitants within broader systems of power differentially. My research aims to achieve this through a micro-scale analysis of everyday life and hopes to contribute to further understanding of the mechanisms at work by examining the role of digital media in the constitution of agencies and actions from the bottom up. Then, as extensively discussed in the fourth section, the concept of diaspora with a particular focus on gender demands an intersectional, comparative, and context-dependent perspective. In this respect, my inspiration to employ the notion of identity in my investigation stems from my desire to critically engage with issues of power and agency. Finally, as explained in the fifth section, I use and adapt Stuart Hall's (1990) theorisation of "cultural identity" through the notion of mediation in order to understand the intertwined relationship between diasporic cultural identity and (digital) media technologies. Thus, I argue that an analysis of digital 
media demonstrates how diasporic migrant women produce and live their cultural identities within a translocational framework that acknowledges their varying social locations and multi-spatial sites of belonging.

In the light of the above, the overarching research question "How do diasporic migrant women living in London mediate their cultural identities at the crossroads of digital and urban spaces?" is guided by several sub-questions:

-How do migrant women themselves recognise the role of digital media technologies in their everyday lives and cultures?

-What role does London, as these women's main site of everyday life, play in the articulation of the relations between the self and others, and different cosmopolitan visions and practices? -How (if at all) do digital media technologies facilitate the constitution of everyday actions and agencies for migrant women in the city?

-To what extent does gender, in tandem with the issues of ethnicity, race, social class, generation, and religion, influence how migrant women use digital media technologies and mediate their cultural identities?

Throughout my thesis, I aim to address these questions through an in-depth ethnographic study of the digital media use and everyday lives of diasporic migrant women in London. By employing a translocational lens, I demonstrate how they mediate their cultural identities in shifting cultural contexts and social locations at the intersection of the urban and the digital. Before proceeding to the discussion of my empirical findings, in the next chapter I explain both the methodological framework and methods chosen via which to operationalise my research objectives. 


\section{Chapter 2: Methodology}

\section{Introduction}

In this thesis, my main objective is to situate the "everyday" cultural identity formations of migrant women at the crossroads of urban and digital spaces. As my study is concerned with the everyday lives of migrant women, I chose ethnography as my main methodological framework, allowing me to delve into their personal narratives - their cultural practices and daily experiences. The urban and digital dimensions of my research require me to formulate a multi-sited ethnographic approach that exposes how the online and offline domains of these women's lives are systematically interconnected (Lane 2018). Research that attempts to align urban and digital ethnography approaches remains limited despite the manner in which contemporary lives now unfold at the juxtapositions of material and "digital streets" (Lane 2016 , 44). Hence, in order to examine "everyday" life and the online-offline continuum upon which it plays out, I combine a set of methods that examine socio-cultural and digital mediarelated practices together, and systematically link physical and digital spaces.

During a one-month period between March and April 2017, I conducted pilot fieldwork in London. This fieldwork significantly shaped the structure of my final research design. In carrying out pilot fieldwork, my initial intention was threefold: to develop a rapport with members of some diasporic community organisations; to carry out a number of in-depth interviews; and to conduct observations in various neighbourhoods and community gatherings. These objectives seemed viable, as I had previously contacted several diasporic organisations via e-mail and felt well-informed about the communities generally by virtue of a comprehensive literature review. The timing of my research was fortunate: In the run-up to the historic Turkish constitutional referendum - the shift from a parliamentary to a presidential system - on 16 April 2017, there were many diasporic groups, associations, and organisations that were campaigning, which helped me to meet and network with many people. Furthermore, as a Turkish Cypriot, my native language of Turkish granted me access as well as an important level of ease and familiarity and, as a result, I was able to immerse myself in the community. The social media accounts of several individuals and groups provided a wealth of material to analyse and allowed me to become aware of several important issues and patterns.

In contrast, getting access to Somali and Romanian communities was a more challenging affair. Whilst I had some Romanian friends from my five-year residency in 
England as a student, snowball sampling through my personal networks seemed to lead only to young, university-educated women. During the entire one-month pilot, and despite introducing myself and asking for help and collaboration, I failed to secure a single appointment with a representative from a Somali community organisation. Despite these obstacles, my month-long fieldwork with the Turkish community was productive and made me aware of some initial methodological concerns to be tackled.

As explained in the previous chapter, the use of a translocational lens proposes an investigation of "the local" that builds upon the manner in which its community and context is formed at the intersections between digitally mediated national and transnational spaces of belonging. Appadurai (1995) argues that translocalities are produced at the neighbourhood level by interweaving national and transnational scales in the formation of both its context and sense of community. Following Appadurai, my initial aim was to focus on the neighbourhoods in which members of Turkish, Somali, and Romanian migrant groups predominantly live in London. However, my pilot fieldwork with the Turkish community led me to realise that limiting my research to the level of neighbourhoods could give a rather limited picture of a highly heterogeneous community that is dispersed across different parts of the city. In addition, from the six in-depth interviews and two meetings with professionals I carried out during the pilot fieldwork, I realised how participants' accounts of their everyday lives and experiences were never confined to one specific physical location. As the inhabitants of a large city, they had to regularly commute for work, visit family and friends, as well as travel across the city for other responsibilities and leisure activities. Indeed, even my informal conversations with some whose daily routines revolved around the respective neighbourhoods in which they lived, contained references to different parts of the city and its inhabitants. These observations allowed me to acknowledge, not only the importance of urban mobility as a physical movement itself, but also how important it was to understand individual and group understandings of the broader context of the city with reference to its many locations, inhabitants, and socio-economic divides. In the light of the above, it became apparent that I could not investigate migrant women's everyday lives and experiences via pre-determined, specific locations within the city (such as neighbourhoods). Rather, I had to investigate the broader network of spaces that actively shape the daily urban lives of migrant women.

In this way, my pilot research revealed two major issues that were to shape my approach, both to the research and the communities. First, instead of limiting myself to "migrant neighbourhoods", it made more sense to encompass multiple locations as they 
emerged - as important lived contexts for migrant women themselves. Second, I had to be attentive to the fact that my positionality as a researcher in the field was not "fixed", and that my personal background meant that I possessed different levels of familiarity towards (or distance from) the three communities under investigation. These issues raised a number of questions that I needed to address from the very beginning, namely: How does a researcher define the physical sites of the city by going beyond the boundaries of the migrant/ethnic neighbourhood? How to decide the sample in a way that captures the heterogeneity of diasporic migrant communities when one does not have the same level of access and familiarity to each group? Finally, how to investigate the digital media that connect different spatial and temporal contexts in order to understand diasporic formations and connectivity without overstating the importance of national, ethnic, and religious categories? These questions and the insights gained from the pilot fieldwork informed my methodological choices and the research trajectory when carrying out my year-long intensive ethnographic fieldwork between September 2017 and September 2018.

The first part of this chapter discusses the rationale and the details of the methodological choices I followed in formulating the ethnographic research design of my study. It explains the inspiration I took from practice theory (Couldry 2004; Cruz and Ardèvol 2013) as a means to study digital media use and employ a multi-sited approach to determine physical and digital sites of investigation in my ethnographic endeavour. I also review the process of participant recruitment and provide a detailed appraisal of the research conducted and considerations applied to, and raised by, this project. The second and third sections provide a comprehensive literature review of epistemological approaches and methodologies specific to the realm of digital media. They outline how, in order to achieve my research objectives, I employ multiple qualitative and quantitative methods simultaneously, as part of a mixed-methods (Alinejad et al. 2019; Leurs 2015) and digital ethnographic approach (Pink et al. 2016). The fourth section is dedicated to explaining how my own identity and reflexivity as a researcher has influenced the research process, addressing issues of access, trust, and insider/outsider positionality. Finally, I examine the ethical considerations raised and how I tackle these at different stages of the research project. 


\section{1 "Multi-sited" Media Ethnography}

In its broadest sense, ethnography refers to employing a range of activities for investigation, such as observation, interviews, conversations in everyday settings, and a detailed account of the field. Grounded in the concept of culture, ethnography utilises qualitative methods to observe individuals and groups in their everyday situations in order to understand how and why routines and patterns occur. Although ethnography was first associated with anthropology, with the development of cultural studies in the second half of the twentieth century, there has been an "ethnographic turn" in the field of media and communications (Brennen 2017, 166, 169). However, despite the fact that ethnography has become a widely employed method since then, there is no clear-cut ethnographic methodological trajectory for researchers to follow in the field (Cruz and Ardèvol 2013, 30, 31; Murphy 2011, 380). In this context, I find inspiration from practice theory and employ a multi-sited approach to guide my ethnographic methodological framework. The former allows me to examine digital media use through the notion of "practice", whilst the latter informs my understanding of the field and the selection of sites (online and offline) for empirical investigation.

Media ethnographies are broadly divided into two categories: ethnographies of media production; and those of media consumption (Murphy 2011, 385). Digital media sites such as websites, mobile applications, and social media platforms, however, blur the distinction between the domains of production and consumption since users can engage with both processes due to the interactive character of the Web itself. The interactive character of the Web has indeed led a number of researchers such as Hine (2008), Kozinets (2009), and Pink et al. (2016) to develop techniques and epistemologies specific to the Web with the aim of gaining a comprehensive understanding of how digital media are used for sociality and connectivity. Furthermore, considering my project's emphasis on diasporic connectivity, it was necessary for me to also investigate the more private domains of digital communication, which play an important role in the transnational lives of migrants. As my main aim was to understand how digital media technologies are integrated within everyday life-worlds, I needed to capture the wide range of ways in which migrant women use digital media for production, consumption, communication, and connectivity across different contexts. This required me to go beyond traditional ethnographic theoretical frameworks such as "production", "reception", or "domestication", focussing instead on the more complex relationship between people and technologies in the age of digital media (Cruz and Ardèvol $2013,31)$. 
Couldry (2004) firmly advocates for practice as a theoretical paradigm in media studies, suggesting that researchers should not only understand media-related practices, but also how they are applied to everyday practices. In this context, Couldry advocates for approaching media practices as open-ended - that is, beyond practices we commonly define as part of "media culture"-yet still shaping our understanding and beliefs about the media. I subscribe to the practice theory approach and operationalise it in order to examine digital media use "as a wider set of practices - most of them with, around and through digital technologies - related to creative processes carried out by individuals or collectives with different goals and purposes" (Cruz and Ardèvol 2013, 32).

In classical anthropology, the notion of the field with which the researcher engages by "being there" is central in any ethnographic endeavour (Murphy 2011, 383). Prior to my pilot fieldwork, I aimed to focus on the Boroughs of Hackney and Enfield (North London) for the Turkish community; the Borough of Tower Hamlets (East London) for the Somali community; and the Boroughs of Barnet and Brent (Northwest London) for the Romanian community. However, as explained above, I ultimately decided not to limit the field to these migrant neighbourhoods, since all three communities were physically dispersed across the city (in terms of residency), and understanding this physical dispersal was deemed essential if I was to capture fully the diversity and complexity of each community. In addition, although their place of residence undoubtedly mattered, urban mobility (or lack of it) also proved to be an important layer of analysis. For example, the women who regularly travelled to different boroughs or neighbourhoods for education and work were exposed to diverse social contexts that affected their everyday experiences in the city. Furthermore, the classical notion of the "field" as a singular and pre-determined space was also problematic for my investigation of digital contexts and sites. When applied to ethnographic investigations, the practice theory approach suggests that researchers should not only engage with pre-determined field sites, but should also examine a wide range of engagements with digital media by making connections amongst multiple online contexts as the fieldwork progresses (Cruz and Ardèvol 2013, 34).

In this context, parallels emerge in the need for scrutiny of multiple contexts and sites in both urban and digital realms to be approached in a flexible manner, rather than being limited to pre-defined online and offline spaces. Since the 1990s, the notion of the field has been re-theorised by anthropologists with the aim of encompassing complex and fluid sites in which cultural practices flourish in an increasingly mediated world (Alinejad 2017, 19, 20). Thus, in contrast to the classical notion of the field as a singular place, the researcher focuses 
on multiple temporally emergent sites in a flexible manner (Murphy 2011,383). This approach is called "multi-sited ethnography", and it has been applied to media research by scholars who focus "if not on cultural completeness, then on linkages and connections" (Murphy 2011, 383). Couldry (2003b, 42, 52) urges researchers of the media to recognise how our increasingly mediated lives go beyond local, physically embedded settings, encompassing instead a wide range of contexts. In this regard, he proposes that researchers should engage with a number of contexts and build up a larger picture based on patterns. The multi-sited approach to the field is deemed to achieve this by allowing the researcher to contextualise the relationship between the media and other practices without limiting the field to pre-determined sites of media culture. I applied this approach to my ethnographic inquiry and examined multiple sites of sociability and connectivity, rather than focusing on predefined "migrant spaces" in my investigation of urban and digital spaces. This allowed me to operationalise practice theory by being flexible and investigating a wide range of contexts with the aim of understanding how media practices are organised across different settings. In this regard, I moved between a number of online and offline contexts (without necessarily immersing myself in all of them) and made connections amongst these with the aim of understanding how people think holistically about, and engage with, digital media (Couldry 2003b, 52, 53).

In order that the research design might be shaped accordingly by making explicit decisions in the field, ethnography requires the researcher to continuously reflect, both on their interactions with people in the field and the observations made (Murphy 2011, 388). Gradually, in relation to my relationships with informants as well as the topics and issues that emerged during the fieldwork, I decided to focus on several physical sites of investigation. This helped me to gain an understanding of how divergent issues and patterns across multiple urban contexts made sense within the broader political and socio-economic framework. For example, I spent a considerable period of time in North London to observe the Turkish migrant community. However, via my interviews with women who did not reside in North London, I also realised that they perceived the "North London Turkish community" to be poorer and less formally educated than the Turkish migrants who live in different parts of the city. This allowed me to realise how one's place of residency is associated with social class, leading me to pay more attention to the social and economic divides that exist within the Turkish community. Indeed, there were a number of middle-class women who openly did not want to be associated with "the North London community". This allowed me to understand internal social class dynamics within the community, and realise what different urban spaces 
symbolise to, and how they are imagined by, the participants (see chapter 3 in this thesis). In this context, my ethnographic research focused on multiple physical sites for each community, encompassing homes, streets, neighbourhoods, cultural centres, mosques, schools, and leisure activity sites.

At this point it is important to acknowledge how the pressure of studying three communities within a period of one year often led me to make strategic decisions and prioritise certain locations over others by following groups and individuals who were willing to participate. For example, despite my initial desire to study Somalis in East London, I made the decision to shift my focus to West London with the intermediation of two young BritishSomali interlocutors. They informed me that West London was also home to a considerably large number of British-Somalis and were rather surprised to hear that East London was a more common site of investigation for academics. Indeed, on numerous occasions, such information led me to revise my research design and adjust the sites and boundaries of the field accordingly. As Morley (2007) writes, most methodological choices tend to be pragmatic, since "research is always a question of what you can do, in the circumstances you face, with the resources available, which is most likely to get you something like the kind of data you want" (cited in Elsayed 2011, 158).

I also implemented a similar strategy in determining online sites of investigation, upon which I will elaborate more in subsequent sections. Although I began with investigating a pre-determined corpus of diasporic websites, I regularly reflected upon my ethnographic findings in order to decide which digitally mediated spaces to focus on for further examination. In this context, I remained flexible by being open to websites, social media platforms, and applications that were shared as cultural sites by the participants. As will be discussed in the following sections, existing research on digital media and diaspora largely focuses on migrants' ethnic, national, and religious online networks, limiting its reach to migrant/diaspora-themed digital sites. Thus, it can be argued that such research reproduces "methodological nationalism" (Wimmer and Glick Schiller 2002) and neglects how migrants' digital connections go beyond their national and cultural affiliations with their countries of origin. In this sense, I believe that my multi-sited approach, which was implemented by incorporating digital sites based on the practices and preferences of participants (rather than a pre-determined corpus of digital sites), allowed me to avoid "methodological nationalism" and capture a complex, hybrid mediation of diasporic cultural identities.

Following on from the above, taking ethnography as the main methodological framework of my research project allowed me to achieve my aim of developing an in-depth 
understanding of the experiences and realities of migrant women and understanding the "sociality" of, and surrounding, digital media. In this way, it proved to be a productive methodology with which to approach migrant women beyond the simplistic category of "digital media users" and gain an understanding of the complexity of their social and cultural worlds in an online-offline continuum. By implementing a multi-sited approach to my ethnography, I examined the field as comprised of diverse yet connected spaces in which digital media become part of everyday life-worlds. Drawing upon a specifically "non-digitalcentric" approach (Pink et al. 2016), I investigated digital media use existing along an onlineoffline continuum and drew connections across multiple physical and mediated spaces. In doing so, I managed to explore a wide range of physical and digital sites and contexts, enabling me to identify and elaborate upon patterns of thought, action, and engagement with the (digital) media.

\subsubsection{Participant Recruitment}

My research draws mostly on in-depth interviews and participant (and non-participant) observation. The interview sampling consists of sixty women (twenty from each community) aged between 18 and 56. As this is an ethnographic, qualitative project, I do not suggest that the sample statistically represents any of the target communities. Nevertheless, I believe that it was important to recruit women from different social and economic backgrounds in order to capture the heterogeneity of these groups and to operationalise the intersectional and comparative approach to diasporic cultural identities. In the beginning of this chapter, I examined the practical impact that my own identity had upon the issue of access and how this meant that I could not rely on the same techniques and strategies for recruiting participants from all three communities. Furthermore, many women were understandably sceptical of an outsider asking them to open up about their everyday lives and experiences. As it was crucial that I was able to observe the women in everyday contexts and ordinary settings, I had to gain their trust - either myself, or through their established social contacts. By employing different recruitment strategies, several women from each community became "key" participants by allowing me to regularly visit their houses and attend social gatherings for closer observation and examination of their everyday lives.

Prior to the pilot fieldwork in March 2017, I posted an announcement asking for interviewees from the Turkish community on several Facebook groups, such as the "Londra'daki Turkler" (Turks in London) and "the London Turkish Meetup Group", as well 
as several student societies. The number of responses to these announcements far exceeded my expectations, with positive responses from forty-eight women who expressed their interest in taking part in my study. I contacted each woman via Facebook messenger and asked about their age and occupation. Ultimately, I arranged six interviews with women between the ages 24 and 41 . Analysis of these interviews revealed how generation (in terms of age) was as important as economic resources and material realities in determining how these women engaged with the city and digital media technologies. On the strength of these findings I decided, in my main study, to aim for as balanced a sample as possible in terms of social class and generation for each target community. Here, it is important to state that I do not interpret social class as a fixed economic category determined solely by the financial capital of a particular participant. Rather, I draw upon Bourdieu's notion of class habitus. As Bourdieu (1984) argues, class is always determined in relation to changing trends of consumerism, public discourses, and practices. In this context, I take the symbolic and cultural status of the participant into account (such as education, occupation, and lifestyle) and critically engage with how these constitute class distinctions in my empirical analysis. Returning to London for my year-long fieldwork in September 2017, I re-established contact with three of the women I had previously interviewed, and who had agreed to participate in the project as observed participants. I regularly spent time with them, either in their houses or outside (alone or with other people) in order to observe their daily lives in home and leisure activity contexts. Additionally, I adopted a snowballing recruitment technique in which I relied on my personal networks for further access to participants. I also held interviews with representatives and members of several associations in North London, such as Millî Görüş and the Enfield Alevi Cultural Centre, which I visited to conduct observations on numerous occasions.

Between January and April 2018, I carried out my fieldwork with the Romanian community. As mentioned earlier, my background as a former university student in the United Kingdom allowed me to rely on my personal networks to recruit interviewees and immerse myself into the social circles of young university-educated Romanian women. However, in order to recruit women from more diverse social and economic backgrounds, it was necessary for me to work with an insider who could act as my "gatekeeper" to the community. For this reason, I posted an announcement on Facebook to recruit a research assistant who could help me with issues of access and translation. Via my online networks, I met Veronica, who worked at a community association as a teacher. Veronica helped, not only with recruiting participants and translating from Romanian to English, but also with 
gaining general insights into the Romanian community. She was present for those interviews in which the interviewees' level of English was limited. Of note here is how the interviews I carried out individually, without the mediation of a third party between myself and the interviewee, felt more personal. In this context, I believe that the setting of such interviews slightly influenced the results, since the data I gathered was sometimes less detailed.

Finally, between the months of May and September 2018, I carried out my research with the Somali community - initially the most difficult community to access. As in the case of the two other communities, I turned to the internet and posted announcements on several Facebook groups. At the same time, I had meetings with representatives from several organisations, however, these did not lead to any long-term collaboration. When my efforts did not prove fruitful, I contacted the owner of the Instagram account Somali Sideways, Mohamed, whom I had been following with great interest for almost two years. Mohamed's Instagram account, depicting Somalis from different parts of the world, had grown at a rather fast pace. I was aware from the very beginning of the project that young Somalis were social media-savvy based on the considerable number of famous young Somalis on the internet with large follower bases - so-called social media "influencers" (Abidin 2015). Therefore, I was genuinely curious about Mohamed's inspiring work and success, and wanted to see if he had any suggestions that might help me to initiate my research. As a result of our meeting, Mohamed agreed to help me by posting a Facebook post that a doctoral researcher was looking for a research assistant to work with British-Somali women in London. With the help of Mohamed, I met two young British-Somali women, Hoden and Hayat, who introduced me to some of their family members and friends. Whilst it was rather easy to establish relationship with young women who were enthusiastic about taking part in my project, older women were unwilling to do more than short interviews. This is the reason why Hoden, for example, was present in the family meetings. She introduced me to her older female family members and translated when required. This helped me to become a trustworthy acquaintance in the eyes of the women concerned. In addition, on the recommendation of Hayat, I collaborated with the HAYA Community Centre, which allowed me to conduct interviews with some of their members and beneficiaries in their Hayes office in West London.

Participant recruitment varied from one community to another with a combination of purposive and snowball sampling techniques. In the initial phase of the research, the internet played a significant role as a tool for recruiting interviewees and finding interlocutors and "gatekeepers". However, limiting the participant recruitment to the individuals and groups I managed to reach on the internet would have inevitably led to a skewed sample of 
participants, encompassing only those women with a high level of online visibility and digital access. Indeed, some women's digital media practices are tailored towards more private and closed forms of communication and sociality, for example those of religious women from Turkey (see chapter 3 in this thesis) or of the first-generation British-Somali women (see chapter 4), neither of which are easily visible or available to a researcher. Thus, I decided not to limit the participant recruitment to publicly visible online individuals and groups, and aimed to gain access to different social groups within each community. In this context, to establish further access to participants, I relied largely on the relationships I had previously forged with community organisations and interlocutors. At each stage, I always began with a small number of people and expanded my sample strategically to ensure balance and diversity.

As my project aimed to work with three different communities over a limited period of time, it would not have materialised without the help of Veronica, Hoden, and Hayat. Not only did they open doors so that I might meet and gain the trust of new people; they also partly directed me to focus on specific subgroups and locations in accordance with their "insider" knowledge, as well as their own social networks and connections. It was indeed a collaborative endeavour, since they helped me to recruit participants, and also thought with me during the process. I now proceed to describe how I conducted my research, investigating people and contexts through in-depth interviews and observation.

\subsubsection{In-depth Interviews}

In total, I conducted sixty semi-structured in-depth interviews with twenty women from each of the three communities. The interviews ranged from forty-five minutes to four hours in length. In some instances, I conducted interviews directly during my initial meetings with participants in ordinary settings or situations, such as at a mosque, protest, or social gathering. However, in most cases, participants did not want to go beyond informal conversations in such settings and preferred to be interviewed in-depth at a later time. The date and location of interviews depended upon the preferences of the interviewees in order to ensure that they found the occasion convenient and comfortable. I also came to realise how their choices often revealed much about their daily routines, responsibilities, or leisure activities, which allowed me to understand the importance of each setting and contextualise my findings accordingly in my empirical discussions. 
Before posing a question and starting the interview, I took the time to inform the interviewees about my project as clearly as possible so that they were well-informed about both the research topic, and my objectives. In many cases, this prompted the participant concerned to talk about certain topics, events, social media platforms, or mobile apps that they either considered important for my research, or important to the way they would be represented within it. Whilst this partly reflected their desire to give socially acceptable answers, it also revealed important insights about their perceptions, feelings, and selfpositioning. This created the need to be flexible, rather than sticking firmly to the interview topic guide, in order that the conversations might be free-flowing and comfortable for the interviewees. For example, despite my aim not to impose ethnic labels, many interviewees talked enthusiastically about their national and/or ethnic affiliations, respective migrant group, intra-community dynamics, etc. Therefore, the decision to present my analysis of the empirical data in a way that dedicates a chapter to each diasporic migrant community reflects the self-identifications of the participants in relation to their countries of origin, rather than a top-down decision taken on my part. However, it is also important to note how such selfidentification did not always suggest loyalty or a sense of belonging to their respective ethnic and/or national group. On the contrary, many also expressed why and how they see themselves as distinct from other members of the community depending on their social class, political affiliation, generation, and gender. This explicit desire to self-represent themselves differently from the "typical" Turkish, Romanian, or Somali migrant revealed some of the ways in which these women seek to position themselves in a diasporic context. Such encounters allowed me to understand how nationality and ethnicity intersect with other axes of identity and come to matter for migrant women's own subjective perceptions of how they fit into different hierarchies of social order through politics of categorisation (Moncrieffe 2007, 1).

In addition to the structured interviews outlined above, I asked permission to follow their online activities for a longer period of time by adding them on social media platforms such as Twitter, Facebook, Snapchat, and Instagram. I will discuss how this method became an important part of my longer-term digital ethnography and the ethical considerations it raises in sections 3 and 5, respectively. All interviewees were asked to sign a consent form and were presented with a voucher for $£ 20$ (approximately $€ 21$ at the time of writing) as a token of appreciation after the interviews.

Based on my theoretical framework, I constructed an interview topic guide that had three main sections. In the first part, I had general questions in order to give the interviewees 
some space to introduce themselves. Later, I invited them to share their thoughts about the city and their everyday routines and experiences. The final part of the interview focused on identifying, mapping out, and elaborating on the digital media spaces and practices with which they engaged. This final section proved to be the most difficult, as some interviewees found it difficult to talk about the role played by digital media in their lives. As digital media are so embedded in our daily lives and often taken for granted, it can be difficult for a researcher to encourage interviewees to thoroughly discuss the subject. The exercise of mapping, which is referred to as a "participatory research technique", helps individuals to reflect on their digital media practices by visualising their online practices and networks (Leurs 2015, 78, 79). Thus, in some instances, I asked participants to draw a map of their favourite digital media applications and social media platforms, and elaborate on their engagements with them as a means to better understand the diverse social meanings assigned to them.

In order that I might fully focus on the conversations rather than taking notes, most of the interviews were audio-recorded on tape. Only eight of the participants did not want their voices to be recorded. On these occasions, I noted down direct quotations at the time and added relevant themes and events discussed in my notebook after the interviews. Regarding translation, I was helped by Romanian and Somali research assistants who assisted me during the interviews as the need arose. Thus, all the interviews with Romanian and Somali participants were conducted and transcribed in English. Seventeen out of twenty interviews with Turkish and Kurdish women were conducted in Turkish. These were transcribed in Turkish and I then translated direct quotations used in the thesis into English. I made the decision to include grammatically incorrect sentences and words used out of context as they were spoken by the participants. Like myself, most women in this study are not native English speakers, and our "broken" English reveals our migrant backgrounds. Quotations are shown in italics in order to have their voice stand apart from the body of the text and to acknowledge that the explanation and contextualisation of their narratives are my own interpretation (Leurs 2015, 96).

I began my research with the aim of examining diasporic identity construction and negotiation at the crossroads of urban and digital spaces. Yet during the initial readings of the interview transcripts, I realised how, as a broad and abstract concept, identity encompasses many different conceptual and spatial layers. This is the reason why I decided to use an "open coding system" to identify themes without imposing a predetermined framework (Brennen 2017 , 187). Once the first round of coding was complete, I ended up with a significant 
number of provisional themes, such as North London, urban mobility, cosmopolitanism, religion, gender, memory, WhatsApp, Facebook, transnational connectivity, and so on. I decided to organise the data into codes under three different categories: axes of identity; sites/platforms; and themes. The category axes of identity allowed me to operationalise the notion of intersectionality by revealing emergent patterns in relation to generation, social class, religion, race, and nationality. The category sites/platforms allowed me to identify the main sites where the participants' digital connections and interactivities took place, such as diasporic websites, youth YouTube channels, familial communication on WhatsApp, Facebook groups, etc. The category themes allowed me to think and contextualise the data thematically. For example, I created the code "urban mobility", since it was an important contextual element in young Somalis' narration of their everyday lives in the city (see chapter 4). Similarly, I created the code "neoliberal cosmopolitanism" for middle-class/upper-middleclass Romanian women, since their cosmopolitan identity performances were largely accompanied by a neoliberal logic (see chapter 5). At this stage, I used the NVivo software (Version 12.0), which helped me to visualise patterns by allowing me to assign the codes under these categories to each participant. By using NVivo, I visualised thematic coding trees and captured patterns that could be explained through assigned demographic features. For example, whilst transnational belonging was an existing theme for all British-Somali women, I could see how codes such as humanitarianism and WhatsApp were assigned to the first generation, whereas codes such as entertainment, memory, and YouTube were assigned to the second generation. This allowed me to establish the relationships between generation, digital media, and transnational connectivity, and examine points of convergence and divergence (see chapter 5). Thus, I could systematically develop categorisations and themes, and visualise patterns. This was followed by a literature review phase and theoretical reflection within the framework of my research topic. This allowed me to come up with the more subtle themes of tactics, performativity, and citizenship, which constitute the core concepts of each empirical chapter.

\subsubsection{Observation}

Earlier, I mentioned how I divided up the fieldwork in three different phases, carrying out interviews with migrant women from Turkey, Romania, and Somalia at different times. Similarly, I also carried out intensive sessions of observation with each community for a period of four months. As Pink and Morgan $(2013,355)$ argue, short-term ethnography is an 
efficient methodological choice for researchers as long as they focus on their topic and objectives, clearly inform participants about their intentions, and invite them to engage with their usual media-related practices during observation sessions from the very start. As they rightly comment, researchers of the internet usually carry out their ethnographic engagement over long periods of time through online involvement, even though the actual encounter is relatively short in comparison to conventional long-term ethnography (Pink and Morgan 2013). In order that I might immerse myself in my target communities, I utilised observational methods. This was done with the aim of treating digital media as an everyday practice - albeit one embedded in other socio-cultural spaces and experiences, rather than a self-contained "world apart" (Miller and Slater 2000, 5). I conducted participant and nonparticipant observation depending on the people and contexts to be studied.

Participant observation is an integral method of ethnography that allows the researcher to interact and develop a rapport with group members in order to understand their cultural values, beliefs, and practices within the context of their everyday lives and routines (Brennen 2017, 170-73). The participant observation sessions were largely carried out with key participants, who allowed me to observe their everyday lives and routines. Obviously, I was only allowed to become part of their world to the extent to which they granted me access. Therefore, the contexts I managed to study were beyond my control, since they were largely determined by the participants themselves. The younger women were more willing to invite me to their leisure activities, whereas older women often preferred to carry out the sessions at their houses.

The non-participant observation method is applied by researchers who do not wish to make their presence obvious, maintaining a distance from the group members in order not to interrupt the flow of events (Flick 2009, 223). The non-participant observation sessions were carried out in neighbourhoods, at cultural centres, community organisations, mosques, protests, and other public social events. I chose where to undertake the sessions strategically, depending on criteria such as access and suitability with my research objectives. Whilst I was free to attend public spaces and events such as protests, neighbourhoods, and community events, I had to gain permission from the directors of cultural centres and community organisations to be present in those spaces as a researcher. I chose to narrow down my focus on groups and spaces that were open to me rather than engaging with many different people and contexts all at once. In this context, non-participant observation allowed me to observe everyday behaviours, contexts, and social interactions regularly and, over time, build a rich ethnographic narrative. 
The interviews allowed me to capture the ways in which migrant women make sense of digital media and how they narrate the role such media play in their daily lives and experiences. The participant observation sessions helped me to observe some of their everyday practices and interactions, and obtain an in-depth understanding of the daily social and cultural settings in which they are embedded. The non-participant observation sessions allowed me to observe behaviours and social interactions in everyday (urban) spaces in ordinary settings without the influence of the researcher. Together, these qualitative, ethnographic methods helped me to achieve my research objectives by contextualising digital media practices in relation to migrant women's everyday worlds and evaluating the relationship between digital media and the city across a wide range of private and public settings.

Furthermore, these observational methods allowed me to understand the similarities and differences between the three communities and how they come into being by giving me the opportunity to reflect on diverse intra-community dynamics, urban contexts, and digital sites. According to Miller and Slater (2000, 9), comparative ethnographic material has the potential to allow researchers to "move between the details of each case-study and the generalities of the Internet at a global level and across contexts". In this context, observational methods that allowed me to delve into the everyday worlds and lives of my participants helped me to confidently draw conclusions out of my data by identifying the characteristics specific to each case whilst theorising the generalities of digital media use amongst migrant women in London.

During most of my ethnographic inquiry, I made use of a tape recorder to record my own thoughts as well as soundscapes. This helped me to systematically record and analyse my observations and to refer back to them later in my writing. However, there were numerous occasions during the participant observations in which I switched to recording on my mobile phone in order not to make my presence as a researcher too obvious. Naturally, I always informed individuals and groups that the tape recorder or mobile phone was recording in order that they might give their consent. I also took pictures of public locations such as streets, mosques, and schools, and added them in my fieldwork diary. Some such sites are the Aziziye Mosque, Enfield Alevi Cultural Centre \& Cemevi, Hendon School, HAYA Community Centre, and neighbourhoods such as Stoke Newington, Hendon Central, and Southall. When important and relevant, some of these pictures are included in the empirical discussion chapters with the purpose of helping readers to visualise the settings. 
Finally, I took many written notes on my observations regarding the locations, people, and conversations I encountered. Such notes were made immediately after the sessions in as detailed a manner as possible. During some non-participant observations, such as protests or other large community gatherings where I did not have to blend in with the group, I kept my notebook to hand and noted down my encounters during the sessions.

In the foregoing, I discussed my ethnographic approach in detail, including the process of participant recruitment and methods of interviewing and observation. I do not see my investigation of the digital domain as being separate from this overarching ethnographic approach and thus, I developed a methodological approach that encompasses both online and offline domains. However, there are several methodological issues and choices specific to the realm of the digital that need to be discussed further. In the following, I discuss literature relevant to the specific examination of "the digital" and the methodological trajectory I followed.

\subsection{Digital Ethnography}

The introduction of digital media technologies has generated much academic debate. How best to study this new communicative environment, and the consequences it may have for individuals and societies, are topics of intense discussion. Starting from the 2000s, several ethnographers began to study the internet as a self-contained entity by immersing themselves in online contexts and focusing on the social activities and interactions that take place on online (e.g., Boellstorff et al. 2014; Hine 2008; Kozinets 2009). Whilst this body of research provides a useful set of methods via which to investigate such online contexts and sites, it largely neglects the relationship between the online and the offline, and thus fails to explain how the internet became a culturally embedded phenomenon (Hine 2015, 192). My study, by drawing on ethnographic methodologies across physical, everyday sites, tackles this methodological pitfall. There is, however, a need to examine what people actually do with such media, and not only what they say they do (Leurs 2015, 88). Thus, in my examination of digitally mediated sites, I employed multiple methods to observe what migrant women actually do with the media they encounter.

However, rather than investigating the "online" as a separate world, I reflected upon my observations in the light of my interviews and (offline) ethnographic findings and insights. In this context, my research methodologically aligns with the "digital ethnography" approach that advocates for employing multiple methods to study digital media in relation to 
other everyday life activities and contexts. On the subject of digital ethnography, Pink et al. $(2016,30)$ state that it is "not a research 'method' that is bounded. Nor is it a unit of activity or a technique with a beginning or end. Rather it is processual". According to the digital ethnographic approach, physical and digital sites are not separate from each other, but rather are part of the same processes that produce locality, materiality, and experiences. Having explained my ethnographic research conduct, I now proceed to reflect on how I implemented several research methods specific to the study of the internet and my investigation of digital contexts as they exist in an online-offline continuum.

Ethnographers observe online engagements and performances by approaching digitally mediated spaces as cultural field sites that are shaped by beliefs, practices, and routines (Hine 2008). I investigated "the online" as a non-participant observer by observing the individuals and groups from a distance without interacting in order not to influence them with my presence as a researcher. I regularly visited digital sites, added my personal reflections in my fieldwork diary, and archived and thematically coded relevant visual and written material. The list of the online field sites I observed can be summarised as follows:

Personal profile pages: I networked with the participants who granted me their consent on social media accounts such as Facebook, Instagram, Twitter, and Snapchat, observing their online profiles over the course of one year. This method allowed me to closely observe them over time and to capture patterns that emerged regarding how they connect, network, and self-represent across digitally mediated sites.

Public accounts and groups: Based on my interviews, I made a list of the online accounts and groups that the interviewees followed and engaged with on a regular basis. Amongst these, the Facebook group The London-Turkish meetup; several young diasporic Somali YouTube channels; Instagram and Snapchat accounts; as well as the diasporic Romanian website Romani.co.uk, which emerged as the most prominent. Combined with my in-depth interviews, I was able to understand how these digital sites play a role in everyday lives and routines of migrant women in a diasporic context.

Private accounts and groups: I did not have access to every online field site, particularly closed Facebook and WhatsApp groups. In this context, I largely relied on participants' own narratives in order to gain an understanding of the meanings and practices that underpin the mediated connectivity that these online groupings facilitate. In addition, some participants 
agreed to send me screenshots for my analysis upon my promise that I would not reveal the names of any group members.

\subsection{Online Data Collection and Visualisation}

Whilst ethnographic approaches have been applied to the examination of digital contexts and sites, there has been a scholarly debate about whether traditional qualitative methodologies are sufficient to capture the Web's connectivity. Recently, there has been a tendency to use quantitative, data-based methods specifically oriented towards the internet-referred to as "digital methods" (Rogers 2013) — to track and visualise online networks and connections. These methodologies utilise a wide range of Application Programming Interfaces (APIs), network analyses, and visualisation software in order to gather and visualise data retrieved from social media platforms. Digital methods have also been applied to research on diaspora, migration, and the media, with the aim of locating diasporas online and examining digitally mediated diasporic formations (Diminescu and Loveluck 2015). For example, Diminescu's (2012) e-Diasporas Atlas Project focuses on the Web connectivity of diasporas by examining hyperlinks. Kok and Rogers (2016) theorise Somali diasporic identity and engagement around a transnational imagined community by focusing on the transnational Web connectivity (via network and Web content analyses) of the global Somali diaspora.

Whilst these approaches provide useful insights into how digital media facilitate diasporic connectivity on a larger scale, they work predominantly with a pre-determined corpus of digital sites based on ethnic, national, and religious categories. Therefore, this body of work tends to reproduce "methodological nationalism" and overlooks the social and emotional significance of digital media for migrants themselves (Alinejad et al. 2019, 22). In this context, in the ERC project Connecting Europe, we demonstrated how quantitativedriven digital methods can be combined with qualitative, ethnographic approaches in a manner that is attentive to the dynamic, intersectional, and temporal nature of diasporic formations. We presented a case study of how, on a transnational scale, a Turkish-Dutch stem cell donation campaign was digitally mediated amongst members of the Turkish diaspora. We tracked and visualised how the campaign was mediated across different platforms via issue-mapping and carried out a face-to-face interview based on ethnographic and feminist research principles (Alinejad et al. 2019). The way in which I incorporate digital methods in my methodology follows the digital ethnographic and mixed-methods approach developed in the broader project. 
My research project aims to examine the relationship between digital media and diasporic identity formation within everyday settings, prioritising the social and cultural meaning-making practices of the individual. Therefore, qualitative methodologies were central for developing the research design and data gathering (both online and offline). However, drawing upon the methodological stance taken in the ERC project, which advocates for using multiple methods depending on the research objectives (Alinejad et al. 2019), I also made use of digital methods when the need arose in order to supplement my findings. For example, by visualising connections amongst various Facebook pages based on likes, I could clearly see the online networks of London-based youth organisations within the Turkish community. This indeed concurred with my ethnographic findings, proving my hypothesis that such connections are formed on the basis of shared political affiliations rather than ethnic or national ties (see chapter 3). Similarly, I used digital methods to study the most mentioned YouTube channels amongst young British-Somali participants in order to retrieve a network of related channels and videos. Through content analysis, I categorised the videos according to their themes and the issues they raised. Later, I invited the participants to reflect on these issues and themes in interviews by asking their opinions and feelings about the way such narratives are framed on YouTube (see chapter 4). This back-and-forth approach, between online and offline domains, helped me to understand how, in culturally embedded settings, online trends and digitally mediated connectivity become socially meaningful through lived experiences. As argued in the ERC project, digital methods become valuable tools of investigation when utilised "with a sensitivity to ethical and theoretical discussions of migration and diaspora" (Alinejad et al. 2019, 21). In this context, our investigation of diasporas in the age of digital media, integrating quantitative, data-based methods into ethnographic approaches has the potential to help researchers "trace how a diaspora comes into mediated being through specific engagements with data and uses of digital media within lived daily existence" (Alinejad et al. 2019, 38).

As explained thus far in this chapter, I utilised a raft of methods and strategies in my in-depth empirical investigation. These methodological steps were taken so as to ensure the highest possible research quality and integrity whilst also contributing to knowledge production. The methodological trajectory I followed was also shaped, not only by my own identity as a researcher in the field, but also by several ethical considerations. In the following sections, I discuss these ethical considerations and how my identity as a researcher has shaped the research conduct and its outcomes. 


\subsection{Identity and Reflexivity}

Complexity and uncertainty, in other words, are not just an academic projection onto the world, but already woven into the fabric of everyday life, part of what situated knowledge must capture.

- Couldry (2003b, 47)

As a researcher who emigrated from her country of origin ten years ago, migration is not only a topic of interest, but also an experience that has defined my entire adult life. In this context, my personal background not only helped me to relate to the experiences of the participants, but also granted me a certain level of credibility due to our shared status as "migrant women”. Furthermore, my almost five-year residency in the United Kingdom meant that I was able to benefit from an established social circle from which to draw my initial research momentum and subsequently maintain it. However, as previously explained, my sample went beyond my personal networks, encompassing participants from diverse socio-economic backgrounds. Therefore, I do not deny the existent power imbalance between myself as a middle-class, university-educated academic and the women about/with whom I produce knowledge. Furthermore, as my project encompasses migrant women from three different communities, multiple aspects of my identity became central to the ways in which similarities and dissimilarities between myself as a researcher and my participants were emphasised.

As the prominent feminist scholar in science and technology studies Donna Haraway (1988) suggests, the knowledge we create is inherently "situated" since such knowledge inevitably comes from our own partial perspectives and positionalities. As Haraway argues, by acknowledging that our epistemologies are embedded in "situated knowledges", we can understand the role we play in knowledge production and become more interpretive, critical, and impartial. In this section, I reflect on how my thesis produces its own "situated knowledge" with a particular focus on my personal identity and how I think it influenced researcher-participant dynamics. In this sense, I do not claim "disembodied scientific objectivity" (Haraway 1988, 576) and acknowledge that my identity and positionality and certain power relations influenced my research conduct and outcomes. Nevertheless, as Haraway compellingly argues, I believe that the more we acknowledge our socio-cultural standpoints and specific ways of seeing things in obtaining knowledge, the closer we get to making accountable observations. 
Whilst conducting this research with women from Turkey, I felt conflicted about my own cultural identity and my insider/outsider positionality in the community. Despite acknowledging shared cultural traits with Turkish people (most importantly the language), I have always considered myself a Cypriot who happened to be Muslim and to speak Turkish. In this context, I refuse to be ethnically (and nationally) defined as "Turkish"-quite the contrary, I am reluctant to enunciate my "Turkishness" at the advent of the ongoing political and geographical division between Turkish(-speaking) and Greek(-speaking) people in Cyprus. Indeed, I think my political commitment for an independent and united Republic of Cyprus free from colonial powers and the so-called motherlands' presence (Turkey, Greece, and the United Kingdom) is the reason why I still feel so strongly about my Cypriot identity after ten years of living abroad. Yet, my background as a "Turkish Cypriot" helped me in my research with the community from Turkey, since I was well-informed about the political and socio-cultural issues from the beginning. This is indeed reflected in my empirical chapter on the community (chapter 4), which the reader may find slightly more contextualised and elaborate than others, as I discuss the findings in a very detailed manner. Here, if we return to Haraway's (1988) notion of "situated knowledge", my partial perspective and positionality may stand as a limitation in obtaining balance (in terms of interpretation and contextualisation) amongst the three different groups in my study.

However, it is equally important for me to state that I do not consider myself to be an "insider" and I do not claim being fully authoritative and insightful in my discussion of the Turkish migrant community. Indeed, although I share common cultural traits with my participants and consider myself knowledgeable about their country of origin and culture, I am not from Turkey and I have never lived there. I believe that this particular positioning allowed me to attain a critical distance whilst rendering it easier to access to the community, and to understand and contextualise my observations and reflections. Furthermore, I regularly consulted my research assistants Hoden, Hayat, and Veronica regarding my interpretation and contextualisation of the findings from the research conducted with Somali and Romanian migrant communities. In this context, I tried to incorporate their "insider" insights into my empirical discussions, thereby compensating for my reduced familiarity (relatively speaking) with those communities. In this way, I believe I have managed to contextualise my empirical findings and provide a detailed presentation of each community in my thesis.

Furthermore, although identity is a central concept in my research, it cannot be studied easily by a researcher since participants may find it difficult to easily provide answers to questions regarding their identity (Leurs 2015, 82). With this in mind, I tried to encourage 
the participants to talk about their identity by initiating conversations about their cultural sense of belonging. On some occasions, this raised participants' curiosity about my own cultural identity and how I would describe it. In this context, my personal background as a "Turkish Cypriot" caused confusion for some participants, particularly for Romanians and Somalis, who (understandably) did not know much about Cyprus. For example, some were rather surprised to hear that I am an EU citizen, which I believe made them keener on talking about Brexit and their experiences due to our shared status as both EU citizens and migrants. Nevertheless, it was interesting to find out that, whilst some did not know that the Republic of Cyprus was also in the EU, many thought that I did not hold an EU passport on the grounds that I was "Turkish". This made me realise how "Turkishness" was taken as the defining aspect of my identity. This is understandable to an extent since, as a country with a large migrant population in Europe, Turkey may be much more recognisable than a small island country like Cyprus. However, I think my perceived "Turkishness" also instantly changed my positionality to being "non-Western" in the eyes of some women. For example, a Romanian participant asked me why I was interested in carrying out research on identity and migration. When I explained how my own personal background-i.e., how the fact that I come from an ethnic and religious minority group in my own country of origin fuelled my academic interest—she replied by saying: "I like how Eastern girls can turn their identity crises into achievements!" Whilst I believe that she meant well by praising me for doing a $\mathrm{PhD}$, it is also an example of how participants may try to read and categorise researchers in ways with which they may not necessarily agree.

Religion was another important component that afforded me a changing insider/outsider positionality depending on the research setting and encounter. As Merriam et al. (2000) articulate, culture is not a monolithic entity. Rather, who belongs to it and who does not—who is an "insider" and who is an "outsider"—is fundamentally ambiguous and context-dependent. Different social categorisations, cultural habits, and knowledges may come into play in our interactions and relationships with people. Nevertheless, the insider/outsider positionality always poses a dilemma for the researcher and influences research activities and context. For example, during my research with pious Turkish migrant women in North London, I was initially worried about fitting into religious settings due to my limited Islamic knowledge and practice. Having been raised in a secular society, I never considered religion to be an important aspect of my identity whilst still identifying myself as 
a cultural Muslim. ${ }^{8}$ However, I became more comfortable once I found out that I was not expected to be intimately familiar with the Qur'an, Islamic prayers, and doctrines. Turkey is predominantly a Muslim country and there are many different ways in which people claim and practice religiosity. In this context, I avoided trying to be seen as an insider by pretending I was religious, whilst simultaneously ensuring I obeyed certain rules (such as wearing a headscarf during prayers) in order to be respectful. Nevertheless, the experience ultimately helped me to become aware of how my understanding of Islam as a moral framework was actually greater than I had anticipated, despite having no formal education or deep interest in the subject.

At the same time, it was interesting to see how my religious identity helped me to be seen as an insider in the eyes of some Somali women, despite the fact that I sought to avoid creating the impression that I was a devoted Muslim. The revelation that I was a Turkish Cypriot was frequently followed by statements of surprise, such as "You're also a Muslim!" or "Why didn't you tell before that you are also one of us [meaning, also a Muslim]?" I believe that some participants instantly felt more connected to me on the basis that I was also a Muslim woman. This helped to induce conversations about Islam and their positionality as British Muslim women in a more friendly and informal manner. Whilst gender and religious affiliations helped to create a sense of similarity, it also presented a challenge because I often felt as I was also expected to contribute to the conversations by opening up about my own experiences. Furthermore, as my understanding of Islam is, to a large extent, shaped in relation to the particularities of the Turkish political context and culture, I was always conscious not to attribute practices I observed to Islam unless explicitly suggested so by my participants themselves.

It was easier to establish a rapport and immerse myself in the social circles of young participants who perceived me more as a friend than a researcher. However, whilst for some, my age helped me to gain an insider status, I remained conscious of the importance of not taking things for granted and ensuring "a reflective distance" as a researcher (Leurs 2015, 83). With this in mind, I was always conscious about initiating conversations about my research topic and being attentive to the details of social interactions that were related to my research objectives. Turning now to women from older age groups, I felt that the fact that I was relatively younger perhaps rendered me less intimidating. This undoubtedly helped to

\footnotetext{
${ }^{8}$ By cultural Muslim, I mean that I am a non-practising Muslim who preserves an attachment to certain rituals of Islam, such as celebrating religious festivals or going to the mosque for funerals.
} 
soften the hierarchical discrepancy between myself as a researcher and them as participants. However, this does not mean that I did not have to be sensitive towards the obvious power dynamics at work. There are many different aspects to a researcher's identity, all equally likely to cause the individual concerned to be simultaneously perceived as both similar and different by participants (Leurs 2015, 82). It cannot be taken for granted that I was privileged to move to the United Kingdom as a university student who was financially supported by her parents. I was already a fluent English speaker and educated in line with the British curriculum from childhood onwards, which helped me immensely to adapt to life in the United Kingdom. In this regard, most of the participants' experiences of migration and resettlement were quite different to mine, which meant that my privileges might have signified dissimilarity and thereby emphasised inequality. Considering this, I was always very careful not to impose any feelings of inadequacy, rather emphasising the shared commonalities in order to build bridges and tackle unequal power dynamics.

Nevertheless, as an academic, I do hold the power to produce knowledge - a fact that in some instances inevitably created an imbalance in power relations. This became most apparent during sessions with some of the women who were worried about addressing my questions correctly. On such occasions, I tried to build a rapport based on our common positionality as migrant women and shared some personal experiences and stories. I explained that there were no right or wrong answers, and that I was curious to learn about their authentic experiences and feelings. My gender defined another important dimension of my rapport with the participants, and helped to me to gain their trust and to convince them to talk more about themselves. Yet this, too, raises concerns about power dynamics, since some may have felt as if they were required to follow my lead and give similar responses. In order to tackle this issue, I was always conscious to steer any attention away from myself so that they understood that they were the real focus of the discussions. Nonetheless, I must of course acknowledge that I had only partial access to their worlds, and I could only capture segments of much more complex realities to the extent to which they were willing to share them.

As explained above, my identity as a researcher meant that I occupied a "middle ground" in the field - I was simultaneously both an insider and an outsider. As Elsayed $(2011,136)$ argues, a researcher can adopt a position of "sameness" with the aim of developing a relationship of trust and building rapport with the participants. Although it is not always possible (or necessary) to achieve insider status in a given community, the researcher can still manage to gather data and understand people and contexts with a "trusted outsider 
status" due to their ability to possess "inside knowledge" (Bucerius 2013). I sought to obtain such a position - that of a trusted outsider who could understand (at least partially) the experiences and feelings of participants from a position of "sameness", given my background as a migrant woman. Multiple aspects of my identity proved significant in the ways in which I gained participants' trust and navigated between the three different communities. I always tried to ensure that my participants were not only the "subjects" of this research project, but that they were also active agents who gave direction to the process and shaped its outcomes. This is also reflected in how I carried out my analysis and determined my ethnographic style of writing. In the remaining chapters of my thesis, in which I discuss my empirical findings, I make an effort to properly introduce my participants, give extensive quotations, and explain the settings in which the interviews and observations occurred, with the aim of ensuring that the women in my study - rather than passive, decontextualised research subjects - are individuals with the agency to represent themselves.

Nevertheless, knowledge production is always a situated process and there is not a singular truth we can attain as researchers. As Denzin (1997) rightly argues, we need to accept "asymmetrical reciprocity" between ourselves and our participants, since our particular social positions and histories render it impossible to completely step into another's shoes (cited in Edwards and Mathner 2002, 24). With this in mind, I do not ignore the power I have in producing knowledge about these women, nor do I try to over-identify with them. In my writing of the empirical chapters, I maintain a reflexive position by acknowledging my own positionality and explicitly stating the methodological choices I made. This is the reason why I let the readers know how some encounters had an impact on my research by raising my interest and encouraging me to delve into certain themes and phenomena further. To sum up, I acknowledge that my identity and judgement as a researcher played an important role at each stage of this study, shaping how the data was gathered, interpreted, and presented.

\subsection{Ethics}

My research investigates women from minority and marginalised backgrounds whose stories are largely absent from (or misrepresented in) the public discourse. Thus, my thesis is concerned with the politics of representation as it recognises these women's 'presence' (Buikema 2018, 83) in their own narratives and life-worlds. This requires me to be attentive to the ethics of representation which is not only concerned with "making present what is absent", but also with "the manner in which the absent should be made present" (Buikema 
2018 , 93). In this context, I ensured that I always introduced myself and informed the participants about the research project by personally explaining how the information they provide would help me to achieve my research objectives. These points were also briefly stated in the consent forms they signed before the interviews. Furthermore, I guaranteed full confidentiality by anonymising their names and using pseudonyms instead. Finally, I did not provide the exact addresses of anyone and I blurred the faces in the photographs I used in my empirical chapters. Thus, informed consent and confidentiality were part of a coherent code of ethics that ensured I was not using any data that could potentially cause harm to the participants.

However, as my sample consisted of women from diverse ethnic and socio-cultural backgrounds, I felt that there were different ethical considerations at stake for each individual and group whilst conducting my research. For this reason, I subscribed to a feminist "ethics of care" which, rather than following a set of universalist principles and abstract criteria, advocates a focus on the particularities of each context, situation, and practice when conducting research with human beings (Edwards and Mathner 2002, 20). Furthermore, feminist research ethics aim to keep ethical considerations at the forefront, specifically "how we formulate research purposes, how we work with others and how we represent" (Preissle 2006, 527). Thus, research ethics should not simply be regulations or rules governing only research conduct. Rather, they are frameworks that should also guide us in our representation of others. I employed this approach at each step of my project by being attentive to each person and situation I encountered and remaining reflexive towards the knowledge produced.

As Hine $(2015,187)$ highlights, ethnographers of the internet may face a number of dilemmas specific to online sites and contexts. I approached groups on Facebook as "online communities" and did not reveal the names of the members. As part of my digital ethnography, I treated online engagements such as likes, shares, and pictures as data belonging to the participants who granted me their consent to observe their social media profiles. Yet I do not claim ownership of this data and I treat it confidentially. In this regard, I did not directly use any names or explicitly illustrate texts or pictures in order to keep the identity of participants anonymous, unless I was given consent to do otherwise. In relation to the incorporation of "digital methods", I only investigated public Facebook pages and YouTube channels and videos. As was argued in the ERC project, digital methods may perpetuate unequal power hierarchies, since researchers obtain and process digital data without including the perspectives of the people who created that data in the first place (Alinejad et al. 2019). In this context, by being attentive to contemporary critiques of "big 
data" from the field of critical digital media studies, I avoided approaching the quantitative data gathered from these social media platforms as subjective or descriptive representations of reality (Alinejad et al. 2019, 35). Following feminist and ethnographic epistemologieswhich argue that "the knowledge of the person being researched (at least regarding the particular questions being asked) is greater than that of the researcher" (England 1994, 243) - I incorporated participative ethnographic methodologies in my analysis and representation of digital data. Therefore, I largely draw on participants' own narratives and reflections about the connections and patterns captured through the data collected and visualised. However, I do not claim that this data is either objective or representative of complex realities that underpin the participants' lives and experiences, since I interpret and represent it in the light of my own ethnographic findings and insights.

\subsection{Conclusion}

In this chapter, I have outlined and reflected on the multiple methodologies I used whilst gathering and analysing empirical data in my research. As established earlier, my main research objective was to empirically examine the digital media practices of migrant women within an online-offline continuum in order to theorise the mediation of diasporic identity at intersections between urban and digital spaces. In order to reach this objective, I implemented both qualitative ethnographic methods and quantitative, data-driven methods. The multiple methods I employed during my empirical investigation allowed me to examine the intersectional, context-dependent, and dynamic nature of diasporic identity formations. At the same time, they helped me to capture large-scale connectivity and interactivity, facilitated by the technological infrastructures of digital media technologies (Alinejad et al. 2019, 39). In this context, my research project methodologically contributes to the emerging mixedmethods approach, which utilises qualitative and quantitative methods simultaneously in the field of digital diasporas (Alinejad et al. 2019; Leurs 2015).

Clearly, having to work with three different communities in a limited period of time often forced me to make certain methodological decisions at the expense of others. My own socio-cultural background made it difficult to achieve the same level of access and familiarity towards each community, leading me to make prompt and pragmatic decisions at several stages. However, I tried to deal with this issue in the best way possible by regularly reflecting on my research design and making myself accountable with the purpose of maximising the efficiency of my year-long field research in London. Moreover, although I was a sole 
researcher in the field, my three research assistants Hoden, Hayat, and Veronica acted not only as gatekeepers and translators, but also as mediators who partly informed my thought process. Indeed, my methodological trajectory involved constantly moving back-and-forth between different methods and making explicit methodological choices regarding the people and contexts to be studied. This is the reason why I remained attentive to reflexivity in my writing by acknowledging how certain methodological choices I made might have impacted the outcomes presented.

In this context, it is important to realise that the knowledge I produce is neither impartial, nor complete. Rather, it is a situated account of complex phenomena and realities. As Leurs $(2015,101)$ succinctly observes, drawing upon Donna Haraway's (1988) notion of "situated knowledges", it is impossible for a researcher to attain a singular, absolute truth. Furthermore, I accept that the methods I implemented and the methodological choices I made inevitably render my research study subject to a certain level of bias. Indeed, my academic engagement with the topic of migration does not only stem from my intellectual aspirations, but also from my own identity and political commitments. Yet I would like to conclude this chapter by emphasising the strengths of my methodological trajectory, which enabled me to capture multiple and subjective ways of using and relating to digital media technologies. The rich and intensive empirical investigation allowed me to examine the complex relationship between diasporic formations and digital media, and uncover the ways in which diasporic identity mediations are articulated at the intersections of the city and the digital in diverse spaces and contexts. 


\section{Chapter 3: Diasporic Nationalism and Digital Tactics: The Case of Turkey's Diaspora}

\section{Introduction}

We will see beautiful days kids, sunny days

we will sail our boats to the blue seas, kids

to the bright blue seas...

—Nazim Hikmet RAN, "Optimism”

"We will see beautiful days; we will see sunny days-definitely!" the speaker on the microphone shouted. In front of the cheering crowd, she continued ever-more loudly: "Dear children! We will make a world where the people do not die because of others' cruelty. We will see beautiful days when weapons become silent and flowers blossom!" She was referring to the poem Optimism by the Turkish poet Nazim Hikmet (15 January 1902-3 June 1963). Nazim - the "romantic communist" (Timms and Goksu 1999), as some describe him—was a left-wing poet who was repeatedly arrested and spent most of his life either in prison or exile. Hikmet's poems have become anthems of resistance for many in Turkey. His words have been used to portray the struggle of a people for whom resistance and patriotism historically go hand in hand. Once again, on 26 March 2017, those people were on the streets of London to rally for what they believed was best for Turkey. They wanted to see the beautiful, sunny days Nazim had promised - days that had not been seen for many years. Despite the gloomy political atmosphere, it was an unusually warm and sunny day for London. Dozens of people had converged on Trafalgar Square, which is a popular meeting point for gatherings and demonstrations located in Central London.

The meeting was organised by the No for Democracy Platform UK (Demokrasi Icin Hayir Platformu, in Turkish) ${ }^{9}$ to rally for the historic constitutional referendum that would take place two weeks later. ${ }^{10}$ The group opposed amendments being suggested by the

\footnotetext{
${ }^{9}$ The No for Democracy Platform was established by the British Alevi Federation, which aims to represent Alevis in Britain (who are largely of Kurdish ethnic origin (Keles 2015) and supported by some Kurdish associations and community centres such as Day-Mer, Kurt Halk Meclisi (Kurdish People's Assembly), and Ciwanen Azad (Free Youth)). At the time of writing, the group continued to advocate for various political and legal issues in Turkey. They share news and information via their Facebook page <https://www.facebook.com/Demokrasi-için-HAYIR-Platformu-britanya$1305423206163418 />)$ ).

${ }^{10}$ The referendum was held on 16 April 2017. The citizens of the Republic of Turkey abroad voted earlier than this date. In the United Kingdom, votes could be cast between 6 and 9 April 2017.
} 
government that would abolish the parliamentary system and centralise power in the hands of the president. The Britain Alevi Federation (Britanya Alevi Federasyonu, in Turkish) was at the forefront of the rally. Yet I noticed many other community organisations, political groups, and women's associations that had already announced that they were also campaigning against the constitutional amendments were absent from the meeting. Zeliha, a woman in her 40s whom I met on the day, explained why she thought other groups were missing:

Everything is like this, divided here in London, just like in Turkey. We all say the same thing now to prevent the presidential system. But we will have different opinions when other issues arise. We unite on this thing now, but then again, it is difficult for so many people and groups to unite all the time.

In an already tense political context, as Zeliha's quotation demonstrates, existing divisionsboth political and ideological-within the migrant community may become even more intense. Such divisions become visible with extensively covered historical events by the media, such as the constitutional referendum.

In this context, this chapter tells the stories of women who carry the burden of the nation whilst simultaneously negotiating new realities as migrants and minorities. I describe the diasporic community from Turkey as a politicised diaspora. Of course, I am aware that placing "homeland" national politics at the centre of my discussion carries with it the danger of essentialism and "methodological nationalism" (Wimmer and Schiller 2002) by representing the community as if it is solely and passively nation-centric. However, my ethnographic research took place during a particular time when Turkish politics seemed to invade many aspects of the lives of my participants. As will be clearly demonstrated, Turkey's tense political climate also rendered the everyday lives and culture of an already fragmented diasporic community explicitly political. In this sense, my theoretical and empirical focus on this (specifically situated) "everyday" foregrounds diasporic national politics as a focal point from which to contextualise and elaborate upon my findings. Furthermore, my intention is not to represent nationalism as the common identifier of my participants. Rather, I discuss how other issues and intersectional categories of identity become entangled in a politicised diasporic context.

This chapter discusses gendered diasporic identity negotiation at a particular time and location. Bringing what I believe to be a new perspective to the field, the chapter uncovers how the everyday lives and practices of migrant Turkish women unfold in a highly politicised 
socio-cultural context. Diasporic politics and nationalism are widely considered to be the preserve of men and here I offer a corrective narrative by studying the notion of the politicised diaspora from the perspective of migrant women. Women are both actors and subjects in the politicisation of diaspora, however, their gendered realities and everyday lives lead them to perpetuate and/or navigate this phenomenon differently to men.

Furthermore, the Turkish media has raised concerns in Europe on the grounds that it promotes national and cultural affiliations with Turkey, leading the diasporic community into a process of so-called "cultural ghettoization" (Aksoy and Robins 2000, 344). However, my research demonstrates that the role of the media should not only be taken into account for its presumed role of reaffirming (or intensifying) attachments to the country of origin, but also for contributing to the further fragmentation in the community (Aksoy and Robins 2000; Giglou, d'Haenens, and Ogan 2018). Such gendered and media-related dynamics raise questions, such as: What does it mean to be the female members of a politicised diaspora? Do the media really preserve national and cultural identity and attachment to the country of origin and, if so, what implications do they have for the female members of the community in London? In short, do digital media spaces and technologies open up new avenues for identity formation for Turkish women living in London?

These questions are fundamental to gaining an understanding of the digital identity mediations undertaken by the female members of a politicised migrant community attempting to manage the sometimes conflicting influences of Turkey, as their country of origin; and London, as their new home. Following on from these reflections and ideas, I draw upon Michel de Certeau's (1984) conceptualisation of tactics as the everyday practices of "making do" of those lacking power. The concept of tactics will be used to examine how the female members of the community develop various (tactical) digital media practices in order to navigate divisions within the community and to create translocal spaces of belonging that encompass both Turkey and London.

Drawing upon an explicitly intersectional approach, the structure of this chapter reflects the specific manner in which diasporic nationalism, in tandem with their varying locations, social categories, and gendered roles, is re-configured in the everyday lives of Turkish women. The first section (3.1) sets the backdrop of my discussion by briefly introducing the community itself. The second section (3.2) discusses how migrant women become active in the politicisation of migrant communities and neighbourhoods with a vivid account of real-life situations and experiences. In doing so, this second section illustrates how these women, drawing heavily on certain digital media practices, create a translocal nexus 
connecting two locales - namely the city and the "home" nation. The subsequent sections further elaborate upon how social categories of class (3.3), religion (3.4 and 3.5), and generation (3.6), which are closely linked with competing narratives of nationhood, are negotiated in a diasporic context. Together, these analyses go beyond dominant contemporary academic perspectives that see diasporic nationalism as a binary, transnational phenomenon reconfigured between a "home" and a "host" nation by showing how diasporic nationalism can be re-configured as a translocal nexus between the global city (in this case, London) and the "home" nation (in this case, Turkey). Concluding, I further elaborate upon this point by addressing the research questions outlined above, and by discussing what this chapter adds to investigations of gendered diasporic identities in the light of the empirical material presented.

\subsection{Who Are "the People"?}

Three distinct waves of migration from Turkey to the United Kingdom have each been initiated by significant political events in Turkey: 1) Alevis emigrating to the United Kingdom following the Maraş Massacre in $1978 ;{ }^{11}$ 2) political refuges following the military coup in 1980; and 3) Kurds seeking asylum as a result of the armed conflict between the Turkish military and the PPK (Kurdistan's Worker's Party). ${ }^{12}$ Most of these migrants settled in London with a high concentration in the North London boroughs of Enfield, Haringey, Hackney, and Islington. It is important to acknowledge the ethnic, religious, and political diversity of the Turkish community in the United Kingdom, as for decades, the members of the community have established distinct ethnic, ideological, cultural, and religious communities (Sirkeci et al. 2016, 1-13). The community's size is estimated to be somewhere between 180,000 and 250,000, although this number also includes Turkish(-speaking) Cypriots who migrated from Cyprus (Sirkeci and Esipova 2013).

In addition to the three phases outlined above, my research also includes participants who have recently migrated for the purpose of pursuing education and employment

\footnotetext{
${ }^{11}$ Alevis constitute the second largest religious group in majority-Sunni Muslim Tukey. Whilst there is an ongoing debate about whether Alevism should be regarded as a separate religion or as a sect of Islam, Alevis have their own distinct rituals and institutions. The issue of Alevism has a long history in Turkey, dating back to the time of the Ottoman Empire (Massicard 2005). The Maraş Massacre was the massacre of more than one hundred Alevi civilians in the city of Kahramanmaras by extreme Turkish nationalists in December 1978. For a brief historical account of the relationship between Alevis and the Turkish state, see Alemdar and Corbacioglu (2012). See also Orhan Tüleylioğlu's (2013) book on the Kahramanmaras Massacre for a more detailed account.

${ }^{12}$ Beginning in 1978, the armed conflict caused major instability and forced displacement from Southern Turkey.
} 
opportunities. Such immigration also has its roots in increasing feelings of social and financial insecurity in Turkey due to the increasing political and economic instability. This is perhaps unsurprising, given recent developments in Turkey, such as the Gezi Protests (2013); the revival in the conflict between the Turkish state and PKK; and the military coup attempt that took place on 15 July 2016. These narratives lead some scholars to conceptualise international human mobility from Turkey within the context of an "environment of insecurity" or as a "conflict model of migration". They draw attention to the environment of (human) insecurity and political, economic, or cultural oppression of certain groups in Turkey (Sirkeci 2003, 2006, 2009; Sirkeci and Cohen 2016).

From the above, it becomes apparent that, reflecting the heterogeneous demographics of Turkey itself, the diasporic community is extremely diverse. This is the reason why some scholars refer to the UK community as "Little Turkey" (Sirkeci et al. 2016). Indeed, there are two fundamental reasons why understanding the fragmented nature of the community and situating my findings accordingly are crucial to my empirical discussion. Firstly, naming the community is both problematic and controversial, given the presence of Turks, Kurds, Arabs, Laz, Circassians, and Zazas in the community (Sirkeci et al. 2016, 2). "Turkish-speaking communities" is perhaps the most used definition in academic and journalistic circles (for example, see Aksoy 2006; Atay 2010; Unutulmaz 2014). This categorisation also includes Turkish Cypriots, which were the first Turkish-speaking community to move to the United Kingdom. However, my study precisely focuses on migrant women from Turkey, rendering any emphasis on shared language irrelevant. Many participants in my study identified themselves as "Turkiyeli" (from Turkey) when they were asked about their nationality and country of origin. ${ }^{13}$ For example, one participant identified herself as "Turkiyeli Kurt" meaning “a Kurd from Turkey”. Yeğen $(2006,137)$ argues that Turkish nationalism of the republican era has principally perceived Kurds as "future-Turks" with an assimilationist logic. However, my participant's intentional avoidance of being identified as (ethnically) Turkish by emphasising her identity based on her citizenship of Turkey reveals how Kurdishness remains a strong ethnic, national and political identity. Therefore, I decided to use "Turkey's diasporas" in the title instead of "Turkish" as an all-inclusive, pluralist

\footnotetext{
${ }^{13}$ For a historical account of the term "Turkiyeli" and how it can be used in order to reform Turkey's minority legislation and Kurdish issue by emphasising civic identity and citizenship in contrast to the ethno-centric term "Turkish", see Grigoriadis (2007).
} 
definition with the aim of emphasising the official name of the country of origin rather than the ethnicity of its (former) inhabitants. ${ }^{14}$

Secondly, the diversity of the community is reflected in my participants' contradictory understandings of the nation and their national and cultural identities. Over the course of my fieldwork, I came across many different definitive labels, such as "urban", "rural", "Westernised", "backwards", and "impious" that women use to describe themselves or others. Such categorisations indicate the deep divisions embedded in the country's history, demonstrating "an acute identity problem" (Taşpinar 2005, cited in Çelik, Bilali, and Iqbal 2017, 217). In this context, these words reflect the "fault lines for "othering"" along which, in Turkey, such categorisations fracture and are linked with one's political affiliation, easily becoming a source of societal pressure, social distance, and dislike (Taşpinar 2005, cited in Çelik, Bilali, and Iqbal 2017, 217). As the following sections will reveal, the research participants provide diverse accounts of Turkey's history and politics, which largely depend on their experiences of ethnic, religious, and political issues in Turkey. Sirkeci et al. (2016, 1-2) confirm this point by stating that "each and every group as well as every individual within those groups has a unique story of conflicting interests and disagreements with what was on offer back in Turkey".

\subsection{Diasporic Nationalism as a Translocal Phenomenon: Blocking and Unfriending}

Whenever we organize an event, big or small, it doesn't matter, they [AK Party opponents] sabotage it. They destroy our banners or threaten to make us stop. Once I put a stand in front of my apartment, they told me that I am just a puppet of the government so I shouldn't be allowed to manipulate other women in the neighbourhood."

The above quotation is from Nuriye (47), who immigrated to London more than 20 years ago. I became aware of Nuriye during the constitutional referendum campaign when some of my

\footnotetext{
${ }^{14}$ Here, it is important for me to emphasise that I do not want to neglect or undermine the aspiration of Kurdish nationhood amongst a significant portion of the Kurdish population in Turkey and elsewhere. On the contrary, I prefer to emphasise the geographical location of origin that rendered all these groups bounded to be citizens of the Republic of Turkey and being subjected to processes of "Turkification" (Grigoriadis 2007, 423). Having said that, I would also like to note that my participants of Kurdish origin never expressed that they support the establishment of a Kurdish nation-state.
} 
North London participants mentioned her name as a person whom they followed on social media - particularly Facebook. Nuriye seemed to be an inspirational figure for these women and she was certainly well-known due to her political activities. The first time I contacted Nuriye, she could not meet me, since she was very busy campaigning for the constitutional referendum (on the side of the "Yes" camp). However, approximately six months later she invited me to her house in Edmonton for börek (Turkish pastry) and tea. Prior to our meeting, I decided to spend some time in Edmonton Green Shopping Centre - an area near to the housing complex where Nuriye lives. As I walked, I immediately felt a sense of familiarity due to the high number of people who spoke Turkish. However, despite the spatial concentration of migrants from Turkey in her neighbourhood, Nuriye, as she reminded me a few times during our interview, has always felt marginalised in the community-even back in Turkey.

Nuriye was born and raised in a small village in Eastern Turkey, which she described as "a highly religious place where people of Turkish and Kurdish origin lived together". Nuriye's migration journey started when her village became drawn into the armed conflict between the Turkish military and the PKK. Like many others, seeking security and better economic opportunities, when she was 22 years old, Nuriye initially moved to Istanbul with her husband and new-born baby. Despite the difficulties she faced in the beginning, Nuriye developed an attachment towards her neighbourhood in the district of Fatih. It was a place where she eventually found "like-minded people with a similar lifestyle". Indeed, Istanbul became an important turning point in her story, since the city's multicultural mosaic of people encouraged her to reflect on her own religious identity for the first time. However, life was initially hard for Nuriye in Istanbul since, as she clearly attested, people outside Fatih regarded her as "backwards" and "visibly not belonging to the city". Nuriye cited her appearance and manner-her rural accent and headscarf - and how they indicated that she was from a lower socio-economic background and made her feel like an "iltica" (meaning "refugee" in Turkish), rather than an "Istanbullu" (Istanbulite).

It was against this backdrop that Nuriye's interest in politics emerged, and gradually evolved into political activism. Today, she volunteers for Turkey's ruling AK Party (AKP), led by President Erdoğan in collaboration with the party's branch in London. She describes her tasks as canvassing women about the party's politics and gaining their votes. However, once again, Nuriye faces a situation requiring great tact. Despite being the largest political party in Turkey, the AKP is detested amongst the majority of those from Turkey now living in the United Kingdom. Nuriye's quotation above offers an insight into how her 
neighbourhood has become an arena in which "home" nation politics result in a perpetual struggle for representation and internal conflict. Nuriye's experience in Istanbul was marked by “spatially-defined limitations and place-bound belonging” (Christensen 2012, 902), leading her to create a space of belonging with the working-class and religious inhabitants of Fatih. However, in London, Nuriye finds it difficult to feel part of the community in Edmonton, since the diversity of political affiliations and socio-cultural backgrounds render the community fragmented and polarised. She articulates this point by saying:

This place [Edmonton] was horrible when I first moved here. Then, we [immigrants from Turkey] gradually started coming here. We brought order to this place. We opened nice shops, restaurants and kept the streets clean. It is hard for people from Turkey to live anywhere else but London. Life is lively here. However, things also get difficult sometimes because most of them look up to secular Western countries as an ideal model for Turkey. The Kurds or Alevis believe that our government hasn't done enough for them. I miss the old days where our people could all unite and fight together because at the end of the day, we are all Muslims.

As with Nuriye, my participants who live in the Turkish neighbourhoods of North London express that these locations offer the best residency options as they can benefit from affordable council housing and ethnic networks and connections. From an outsider's perspective, North London can be easily seen as a replica of the "Little Istanbuls" of Kreuzberg in Berlin or Keupstrasse in Cologne, Germany. Whilst the spatial concentration of the community in these areas has developed in the face of historical ethnic segregation and unemployment, these community neighbourhoods provide vibrant living spaces and economic markets for migrants. Throughout the areas of Green Lanes, Stoke Newington, and Dalston, one can see numerous Turkish and Kurdish shops, restaurants, cultural centres, mosques, and newspapers serving the local community. However, Nuriye's thoughts above amply reflect the daily context of the migrant neighbourhood, in which competing national imaginaries and identity politics form sub-groups that turn their members against each other. Her narration of everyday life in Edmonton (in parallel with her life in Istanbul) is representative of the experiences of many other participants whose everyday lives echo the fault lines of modern Turkey and create parallel dynamics between the "home" and the "host" countries. Thus, despite its outward appearance as a typical migrant neighbourhood, it is in fact home to multiple political and cultural organisations and a diverse population, reflecting 
the heterogeneity of the communities. These community neighbourhoods encapsulate diverse political and cultural groups, leading to a fertile local culture where competing national imaginaries become embedded in the everyday lives and subjectivities of women. In this context, showing a high level of awareness about their intra-group positionalities, my participants have to "negotiate, contest or pragmatically constitute their identities" (Christensen 2012, 893) in their everyday lives.

In this context, digital media play an important role in how migrant women negotiate their diasporic identities and shape the migrant neighbourhoods in which they live. The digital mediation of nationhood and the constitution of a diasporic transnational community are aptly reflected in Anderson's (1992) concept of “long-distance nationalism”. According to Anderson, the internet and transnational communication enables the preservation of an “imagined community" for diasporas. However, Anderson's thesis fails to explain how, for the politicised diaspora, the nation is not a fixed category. The perseverance of competing national imaginaries - so clearly reflected in Nuriye's narrative - proves that for the members of this community, the imagined community is far from unitary. In their research on transnational Turkish television in Europe, Aksoy and Robins $(2000,359)$ revealed how audiences preferred channels and programmes that "reflect back to them their ideal sense of Turkey". It is interesting to observe the similarities that have emerged between television audiences and the users of digital media over the last two decades, as the women in my study move across different digital spaces, variously forming and dissolving connections and networks in relation to their ideal sense of Turkey. In the case of Kurdish broadcast media, Smets $(2016,752)$ points out how the nation is constructed differently by various actors, since "they have opposing ideas of how this imagined nation should be embedded in a state". The evidence from my research demonstrates that Smets' argument is not only applicable to Kurdish minority media, but also resonates within the context of wider diasporic community dynamics with its origins in Turkey in the age of digital media. The digital media practices of the women in my study are also tailored towards forming connections and networks in line with their respective political affiliations, each promoting different versions of how the "imagined nation" ought to be.

The existing body of academic research demonstrates how transnational media spaces promote "home" nation politics and help to retain an attachment to the country of origin for diasporas (Alonso and Qiarzabal 2010; Brinkerhoff 2009; Diminescu 2008). Several prominent media events that took place during my fieldwork allowed me to observe firsthand how diasporas come into being through digitally mediated transnational networks of 
news and information. ${ }^{15}$ Such networks serve to intensify divided loyalties and polarisation, particularly at the climax of important political events. For example, I vividly remember the time when Zehra (37) and I were waiting for the lift when two women speaking in Turkish entered the apartment building. After a short exchange of glances in the entrance, the women, continuing their conversation, decided to take the stairs. A few seconds later in the lift, Zehra told me how she used to be friends with the two women we had just seen. One of them found out that Zehra was an AKP supporter through her social media when she shared news footage of President Erdoğan, on which she commented by saying "Maşallah" (meaning, "[how] great"). Following her Facebook post, one of the women called her on the phone and furiously asked whether she was "Tayyipçi”, meaning a supporter of President Tayyip Erdoğan. The incident culminated in these two neighbours unfriending and blocking Zehra on Facebook which, according to Zehra, meant "ending their friendship also in real life". Zehra's story, which is by no means an exception, clearly demonstrates how the digital mediation of Turkish politics has very real implications for these women, who have to (re-) arrange their social relationships and networks in line with their diverse political affiliations.

In the context of an increasingly scrutinised and censored mass media sphere in Turkey, Çiğdem Bozdağ (2019) demonstrates how social media has become a crucial tool via which citizens can voice their opinions. In her study on the representation of refugees on social media, she argues that Twitter - a key platform for discussing politics in Turkey-has become a mass-mediated site via which citizens articulate bottom-up nationalism and ethnocentric understandings of citizenship. In this context, debates about citizenship are framed in relation to competing national imaginaries and deep political divisions. Inevitably, within this framework, discourses of "othering" become publicly manifested. My empirical investigation provides strong evidence of the emergence of parallel narratives in Turkey and London, confirming the centrality of social media to different social groups as a means via which to mediate information and opinions in a manner that potentially normalises discrimination and othering along the lines of political affiliations. In this context, the digital media spaces in which my participants are embedded indeed reflect contemporary Turkish society as defined by increasing social distance between different ethnic, cultural, and political groups (Çelik, Bilali, and Iqbal 2017).

\footnotetext{
${ }^{15}$ Most importantly, the constitutional referendum (16 April 2016) and the military intervention of Turkey in Afrin, Syria (20 January 2019-present).
} 
The daily lives of most of these women are confined to the migrant neighbourhoods in which they live, adhering to the gendered social norms and responsibilities that restrict them to certain spaces. Thus, they largely socialise and support each other as neighbours and friends within a community defined by the neighbourhood in which they live. Yet, the politicised nature of the digital media space they also inhabit affects their gendered sociality and connectivity, leading them to use the affordances of social media platforms such as deleting, blocking, grouping, and commenting as tactics to create scattered, homogenous networks - both online and offline. For example, my interview with Serra (33) clearly demonstrates how the often fragile balance between community members can quickly destabilise when extensively covered national events render it impossible to keep politics out of personal relationships and away from social networks. Scrolling down her Facebook profile during our interview, Serra tells me:

There was the Marmara incident [a] few years ago. Erdoğan was the prime minister then. There was an article on the issue on social media. It was about seeds imported from Israel. The article was about fighting, resisting [against Israel] effectively rather than spilling Coca Cola in the streets. My friend blocked me on Facebook because I shared it. Imagine! For three years, you are together 24/7 in a foreign country. You are the person whom she would ask for antibiotics when she is ill. The social media also has its disadvantages. However, this is about our mentality, our ignorance. We don't have the capability to question. There is a saying in Turkey "Don't speak politics with your loved ones". Maybe it's true because she just deleted and blocked me on Facebook for sharing an article that criticised the government's seed trade with Israel!

The "Marmara incident" Serra mentions above occurred when, on 10 May 2010, using violence, Israel stopped the MV Mavi Marmara - a ship carrying humanitarian aid for Palestinians in Gaza. The incident caused the death of 10 civilians on board the ship and evolved into a major political crisis between Israel and Turkey. The incident led to immense unrest in Turkey, including the emergence of a movement on social media calling for people to boycott companies that support the state of Israel. In the midst of this political chaos, videos of people, including small business owners, who spilled Coca Cola in the streets as a form of protest became extremely popular in a short period of time. However, Serra expresses that she wanted to share a "serious article" about Turkey's import of seeds from Israel in order to draw attention to how much Turkey actually contributes to Israel's economy through 
international trade. Sharing an article that may be of interest to our Facebook friends is a seemingly mundane act. However, for Serra, this simple action cost her a friend with whom she had been very close for her first three years in London.

Zehra's and Serra's stories indicate how the transnational mediation of Turkish politics via women's own social media profiles can alter spaces and networks of sociality and perpetuate polarisation in migrant neighbourhoods. Similarly, the mediation of local events may also destabilise delicate community dynamics, rendering practices such as unfriending and blocking vital tactics in the homogenisation of social networks in digital space. For instance, I recorded such an incident when a national commemoration event caused an enormous online debate on Facebook. On 18 March 2017, the Turkish Embassy in London organised a commemoration ceremony for the Battle of Gallipoli in the martyrs' cemetery in Portsmouth. A group of Union of European Turkish Democrats (UETD) members were accused of holding an "Evet" (meaning "Yes") banner during the ceremony. This resulted in discontent amongst some community members on the grounds that the UETD was using the event to their own advantage - to campaign for a constitutional referendum at the cemetery. When Londra Gazete (the London Turkish Gazette) shared a post about the incident including a picture, a heated online debate begun on Facebook. The members of the UETD blamed Londra Gazete for photoshopping the picture to mislead and turn its readers against them. In the end, many followers of the paper participated in the debate, expressing their anger and disappointment with the UETD on Facebook. In the run-up to the referendum, I observed how this incident evolved and became a major divisive issue in the community. Unsurprisingly, women had different accounts and interpretations of the event in relation to their own political affiliations. Yet both sites seemed to accuse each other of being biased and subjective. One of the participants, Melek (44), who identifies herself as " a real AKP and Erdoğan supporter", expressed her frustration whilst also reading the comments below the post during our interview:

They have now found something to criticise us and do it publicly on Facebook. When I put President Erdoğan's picture as my profile picture on Facebook, I received many criticisms. If they use derogatory words, I just unfriend them, which means they have no right to comment. But some still try to do so. Then, I just block them because I don't want this kind of people neither on my Facebook nor in my life. 
The above examples reveal how the political and ethnic heterogeneity of the community lead to a "tense co-existence" (Christou and Sofos 2019, 540, 541). In this context, digital media certainly intensify existing polarisation in the migrant neighbourhoods of North London. Yet the women themselves also actively contribute to the politicisation of their neighbourhoods through their digital media practices by further mediating the "home" nation's politics on social media and adopting tactics of debating, blocking, and unfriending to create scattered, homogenous social networks. These fragmented online networks indeed shape the dynamics of gendered social relationships in real (offline) life and change the ways in which they practice and experience the "lived space" (Lefebvre 1991) of their neighbourhoods. It is important here to acknowledge how these women (who tend to live more within the local sphere than men) become active in re-configuring and perpetuating diasporic nationalism at the micro (community neighbourhood) scale. Yet they also use digital media to constitute actions that transgress the boundaries of the "local" and articulate the nation in its contexts and communities. Thus, they actively "divide" the urban space between different political and social groups. In this context, I argue that they should be acknowledged, to use Çağlar and Schiller's (2018) term, as "city-makers" who shape the "lived space" of the city (Lefebvre 1991) through multiple digital tactics. These digital tactics intensify intra-community conflicts by reinforcing symbolic boundaries and creating parallel social patterns between London and Turkey.

Having focused so far only on migrant neighbourhoods, the following section extends this focus to the broader urban context. By focusing on middle-class participants, I argue that digital media intensify spatial and socio-symbolic fragmentation within the community by facilitating social networks that intentionally exclude those who do not have the same political and class-based identities. Therefore, it highlights the often neglected role of social class in diasporic national formations by demonstrating how diasporic nationalism is translocally manifested at the intersections of politics and social class.

\subsection{Politics, Social Class, and Exclusionary Social Networks in the City}

Over the course of my fieldwork, I was told by some participants that they preferred not to reside in neighbourhoods of North London highly influenced by Turkey. I was surprised to hear that even some members of political associations and cultural centres preferred to live elsewhere in the city, although they had to regularly commute to the north for work. For these women, North London was apparently perceived as a typical ethnic enclave, its community 
"inferior" due to their working-class background and low level of education. As fashion and art consultant Zerrin (46), who lives in Bromley, South London, comments:

The community in London is divided into two. On the one side, you have educated people with amazing careers. On the other side, you have people who are not educated. You may have seen them if you went to North London. Men who work in kebab shops and women who do not even speak English. These are the ones who are looked down upon.

Sema (35), who works for a cultural centre in Dalston, but lives in West London, makes a similar comment, emphasising the limited urban mobility amongst women in the community:

They are stuck in North London, knowing nothing about what's happening in London; be it seeing a theatre play or just seeing the sights. There are people who fly all the way from Japan to here to see a West End show, however, some of the women in our community don't even know what exists in South London.

As in the case of Zerrin and Sema, most middle-class participants avoid these neighbourhoods in order to physically and symbolically distinguish themselves from the North London community which, according to them, consists of migrants from Turkey with lower socio-economic status than them. In their narratives, it becomes obvious that levels of education, ethnicity, religiosity, and class are often conflated with identity traits. In this regard, although their everyday lives are not embedded in politicised migrant community neighbourhoods, I believe that these women are also active actors in a translocal reconfiguration of diasporic nationalism in the broader context of the city. More precisely, they actively reinforce Turkey's existing fault lines in a diasporic context by alienating themselves from political refugees, ethnic minorities (such as Kurds and Alevites), and the conservative religious groups of North London. By doing so, they reaffirm secular and ethnocentric perceptions of the imagined community, as well as their own political and social identities.

In contrast to the participants in North London, who experience limited (or a total lack of) mobility, middle-class women were much keener to meet me in public spaces such as cafés, restaurants, or parks. In typical “Londoner” style, for reasons of convenience, we mostly met in Central London. Participants mostly chose to meet me in well-known Turkish cafés and restaurants, which some of my participants praised for successfully representing 
Turkish cuisine to foreigners and tourists with high-quality food and good service. In fact, neither the food, nor the service differed significantly from a standard Turkish restaurant in the north. As the research progressed and I obtained greater "insider status" in the community, I started to realise how my participants' narratives about being detached from the Turkish community does not always reflect reality. Throughout my research, I repeatedly saw on social media platforms how they indeed had Turkish migrant friends living in London, attended Turkish cultural events, and frequently shared these online. For instance, my observation was confirmed later in a follow-up interview with Sertap (40), whom I challenged by drawing attention to some of her own Instagram pictures and stories that recorded such occasions.

Melis:

I saw that you have many Turkish followers and you constantly share content for Turkish people on Instagram. You have many likes and comments from Turkish people. You meet some of them, I saw on your Instagram. I was surprised because I thought you did not like Turkish people much.

Sertap:

Now with the social media, you find out about people whom you can get along-similar background and lifestyle. I try to meet some and have some Turkish people around now. Mostly for my daughter because she likes Turkish culture and people so much. Once I shared something about Arabs and Islam. Many people insulted me because I said "dirty Arabs" in one of my videos. If we do not do something about it, Turkey will also become a backwards country. I also never liked religious people when I was in Turkey. I mean I said dirty Arabs because extreme religiosity brings nothing other than dirt and corruption. But also, many others supported me and agreed that we should not be like Arabs. I did not know there were such Turkish people in London. I think we are just becoming more aware of each other because of social media.

Sertap's statements about Arabs and Islam were undoubtedly racist and Islamophobic. It is important to note that publicly revealing anti-religious sentiments on social media was also performed by some other middle-class participants who perceive secularism as an attribute 
specific to the middle-class, educated section of Turkish society. Here, once again, the conflict is essentially about competing national projects that place religious (Islamic) and secular (Western) national imaginaries in opposition. Sertap's quotation shows that, despite the fact that her mediated assertion about Islam and Arabs on Instagram led to a backlash, it did not have any significant repercussions for her everyday life. This indicates the contradictory implications of digital media on sociality and communication. On the one hand, despite the backlash she received online, this has indeed not affected her social networks in real life, which have already excluded people with religious beliefs and conservative lifestyles. On the other hand, her Instagram post led to some kind of awareness towards the existence of "like-minded" members of the community. This example demonstrates how, whilst the middle-class physically and socially distance themselves from "North London", they also create exclusionary networks of interaction and socialisation through their digital media practices. Sertap's case indicates this at the level of the individual, however, I also observed how similar digital media practices are employed by particular groups and organisations.

Online research reveals an extensive list of groups and pages representing the Turkish community on Facebook. Some of these groups have hundreds of members, such as Londra'daki Turkler (Turks in London), the London Turkish Meet-up group, and other smaller groups, such as mothers' and expat groups. The London Turkish Meet-up group emerged as a highly popular site amongst middle-class participants, who described the platform as somewhere to find "like-minded", "well-cultured", and "educated" people. The group's administrator, 44-year-old Ceyda, describes the purpose of the platform as providing help and advice regarding legal procedures and practical issues, and arranging gatherings for members to meet and network. Meetings are generally held in Central London because, as the members live in different parts of the city, the centre is the most convenient location for everyone. In this context, the Facebook group takes on the symbolic role of "social centrality" (Hetherington 1998, cited in Christensen 2012, 895) by compensating for the fact that these women, in contrast to the those in North London, do not have the opportunity to meet and socialise in their own neighbourhoods. More specifically, the Facebook group compensates for the lack of a physical location of "social centrality" for a sub-group of people with similar social and cultural backgrounds, allowing them to connect and network despite their spatial fragmentation. In this sense, whilst the group allows women to establish digitally mediated networks of sociality and support, it indeed facilitates ethnic, political, and class-based sub-group formations, and reinforces existing divisions within the community. 
My interview with Ceyda further confirmed my observation when she told me that she initially took over the group's administration for herself to meet and socialise with "likeminded Turkish women". However, and much to her surprise, the group has grown enormously in the last few years. Whilst I do not think that Ceyda intentionally used the phrase "like-minded Turkish women", such statements were typical amongst the middle-class participants, hinting at the underlying ethnic, class-based, and secular understanding of their national and cultural identity. When I asked Ceyda whether my assumptions about the member profile of the Facebook group were accurate, she mentioned that she tries to prevent posts that contain political and religious content. She explained how she uses her administrator approval rights and blocking as key tactics to avoid controversial topics that can offend certain groups, adding that "politics and religion have frequently caused fights in the past since members are largely secular people". Despite Ceyda's efforts, there have been a number of incidents in which women wearing headscarves received hostile, mocking comments under their posts. This prompted Ceyda to delete the posts and to block such commenters from the group. Considering Turkey's socio-political context, where religion is a highly politicised and divisive topic, such incidents clearly demonstrate how identity and belonging are very much contested in women's digitally mediated socialisations. This was brought into sharp focus during a breakfast gathering in the Antalya Restaurant in Bloomsbury, Central London, when Beren (40) told me why she liked the Facebook group:

When I first attended the group's meeting I was surprised by the quality of the people! I didn't know such people from Turkey existed in London. I thought they were all uneducated. They are mostly in North London though and they are surrounded with Turkish people anyway. However, we need a platform as such to help each other and to meet to teach our kids Turkish culture with like-minded, same-cultured people.

Meltem (37) seemed to agree with Beren, stating:

I mean I wouldn't hang out with people like that [referring to the "North London community"] in Istanbul so why would I do [that] here in London? For so long, I wanted to exclude myself from the Turkish community here because they are conservative and closed. I didn't come here as a refugee, so I don't understand why [I would] hold on to past grievances so much. I want to know people who came here for education and work like me. This is the good thing about this group. 
These statements are intriguing, demonstrating that whilst the London Turkish Meet-up group allows women to build networks of sociality and support, they implicitly exclude certain ethnic, political, and cultural groups. As demonstrated in her quotation above, Meltem does not "understand why [she would] hold on the past grievances so much" with reference to the community members who hold onto their "home" nation-oriented political and cultural identities and, in doing so, revive the divisions of their country of origin in a diasporic context. However, she also contradicted herself, stating that she would rather not "hang out" with the people of North London since she did not have social relationships with them even when she lived in Istanbul. Hence, she justifies her socio-spatial segregation from the North London community with a logic that indeed holds onto Turkey's historical fault lines based on her secular, ethno-centric, national imaginary.

These examples and the participants' narratives demonstrate that, as in the case of the North London community, middle-class women also use various digital tactics to create homogenous mediated networks of socialisation and connectivity. Differently from the case of women in migrant neighbourhoods of North London, these tactics are not only employed in relation to political affiliations, but also in relation to social class. By using digital media to create divided networks of communication and sociality, they generate distinct spaces of belonging in the city and reinforce established political and socio-cultural identities, which are firmly embedded in their competing national imaginaries. These digital tactics help them to maintain the socio-symbolic boundaries between the middle and the working class, and between the secular and the religious in London. In this way, they allow for the formation of sub-groupings and networks that exclude the "North London community".

Thus far, the discussion has focused on how diasporic nationalism is translocally reconfigured by women who employ various digital practices that intensify the politicisation and polarisation of the Turkish community in London. These digital practices are tactfully employed to create scattered networks of sociality and communication, reinforce the creation of homogenous sub-groupings, and render the "lived space" of the city divided. In this context, they allow the women to maintain fragmented political and socio-cultural identities in line with Turkey's politics, socio-political fault lines, and competing national imaginaries. However, diasporic identities are "not just an extension of the nation" (Georgiou 2006, 8889). Rather, they constitute multi-layered cultural formations that connect urban, national, and transnational influences. The following two sections, with a particular focus on the intersections of religion, nationalism, and cosmopolitanism, demonstrate that whilst Islam, as 
a moral framework and practice, maintains a (trans)national and cultural sense of "belonging" to Turkey, it also merges readily with an urban cosmopolitan ethos. In this context, the following discussion unearths how pious women develop various digital tactics to claim agency and recognition in the city - a translocal nexus that connects their urban and national imaginaries.

\subsection{Religion, Nationalism, and Cosmopolitanism: Digitally Embodied Performances}
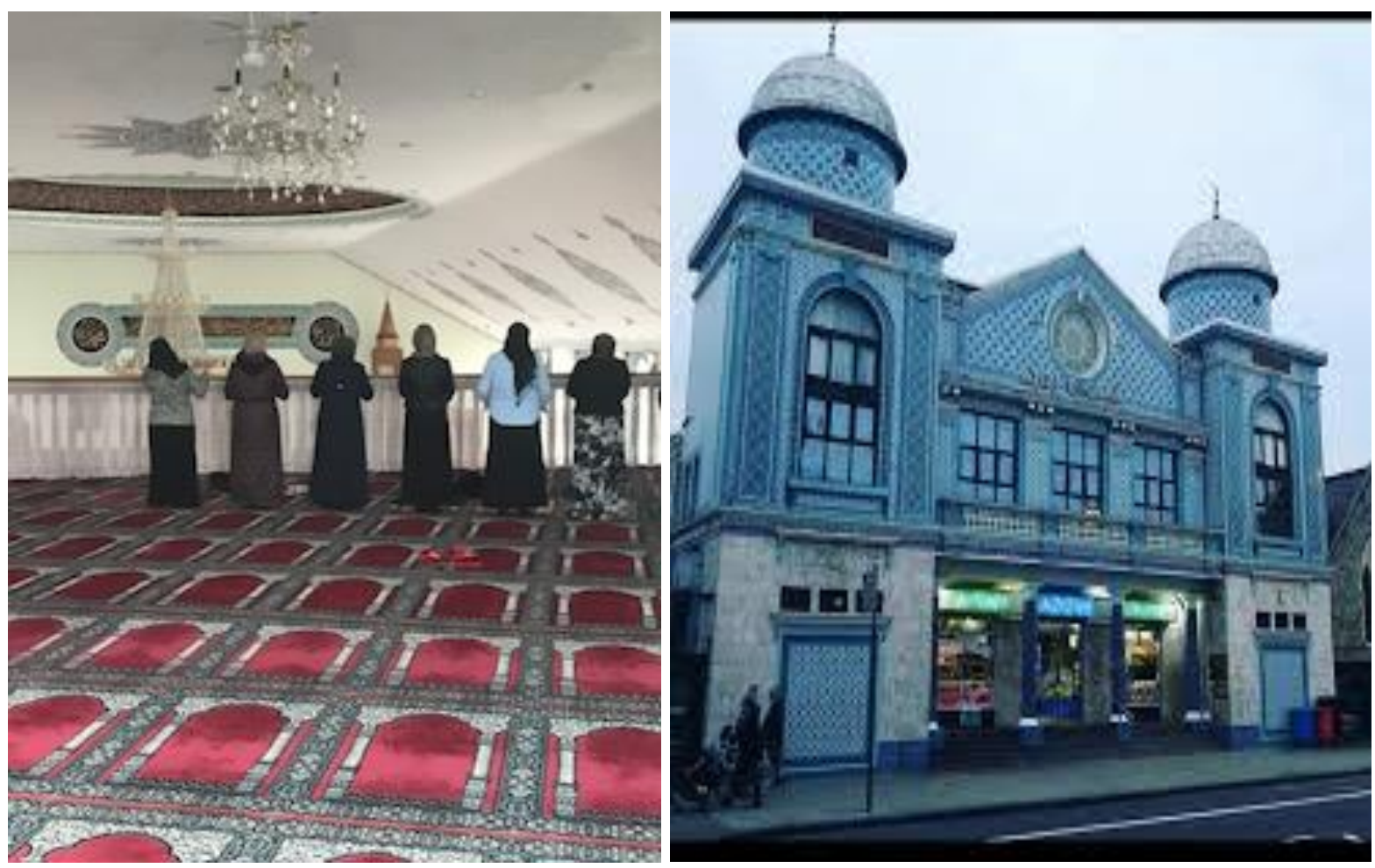

Figures 1 and 2. Aziziye Mosque, Stoke Newington, London. Pictures taken by Melis Mevsimler on 22 March 2017.

I vividly remember my first day at Milli Görüş, a Turkish origin religio-political movement and one of the largest Islamic organisations in the West (Yukleyen 2009). I contacted Duygu (30), head of the young women's branch of Milli Görüş, for an interview. In our brief conversation on the phone, she told me:

I have to go to Istanbul for a while to sort out some practicalities for my residency application. However, I will speak about you to Zeynep Hoca [an Islamic teacher or preacher in Turkish]. You can go to the sohbet [a traditional religious meeting] and interview some women. I call you when I get back. 
After we hung up, I was left with mixed feelings about the opportunity that had arisen. Sohbet is the Turkish word for conversation (derived from the Arabic word suhba) and refers to the pious practice of reading and conversation (Jassal 2013, 188, 189). I had never participated in a religious sohbet meeting in my life. I was also very conscious of my limited Islamic knowledge and was afraid to be seen as an outsider. The only thing I knew about this discursive practice was that it was a religious tradition revived by the transnational Islamic and political Hizmet Movement led by Fettullah Gülen. This was only a year after the Hizmet Movement had allegedly organised a military coup to overthrow the Turkish government (on 15 July 2016) and was declared a terrorist organisation. Hence, it was not surprising that many were cynical towards the practice.

Given the circumstances, I was naturally nervous on my first day at the sohbet. The meeting was held on a Wednesday in a small room behind the Milli Görüş office in Stoke Newington. The small room was sparsely furnished-some cushions on the floor, some Arabic and Turkish books on the shelves, and a small kitchenette. Half an hour before the start time, women gradually began to arrive, and two women started serving tea. After introducing myself, I started chatting with a group of women. When she learnt that it was my first time in sohbet, Nur (56) handed me a ring-like digital device with a screen and button: "You can use this like tesbih [Islamic prayer beads] for zikir. ${ }^{16}$ It's easy. Just repeat after us when we say Estağfurullah [may God forgive] and press the button." The device Nur gave me is called zikirmatik. Zikirmatik is a digital form of tesbih that is used to count the number of times short phrases/prayers are rhythmically repeated for performing the devotional act of zikir. Zeynep Hoca opened the sohbet with a prayer from the Kuran (Turkish word for the Qur'an). She then took her mobile phone in her hand and started reading from it. She told a story about a very poor woman who refuses to steal bread even though she and her old mother are starving to death. The Prophet hears about this devoted woman who does not do the haram (meaning "forbidden" by Islamic law) thing by stealing, and he decides to marry her to one of his sons. Zeynep Hoca advices women to think about this story whenever they find themselves in desperation and remember that Allah always rewards those who remain on the right path:

\footnotetext{
${ }^{16}$ Zikir is an Islamic devotional act, in which prayers and/or phrases are repeated. It can be counted on prayer beads.
} 
You see how our memleket [Eng: homeland] is getting immoral day by day. We see it in the news, we watch it on the screens. We should not give up. We should work to fix it. Staying devoted Muslims at the heart of the Christian world and raising our kids accordingly is a service to Europe as well. Corruption and immorality are everywhere. You see how Europe is treating Muslims, but we should remain on the right path and be always faithful to Islam and Allah.

Zeynep Hoca's closing words to the sohbet indicate how the continuous mediation of homeland in the news and on the television reinforces the idea that their ideal Turkey is something yet to be achieved. For most of the women I spoke with in this group, Turkish soap operas, as an example, are the solid proof of the slippage and degradation of religious values and social norms in Turkey. Moreover, the mainstream representation of news from the perspective of an authoritarian government achieves its goal in portraying Muslims as subjects who are under attack both in Turkey and in Europe. In this context, my pious participants regard their Muslim identity and culture as in need of defence, and their efforts to preserve Islam are as old as Turkey's modern history.

Religion has always been a very polarising issue in Turkey. Following the French model of laïcité, Turkish nationalism was based on the idea that religion should be performed solely within the private sphere. This meant severely limiting the depiction of religious identity and the use of religious symbols in the context of civil and societal expression (Elshtain 2017, 128). I still remember the evening news from my childhood that showed how young women university students would be taken out of their lecture halls by the police because it was illegal to wear a headscarf in public universities. By revoking the infamous headscarf ban in public institutions in 2013 (including in the parliament and courts, along with the universities), the AKP managed to keep its promise and solved the headscarf issue to "democratise the country". Yet despite the political reforms and changing societal dynamics, the Turkey that many pious women - particularly the older ones who emigrated decades ago - remember is one in which their religious subjectivities and performances marked their outsider status in society. In this context, everyday mediations of the homeland feed into a unifying narrative that connects what was lived in the past with present-day constructions of Turkey. As Georgiou $(2006,88,89)$ argues, this mediation of the homeland may in effect serve the construction of a past that conflicts with the present. In this context, the transnational mediated circulation of news and cultural products politicises the community by reinforcing an imagined homeland that seems to be "frozen in time" (Georgiou 2006, 89). 
This conveys the message that Turkey and its Muslim identity are in danger, idealising Turkey as a homeland that must be defended. This undoubtedly raises the question of how you might defend such a homeland - especially one in which you no longer live.

Zeynep Hoca's words, which urge the women to protect their religion and faith, may offer a clue to the above question. Hoca suggests that by keeping their faith and "staying on the right path", they indeed fight towards achieving their ideal sense of Turkey. Furthermore, by invoking the prevailing Islamic concept of $d a$ 'wah (to invite all people to Islam), she also suggests that encouraging others to follow Islam is a service to Europe, despite its mistreatment of Muslims. Hoca's words reflect how the pious participants in my study not only construct a present homeland, but also give meaning to their presence in their new homes via their faith. In this context, religion becomes part of their search for "ontological security" (Giddens 1991) by giving them a purpose in preserving their faith and experiencing a sense of (diasporic) continuity. Despite the fact that their presence as Muslims in the United Kingdom disrupts the imagined white, Christian unity of the (British) nation, they live their religious identities, "inhabiting their own imagined space, thus becom[ing] subjects in a cosmic history of their own making" (Metcalf 1996, 4). As will become clear as the discussion progresses, this religious orientation, which creates a sense of continuity between Turkey and London, gives rise to an implicit cosmopolitan ethos through which they claim, create, and live their own spaces of belonging in the city.

First, I would like to return to North London, where my pious, working-, and lower middle-class participants largely reside. In the previous section, I examined North London with a particular focus on the inner dynamics of the community. However, these boroughs of North London rank as highly ethnically diverse places that are home to a multitude of religious and cultural backgrounds and lifestyles. ${ }^{17}$ In their study on Turkish-speaking migrant women living in London, Saner and Dedeoğlu $(2017,187,188)$ argue how the encapsulation of these groups in North London prevent (especially) these women from experiencing the urban landscape of the multicultural global city freely by creating a sense of alienation from the host culture and its inhabitants. My study complements their findings in the sense that the participants generally express how they do not like to mix with yabancilar (foreigners) in their neighbourhoods. Hatice's (40) words explicitly reveal this point:

\footnotetext{
${ }^{17}$ For example, Hackney ranks as the $6^{\text {th }}$ most ethnically diverse borough of London, whilst Haringey is the $9^{\text {th }}$, and Enfield is the $15^{\text {th }}$ most diverse out of 50 (London Datastore 2011).
} 
We are not friends with English people as their culture does not fit us, we of course speak to them and be acquaintances, but we wouldn't go and visit their homes. Sometimes our kids' friends come over and none of the families call us to ask about their children. This is not normal for us, as in our culture a mother should be worried about what her kids are doing. This is the reason why we don't send our children to their friends' houses.

Continuing, Hatice gave the following as an example of the cultural incompatibility between Turkish culture and "foreigners", although her opinions about living in London were as yet highly positive:

I can say that in London we can live our religion free and untouched. If we were in Turkey, we wouldn't have been able to be free as such. You might know how you could not find a job in Turkey until 4-5 years ago if you wore a headscarf. Of course, English people would be friends with English people, but at least they don't show it in our face. So, living in London gives you the freedom of depicting your religion, however, of course being away from Turkey hurts us. Europe, for example, is a union that is anti-Muslim. But in the UK, racism and discrimination are really almost non-existent. Everyone minds their own business hereSomalis, Nigerians-everyone is here. I don't see myself as European, but I am British. More importantly, I am Muslim and a Turkish citizen, but I am also British.

I see Hatice's comments as reflecting the complex and multi-layered nature of my pious participants' multi-layered identities. Hatice articulates her diasporic identity in relation to different, albeit intertwined positionalities and spatialities in a fluid and contextual manner. Hatice sees herself as "British" rather than "English" or "European", since "British" is perceived as an inclusive civic category that does not challenge her ethnic origin, religious identity, or Turkish citizenship. Similarly, multiple locations such as Turkey, London, and Europe are described, not only by their perceived material and political conditions - such as the presence of Somalis or Nigerians or the headscarf ban in Turkey-but also by relational and symbolic associations (such as Europe being "an anti-Muslim union"). In this context, the multiculturalism of the city is pivotal to the manner in which Hatice negotiates these different locations and their political and symbolic associations. She feels the need to disengage from Europe, which she regards as neither compatible with, nor accommodating towards, Islam. Conversely, she perceives the United Kingdom and its national identity as open and tolerant. Yet, Hatice has never lived anywhere other than London in the United 
Kingdom, and it is obvious that her articulation of Britishness is closely linked with her urban experience. North London, as she perceives it, is a place with almost no racism and discrimination, since different ethnic and cultural groups "mind their own business" and manage to live together. In this context, it is an emancipatory place where she can freely live and express her religion, even compared to Turkey where religious freedoms, according to her, are curtailed. In this context, in line with the experience of Hatice, my pious participants' articulation of identity presents a paradox: On the one hand, they experience limited urban mobility and hold a culturally reserved attitude towards "foreigners" in their neighbourhoods. Yet, on the other hand, their articulation of identity reveals their cosmopolitan ethos on the basis that cultural difference is perceived positively as a valuable, emancipatory virtue. More precisely, the "conviviality"-in this case, meaning "the processes of cohabitation and interaction that have made multiculture an ordinary feature of social life" (Gilroy 2006, xv) that exists in the spatialised contexts in which their everyday lives are embedded, helps them to achieve a sense of belonging in the city since their religiosity can be freely and publicly expressed.

Once I had fully grasped the centrality of religion in shaping these women's complex negotiation of cultural identity, I began to understand how their everyday lives in the city are indeed shaped by a high level of reflexivity and a situated cosmopolitan imagination. Christensen $(2012,901)$ defines "cosmopolitan reflexivity" as a capacity that allows one to achieve a cosmopolitan disposition that simultaneously encompasses particularistic subjectivities and universalistic sensibilities:

In many instances, reflexivity manifests itself as a self-regulated expressive capacity not necessarily engendering instant social change by radically shifting the power geometry but nonetheless enabling individuals to live ethically, culturally in an inbetweenness by continuously forming and adapting comfort zones around attaching locality and disembedding universalism.

(Christensen 2012, 901)

Christensen's definition of reflexivity may help us to grasp how the pious women in my study do not formulate cosmopolitan identities based on the ideologies of normative universalism or idealism. On the contrary, they develop cosmopolitanism as a vernacular quality (Bhabha 2000; Werbner 2006) that allows them to freely live their particularistic religious and cultural identities. This synthesis of universalism and particularism manifests itself, not as a radical political and social action that aims to reverse power relations, but 
rather as an everyday capacity that permits them to adapt and to form a sense of attachment to the multicultural city. Here, we see how an urban cosmopolitan ethos and religious-oriented national imaginary intertwine in the way in which these women, in a diasporic context, claim recognition and belonging.

When we observe and contextualise these women's digital media practices at the juxtapositions of nationalism, religion, and cosmopolitanism, we see how diasporic identity is mediated in complex, unusual ways in the city. One of the first things I initially noticed, was how some women had set the ezan (Islamic call to prayer) as their ringtones. It was very common for our sohbet to be interrupted by the sound of the ezan by someone who had forgotten to switch their phone to silent mode. When this practice proved to be widespread, I began asking why they preferred the ezan as their ringtone, to which one of my participants answered:

Initially I got worried about what other passengers would say when I took the bus. You know it [ezan] could not be in Arabic back in the day in Turkey. But, it's okay if we are Muslims and we show it. There are others [other religious groups] who show it, too. I carry my phone everywhere so I can hear [the] ezan when my phone rings and it soothes me.

In Islam, the ezan not only notifies the time of prayer, but also holds a symbolic significance by reminding the basic principles of Islam and creating a sense of communion. Whilst the ezan is traditionally delivered in Arabic, it was called out in Turkish for almost three decades in order to "Turkify" the ritual as part of the efforts to nationalise the religion in Turkey. ${ }^{18}$ The above quotation clearly demonstrates how the sound of the ezan as a ringtone, accompanied by the affordance of the mobility that a smartphone entails, serves an important function by allowing the participant to claim acceptance and recognition in the public space. It also highlights the importance of past subjectivities - those associated with the country of origin - in shaping present understandings and experiences of the public space in London. In her research on people of Mardin in Southeast Turkey, Costa (2016) demonstrates how, in the age of digital technologies, social media in its lived, practiced, and imagined forms challenges traditional understanding of public and private. By following Nilufer Gole's proposition of "viewing the public sphere in contemporary Turkey as a stage for the

\footnotetext{
${ }^{18}$ The Turkish ezan met with significant resistance. Many perceived it as part of the suppression of religious freedom for the sake of secularism. The ban on the Arabic call to prayer was revoked in 1950 (Azak 2008).
} 
performance of the modern subject", Costa $(2016,167)$ demonstrates how social media use should be understood in relation to the contemporary imaginaries of public and private, which have been shaped as a result of processes of modernisation and secularisation in Turkey. Considering the contemporary political context in Turkey, Costa $(2016,174)$ argues that social media has generated online spaces of "new public conservative performances" with the introduction of an Islam-oriented definition of public and private space by the AKP government. As captured in the words of the participant above, the prohibition of the Arabic ezan was regarded as an effort to suppress Islam's visibility and to establish a "modern" (secular) public space in Turkey. Thus, the practice of setting the ezan as a ringtone in Arabic — its original and most recognised form—reflects a thought process that both marks and represents a Muslim identity and indicates the presence of an inclusive public space in London (Ebin 1996). Whilst this "public conservative performance", in Costa's $(2016,174)$ words, reflects Islam-oriented national imaginaries, it also becomes a politically and emotionally meaningful practice for the participant who enjoys freely expressing her religious subjectivity in the public space, and supports other religious groups to do so.

In this context, I believe the practice of setting the ezan as a ringtone challenges us to re-consider the relationship between religion and the media. This is best achieved by gaining an extensive understanding of the notion of mediation beyond traditional modes of the mediated representation of religion (via film, television, etc.) and understanding the materiality of mediation through personal embodied (in this case, digital) performances (Meyer 2009, ix). As Georgiou $(2010,27,29)$ argues, the city is a place in which various media are used in creative ways to strategically seek recognition and representation, and perform identity. In this context, I believe that the fact that some participants use their smartphones to articulate their Islamic religious identities in the public space should be understood as a form of embodied performance - an audible presence via which to claim agency and recognition as Muslim citizens in the city. In 1996, Eade (1996) argued how the public presence of Muslims and Islamic identity through the increasing visibility of mosques in urban landscape generated concerns over the "Islamisation" of public space, leading to heated debates about British identity and culture. More than two decades later, today we are witnessing how the public visibility of Islam has increasingly become a major source of concern, not only in Britain, but also across Europe. Ongoing debates surrounding various issues - from the public visibility of mosques and minarets (Gole 2011) to the use of amplifiers for the ezan (Arab 2015, 2017) — question the legitimacy of "visible" Islam, as well as Muslims' right to perform their religious and cultural difference in the public space. 
Whilst this raises important questions about the place and future of Muslims in Europe, it is equally important to recognise and discuss how the "visibility of Islam" becomes a form of agency by Muslims who seek "Muslim citizenship" (Gole 2011, 383). In this context, I propose that setting the ezan as a ringtone should be understood as a digitally embodied performance of Islamic identity, as well as an intentional and tactful digital practice that aims to represent and perform the self and generate a public space that is open to diversity. ${ }^{19}$

\subsection{Religion, Nationalism, and Cosmopolitanism: Super-private Online Spheres}

Such digitally embodied performances revive the idea of an open and inclusive public space in which the Islamic self also becomes visible in the way in which these women use social media platforms. My research provides evidence that suggests that public-facing online platforms such as Facebook, Instagram, and Twitter are not considered to be compatible with religious beliefs. Some of the participants, for example, expressed concerns about their children's social media use on the grounds of revealing too much about their private lives on public social media platforms. Such assertions clearly echo the ongoing debate in Turkey about restricting social media use to protect the privacy of personal and domestic life in relation to the notion of mahremiyet (Costa 2016, 167, 168). Sehlikoglu $(2016,1)$ defines mahremiyet as an "institution of intimacy" that draws boundaries between the public and the private sphere based on the normative social rules of Turkish culture. In this context, social media use is largely tailored towards using apps and platforms such as WhatsApp, Facebook Messenger, and Skype, which allow for maintaining personal and familial relationships within "super-private" online spheres (Costa 2016).

These super-private online spheres have cultural and emotional significance for my participants, since they facilitate transnational communication with their loved ones in Turkey. Some of the women in my study expressed how voice- and video-calling their families back in Turkey is a nice way of passing the time when they commute by bus or on foot whilst carrying out their daily routines in their neighbourhoods. Whilst performing daily tasks such as the school run, doing groceries, or visiting neighbours, they establish a routine of "mediated co-presence" (Madianou and Miller 2012) by showing their surroundings to their loved ones and sharing glimpses of their everyday lives. When specifically asked about

\footnotetext{
${ }^{19}$ See Van Doorn's $(2011,338)$ argument for recognising the "materiality of everyday digital practices" and the notion of "embodiment" in material and virtual settings in the age of digital media.
} 
the content of such video calls, it was intriguing that two places were repeatedly mentioned: Aziziye Mosque and Sulemaniye Mosque, which are in Stoke Newington and Dalston, respectively. Some of the participants had even shared pictures of Aziziye Mosque on Facebook, which is just across the street from Hasene, where the sohbet gatherings were held (Figures 1 and 2). On the one hand, and as previously discussed, the presence of mosques has been the subject of a great deal of public debate on the basis that it leads to the so-called "Islamisation" of the public space and disrupts British identity, community, and culture (Eade 1996). On the other hand, for my participants, it seems that these Islamic places and symbols - those explicitly visible and recognised as Muslim — help them to feel at home by creating spaces where everyday patterns and imaginaries of religion can thrive (Metcalf 1996). This could not have been expressed more clearly than in the words of Merve (48), who stated:

I learnt to read Kuran in Arabic when I came to London. They allowed us to have Kuran classes! We didn't have it back then [in Turkey]. It is nice to know that you can have such things here. When my mum comes to visit, I will bring her to the mosques here in London. Now, I can show it if we talk on my phone when I'm outside. Or the kids take pictures and send it to other family members also - they are good with that sort of stuff. In this sense, people respect you here and we also accept them as who they are.

As the quotation above shows, the mosques in North London are places that hold crucial significance for Merve, who lacked (or had limited access to) religious teaching and experienced suppression of her religious expression back in Turkey. Therefore, the mosques are not simply places where she engages with religious activities and rituals. Rather, their presence as public spaces symbolise her recognition and acceptance as a Muslim woman in the city. Thus, not only does she show her family important places in her neighbourhood, but she also carefully conveys the message that she maintains her religious subjectivity and feels part of the community in North London. In this context, by achieving the sense of recognition and acceptance that she lacked or had very little of back in Turkey and conveying this to her loved ones, Merve indeed reveals a sense of attachment towards the city and appreciates its cosmopolitan character. In this context, despite the common understanding of the role of religiosity on diasporic identity, for Merve, these spaces do not perpetuate a cultural ghettoisation. To the contrary, they allow her to feel accepted, develop a positive attitude towards cultural difference, and articulate cosmopolitan worldviews. 
To conclude, my discussion of the digital media use of my religious participants marks the nexus between the "home" nation and the city in opening up avenues to perform religiously framed national identities alongside a situated cosmopolitan imaginary in the public space. In this context, the digital becomes central to the ways in which they articulate their identity by simultaneously reconciling their religious identity and cosmopolitan imagination in their everyday practices (Elsayed 2016). Despite simplistic preconceptions of Muslim communities, the centrality of religion in their daily experiences marks a "reflexive" negotiation process that allows them to claim agency and recognition, and to position themselves as cosmopolitan subjects in the city. Multi-layered identities and multiple attachments (Georgiou 2006) are performed via imaginative, tactical, and embodied digital engagements with the outside world. In this context, I argue that the everyday digital practices of my religious participants in North London reveal a particular kind of vernacular cosmopolitanism that is neither explicit nor expressive, but can only be captured and understood within a framework that is attentive to everyday local practices and rooted in new identities and overlapping loyalties. In the next section, I turn my attention to the younger participants in my study. By taking young migrant women as a separate social group, I uncover how their generation-specific urban lifestyles and digital practices filter and negotiate their cultural identities with different motivations and styles than those of the older women discussed thus far.

\subsection{Generation: Youth Identities and Affordances-in-practice}

In my discussions with the younger members of the community, I became increasingly aware that they felt restricted and oppressed when engaging with important political and social issues within the politicised social dynamics of the community in London. In one instance, I was contacted on Facebook by a young PhD candidate who volunteered for a small think tank on Turkish and Middle Eastern politics. He informed me that an event — for which my status appeared as "going" on the Facebook page_-was cancelled since the speaker was not approved by the Turkish Embassy in London. Although this initially surprised me, it came as less of a surprise to the student, because the speaker was a former Turkish BBC journalist who is now blacklisted by the Turkish government. Over the course of my fieldwork, I was informed on multiple occasions by other students based in various universities in London that the Turkish Student Union of UK (TUSU) closely scrutinised Turkish student societies and indirectly intervened in their events. Despite my request to have an interview with a member 
of the TUSU, I was never given the opportunity to hear what she had to say about these allegations.

On 4 December 2017, I attended a debate held at the House of Lords (one of the two chambers of the UK Parliament, the other being the House of Commons), which was organised by the Union of European Turkish Democrats (UETD-UK) Youth on the topic of Turkey-US relations. As also mentioned above in the discussion of the Gallipoli Commemoration, the UETD is a pro-AKP lobby group. A previous event (also held at the House of Lords) was disrupted by protestors in the audience-yet another incident that caused major conflict within the Turkish community. Therefore, I was keen to speak to its young female membership in order to understand the nature of their engagement with Turkish politics in London. Attending the event revealed that some of the young members of the union in fact wanted to leave to establish their own think tank. They told me that the union did not allow them to freely decide the content of their events. Therefore, they wanted to create an "objective and more open-minded space" for helping young people to freely engage with Turkish politics and also to connect with other youth organisations in the United Kingdom.

During my digital ethnography, I observed that youth organisations in the Turkish community make extensive use of Facebook. I noticed that the live streaming of meetings and events was a common tool used to reach out and promote group-specific political ideas to a wider audience. In the early phase of my fieldwork, I wanted to confirm whether my observation that Facebook was a popular platform for youth political engagement was indeed accurate. In this context, I decided to carry out a small-scale research with UETD Youth UK's Facebook page. My intention was to gain an understanding of the political organisations and groups with which they were connected, as well as the types of issues they engaged with online. Overall, I was curious to see whether the networks and issues identified were indeed compatible with the UETD's politics and agenda. By using Netvizz (a tool for data extraction and analysis for Facebook (Rieder 2013)), I was able to ascertain which other Facebook pages (whether those of groups or specific topics/issues) the UETD Youth was connected to. Although superficially, the UETD Youth UK seemed to run its Facebook page in an open and inclusive manner, its digital connectivity was in fact largely limited to the UETD, the Turkish Embassy, and the Turkish consulate. 


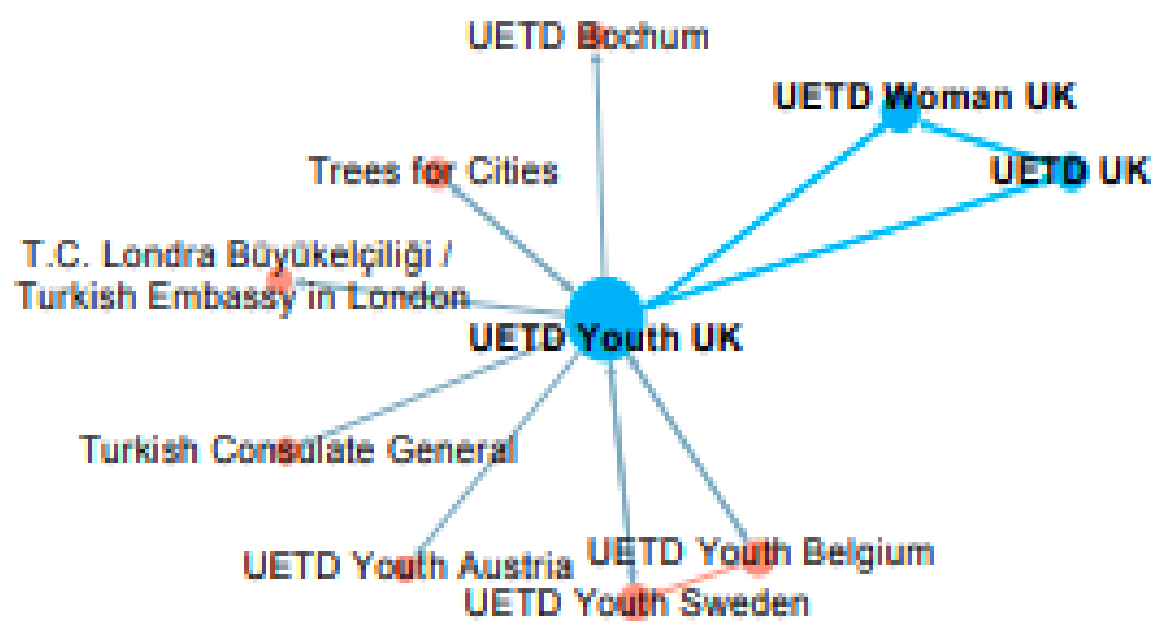

Figure 3. The network of UETD Youth UK on Facebook (visualised by Gephi Version 0.9.2).

This finding led me to question my initial observation about the popularity of Facebook for young politically engaged members of the Turkish community. Facebook it seems, is a platform that is only used to reach out to existing members and announce live streaming events, rather than connecting with a broader network of groups and issues. In the light of this finding, I pursued another online data collection and visualisation project, this time on other well-known and active political youth groups, with the aim of comparing them with the UETD Youth UK. This examination of the digital connectivity of several other youth groups in the community, this time via their page likes on Facebook, gave very different results than those of the UETD Youth. For example, as shown in Figure 3, the network of the Kurdish and Turkish association Day-Mer Youth and Londrali Gençler (Youth from London) not only shows how they are connected to other anti-Turkish Government diasporic community organisations, but also with some left-wing youth organisations in the United Kingdom. 


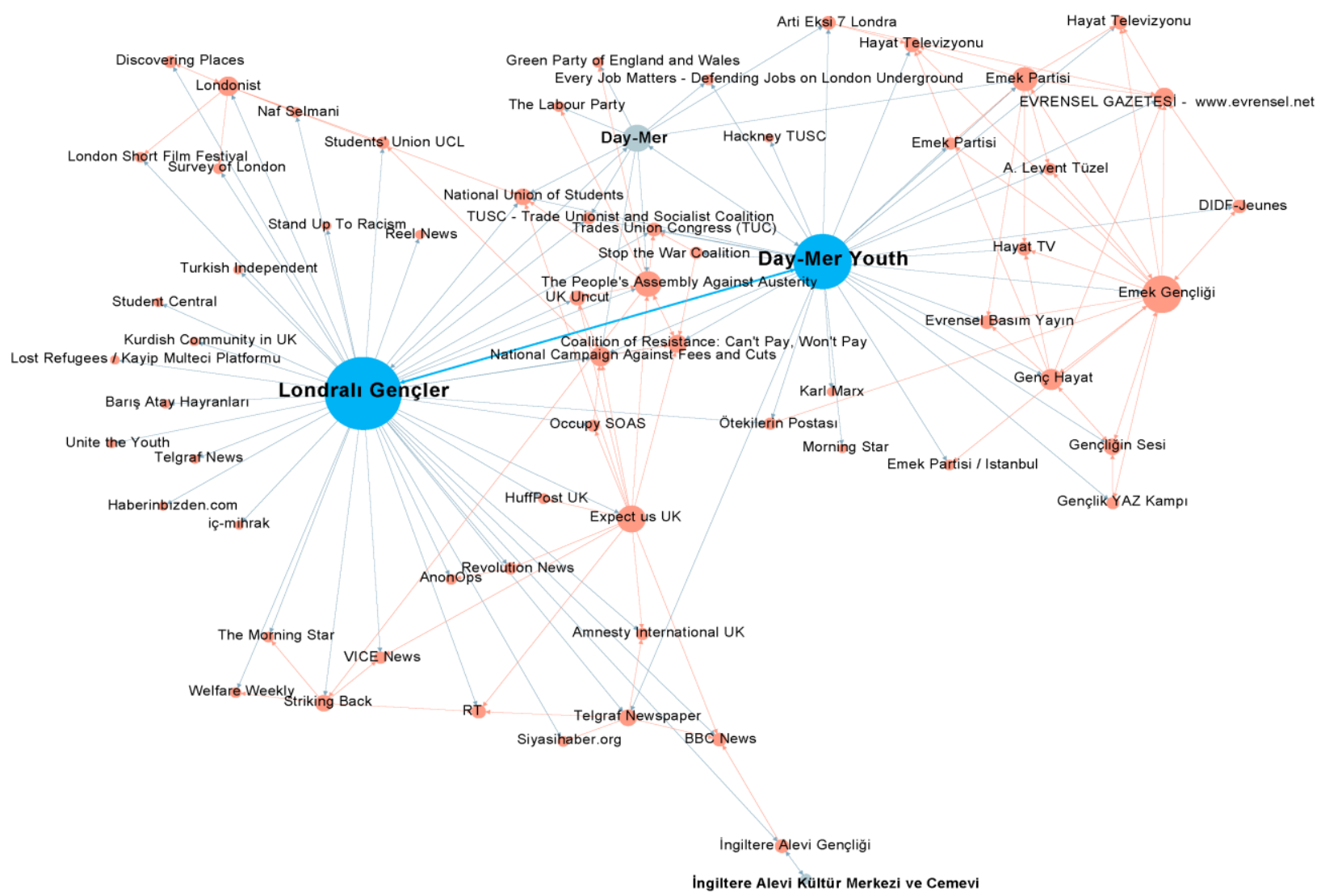

HOW TO READ THE NETWORK:

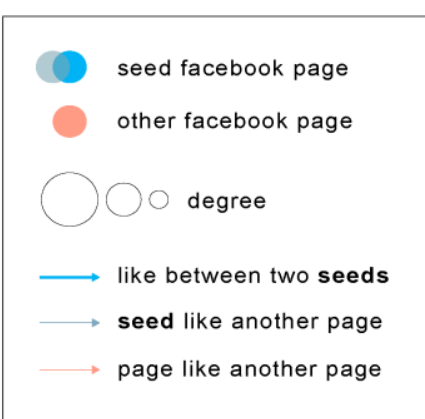

Figure 4. The networks of Londrali Gencler and Day-Mer Youth on Facebook (visualised by Gephi Version 0.9.2). 
The results illustrated above show that the minimal digital connectivity of UETD Youth was not typical of all youth associations. To the contrary, Day-Mer's and Londrali Gençler's digital connectivity echoes their asserted affinity with left-wing politics in general, and also confirms the information I obtained about UETD Youth's limited scope in its political involvement. The revelation of such profound differences between the various groups provides important insight into how the networked connectivity and sense of belonging of young members of the Turkish community operates in a complex environment. Youth identities and experiences within the community are shaped and practiced in a restrictive social context in which some young people have to shoulder the burden of an authoritarian government and carefully manage their online presence accordingly.

These empirical findings raise an important question specific to the case of the young women of the politicised diaspora, namely: How do these young women negotiate their identities when they are forced to juggle between the burden of the nation on the one hand, and their aspirations and choices as young urban dwellers on the other? I believe this question is fundamental if we are to understand how generation-specific modes of living and digital media practices offer a distinctively situated entry-point into the negotiations of diasporic identity.

My observations during, and subsequent reflections upon, my fieldwork suggest that young members of the community are indeed avid users of social media. This generation of women have had access to the internet and digital technologies from an early age and have indeed experienced a "world connected through flows and networks" (Georgiou 2010, 17). These young women can be distinguished from the women discussed in previous sections, not only by how they use a wider range of social media platforms, but also how they use public-facing platforms with explicit performances of their hybrid identities and social imaginaries. In doing so, these young women make use of various social media platforms by giving different meanings and assigning different functions to them in a carefully crafted manner. Hence, in order to understand the type of media-saturated environment in which they are implicated, I needed to understand their digital media use within a holistic framework that takes into account the manner in which platforms assume different functions and operate in a relational environment as "polymedia" (Madianou and Miller 2012). In line with the nonmedia-centric framework of my research project, I aimed to examine the ways in which these platforms are used in meaningful ways by acknowledging user agency in the utilisation and appropriation of the affordances of the various platforms. 
The notion of affordance was invoked in the previous sections, in which I discussed properties such as blocking and unfriending, and the use of mobile phones, respectively. In this section, I would like to extend my discussion on the notion of affordances in relation to social media, since young women utilise a broad range of social media platforms and make explicit choices in how they make use of their varying visual and written properties. As Costa's (2018) notion of "affordances-in-practice" suggests, recognising the actual uses of platforms within situated socio-cultural contexts challenges platform-centric approaches that emphasise the role of technology (such as the architecture of the platforms or algorithms). Such an approach leads us to recognise the agency of the user and the relationality between people and technologies. In this context, I believe that the notion of "affordances-in-practice" brings out the specificity of young women's digital media practices by allowing me to discuss how they self-fashion their diasporic identities by using and moving between multiple social media platforms. Following on from this, by discussing the multiple use of several social media platforms, I argue that the ways in which these young participants construct, represent, and live their hybrid cultural identities through social media should be understood in terms of "digital tactics".

Operating in a politically tense and highly scrutinised social context, the social media practices of youth organisations are closely monitored and (self-)censored. However, their individual social media practices, for example on Facebook, indicate how some young women carefully constitute and perform specific political identities that reveal very different commitments and affiliations. In his study on second-generation Dutch Moroccans, Leurs (2015) reveals how young people constitute their identities online by using the digital infrastructures afforded them by various social media platforms. He argues that creating and circulating images, sounds, hyperlinks, etc. should be seen as the ways in which young people perform digital identities "that can be symbolized and, for example, be digitally circulated as distinct markers of identification" (Leurs 2015, 45). Thus, Facebook can be seen as an important platform for the political engagement of young people. This supports Leurs' $(2015,26)$ argument that the digital identification processes of young people should be understood as "micro-political acts" through which young women carefully represent their identities and political affiliations. For example, one of the young female members of Enfield Alevi Cultural Center, Kader (19), expressed how she carefully creates her online public image: 
I like Facebook because people speak their truth there. They can silence the media, but they can't silence us there. I always like and share other Alevi centres' events-to show we are here. Also, I post our events, such as the singing event we did and other centres [Alevi cultural centres] learnt about us [Enfield Alevi Youth] when they saw those videos.

Later during our interview, Kader continued:

I also posted about the fact that I was elected as young officer to work with minorities for the local council in Enfield. I will study politics next year so it's really good for me. Everyone was very supportive with their comments.

As we can see from Kader's quotations, she manages her Facebook profile in a careful manner in order to build a "public presence" online (Couldry 2012) that reflects her hybrid, multi-layered identity. She refers to Turkish politics by saying how Facebook is an emancipatory tool in times when the mainstream media are silenced by the Turkish government. She ensures that her Alevi identity and belonging are visible through purposeful actions such as likes and shares. At the same time, she does not limit her digital performativity to Alevi politics alone and reveals her commitment to cosmopolitanism by proudly posting an announcement of her admission to the young officer position. Thus, Kader seems to be successfully using the specific platform affordances of Facebook, such as posting, liking, and sharing, to (self-)represent and perform her rooted religious and cultural identity as an Alevi, as well as her cosmopolitan orientation as a young Londoner.

Whilst Facebook emerges as a central platform for public performances of political identities, as already mentioned, displaying political affiliations - particularly those that do not fall in line with a given government's ideology and rhetoric — can be a highly problematic and restrictive issue for young people. However, despite the fact that this may prevent many from explicitly engaging with politics on public social media platforms, young female members of the community seem to find alternative ways to display modes of identity and belonging by carefully negotiating both their audience and their content online. ${ }^{20}$ They distinguish different social media platforms based on what aspects of their identities they can perform, and to what extent. Some young women use Instagram on a daily basis and perceive

\footnotetext{
${ }^{20}$ See also danah boyd's (2014) discussion on the social media practices of young people that cater for specific audiences.
} 
the platform as a "smaller" and "safer" platform than Facebook - a place to exchange glimpses of life with their friends. As their Facebook faces a wider public, also including people outside their close social circle (such as distant family members or colleagues), Instagram is perceived more as a "fun" platform that connects them with their friends and gives them the sense that they are less likely to be monitored or in some other way exposed to surveillance. In this sense, Instagram is the key platform where they can display social and cultural content from their everyday lives that reflect their hybrid identities.

In this context, my interviews, which specifically aimed to uncover how younger women manage their social media profiles, show that London plays a major role in how they negotiate and self-represent their cultural identities with a cosmopolitan orientation. One of my participants, Özen (25), told me how she always watched American films and listened to Western music when she was a teenager. She closely followed Western cultural productions and learnt about British culture from the British TV series Skins before moving to London. As a member of an upper middle-class family in Istanbul, she describes herself as a teenager who was very "interested in other cultures and wanted to learn about the world cultures". She considered transnationally mediated cultural products as contact opportunities with the world-particularly with Western culture. This indeed demonstrates how young people actively use the internet and social media platforms to articulate their globalised cultural imaginaries. As Cicchelli and Octobre (2018) suggest, the use of digital media by young people leans towards internationalised youth cultures and an aesthetico-cultural cosmopolitanism. This aesthetico-cultural cosmopolitanism unites young people across the world who adopt and perform similar globalised cultural identities at a distance. Later in our interview, when Özen speaks about her experience in London, it becomes apparent that London's cultural diversity and her status as a migrant seem to have led her to understand "world cultures" with a cosmopolitan imaginary that is more "grounded in practice" and constituted with "sensibilities for a politics of solidarity" (Leurs and Georgiou 2016, 3075), rather than solely through a Western-centric frame. When she showed me her Instagram account, she narrated how she likes to share images of the migrant neighbourhoods and their ethnically and racially diverse inhabitants. She also told me that she could not imagine herself enjoying cultural and ethnic diversity as much as she does now when she still lived in Istanbul, because she tended to only socialise with "middle-class Turkish people" from a similar socio-cultural background. The platform-specific affordances of Instagram allow young people to generate visual content, geo-tag locations, and add written texts as captions to perform an "authentic" self (Loveluck 2017) with a cosmopolitan disposition. In this 
context, cosmopolitanism becomes an important tool that can be embodied and discursively asserted within the urban context of multicultural London.

However, it is important to acknowledge that for these young women, cosmopolitanism is not solely about narrating a positive attitude towards difference or performing an authentic self. Rather, it is also about "selective commitment" (Georgiou 2006, 96). Whilst it was very common for my participants to narrate cosmopolitanism as a daily lived reality and performed cultural identity, it was interesting to realise the care with which they select which aspects (and to what extent) of their specific identities become parts of such cosmopolitan expressions. For example, during our interview, second-generation, half Turkish-half Sierra Leonean Clara (21) explained how she likes to refer to Turkish culture in her posts by incorporating Turkish food, music, and fashion: "Turkish people love seeing someone half black-half Turkish and how my foreign friends here also learn about Turkish culture from me." Clara sought to increase her popularity on Instagram and wanted to draw more attention from people in Turkey with the hope that a substantial follower base will eventually help her to launch her music career. Despite her knowledge of the popularity of television series in Turkey, she told me that she does not want to include or refer to them in her content because "they always show problematic romantic relationships and portray women in a negative light, but my platform is more about having fun". Thus, it is apparent that Clara pursues a tactical hybrid identity performance by selectively engaging with Turkish culture and deciding what aspects of "Turkishness" concur with the "authentic" diasporic self.

Yet I would add a note of caution here that the cosmopolitanism of young people is not always explicitly mediated via online public spheres, once again revealing how multiple affiliations and varying social locations inform vernacular cosmopolitan identities. For instance, the young female members of Milli Görüş, discussed extensively in the previous section, primarily use a closed WhatsApp group for the purpose of organisation and promotion of the association. In contrast to my other young participants, they do not like to reveal much about their personal lives and daily experiences on social media platforms, where they can be exposed to public scrutiny. However, I also discovered from my lengthy conversations with some of them that they are avid users of platforms such as Twitter and YouTube. Such alternative platforms are used to follow trends and issues, ranging from politics and fashion to religion in a global context. As social media platforms, Twitter and YouTube do not necessarily require their users to expose themselves publicly. Rather, they allow young religious women to pursue their interests and engage with other people whilst 
maintaining a certain level of "invisibility". Therefore, on the one hand, they employ the notion of mahremiyet by carefully self-monitoring where and what they share publicly online whilst, on the other hand, the cosmopolitan orientation that frames their interests and choices is revealed in their mediated connectivity with the rest of the world. I believe that such practices are strong indications of how these young women use the digital infrastructures of different platforms tactically in order to negotiate their multiple affiliations and sites of belonging.

\subsection{Conclusion}

In this chapter, my main objective was to shed light on how participants who are originally from Turkey use digital media tactfully — as interventions via which to mediate their identities and sense of belonging as women members of a politicised diaspora. In this context, I examined specifically what it means to be a woman in a politicised diaspora. The account I have presented in this chapter addresses this question by demonstrating how for such women, diasporic nationalism becomes a translocal phenomenon that connects the contexts of a "homeland" nation and the global city. From an intersectional perspective that takes social class, religion, and generation as its core themes, it has uncovered the ways in which migrant women themselves intertwine these two socio-spatial layers, depending on their varying social locations. Thus, my discussion diverges from previous research on digital diasporas centred primarily on the transnational connections between nation-states, by solely focusing on ethnic, national, and religious affiliations (Alonso and Oiarzabal 2010; Brinkerhoff 2009; Diminescu 2008). It advocates for a recognition of the way in which digital diasporas also come into being in situated material settings on a translocal nexus between the city and the "home" nation in relation to the multiple, intersectional social locations of the migrants themselves. Within this framework, I would like to return to the remaining research questions outlined in the introduction, which aim to delve into the role and impact of the city and digital media in the co-constitution of these women's cultural identities and sense of belonging. To recap, these questions asked: Do the media really preserve national and cultural identity and attachment to the country of origin? If so, what implications do they have for women members of the Turkish community in London? Or, perhaps, do digital media spaces and technologies also open up new avenues for identity formation for these women, who now live in London? 
In a diasporic context, digital media revive the competing national imaginaries and socio-political identities that are embedded in "home" nation politics and history. Of course, this has profound implications for the everyday lives and practices of the female members of the community in London: These digitally mediated transnational spaces and networks not only maintain a sense of attachment towards Turkey, but also contribute to the further fragmentation of an already polarised community. More precisely, migrant women use the affordances of social media platforms and digital applications - such as blocking, unfriending, and grouping - as digital tactics via which to perpetuate the politicisation of the community. Different political affiliations also intertwine with class-based identities. In this context, the city — as the migrant women shape and experience it — is constituted of socially, symbolically, and spatially divided groups. What we see here is how the diasporic community is formed through a nation-oriented framework and how urban spaces become reflexive of its political and classed divisions.

However, although the politicised diaspora is nation-oriented, digital media also open up new avenues for identity formation for these women. In this context, London's multicultural dynamics and culture play a significant role in co-constituting my participants' cultural dispositions and social imaginaries. This is reflected in my participants' digital practices of self-representation in the city, which they perform with cosmopolitan horizons. Whilst different social categories such as nationality, gender, religiosity, and generation inform their particularistic subjectivities, these also give birth to multiple situated cosmopolitan imaginations. For example, the analysis in section 3.4 illustrates how religious participants use the portability of mobile phones to curate embodied public performances of their diasporic urban identity in the city. Whilst their religious affiliations are filtered through Turkey's history and culture, they are also negotiated through an urban cosmopolitan ethos. The analysis in section 3.6 also confirms the important role both the city and digital media play in the identity production of migrant women by illustrating how young participants utilise the affordances of various social media platforms in order to navigate politicised intracommunity dynamics on the one hand, and to perform their own cosmopolitan youth identities on the other.

To conclude, this chapter reveals the manner in which nation-oriented diasporic identities intertwine with varying social locations and become part of hybrid, cosmopolitan articulations of the diasporic self in the city. Thus, this chapter presents a novel and nuanced account of the complex and dynamic relationship between digital technologies and gendered identities in the investigation of diasporic nationalism. In this context, it identifies and 
contextualises the digital practices of the female members of the politicised diaspora as carefully crafted, tactful interventions that connect national and urban contexts, and negotiate their multiple attachments. 


\section{Chapter 4: Generation and Mediating the Diasporic Self: The Case of the Somali}

\section{Community}

\section{Introduction}

In the car park, there are old men crying.

They are holding onto one another like poplars.

You tumble like them, like freshwater,

from the coach station. Leave the greens of Golders

behind you. You are back where it begins.

Temple Fortune. Gospel Oak.

Make your slow diasporas through Neasden narrow lanes, steal the night's milk \& drag yourself northwards

sure as a needle's compass.

These parts aren't what they used to be.

But neither are you.

—Momtaza Mehri, "Our Father Who Art in Hendon"

As we waited outside the door, Hoden light-heartedly whispered "I hope the kids are not home...". Her sentence was interrupted when a boy around ten years old opened the door for us. Behind him a girl, who looked a bit younger, was standing. She seemed to be surprised to see us and said, "my mum is not home". I followed as Hoden entered the house and took off her shoes in the corridor whilst she said: "I know she is with my mum; they are doing shopping. They will be here soon." We entered the living room, where another little boy and a teenage girl in their school uniforms were sitting on the couch in front of the television. Hoden told her cousins that the next day she was going to Hargeisa, the capital of Somaliland, for a conference. This raised a discussion amongst the kids, who told Hoden things such as how they would never want to go to Somalia, especially in summer, since it is very hot and there is nothing to do. The teenage girl said: "I never want to go there actually." One of the boys nodded in approval, saying: "Yeah, Somalia is so savage!" Hoden, who had told me earlier about how she was inspired by young people from the diaspora who returned to Somalia to work on "societal issues and humanitarian projects", seemed upset by their 
comments. She told them that they could never know what Somalia is like, because they had never been there. Yet this was still not strong enough to convince her cousins, who believed themselves to know enough because they had seen it many times on television. The conversation ended abruptly when Hoden's mother Rada (42) and aunt Hawa (40) entered the room with shopping bags in their hands and the children were immediately sent upstairs to their rooms.

When I told Hawa about the conversation between Hoden and the children, she told me that it was her fault that they did not know much about Somalia. She was upset about the war and felt ashamed of the way people had treated one another, so she preferred not to tell them much. However, Hawa also proudly added how she taught her kids about Somali culture so that, even though they may not have a positive view of Somalia, they knew they were Somalis and Muslims. It seems that, at least to a certain extent, Hawa chose to teach her children about Somalia on a cultural and moral level, rather than through a historical and political narrative. However, later in our conversation, Hawa gradually revealed how her efforts to teach her kids selectively about Somalia were contested by her children, who "come to me with phones in their hands and tell me mum this happened or that happened, this is why there was a war or this is what's happening now, so they learn things although you don't want to tell".

Throughout the course of my fieldwork with the British-Somali community, I had many conversations and personal reflections that reminded me of the day I spent in Hawa's house. My research provides strong evidence of how British-Somali women articulate, practice, and self-represent their identities differently in relation to varying temporal and spatial contexts across generations (Anthias 2009b, 7). Although generation is also one of the axes I highlight in my analysis of Turkish and Romanian migrant communities, the high sense of reflexivity that British-Somali participants demonstrate about generation-specific experiences and digital practices has led me to explicitly invoke an intergenerational perspective for my analysis in this chapter. The following statement made by Rada clearly exemplifies this choice, demonstrating how the British-Somali women in my study narrate intergenerational dynamics and changes in tandem with gendered experiences and limitations:

Girls are easier; boys are harder to control. I tell my son, 16 years old now, all the time to study hard, to go to university so he can be like Hoden, like you. Or I ask him if he wants to be like me? But he doesn't want to go and it's sad because of -I don't know if you know what 
is going on with Somali boys now. Girls are better, they study harder. They will do much better than us.

When it comes to the second generation, the epigraph from the British-Somali poet Momtaza Mehri (26) demonstrates how young women also narrate their lives and experiences in relation to previous generations of diasporic Somalis. For example, Ashakayf (25), who was training to become a primary school teacher at the time, told me that she firmly believes that the next generation of British-Somali women will do well by taking their mothers as examples:

I feel like Somali girls are very strong women. We get that from our mothers, because even before the war and my parents made their way from Somalia, Somali women were the ones that always had to be the breadwinners. I mean that they are always the ones that keep the house standing, either cooking the food, or cleaning the house, doing everything. So, mostly, I don't want to say useless, but Somali men never really did anything because they are used to the easy way in life, whereas Somali girls are very, you know, from a very long time ago always been determined and strong, you know.

These statements, which so vividly reflect the importance of gendered and generational dynamics - both the continuities and the ruptures between these two generations-led me to ask several important questions: Do two generations of British-Somali women mediate their diasporic identities and cultures differently? In what ways do their experiences and lifestyles differ in London? What role does digital media play in the articulation of gendered and generational identities and experiences? Addressing these questions from a gendered (female) perspective, this chapter contributes to the existing body of literature on diaspora and generation.

Central to my analysis is the processual character of diasporic cultural identity that is negotiated between "roots" and "routes" (Gilroy 1993). Whilst "roots" metaphorically convey one's identification with, and social and emotional dispositions towards, a place of origin, as well as a shared culture and common historical experiences, "routes" signify the changing and fluid character of cultural identity in relation to new encounters, mobility, time, and culture (Gustafson 2001, 668, 669; Leurs 2015, 44). My research provides strong evidence that the processes and experiences that shape these women's journeys from "roots" to "routes" rely heavily on the digital media they use, and thus sheds light on the entwined 
relationship between British-Somali identity and generation with a particular focus on the role of digital media - a topic that until now has remained under-researched.

In this context, I focus on British-Somali women's digital media practices and unpack how they mediate their diasporic selves via generation-specific identity performances in both urban and digital spaces. As Judith Butler (2003) famously articulates with her notion of "performativity", gender identities are socially constructed via performances-both physical actions and vocalisations - rather than representing something innate that we are. In my discussion, I examine how first- and second-generation British-Somali women perform their diasporic selves at the intersections of various axes-generation, clanship, religion, and race - in tandem with gender. In this regard, I argue that digital media are central to how British-Somali women in London not only represent and render their identities visible, but also enact those identities (Leurs 2015, 28) by performing multiple facets of their diasporic selves.

This chapter is organised as follows: In section 4.1, I introduce the Somali community in London. In sections 4.2 and 4.3, I look at the ways in which my first- and secondgeneration participants mediate their diasporic identities and cultures by analysing the digital media practices that connect them with transnational Somali communities. In this context, I discuss how two generations locate themselves within, and perform their diasporic selves as part of, the global Somali diaspora, and what this reveals about their generation-specific diasporic subjectivities and experiences. In section 4.4, I focus more closely on the everyday experiences and realities of second-generation Somali women in London. This refined focus allows me to draw parallels and comparisons with the first generation. I look at how the specific experiences and expectations of these women as young urban dwellers impact the ways in which they use the internet and engage with social media platforms in search of social and cultural mobility in the city. By focusing primarily on religion and race, I argue that they seek to challenge the intersectional marginalisation they face and articulate (and self-represent) their unique urban identities as black Muslim women.

\subsection{Who Are "the People"?}

The UK Somali population is estimated to be 101,000 (Open Society Foundations 2015, 14) of which around 65,333 live in London (Open Society Foundations 2013, 27). The UK Somali diaspora is second in size only to the United States, and despite having a common 
language, ethnicity, and religion, it is demographically very diverse along the lines of clan membership and territorial associations (Osman 2017, 4, 39). Somali immigration to Great Britain began in the late eighteenth century when (mostly) men from the former British protectorate of Somaliland settled in cities such as London, Cardiff, and Liverpool to work for the British Merchant Navy. This was followed by economic migrants (also predominantly men) who came in the 1960 s to work in the expanding steel industry. Soon, wives and children began to join the men, further expanding and firmly establishing the UK Somali community (Harris 2004, cited in Liberatore 2013, 282).

By the early 1980s, there was growing unrest and an armed resistance in Somalia against President Siad Barre. Barre was accused of nepotism, oppression, discrimination, and the promotion of clan ideology and politics. In 1991, different clans started to take over the control of areas and eventually co-operated to overthrow Barre. There were numerous clanbased armed opposition groups and, due to the growing power vacuum and the lack of any central authority, rape, murder, and violence became widespread. Somalia became a "refugee-producing nation", and to this day millions of people in Somalia are still in need of humanitarian aid and relief work (Hopkins 2010). Against the backdrop of the ongoing civil war, the largest migration from Somalia to the United Kingdom occurred during the late 1980s and early 1990s. The Somali civil war (1989-1991) forced millions of Somalis to settle in neighbouring African countries as well as in Europe, the United States, and Canada, and today these communities constitute the global Somali diaspora (UNHCR 2008). Since the beginning of the 2000s, the Somali community in London has also grown due to internal migration from other British cities, family reunions from Somalia, and the arrival of mainland European Somalis, particularly from the Netherlands and Scandinavia (van Liempt 2011). ${ }^{21}$ Today, the Somali community in London is one of the largest in Europe and is predominantly concentrated in the boroughs of Tower Hamlets, Camden, Ealing, and Lambeth (African Culture Blog 2016).

However, as the Open Society Foundations $(2013,25)$ states in its extensive report on the Somali community, it is difficult to accurately estimate its size and demographics since the UK Census does not include British-Somalis as an ethnic group under a specific

\footnotetext{
${ }^{21}$ In her research on Dutch Somalis' migration to United Kingdom, van Liempt $(2011,254)$ argues that "the presence of a large Somali community in the UK, economic and educational opportunities in the UK, and differences in integration policies have influenced Dutch Somalis' decision to relocate".
} 
category. ${ }^{22}$ In this regard, the Somali community is incorporated within the category "black African". However, this categorisation fails to acknowledge Somalis' national, ethnic, religious, and cultural differences from neighbouring African countries. This lack of a specific category for Somalis leads, not only to a misrepresentation of the community, but also to a failure to fully understand the experiences and needs of British-Somalis. Moreover, although there are a significant number of Somali community organisations, the community is underrepresented in local and national bodies, making Somalis one of the most "silent" communities in United Kingdom. This, coupled with the fact that media representations of Somalis tend to be largely negative, focusing on issues such as gang membership amongst young men, knife crime, and female genital mutilation (FGM), results in further stereotyping of the community. Whilst the debate on the categorisation of British-Somalis echoes a larger problem of monitoring and engaging with ethnic minorities in the United Kingdom (Open Society Foundations 2013, 24, 25), it is necessary for me to note the (largely neglected) complexity and heterogeneity of the community for several reasons.

First, fifteen out of twenty of my participants are originally from Northern Somalia, a former British colony known as "British Somaliland". British Somaliland gained independence in 1960 along with the south (formerly colonised by the Italians), uniting to establish the Somali Republic. Following the collapse of Barre's regime, Somaliland declared its independence as a separate state, although it is internationally recognised only as an autonomous region of Somalia. ${ }^{23}$ Some of my participants indeed refer to Somaliland as their country of origin rather than Somalia. Whilst my study does not focus on regional politics and divisions in terms of nationality or allegiances to different states, it is important to note how different territories are dominated by different clan families, since these indeed shape British-Somalis' political and social identifications (Osman 2017, 39). Somali social structure is organised according to kinship and "based on an agnatic (patrilineal) lineage type-known

\footnotetext{
${ }^{22}$ The Office for National Statistics (ONS) incorporates "Somalia" as a category for country of birth and nationality (https://data.london.gov.uk/dataset/office-national-statistics-ons-population-estimatesborough). On its website, the Anti-tribalism Movement (ATM) states that they believe Somali-British population to be much higher than official statistics, between 250,000 and 400,000. In this regard, they advocate for the inclusion of "Somali" as an ethnic category and state that they expect this to be enacted for the 2021 census by the government on the recommendation of the ONS (https://theatm.org/2018/06/04/the-need-to-include-somali-ethnicity-on-national-census/).

${ }^{23}$ There are other regions that are semi-autonomous and semi-independent in Somalia, such as Puntland, Jubaland, and Southern West (to name a few). However, Somalilanders are the only ones to have declared themselves a fully independent nation-state and are currently seeking international recognition as a separate country.
} 
as [the] clan" (Gundel 2009, 7). Most of my participants are from the Isaaq clan from Somaliland, whilst the rest are from the Darod and Hawiye family clans from central and southern Somalia. ${ }^{24}$

Second, as mentioned above, Somali immigration to the United Kingdom has occurred in several distinct waves. Thus, it is important to note that my study only looks at the experiences of female Somali refugees and the female descendants of refugee parents. My first-generation participants all came to London as refugees and, as is the case for many refugee communities, benefited significantly from established, network-based connections that helped them get there (van Hear 2009, 181). In my conversations with the HAYA Community Centre, I was informed that the Isaaq clan constitutes the largest group in the British-Somali community. As previously stated, Somaliland had been a British colony and, as a result, there was already a Somali community in the United Kingdom. Therefore, during the civil war, many Isaaq clan members joined relatives who were already established in London (Liberatore 2013, 288). However, to my knowledge, there are no official statistics detailing the regional origins and clan memberships of British-Somalis in the United Kingdom.

Turning now to my second-generation participants, seven out of ten were born in London, whilst the other three arrived as teenagers from Sweden, the Netherlands, and Egypt. In the light of the above, my study is founded on the conceptualisation of the British-Somali community as a refugee diaspora whose displacement and resettlement have taken place in the context of conflict and war (van Hear 2009, 180). As Hopkins (2010) highlights, whilst there has been increased interest in the experiences of refugee women, there needs to be further investigation into whether the various agencies concerned produce effective policies and practices to assist them in receiving countries. My study contributes to existing literature on refugee diasporas by examining the gendered dimensions of female Somali refugees' lives and experiences in the context of their resettlement.

\footnotetext{
${ }^{24}$ The Isaaq are the primary population group in Somaliland (Gundel 2009). Whilst there is some debate about whether the Isaaq can be described as a family clan on its own, the majority of my participants identified themselves as members of the Isaaq. Between 1987 and 1989, 200,000 members of the Isaaq were massacred at the orders of Siad Barre's government - an episode referred to as the "Isaaq genocide" (Einashe and Kennard 2018). The Darod is the largest majority clan family with clan branches in eastern and southern Somalia. Siad Barre's army was largely dominated by his Merehan clan from the Darod clan family (Hill 2010, 7). The Hawiye mostly inhabit central and southern Somalia. Today it is the most dominant group in the Somali capital, Mogadishu (Hill 2010, 12).
} 
Finally, British-Somali pupils are largely depicted as one of the worst performing black and minority ethnic groups in the United Kingdom (Dernie, Lewis, and McLean 2008; Open Society Foundation 2013). Although there are no national statistics available on the issue, local statistics in the boroughs of Tower Hamlets and Camden reveal the importance of taking gender into consideration when it comes to discussing the educational achievements of British-Somali students (Open Society Foundation 2013, 50-65). Somali girls in both boroughs do well at school and the number of Somali girls attending higher education is considerably higher than boys. Whilst cultural gendered expectations may intervene in the higher education of girls - who are expected to marry when relatively young (Open Society Foundations 2013, 52) - it is undoubtedly important to take into consideration that Somali girls increasingly perform better in the British education system. Indeed, most of the young women in this study have recently attended higher education and are currently working. In this regard, whilst I acknowledge that my discussions of the second generation in this chapter may be unique to these relatively more educated second-generation British-Somali women, I believe that it is important to understand the experiences of these women beyond the dominant negative stereotypes that stigmatise British Muslim women in the United Kingdom.

\subsection{First-generation Somali Women and Diasporic Humanitarianism}

Faduma (46) brought a blank piece of paper and a pen from her children's room and sat on the floor. I sat next to her and watched as she drew a tree-like diagram. She pointed to Isaaq on the top of the diagram and said: "So, if someone comes from the south, I just say Isaaq and they will know who I am." Then she pointed at a branch underneath Isaaq, called Habr Awal. "Someone from the north, I say this, but within Habr Awal, I would be sub-clan Sa'ad Musse and this is the group I was talking to you about."

Faduma had decided to give me an insight into her clan family, since I was finding it hard to understand the differences between her five WhatsApp groups. She opened the application on her smartphone and tapped on these different groups consecutively, proudly showing me how Somalis the world over were involved in collecting money to help those back in Somalia. She was happy about her involvement in "re-building Somalia", donating money to what she referred to as "reconstructive projects" that aimed to build roads, schools, and hospitals. It was relatively early on in my fieldwork and I asked her whether these were major diasporic Somali groups of which I should have been aware for their active use of 
digital media. Faduma told me that she was not entirely sure, but that she was added to these groups by people whom she knew personally, since these WhatsApp groups aimed to raise money with the goal of "helping the country". She did not always have sufficient money to donate to all of the projects in each group and she was most active in two of them. She also advised her grown children to spare some money every month for donations. I made a note of the names of the two groups in order that I might research them further the next day.

However, despite browsing a list of UK-registered Somali associations that carry out projects in Somaliland, Faduma's two groups were nowhere to be found on the internet.

In the beginning of my fieldwork, my main connections with the Somali community were second-generation women who later introduced me to the older women in their families. Some of these young women mentioned to me how WhatsApp would become an important platform upon which to focus when I met their older female family members. One such younger women even joked about how any such research project about digital media should be carried out with women from her mother's age group, since her mother "has [a] crazy amount of WhatsApp groups, it's message after a message. I guess she is into digital stuff more than I am". Thus, in my second meeting with Faduma, I decided to ask once again about these groups to understand how they are formed and maintained in the absence of an overarching physical, established organisation. How do they carry out these fundraising projects on WhatsApp? Do these groups exist solely online? Who gathers all this money and ensures that it is spent for the projects in Somalia? How does Faduma know that her money is spent for the right purpose?

Faduma explained that she was not one of the main organisers, but that such groups are widespread amongst Somalis. Importantly, they did not only comprise British-Somalis, as they are run and supported by Somalis in different parts of the world. In most cases, these are registered organisations in Somaliland that work closely with regional authorities. She started to mention the two groups that were "closer" to her again by emphasising that she mostly gave money to these ones. The reason for this sense of affiliation was not because of what these organisations stood for, or the kinds of projects they carried out, but rather because they aimed specifically to help "her people". I found it difficult to understand the reasoning behind Faduma's hierarchical perception of these WhatsApp groups and why she prioritised two of them over the others. I then discovered that although four out of the five groups with which she engaged included only members of the Isaaq clan, she largely prioritised her subclan group and another, relatively smaller group, as they both worked exclusively with the village in which she was born. Therefore, the tree diagram demonstrated how Faduma ranked 
her WhatsApp groups according to the degree of kinship and geographical proximity (to her birthplace). In this way, I became more able to understand how she felt two of them were "closer" to her than the others.

These WhatsApp donation groups illustrate how digital media facilitate financial transactions between countries of origin and receiving countries, in this case specifically for those members of the Somali diaspora who are engaged in efforts to rebuild their war-torn country and/or particular regions within it. As Van Hear $(2009,283,284)$ suggests,

the financial aid that refugee diasporas provide for their countries of origin emerge from a number of different motivations. He reveals how their inclination to engage may be shaped by personal or private motivations, such as the imperative to protect one's family, kin, or friends; by wider humanitarian concerns for the community, society, or nation; or by harder political motivations that may involve religious fundamentalism or ethnonationalism.

(Van Hear 2009, 283 - 84)

Throughout their discussions and narratives, my participants remain well-informed of Somalia's political and economic hardships, and express much enthusiasm towards playing their part in reconstructive efforts to help the country to recover. Indeed, this concurs with media studies scholar Osman's $(2017,4)$ description of the members of the Somali diaspora as "geographically abroad, but psychologically and emotionally ... very much resid[ing] in their homeland".

The imperative of "reconstructing the country" in this context should also be understood from a historical and societal perspective, keeping in mind that Somalis have been living in a country that suffers from the lack of a functioning government and state for almost three decades. As Samatar (2016) states, following the collapse of the Somali government and the failure of the state to provide public services and institutions, society itself has taken up the role, pursuing "state affairs" through grassroots organisations and groups in order to fill the void. In this context, several studies have been conducted into the humanitarian incentives of diasporic Somalis. Such studies provide valuable insights regarding the types and form of remittances and other financial contributions (to households, kin, and community projects) made for the recovery and reconstruction of Somalia (Hammond 2007; Horst 2008; Lindley 2010). These payments clearly demonstrate the significant extent to which such financial transactions constitute an important part of the transnational lives of diasporic Somalis. Osman's work $(2017,119,135)$ makes a valuable contribution here, drawing 
attention to the role of the diaspora in enabling humanitarian support and developmental progress in Somalia by creating a transnational politics of solidarity and mobilisation.

In line with this body of literature, it appears that the WhatsApp groups used by my participants create sites via which they can operationalise transnational networks of solidarity and mobilisation, encompassing members of the diasporic community across the world. Indeed, it soon becomes apparent in my participants' narratives that these WhatsApp groups help them to think (or imagine) that there is a strong global Somali community of which they feel part. In this context, although superficially, these groups seem to mainly maintain financial, ethnic, or cultural ties with the country of origin. As members of a global diaspora, these women articulate a diasporic identity and sense of belonging that operates across transnational distances and that does not exclude, but rather goes beyond, the "home nation host nation" nexus. In this context, my interest in WhatsApp donation groups is not about evaluating the social and economic impact they make in Somalia or Somaliland, or even discussing their value or effectiveness. Rather, by drawing upon the meanings my participants assign to these groups, in which every-day, bottom-up humanitarian practices (Ong 2019) take place, I look at them as digitally mediated spaces in which first-generation British-Somali women living in London perform their diasporic identities on a transnational level as part of the wider global Somali diaspora.

Another participant, Ifrah (48), explained that she was sponsored to come to London by some relatives who had already been living in London for many years. However, as soon as she arrived in London, they abandoned her. Whilst she made it clear that she did not want to talk in any depth about her saddening first couple of weeks in London, she also added how some other sub-clan members heard about what happened, and one of the families invited her to stay with them for a while. My next question - whether she knew this family beforehandyielded a crucial insight into the centrality of clan membership in Somali culture, and how it constitutes a valuable asset of solidarity and support:

Ifrah: "In Somalia, we always left the doors open so family could come and go anytime. We shared food, we shared everything. People could stay at each other's houses; cousins could sleep in the same beds. When I came here, it was again people in clans helping out each other because Somalis always help each other. Here, I again found people thanks to people in my clan." 
Melis: "So, your clan family helped you when you came to London first. What about Somalis from other clans? Would they also help?

Ifrah: "It depends. Well, I don't know. You are a Somali still, but I mean not close, not family you know."

Later, during our interview in which we discussed Somalia, Ifrah's words echoed what the majority of the participants said about clannism: "Tribalism is a bad thing, our biggest problem. We have everything. Big country, beautiful country. Small number of people. Stupid people still follow tribes. This is why tribalism is a big problem in Somalia." I take Ifrah's comments as a reflection of how my participants see the socio-cultural significance of the clan structure and kinship within Somali culture. The notion of kinship is central to understanding the collapse of the state and emergence of civil disorder in Somalia due to traditional allegiances to clans and a lack of commitment to state government and any centralisation of power (see Lewis 1992, cited in Samatar 1992, 626, 627). However, Samatar (1992) argues against this line of thinking, instead drawing attention to the societal and economic problems postcolonial Somalia has encountered in the face of a deteriorating traditional system of social structure and competitive capitalist ideology. In this regard, he makes an insightful intervention by explaining how traditional Somali traditions were organised around communal values and equalitarian relations based on blood ties (kinship), Xeer, and Islam. Whilst genealogy has always been central to the Somali social structure, Xeer refers to the socially constructed contract to ensure security and social justice in the distribution of material and organisational resources within households and lineages (Samatar 1992, 630).

Liberatore $(2013,88)$ argues that migrant Somali women go through "a process of selection", choosing between a set of cultural elements. Whilst they reject "bad parts" of their culture, such as clan ideology or FGM, they retain the "good parts", such as their style of dress, food, or kin values. Following Liberatore's thesis, it therefore seems understandable why Ifrah clearly praises kinship values — such as helping and sharing — whilst disavowing divisive clan ideology, calling it "tribalism", which is the common English word used to refer to clan-based social structures. Ifrah's narration of her own clan family as a network of solidarity by distinguishing it from tribalism reflects her selection of different cultural elements as "good" and "bad" values. Ifrah also uses WhatsApp on a daily basis and she is a member of various WhatsApp groups. When I asked her about these, her answer echoed that 
of Faduma. However, she elaborated upon the importance of kinship as a motivation for engagement even further:

One of my cousins called one day and said she didn't have money for a doctor and medicine for her child. This is so sad. I have got everything here, the doctors, the hospitalseverything. That's why people make WhatsApp groups. They are the ones that are purer [i.e., more specific]... Because the village is one village, we all came from that village. The hospital is built, then it helps the village. The school is built, the same school we all came [i.e., attended], your mother or your father came. But there are some WhatsApp groups [that are] much larger...Because with a big group, then the attempt is to do the bigger region, not just the village.... Then, you are not helping your cousin, but maybe you want to help your cousin. It depends on the manager, but also the people in it. For me, the purer the group is, it's more likely to survive.

Ifrah's statement, in which she compares herself to her cousin, who does not have access to health facilities and medicine, demonstrates how the financial transactions that take place within these groups are motivated by egalitarian appeals for the redistribution of resources between relatively more affluent diasporic Somalis and those who remain in Somalia. At the same time, Ifrah ranks these groups in terms of their target beneficiaries, reflecting the selective modes of transnational engagements and financial transactions that exist amongst my participants. Whilst she expresses emotional dispositions that encourage her to pursue philanthropic, community-level projects - to build hospitals and schools - she also makes it clear that she prefers "purer" groups that specifically help her village. In this context, she prefers smaller groups because this reassures her that her money is going to a project that is focussed on a specific location and ensures that her kin will benefit. In this regard, whilst these WhatsApp groups are based on ideals concerning the equal distribution of wealth, the manner in which Somali women selectively engage with them reveals how the politics of solidarity operates within the framework of a clan-based understanding of Somali society (Osman 2017, 135).

Furthermore, these examples are also indicative of the need to expand our understanding of the concept of family when studying the transnational connections and financial transactions of migrant communities. Current research on migration has extensively documented the need to go beyond a Western-centric understanding of the "nuclear family" towards a more transnational conceptualisation of family that captures the "institution of care 
circulation" facilitated by media technologies (Bachmann-Medick and Kugele 2018, 7). In the case of the Somali diaspora, such transnational collective efforts, facilitated through online groups, constitute an important part of "care circulation" and are shaped by extended family affiliations. As can be seen in the case of Ifrah above, the members of her clan helped her when she first arrived in London because they were her family, although Ifrah did not know them personally beforehand. Thus, as in the case of the remittances that migrants send to their immediate family members, these transnational engagements, which are so shaped by kin affiliations, are also more than simple economic transactions (van Hear 2009, 182). Rather, they also have social and affective dimensions, since they constitute meaningful transnational networks that are not defined by ethnic or immediate familial ties. Instead, they are sustained by members of extended family groups that are dispersed across the world. This point is aptly reinforced by Asia (46), who takes an active role in an association registered in Somaliland through the WhatsApp group "Gaaroodi Sisters":

In here [London] we [diasporic clan members] don't have a chance to live to be closer [because of now living in different countries]. But we still do the clan things because we have this WhatsApp group. We're communicating, we're making the group and we're making contributions.

As van Hear $(2009,182)$ reminds us, although the financial dimensions of diasporic economic engagements are evident, it is important to note how they also help repair and expand social relations in post-conflict societies. Indeed, these WhatsApp groups allow Somali women to re-establish meaningful social networks, fulfil familial obligations, and achieve a sense of being part of their kin regardless of physical borders and distance. Indeed, as Asia's statement demonstrates, these groups are diasporic cultural formations that transnationally revive sociality and connectivity amongst groups that had existed prior to the conflict.

In this regard, parallels appear with Horst's $(2013,239)$ work on the "civic participation" of refugee diasporas, suggesting that Somalis in the diaspora view their responsibilities towards their country of origin based on what happened to their kin groups during the conflict, rather than their ethnic or national ties. Prominent diaspora studies scholars such as Safran (1991), Van Hear (1998), and Cohen (2008) use the Jewish diaspora as an archetype to create typologies that can then be employed to decide whether a given ethnic group can be classified as diasporic. Cohen $(2008,161)$, for example, highlights how a 
continuing connection with an ancestral home and a strong ethnic consciousness are two of the main characteristics of global diasporas. My study does not entirely contest this typology, since most of my first-generation Somali participants are members of several large WhatsApp groups in which together, regardless of their clan affiliations, they engage in large-scale development projects and humanitarian incentives. Yet, as I have demonstrated via a number of examples, a closer look at my participants' engagements with WhatsApp donation groups demonstrates how they chiefly define their sense of belonging via their particular sub-group affiliations, which are based on kinship rather than ethnicity and/or nationality.

My research sheds light on the central role digital media play in this context. I explored in the last chapter, in relation to my fieldwork findings at Millî Görüş, how some pious women utilise mobile messaging applications such as WhatsApp to create "superprivate" online spheres (Costa 2016, 165) through one-to-one communication or small groupings. Whilst in the case of pious migrant women from Turkey, WhatsApp (and other messaging applications) yield private and closed forms of communication, first-generation British-Somali women come together and navigate across multiple online spheres that vary, both in terms of their size and scope. By ranking these according to their clan-based affiliations, these women use WhatsApp to take part in multiple social groupings and experience different levels of sociality between them. Miller (2015) makes a similar point regarding digital platforms and mobile applications by arguing how a particular focus on user practices challenges us to think beyond the "public media versus private media binary" that existed prior to the emergence of social media. In this regard, he argues that we need to recognise the different degrees of "scalable sociality" users generate by using the affordances of new platforms that yield greater choice over the degree of privacy or the size of group with which they may wish to communicate or interact (Miller cited in Borgerson and Miller 2015). In this context, Miller urges us to pay attention to how local social and cultural factors shape users" understandings of "public" and "private", and scale their online sociality accordingly, given the affordances of a given platform.

In this context, my study presents an interesting case in which differing scales of sociality are not confined to a specific local area, but rather are constituted on a localtransnational nexus in a diasporic context. Local social and cultural factors are obviously important in the sense that members can join these donation groups and have access to greater material resources in London than their counterparts in Somalia. Moreover, they attribute different roles and responsibilities to women - both in the context of civil society, and in the context of nation-building. Asia, for example, referred to her English neighbour 
who crowdfunds for the United Kingdom National Health Service (NHS) and says: "Women are expected to participate here. They are expected to be active." Online networks of sociality are spaces of transnational belonging that connect members of the diaspora dispersed across different physical localities. Here, what we see is a "translocal" scale that articulates from "private" to "public"- the positions between emergent social spaces that are assigned different meanings and levels of sociality within a clan-based socio-cultural framework.

Thus, members generate a "scalable sociality" through their use of WhatsApp, allowing them to perform their diasporic selves transnationally and in line with their ethnic and kin affiliations. Although these multiple online groupings are defined by their particular identities, members are able to move between them and, importantly, to decide to what extent to become part of them in line with their own specific cultural affiliations, financial abilities, and responsibilities. Thus, whilst on the one hand, WhatsApp facilitates a sense of belonging to a broader transnational Somali community encompassing Somalis across the world based on their shared ethnic ties, on the other hand, it is clear that they engage more with smaller and more specific groups that better reflect their particular clan-based identities. In this way, such groups allow women to perform a specific diasporic self-one that helps kin in Somalia, maintaining an equal distribution of wealth amongst kin households, regardless of physical distances. Performances of belonging - in the form of organising, mobilising, and donating to "reconstructive projects" - not only to Somalia, but also to the wider Somali diaspora, are enabled and enacted via these groups. In this manner, by performing diasporic belonging, the selective commitments of the group members create a continuity between Somalia and London, allowing them to enact particular identities and alignments on the basis of their kin affiliations in translocal and transnational contexts.

Having focused thus far on the digital practices of first-generation Somali women, I would now like to continue by discussing how the second-generation British-Somali women in my study connect and socialise with diasporic Somalis from different parts of the worldspecifically the different motivations and modes of sociality they express. In doing so, I demonstrate how they perform their diasporic identities and sense of belonging as part of the global Somali diaspora within a youth-oriented digital social milieu that reflects their generation-specific experiences and expectations. 


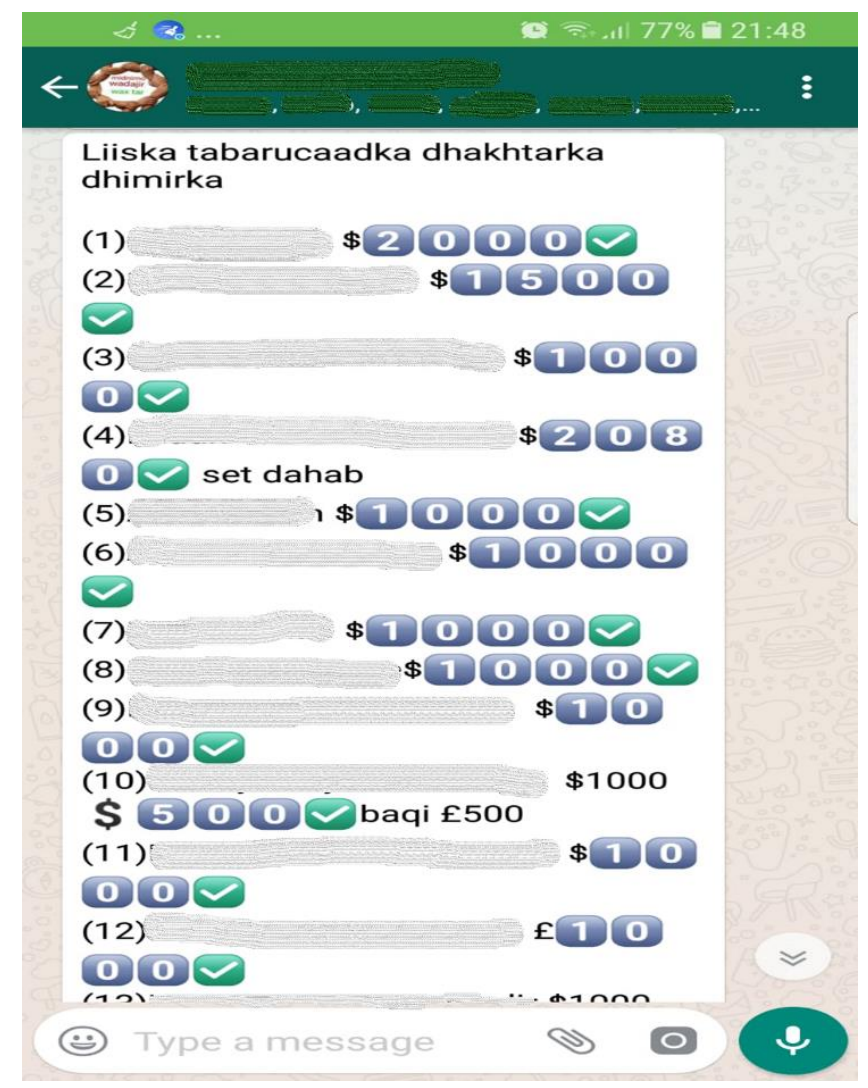

Figure. 5 A screenshot from the WhatsApp group "Gaaroodi Sisters", shared by Asia on 11 September 2018.

\subsection{Second-generation Somali Women and Transnational Youth Culture}

"Both of us illiterate, she would tell me stories that felt as though everything useful should be spoken, not written down."

Hibaq (48) opened a small box that contained many papers, some souvenirs, and four cassettes. Showing to me the cassettes, she said:

I don't know where some others are, but some are here. They are mostly songs or poems by my mum. We're oral people, we love to tell stories, poems about people, about everything. The only way my family found out I was alive was because someone was going to visit their own family in their area and said by the way I saw your daughter-she is living in London, she is alive. 
Hibaq's family lived in the Somali countryside and when she was a teenager, in the interests of her education, her parents sent her to live with her aunt in the capital, Mogadishu. When the violence in Mogadishu escalated, like many others, she escaped without having the opportunity to let her family know. After a long journey, she arrived in London with one of her neighbours whose relatives had already settled in London. Hibaq's family found out that she was alive and living in London via a third party who returned several years after her displacement. Hibaq's story is far from exceptional. Rather, it is one of the many stories I encountered that illustrate how the sharing of information by word of mouth was crucial for many Somalis trying to find the whereabouts of, and reconnect with, their loved ones in times of limited communication. Like Hibaq, other first-generation participants also sent letters and cassettes to their family members with the help of people who could still travel to Somalia. Recording and sending cassettes appeared to be common amongst my first-generation participants, who expressed how important it was to hear news, songs, and poems from their families, whom they could not visit for the foreseeable future.

According to Olden (1999), the sharing of news by word of mouth has been enormously important for many refugee groups from Africa, who relied on trustworthy personal contacts rather than institutions to establish cross-border information networks. In addition, he highlights how oral communication may have been even more important for Somali refugees, as it is such an integral part of Somali culture, considering that a written Somali language was not introduced until the 1970s (Olden 1999, 215). In relation to my own research, the stories and experiences frequently relayed to me during my fieldwork complement Olden's thesis, since my participants emphasise how Somalis are a very information-oriented people and how Somali culture has a rich tradition of oral communication. Songs, poems, and anecdotes are fundamental to the communication of feelings, knowledge, and news. Oral communication is also paramount to the transmission of knowledge and historical and cultural references across generations in Somali culture (Olden 1999). This is beautifully articulated in the words of the young British-Somali author Hanna Ali. As quoted above, in her book entitled The Story of Us, she tells of a Somali grandmother and granddaughter now living in the United Kingdom.

Hibaq's story also reveals how the experience of displacement and resettlement has rendered digital media so fundamental to the transnational lives of Somali refugees and their families. Hibaq explained how they still continued to share news, experiences, and feelings in the form of songs and poems, their culture and traditions now mediated through letters and 
cassettes. As the personal narratives and experiences in this section will vividly illustrate, transnational connections are also central to second-generation Somali women-how they create networks of information through which they share news, memories, and experiences. Yet, these digitally mediated transnational connections reflect changing socio-temporal factors and distinct generational experiences, especially regarding the manner in which the narratives that young people share about Somalia and Somali identity and culture differ from those of previous generations. In this context, digital media play a central role in the way these second-generation Somali women create a transnational social milieu that connects young members of the global diaspora through their shared ideas and generation-specific experiences. In this section, by referring to my second-generation participants' engagements with a number of social media platforms, I discuss how these youth-oriented online spaces introduce them to alternative performances of cultural identity and shape their understanding of themselves in a wider, diasporic context.

One of the most prevalent recurring topics of discussion with second-generation Somali women during my fieldwork was the misrepresentation of Somalia by the Western media - specifically the way in which such media disregard its history, local dynamics, and social infrastructure. My participants frequently noted how the representation of Somalia not only negatively affected how others perceive them, but also the way in which they perceive themselves. As Osman $(2017,124)$ states, "the approach of the international community has manifested itself amongst the Somali people in the form of lack of dignity and misrecognition”. Being aware of the way in which the Western media represent them, my participants displayed an understandable degree of sensitivity towards their positionality within both British national and global contexts. Colonialism, the failure of state government and democracy, and the negative perception of Somalis as black Muslim Africans, all mean that they find themselves under constant scrutiny, struggling to mediate between the past and the present.

This struggle becomes apparent in the ways in which memory narratives regarding Somalia's history, as well as the current situation and issues facing the country are communicated and discussed between the generations. As demonstrated by Hawa's story in the introduction to this chapter, the fragmented transmission of Somali history, particularly the causes and consequences of the civil war, was a common intergenerational issue. The reasons for this incomplete recounting of history vary, from the traumatic experiences of parents during the war, to a sense of humiliation and a broader endeavour to create a positive portrayal of the ancestral home to subsequent generations. Often, and despite the best efforts 
of parents, accessing information about Somalia and the civil war proved easy for children who are constantly exposed to news about Somalia in the media. This intergenerational dynamic is best described in the words of 22-year-old Asha, a university student in London:

My mum never really spoke about it. I mean, I asked her what happened, but she never wanted to really talk about it because the reason that she left the country was due to the war. It was this, when the civil war occurred and I think it was a bad experience for her, coming and fleeing the war. So, she didn't really like to speak about it. She's really reserved. But I knew about it obviously due to the media. You read about what happened and how the Somali Civil War broke out so-I mean, I never brought it up because I didn't want to obviously make her feel, like she had to remember all those bad experiences.

The intergenerational transmission of collective memory - narratives of a "homeland"-is considered to be of pivotal importance to the survival of diaspora (Lacroix and FiddianQasmiyeh 2013). However, as Asha's statement above illustrates, any such transmission of historical and cultural memory takes place within the context of a particular history, in this case the civil war, which is often seen as taboo within Somali households. This creates a void that is inevitably filled by the images and narratives constantly produced by the Western media. Indeed, another participant, Sagal (20), also a university student, shared similar reflections, expressing how she used to find it hard to relate to Somalia (and Somali culture) in the same way as older members of the community, even though she was exposed to Somali media outlets whilst growing up:

So, you've got the Somali Channel and like a few other things. Whenever I watched it, I'd be so alienated from that as a child, because they just talk about politics and I wouldn't understand half of what they were saying. I just found it really boring. Because with like the Somali Channel it will be the elder people who are sort of speaking about Somalia. And it's sort of alienating, because with them it's like a whole different narrative that I'm not as connected to. So, there is definitely a generational gap there, like you have anywhere. But, when you sort of move to London from another society, it gets even bigger, because they're sort of all in touch with back home more than us. And they sort of expect us to be as in touch with back home, but that's unrealistic as we are born here. A lot of us haven't ever been back. A lot of people do expect us youth to be as into our culture and they don't take into consideration that it's natural for us to be a part of this society that we are born in. 
Such strong assertions, shared right across the second generation, reveal a profound intergenerational discontinuity in the construction of memories and narratives deemed fundamental to the development of a "sense of group belonging in a spatio-temporal order" for diasporas (Lacroix and Fiddian-Qasmiyeh 2013, 692). As Hammond (2011) explains, the discrepancy in lived experiences and the lack of a vivid collection of memories in Somalia amongst the younger generation create an intergenerational conflict and fragmentation for the Somali community in the United Kingdom (cited in Osman 2017, 39, 40).

However, whenever this intergenerational dynamic was raised in my discussions with second-generation Somali women, they also enthusiastically mentioned the impact of social media in helping them to learn about Somalia and Somali culture and traditions from a different perspective. For the younger generation, social media offers new, different viewpoints from the memory narratives selectively communicated by older generations, as well as those imposed upon them by the international community and Western media. These social media platforms are considered spaces in which they can construct and disseminate new images and narratives about Somalia - both in terms of the past and the present - and their culture and identity by facilitating an intra-generational exchange of information and experiences. Thus, these online spaces allow my younger participants to see Somalia in a different light and engage with a number of cultural sites where they can perform their diasporic selves within a youth-oriented transnational social milieu —or "transnational habitus", to borrow Nedelcu's (2012) term. Indeed, as Nedelcu $(2012,1345)$ argues, habitus in this context refers to digitally mediated socialisation processes that create new practices, skills, and representations, allowing migrants to harness (their) otherness at a distance.

One of the most mentioned sites of this youth-oriented transnational habitus is YouTube. For example, it was during my meeting with Sagal (quoted previously) that I heard the famous phrase dhaqan celis for the first time. Dhaqan celis refers to a person who is "returned to culture" by being sent back to Somalia or to Somaliland for religious and traditional "treatments" with the purpose of recovering from "bad habits" (Tiilikainen 2011, 71, 77). ${ }^{25}$ As I heard many times from my participants, dhaqan celis is a form of punishment for second-generation Somalis who have "bad habits" or "misbehave", whether it be drugs, crime, or not behaving appropriately in accordance with religious and traditional norms. In other words, they are "returned to their culture" by being sent back to Somalia to recover

${ }^{25}$ The Somali term "dhaqan celis" means "returning to culture". 
from the bad influences and corruption of the west (Tiilikainen 2011, 78). In this context, for the younger generation, going back to Somalia is unsurprisingly associated with negativity, implying a failure to "achieve" or "be good enough" to stay in the West. For example, several British Channel 4 documentaries posted on YouTube revealing the experiences of young people were specifically mentioned by some of my participants. They were cited for creating a sense of alienation from Somali homelands as a result of watching their peers' difficult experiences and lack of success in trying to adapt to the "traditional" way of life in Somalia. ${ }^{26}$

Nevertheless, as my research progressed, I discovered that there was also a growing list of YouTube videos that show young returnees' experiences in Somalia from an entirely different perspective. For example, the film most cited by my participants was a YouTube video entitled Return to Somalia: Aliya's Story. The video depicts Canadian-Somali Aliya and her journey to establish a school in Somalia. ${ }^{27}$ According to the participants, Aliya's Story highlights the valuable contribution that educated young Somalis can make. For example, one of my participants mentioned how this story shows that educated young Somali women are appreciated and respected in Somalia in contrast to what many people believe, especially considering the fact that Aliya “is not properly covered and she obviously doesn't behave like many other women there". In several other cases, stories shared on social media were cited as inspirational to those wanting to live in Somalia, even if only for a while, for the purpose of playing an active role in the reconstruction of the country.

Thus, it is important to recognise how philanthropic incentives facilitated through digital media appear to be an intergenerational trend, although they are informed by different motivations and styles of engagement. This is best observed in the considerable variation in methods used to access the sites and practices through which they become part of the transnational diasporic community by pursuing humanitarian goals. First- and secondgeneration women prefer different digital technologies, depending on the affordances of each platform. For example, whilst first-generation Somali women prefer to use the messaging application WhatsApp, the second generation prefers to engage with public-facing social media platforms such as Twitter, YouTube, Instagram, and Snapchat. In this context, for the majority of my younger, second-generation participants, by representing Somalia and the

\footnotetext{
${ }^{26}$ The videos about returnees to Somalia by Channel 4 can be accessed via $\langle$ https://www.youtube.com/watch? $\mathrm{v}=\mathrm{dhSgP} 8 \mathrm{~T} 97 \mathrm{m0}$ > and $\langle$ https://www.youtube.com/watch?v=tzRKeeZXFGQ>. $27\langle$ https://www.youtube.com/watch? $=y=y$ Dxnlhei-Ss \& $\mathrm{t}=21 \mathrm{~s}\rangle$.
} 
second generation's experiences there in a more positive light, such videos fill the void of not having any lived experience or collective memory of Somalia. Furthermore, they also help challenge the negative connotations associated with going back to Somalia by introducing alternative narratives about their peers' experiences, thus leading them to reflect differently on their positionality as young members of the Somali diaspora.

Whilst sharing their opinions and experiences online allows the second generation to relate to Somalia differently to previous generations, it is important to also acknowledge how they challenge negative news coverage of Somalia and the misrepresentation of Somalis by the Western media. In this context, Twitter was often cited. Words such as "intellectual", "news-oriented", or "youth-oriented" were used to describe the role played by the platform in allowing young Somalis to learn about Somali history and politics, and to connect with other young Somalis around the world. Somali Twitter-like Black Twitter-refers to an online subculture that consists of Somali users who use the social networking platform to share knowledge and news, as well as experiences and opinions with each other. For example, Sahra (26) described how following the work of the Toronto-based Canadian-Somali photographer Yasin Osman on Somali Twitter allowed her to recognise the biased depictions of Somalia propagated by the Western media. In this context, she emphasises the key role young Somalis play in creating new narratives:

Through his Twitter he'd be posting videos of Somalia and like his interactions with the people. And for the first time that makes me want to go back and visit. Because I feel like I experienced it somehow through his videos and just seeing like a different narrative. Because through the media you always see like headlines about how Somalia was bombed. Or how there was a flood. And he just got out of that narrative and spread such positivity. And it made me realise that my country is beautiful. Like every country it has issues, but [the same] much beauty as well. Like, the media doesn't shed light on a lot of things. But somehow Twitter manages to get all of these things and shed light on it. Because I guess it's run by youth, so you pick up the issues that we think need to be heard.

As we can see from Sahra's statement, Somali Twitter encompasses explicit performances of diasporic youth identity enacted by the second generation who return and present alternative narratives about Somalia. Such narratives present significant challenges to those imposed by Western media outlets. Therefore, Somali Twitter demonstrates the increasing awareness of 
young Somalis and their broader endeavours to represent themselves and Somalia in a more accurate and positive light.

In this context, one can also argue that Somali Twitter helps young Somalis to create and exchange what Tölölyan $(2007,654)$ terms an "emic discourse that diasporas use to talk about themselves to themselves". As Tölölyan suggests, emic discourses produce various forms of self-representation and self-knowledge in written and oral archives, which today also thrive on the internet. Following Tölölyan's thesis, Somali Twitter can be seen as a mediated archive of emic discourses in which the opinions, experiences, and memories of younger generations are collected and shared. This is an important illustration of the fact that self-representation and self-knowledge cannot be analysed in isolation, outside of the notion of generation, as the memory and identity narratives of refugee diasporas are (re-)produced in different temporal and spatial contexts.

In this light, it is important to acknowledge how Somali Twitter should not only be seen as a space that creates an intra-generational dialogue about Somalia, but also demonstrates young people's attempts to find new repertoires via which to portray themselves and to re-imagine their positionality in the context of the wider Somali diaspora. For instance, during our interview, Zainab (24) mentions the fact that young Somalis are always represented "from a negative perspective" in the UK media, and how this affected her self-esteem whilst growing up. In this context, Zainab mentions the lack of positive role models in the community, which is considered a general issue for British-Somali pupils and teenagers in the United Kingdom (Dernie, Lewis, and McLean 2007, 31). According to Zainab, Somali Twitter allows her to imagine herself and her future differently:

For example, you do not know the fact that you have Somalis that go to Princeton, Harvard, you find some Somalis that are all over the world doing so many things. So, that is one thing I would definitely say about social media, Twitter especially. Then you start telling yourself you can do it too. It helps to envision yourself and your future differently.

I see statements such as those made by Sahra and Zainab as part of a collective trend amongst the second generation, who turn to social media platforms such as YouTube and Twitter as spaces in which they can create and/or engage with new forms of self-knowledge and selfrepresentation. These platforms become sites of a digitally mediated diasporic youth culture in which young members of global refugee diaspora establish cultural ties with each other and engage with creative diasporic identity performances on a transnational level. In this 
context, they allow second-generation Somalis in the West to deconstruct mainstream representations and to imagine their identities, expectations, and aspirations as young diasporic Somalis differently.

In these youth-oriented transnational spaces, we can also observe how some aspects of Somali culture are incorporated and adapted by young people as part of their diasporic identity performances. I was often informed about the popularity of Snapchat and Instagram amongst Somali people worldwide, particularly amongst young Somalis who like to share entertaining pictures and videos. Yet, understanding such visual content within a cultural context, as well as the meanings given to it by my participants, allowed me to better grasp how these social media platforms allow young Somalis to integrate and appropriate certain features and practices of Somali culture within a mediated diasporic youth culture. In this context, two Snapchat accounts in particular, Somali features and SomalidaAduunka (Somalis in the world), appear to successfully achieve this by connecting young Somalis from different parts of the world in creative and entertaining ways. Although their importance has now diminished, these accounts were very popular channels during my fieldwork. Young Somalis would use them to share moments from their everyday lives and introduce the cities and/or countries in which they lived. In this context, through common cultural references and shared experiences, these accounts effectively created a sense of familiarity and group belonging amongst diasporic Somali youth across the world. Illustrating this point, Idil (25) told me:

There was this guy from Toronto. He was mentioning how he tried to learn a Somali song, but then his granddad sort of laughed at him for saying the words wrong. I relate so much because I found it hard to speak with my grandad before. I started listening to some Somali songs and some poems because I started hearing them on social media. This helped me a lot. I learnt so many words. But, it is funny to see how other people of my age also go through similar stuff.

Similarly, the importance, not only of producing, but also of consuming alternative diasporic identity performances, is also manifested in my participants' motivations for engaging with gendered spaces in which diasporic Somalis show each other how they negotiate certain traditions. Somali bridal and wedding Snapchat accounts are good examples. Weddings and parties are very important community events in Somali culture, particularly for women who dress in traditional clothes, make music, dance, and socialise with other women (Guerin, Elmi, and Guerin 2006, 106, 107). Snapchat accounts that share moments from wedding 
preparations and parties are very popular amongst the female members of the community. Yet, younger women highlight the significance of the transnational connectivity these accounts entail by emphasising that they like to see how such cultural traditions are now performed by diasporic Somalis across the world in their own unique ways and styles. For example, Isra (23) told me that, although she does not foresee herself marrying anytime soon, she avidly follows such accounts because they show

that wherever you are, you are still Somali. The weddings are so beautiful, colourful. Maybe the things are not how exactly they were, like not really traditional, but it helps you to see how the diaspora is doing, how they are adapting.

Together, the above examples demonstrate how Somali diasporic youth culture flourishes on multiple social media platforms and how these represent important cultural sites for my participants, who engage transnationally with youth-oriented information and social networks. These social media platforms indeed facilitate the establishment of an imaginary transnational community that is not constituted through personal and/or familial links or clanship as in the case of the previous generations, but rather through generation-specific shared experiences, interactions, and ideas. In this context, they allow second-generation Somalis across the world to form their own groups and perform their diasporic identities and cultures not only differently from older generations, but also in opposition to the dominant Western-centric discourses imposed upon them. Thus, my participants' accounts of these cultural sites reveal their desire to produce and transmit alternative historical narratives and cultural references, and to position themselves within the diasporic community in a way that reflects their own unique generational experiences and expectations.

Throughout the course of my fieldwork with the Somali diasporic community, I was frequently reminded of the importance of sharing knowledge, stories, and feelings through oral communication within Somali culture. Indeed, if we study youth-mediated spaces from a media and communications perspective, we can observe how these significant cultural and communicative practices have not diminished, but rather, to borrow Bolter and Grusin's (2000) term, are being "remediated" in a digital media environment. This remediation takes place via generation-specific modes of digital connectivity and sociality. Whilst secondgeneration British-Somalis, like previous generations, are an "information-oriented" group, the styles and formats of their particular digitally mediated information environment seek to 
provide new lenses and contexts via which to (re-)imagine Somalia, performing their diasporic selves in ways that reflect their own experiences, motivations, and aspirations.

Having thus far focused on my participants' digital modes of sociality and connectivity with the wider Somali diaspora, I would now like to turn my attention to how their lives and experiences in the urban environment (in this case, London) impact their diasporic identity performances. Following my discussion of digitally mediated youth culture, in this section I examine how the second-generation Somali women in my study engage with youth-oriented diasporic spaces in order to negotiate their religious and racial affiliations, challenge various intersecting forms of marginalisation, and perform their diasporic selves as young city dwellers.

\subsection{Second-generation Somali Women in the City}

Whilst I initially met Hamada (27) in Central London, close to her workplace, we decided that it would be better to go to a cafe in her neighbourhood, since the places nearby were very busy and loud. On the train, we talked happily about how London makes her feel part of the world, since it gives her the opportunity to be exposed to different sights, languages, and cuisines. After all, London is widely perceived as a so-called "melting pot" of cultures, allowing its inhabitants to feel as if they live in more than one city. Indeed, all it takes is a tap of a transportation card, getting on an underground train, and one can travel to different places in a matter of minutes. Hamada's favourite place was West London, particularly her neighbourhood in Acton - the place where she lived with her family and felt as if she fully belonged. Hamada told me that, although she was born and raised in London, the first couple of months when she started going into Central London to attend university were strange for her. She explained why, saying:

West London is very cosmopolitan, it's very multicultural. Being a Somali in West London isn't something that is out of the ordinary. Whereas it's when I came to university that I felt my ethnic identity. I didn't know my own, I didn't recognise my own skin colour, if that's the thing, until I came to university. Because in West London, there're a lot of Somalis, there're a lot of other ethnic groups.

Although it may seem to contradict our initial discussion about London, like most secondgeneration participants, Hamada's comment indeed raises a very important point about the 
racial complexities of urban life. On the one hand, the second-generation British-Somali women in my study expressed how they never wanted to live anywhere else in the United Kingdom other than London. For them, London is a tolerant, cosmopolitan, and open-minded global city that offers many opportunities for education, careers, and lifestyles-qualities that distinguish it from other UK cities and towns. Positive comments such as these concur with those of first-generation Somalis, who also highlight the importance of multiculturalism and the economic opportunities London offers. These are indeed important qualities of a city that attracts Somalis from other European countries and who, according to them, want to live in a place where they can freely practice their culture and religion, and establish businesses with other Somalis. Indeed, whilst discussing Brexit, one of my first-generation participants expressed fears that London might lose its multicultural quality when freedom of movement within the EU ends: "London makes it easier to hide. If all the immigrants leave, then it will be hard for us to hide. It will be like those English towns where everyone is white and you are not."

Yet despite the similar perspectives of first- and second-generation Somali women, in the course of my fieldwork it gradually became apparent that London generates contradictory realities for the second generation. For these young women, whilst their multi-ethnic neighbourhoods allow them to view multiculturalism positively and foster a sense of attachment to the city, their everyday lives, operating within a broader urban context, can be a constant reminder of their otherness. More precisely, for these young women, London does not necessarily appear to be a "shield" that allows them to successfully "hide". On the contrary, it may trigger everyday experiences and feelings of difference, otherness, and exclusion. For Hamada, it was university that led her to go beyond the comfort of her neighbourhood and made her stand out, sometimes being "the only black student in some classes". Thus, physical mobility within the city not only entails racial identification for these young women, but also acts as a constant reminder of their "otherness" based on religion. This echoes the words of Sagal (20) when she described her experience of using public transport from her neighbourhood in West London to her university campus in Central London:

And when I was on trains at first, I felt very self-conscious, because I was taken from a world where I was the norm to a world where I'm still basically "the other". I used to think, oh, why are they looking at me? Even if you don't talk to them, just passing by them on the train. I think public transport is a big thing. [pointing at her headscarf] Like, when people are not 
sitting next to you, you question whether it's because of the way you look or if you're overthinking it?

Despite the shared positive narrative of both generations that praises London's cultural openness and inclusivity, second-generation women express greater concern regarding their everyday experiences of racism, discrimination, and marginalisation. They convey an acute awareness of the intersecting axes - the social and economic hierarchies and inequalitiesthat exert such a profound effect on their place in the city as black Muslim women. My observations reveal how these diverging reflections on urban life across the two generations are shaped by their different levels of urban mobility. Most of my first-generation participants live in the same neighbourhoods with (or in close proximity to) their clan/sub-clan families, which also appear to constitute their main social networks within the city. Only a small number work (part-time) and those that do prefer jobs closer to their places of residence. It seems that for these women, neighbourhoods with significant Somali populations, around which their daily lives are centred, provide a sense of refuge. Importantly, these neighbourhoods are home to many other ethnic communities, largely those of working-class and lower middle-class backgrounds, rendering the negotiation of difference conceivable in these localised spatial contexts through the inhabitants' shared identities based on social class and ethnic minority status.

Those second-generation women in my study who are either in higher education or working enjoy an increased level of urban mobility, as well as greater access to culturally diverse environments than those from the first generation. However, paradoxically, as the statements of Hamada and Sagal demonstrate, neither a greater level of physical urban mobility nor daily encounters with difference guarantee any lessening of the sense of otherness that they feel in the city. As Amin $(2013,5)$ argues, when we study daily urban life and multiculturalism, we should not ignore the "darker aspect of everyday encounters of difference, which are always mediated by conflicting vernaculars — one at ease with difference and the other fretful, ready to pounce on the stranger". It is important to note here that I am not suggesting that first-generation British-Somali women do not face any form of racism and/or Islamophobia, or indeed that second-generation women simply have greater levels of awareness. Rather, my aim is draw attention to the possibility that secondgeneration Somali women experience the "darker aspects" of multiculturalism to a greater extent because their physical mobility and higher level of exposure to culturally and socially diverse environments render them more likely to be situated in different spaces and contexts 
in which their bodily differences (such as skin colour and headscarf) mark their "otherness" within urban social hierarchies (Amin 2013, 4). In this context, and as the lived experiences and personal reflections of my participants illustrate, the increased urban mobility and educational successes of the children of migrants compared to their parents does not necessarily guarantee social and cultural mobility.

Paradoxically, in contrast to a social context shaped by ethnic, religious, and racial divisions, the second-generation participants still praise the city's potential for allowing them to create spaces of representation and inclusivity in which they can challenge their positionality within the urban social hierarchy. Lefebvre (1991) argues that the city is not only made up of its material infrastructure, physical spaces, and systems of power, but should also be recognised in relation to its inhabitants' subjective bottom-up understandings and experiences. Despite its tangible realities and obvious systematic inequalities, London acts as a vessel for a collective bottom-up endeavour of diasporic identity negotiation and cosmopolitan imagination for the second generation. Hence, London's symbolic and imaginary elements play a crucial role in establishing a cosmopolitan framework within which they can find their place and create spaces of belonging in the city. In this context, I see the way in which my second-generation British-Somali participants engage with social media platforms as reflective of their collective efforts to perform their diasporic identities, with an emphasis on cosmopolitanism and in a way that permits social and cultural mobility. As Jensen (2019, 97-99) argues, urban mobility is not only a physical movement, but also pertains to political, social, and cultural recognition. According to Jensen (2019, 97-99), socio-cultural mobility for urban dwellers today emerges at the intersection of materiality and digitality, which together constitute a hybrid space and negotiate the movement of ideas and information. In the remainder of this section, I uncover the ways in which second-generation Somali women produce and perform their diasporic selves in this hybrid space with the aim of achieving social and cultural mobility in the city.

As part of my empirical investigation, each participant was asked to list the online sites that mattered to them, such as those that offered informative or interesting content. By the end of my fieldwork, based upon their answers, I compiled an extensive list of people, sites, and written and visual content. In the case of my second-generation participants, what emerged was not only the wide range of issues tackled online, but also how they narrated the importance and relevance of these thematically in our discussions about urban life. In the previous section, I discussed the importance of YouTube for the second generation as a social media platform where they share information and create their own mediated systems of 
representation of diasporic Somali identity and culture within a youth-oriented "transnational habitus" (Nedelcu 2012). YouTube also emerges as an important social media platform where it is possible to engage with urban and youth-oriented cultures. In this context, in order to visualise and categorise the kind of issues and themes they engage with on the platform, I decided to carry out a small-scale inquiry into the videos most mentioned by my participants from six different channels. Figure 6 lists the names of these YouTube channels (on the left side) and videos (on the right side), and figure 7 illustrates the issues and themes each video engages with, and how they relate to each other within a network. 


\title{
Somali Diaspora
}

\section{Network of Issues-Themes}

\author{
Videos from the channels:
}

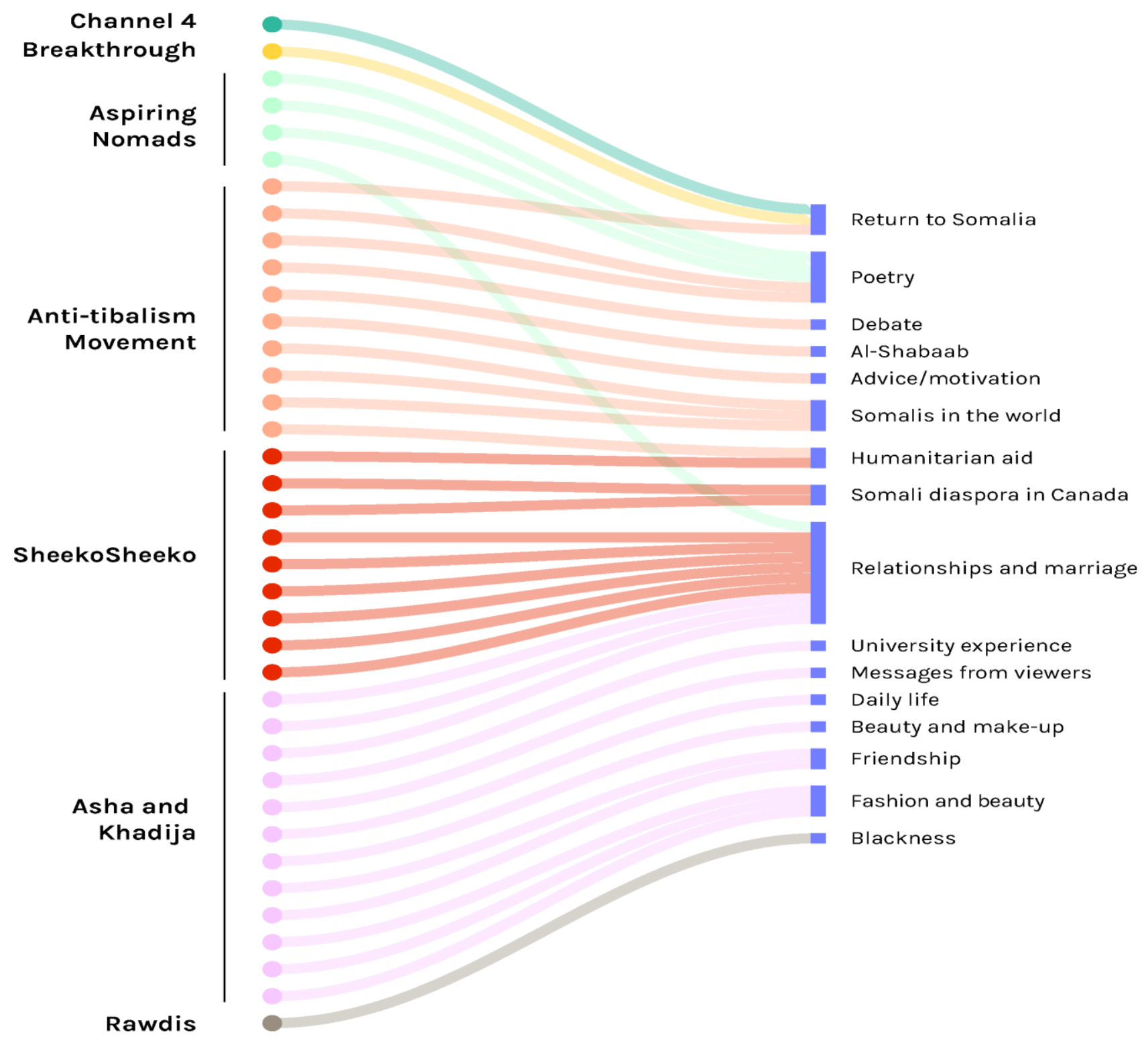

Figure 6. The most mentioned YouTube channels and videos by the participants. 


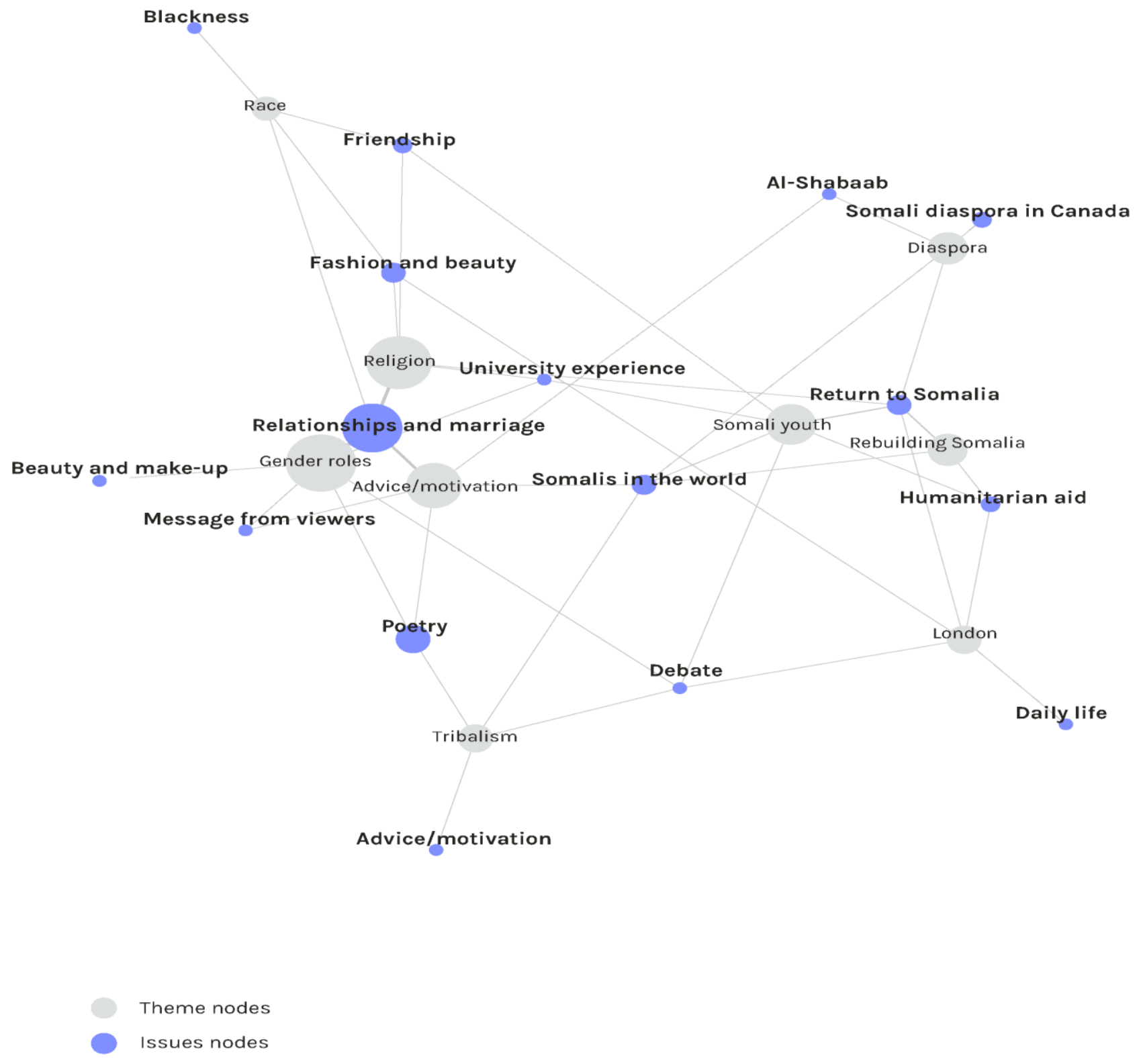

Figure 7. Network of issues and themes based on the most frequently mentioned channels and videos on YouTube. The size of the dots correlates with the number of times each issue or theme was present in a video (visualised by Gephi 0.9.2). 
I categorised the issues, shown by the blue dots in Figure 6, with regard to the topic of the main content of the video specified by the YouTube channels who put them online. These videos encompass a wide range of issues, from returning to Somalia, poetry, and fashion, to relationships and marriage. By taking my interviews and conversations as my starting point, I also categorised these videos thematically, shown by the grey dots in Figure 7, in order to see how these young women, as the audience, receive the content and perceive its importance and relevance in the light of their interests and lived experiences. Figure 8 below demonstrates these themes only and how they operate and relate to each other within a network more clearly. Here, their relatedness refers to the manner in which, for example, religion becomes a topic of discussion in a video about university experience, as well as in videos about fashion and beauty, or relationships and marriage. 


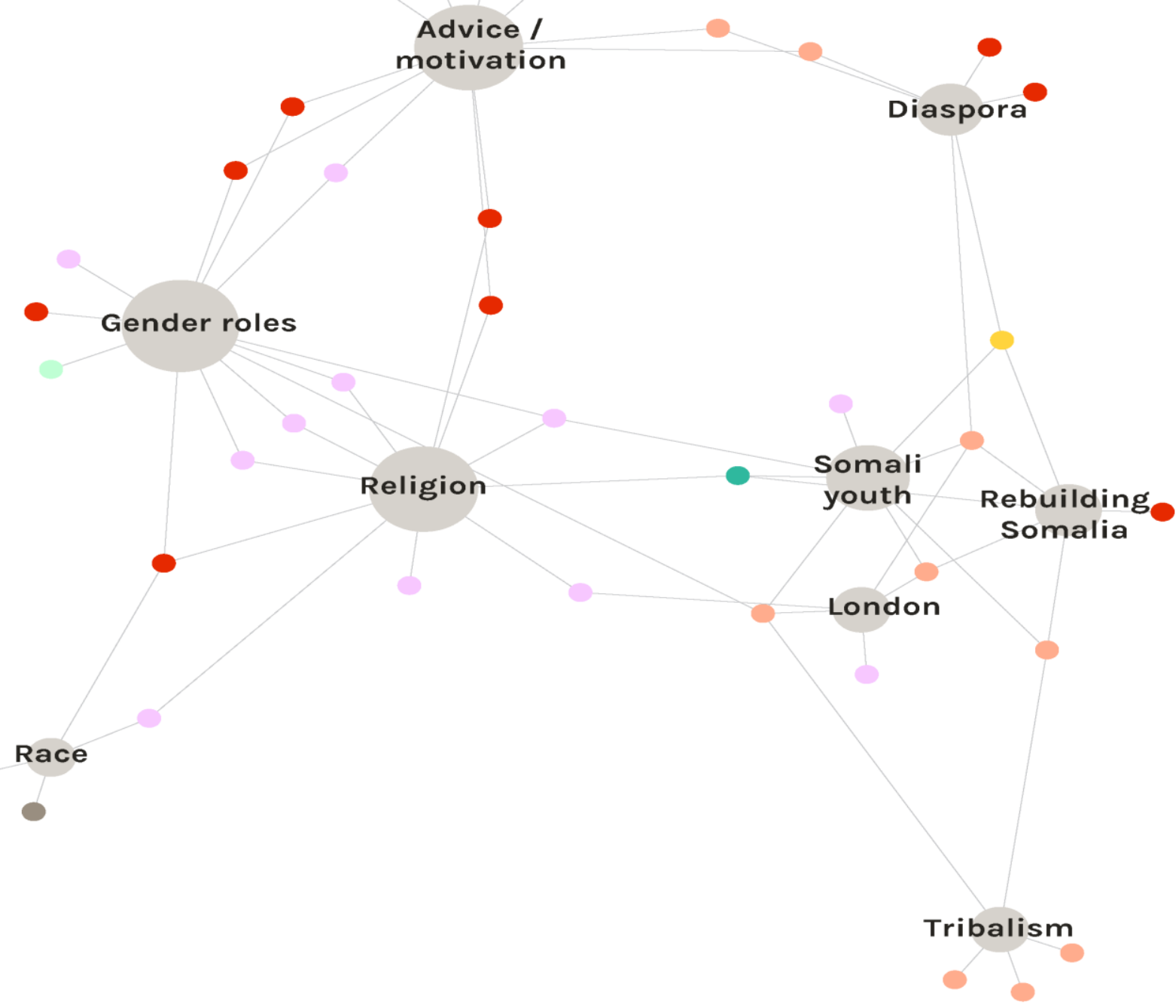

Figure 8. Network of broader themes based on the most frequently mentioned channels and videos on YouTube. The size of the dots correlates with the number of times each theme was present in a video (visualised by Gephi 0.9.2). 
These visualisations provided valuable insights by revealing how these YouTube videos, mostly with light and entertaining content and style, are indeed part of a broader cultural space in which young diasporic Somalis tackle a specific range of generationally important topics and issues that shape their lives and experiences. In the following, I discuss further evidence in order to elaborate on this point by showing the links between these themes and urban life, primarily focusing on religion and race. In this context, I will discuss how these young women, who encounter intersectional marginalisation in the city, aim to negotiate their religious and racial affiliations and articulate their urban diasporic identities through these youth-oriented digitally cultural spaces.

The specific manner in which religion was narrated as an aspect of identity by my participants suggests how their visibility as Muslim women often generates experiences of discrimination and/or a sense of alienation. For example, a video called "GIRL TALK: UNI EXPERIENCE/ADVICE" by the YouTube Channel "Asha Everyday" shows three young university-educated British-Somali women talking about their university experiences and giving advice to their audience. ${ }^{28}$ They have a discussion about the Islamic law of gender segregation, which requires the separation of men and women who are not relatives. In the video, the women get into a heated debate, as they disagree about whether this can and should be observed, since men and women are expected to mix in classes and projects in UK universities. Whilst Islam was highlighted as providing a meaningful framework for personal and community life by all of the women in my study, there were diverging opinions regarding the expression and practice of being a Muslim. This indeed contradicts dominant media narratives in Western countries, which represent Muslim women as a homogenous group (Cooke 2007, 139). Just like the three young women in the video, my second-generation participants expressed diverging opinions regarding how best (or to what extent) to practice certain religious doctrines in their social lives in a manner that would permit them to maintain their faith whilst also pursuing their educational and professional aspirations. Muslims - as is the case of any other cultural group - are obviously not a homogenous group and it is important to note how such diverse interpretations fuel a sense of ambiguity and confusion for those who, in a diasporic context, question the viability of dominant Islamic practices and doctrines. For instance, Roukiya (28) narrates the difficulty many young Somalis face when trying to adhere to Islamic principles:

${ }^{28}\langle$ https://www.youtube.com/watch?v=kI4ZvK2QMmg\&t=1322s〉 
You know it's haram to drink. You know it's haram to smoke or to do drugs. In Somalia, everyone is Muslim, so there is no problem. But here, there are a lot of temptations. The temptation is prevailing, everywhere, and everyone does it. But, we young Somalis don't speak about it. ${ }^{29}$

In line with the intergenerational discrepancy that exists regarding the transmission of history and memory described in the previous section, religion also generates a sense of intergenerational distance. In this context, like many other young women I met, Roukiya seeks guidance from podcasts and several YouTube channels that are run by young Somalis. The channels mostly present debate-style programmes in which young people exchange their personal experiences and provide advice and motivation. For instance, the Toronto-based channel Sheeko Sheeko (meaning Gossip, Gossip) employs a round-table format in which a group of young people discuss topics and events that matter to young diasporic Somalis. Roukiya mentions one of Sheeko Sheeko's videos, in which a group of men and women discuss dating, marriage, divorce, and Islam. ${ }^{30}$ She was particularly interested in talking about their discussion of halal dating and gave it as an example to explain how the internet and social media platforms help her reflect upon religious principles and established gender roles in Somali culture: ${ }^{31}$

They were discussing, for example, if we should be dating before we make the decision to get married. If we do, like, how long should it be like? How do you meet-with friends or family members or do you meet alone? There were men who, like, sort of implied when a woman dates a man, it may be inappropriate and how our parents did not even know each other at all. But girls were arguing that it is important to know whom you are marrying because Somali men, I don't want to generalise, but they are not always the best husbands and fathers. We're Muslim so maybe dating would be different than for other people-how much time you spend together or whether it is under the supervision of your family. However, it is for sure that I want to know the man I'll marry well enough to make the decision. And, to see how girls question the boys and make them see things from their own perspective is important. South Asians and Arabs always talk about these things on social media platforms,

\footnotetext{
${ }^{29}$ Haram refers to something forbidden by Islamic law.

${ }^{30}\langle$ https://www.youtube.com/watch? $\mathrm{v}=\mathrm{q} 96 \mathrm{OS} 1 \mathrm{shMjo}>$

${ }^{31}$ Halal refers to something permissible by Islamic law.
} 
they talk about such issues. So, it's good that now Somali women are pushing for this as well. You can learn so much from other people's experiences.

Roukiya's account of Sheeko Sheeko's halal dating programme demonstrates how digital media allow her to engage with "cultural spaces" that raise moral questions and represent aspects of diasporic youth identities (Dwyer 1998, 59). As Roukiya states, second-generation participants see these cultural spaces as fields in which they can encounter new, alternative diasporic identity performances that allow them to then reflect upon the challenges women in their community face from a different angle and to imagine themselves from a more empowered perspective. As Werbner $(2015,7,8)$ suggests, cultural hybridity is articulated when different cultural meanings are actively and strategically negotiated from the bottom up by ordinary people. These digitally mediated cultural spaces are indicative of how young women in the community articulate their hybrid diasporic identities by negotiating social and cultural practices that are seen as Western (such as dating) in line with their religious affiliations and through a newly created collective repertoire of instructions and boundaries.

These instructions and boundaries demonstrate the fundamentally cosmopolitan dispositions of young Muslim women in their negotiation of different cultural practices, values, and traditions, and in the production of their hybrid and multi-layered diasporic identities. As Cooke (2007, 139-52) compellingly argues, Muslim women across the globe frame a new kind of cosmopolitanism - an agency to empower themselves and to produce their own self-identifications. They use digital communication technologies to establish transnational connections that create translocal contexts and inform their resistance against hegemonic Islamic discourses in specific contexts, places, and identities. In my study, such transnationally mediated cultural sites are interpreted by young Somalis in line with their specific identities and experiences in London. This indeed reveals how their materiality and digitality mutually constitute a translocal nexus in which discourses and practices of Islam are (re-)negotiated within a cosmopolitan framework. Several scholars suggest that the religiosity of Somali women intensifies in global diaspora, since they utilise Islam to create a sense of continuity between the past and the present, and to deal with the trauma and pain of the war and their subsequent displacement (McGown 1999; McMicheal 2002; Talle 2008; Tiilikainen 2003). In this regard, these studies demonstrate how Islam enables Somali women to establish a sense of home and help maintain their established cultural identities by providing a moral framework for ideology, practice, and ritual in diasporic contexts. Whilst I do not dispute the data presented by this body of work in the case of the first generation, my 
study contests these claims and assumptions in the case of the second-generation BritishSomali women.

For young second-generation women with no vivid memories of Somalia, Islam on its own does not provide an "enduring home" (McMicheal 2002, 171). Importantly, this does not mean that religion does not offer a meaningful moral and cultural framework for their everyday life-worlds. Indeed, Islam appears to be fundamental to how these women create a sense of identity and group belonging, however, their reflexive interpretation and imagination of themselves as young urbanites is not confined by their faith or religious identity. Their narratives reveal how Islam is also a cultural imperative —one that must be negotiated across different social settings, such as university campuses or workplaces, as they fulfil their responsibilities and aspirations. Thus, as the first generation of women to be born and/or raised in London, they are in a position to create their own unique rules and styles via which to enunciate their religious affiliations. This they do very differently to first-generation women in the community, whose experiences, memories, responsibilities, and aspirations differ significantly from theirs. Here, we see how gendered, generational, and religious identities and experiences provide an intersectional framework through which these young women seek to represent and perform their ideal diasporic selves in the city. I argue that digitally mediated transnational cultural sites create translocal contexts that expose young Somali women to the possibility of alternative diasporic identity negotiations and performances, thus allowing these women to (re-)articulate Islamic norms and practices in an urban context.

As such, subjective interpretations of Islam and its doctrines reveal the "selfconstructed cosmopolitan project” (Mignolo 2000, cited in Elsayed 2011, 233) of young Somali women. However, intersecting religious and racial narratives appear to pose problems. In my empirical investigation, I often encountered diverse and ambivalent assertions about the racial identity of Somalis. Firstly, for my participants, Somalia's location in East Africa was often cited as distinguishing Somalis from other Africans, rendering them geographically "other" within a wider African continental context. Whilst the community itself identifies strongly as East African, it is important to understand that Somalia's predominantly Muslim identity is perceived to be one of the reasons why there are important social and cultural differences from neighbouring East African countries such as Kenya, Ethiopia, and Eritrea. 
Second, a strong relationship with ethnic Arabs has prevailed throughout Somali historyprimarily due to their shared Islamic faith. ${ }^{32}$ Indeed, according to my participants, Somalis are often identified as Arabs in London-something particularly true for my veiled participants. Some participants refuted these perceptions, since they regarded such associations to be the result of the imposition of a particular cultural identity - the result of being forcibly categorised as such by Christian-majority African countries. Such dynamics and tensions indicate the need to carefully investigate the close intersections of gender, race, and religion, as well as the ways in which these mutually shape dominant discourses surrounding blackness, racialising these young women in ways with which they fundamentally disagree.

Finally, Somalis are distinguished from other black minority groups by their physical features, which my participants list as "relatively more European facial characteristics", "lighter skin tone", and "soft hair texture". It was common amongst my participants to note how these physical characteristics were often as important as their headscarf in leading them to be marked as Arabs by their black African peers in London.

One need not look at Africa in terms of race or blackness essentialized but rather, like the shifting Derrida signified, the idea of Africa (whether the shape on the map or its largely black race) as being situated on the intersection of different races. This means that the core values of being African (in this case being black) may be celebrated in literary texts, but with a caveat: purist notions need not be accepted unquestioningly in the light of modernity and globalization.

(Kaula 2009, 26)

As Kaula $(2009,23,26)$ states above, African identity and blackness are complex and relational concepts and practices that always entail elements of otherness as a result of the continent's history of colonisation and contemporary forces of globalisation. The three points outlined above reflect the precarious racial identity of young British-Somalis and confirms how African identity and blackness remain unsettled categories of identity and discourse in a diasporic context.

This often came to the fore in my fieldwork, in the accounts of my participants and their experiences in educational and professional settings. For example, some participants narrated how they did not feel part of black student communities during their time in

\footnotetext{
${ }^{32}$ Somalia joined the League of Arab States in 1974. It was the first non-Arab member of the League.
} 
university. This is because they are seen as outsiders, unable to participate in social gatherings that involve the drinking of alcohol. Similarly, some mentioned how they are marked as outsiders by their peers on the grounds that because of their physical appearance, Somalis do not share similar experiences as other black British people-for example, racial profiling. These accounts are of course subjective interpretations of my participants' understanding of their positionality within the broader black African community in London. Yet, they still show that for these young women, geography, religion, and physical features act as parameters that distinguish them from the dominant racial stereotype and indicate their otherness within black African communities in London.

The patterns described above are also reflected on the various social media platforms my participants use to engage with racial identity politics. Across a range of popular BritishSomali social media platforms, I frequently witnessed how the awareness and resentment of young Somalis regarding their positionality within the black African community is manifested online. In this context, I was informed by some young women that I should examine Somali Twitter, keeping in mind that it is not part of Black Twitter. In many cases, the constant discussions and rows between the users of Somali Twitter and Black Twitter are thought to confirm that other black Africans do not see them as part of the wider black community. I was made aware of the way in which West Africans and Somalis frequently provoke each other on Twitter, often engaging in heated debates. As an example, following our interview, one of my participants sent me the Spiderman meme below (see Figure 9). The comment beneath by a user, stating that Somalis "have no friends but only cadows [enemies]" was, for my participant, indicative that Somalis were not accepted as "black and African enough" by West Africans in London. In this context, for my participants, these social media platforms act as mediated spaces in which they claim their blackness, not only with the purpose of owning their differences, but also to articulate their "unique" identity via a common form of cosmopolitan, urban imaginary. 


\section{Somalis and west Africans cussing each other on Twitter .}
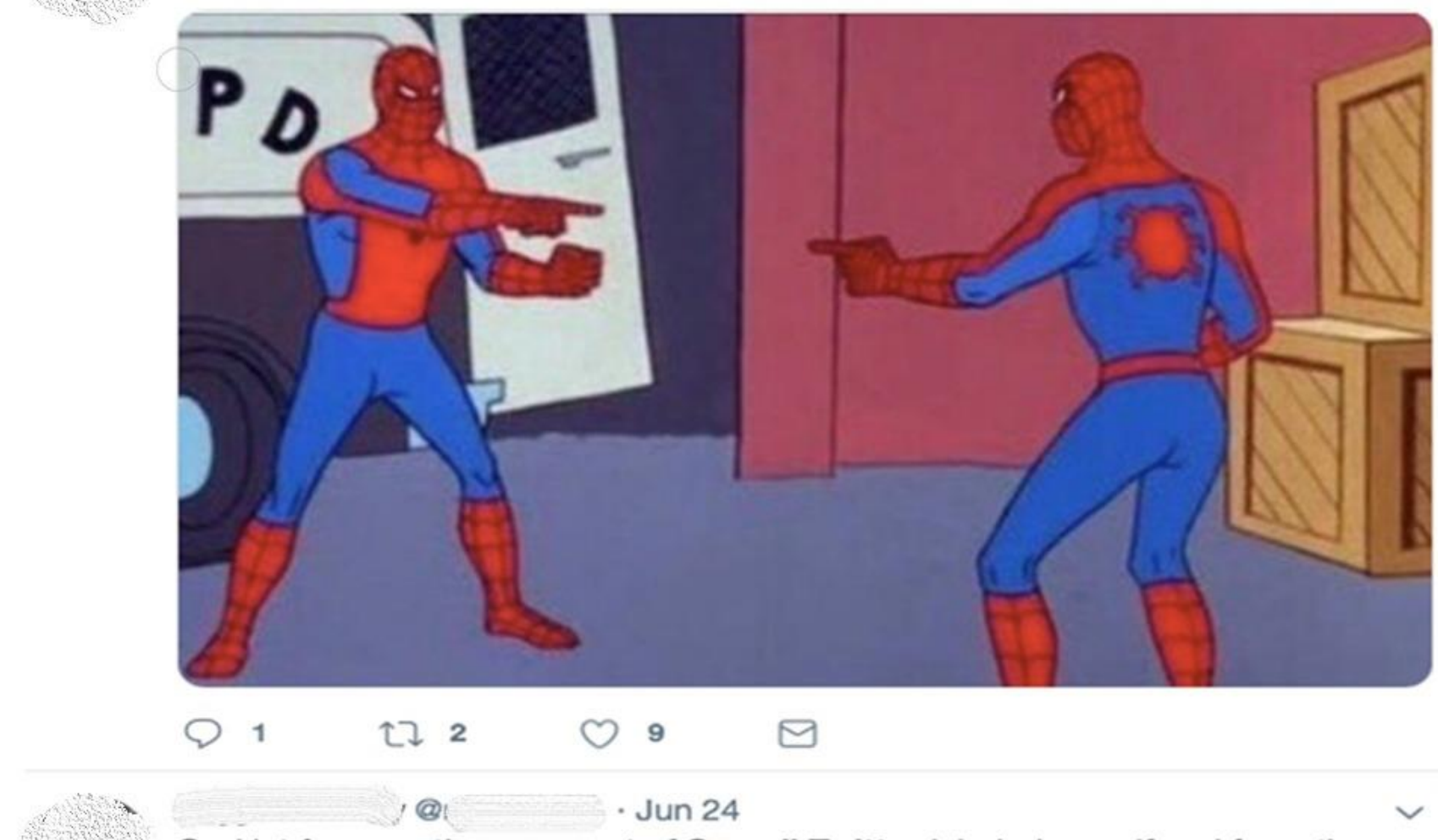

God jut few months ago most of Somali Twitter labeled myself and few others in Twitter halgam against galonimo anti blm anti qomu lut agenda

I'm proud many young Somalis are waking up to the reality that we have no friends but only cadows

Figure 9. Anonymous (2018), The Spiderman Meme. Twitter, 24 June, Accessed on 28 August 2018.

I can illustrate this even more clearly by discussing the channel of a British-Somali female YouTuber named Asha, whose YouTube channel "Asha Everyday" (cited previously) was very popular amongst my participants. The YouTube channel Asha Everyday is owned by a young British-Somali woman called Asha, who shares moments from her everyday life. She also collaborates with her friends or other YouTubers to form discussion groups. In an interview with the popular fashion and lifestyle magazine Cosmopolitan UK, Asha describes her target audience as "someone who looks like me-a young, black, Muslim woman" ${ }^{33}$ For my participants, Asha seems to reflect how a young British-Somali woman can claim and embody different aspects of her complex identity and unapologetically negotiate them by

\footnotetext{
33 < https://www.cosmopolitan.com/uk/love-sex/relationships/a13449764/muslim-datingmisconceptions/>
} 
being "fun", "successful", and "empowered". In our discussions, my participants frequently mentioned how young people from other ethnic, religious, and cultural groups in the city use social media to create joint cultural sites in which they represent their own unique hybrid identities. For example, Idil (25) explained how the children of South Asian migrants, particularly those of Indians, are "successful" because they have neither assimilated nor rejected their roots and culture, but found a way to present themselves as a distinct community of people who can "show their unique qualities". Idil went on to emphasise the key role social media play in this process, stating:

It's good to see that now Somali women are trying to show how they can do it too. We do not have to be like any other, we should be ourselves and not hide. We can achieve so much but we need to show who we are. Asha and her friends show it. They show how we do not have to be Christian to be black for example. Back in my school everyone's parents were from a different place which made it an amazing experience to me. Everyone is different here [in London]. Learning about our differences is an amazing thing, you know. We should also show that we have opinions about how things should be like.

The city is key to how Idil reflects upon cultural difference as a positive quality. The coexistence of different identities and cultures in the city allows her to develop vernacular cosmopolitan horizons and practices. Vernacular cosmopolitanism, in the sense of negotiating different cultures and traditions on a day-to-day basis (Bhabha 2000), underpins Idil's urban imaginary. More precisely, whilst remaining aware of systematic inequalities, Idil still imagines the city as a space that leaves room for different ethnic and cultural groups to develop "their unique qualities" and to perform their hybrid diasporic identities. In this context, her urban and diasporic identity and sense of belonging are negotiated within a cosmopolitan framework. Indeed, her narrative diverges from the accounts of the first generation, who see the city's cultural diversity as a quality that helps them to "hide" from the white majority in Britain. In this sense, Idil's statement echoes most second-generation understandings of the city as an arena in which they can put themselves forward, rather than allowing others to define who they are. The success of Asha as a female YouTube phenomenon confirms how they can perform their own unique identities and eventually achieve social and cultural mobility in the city.

In this context, my study reveals the different translations and articulations of cultural difference amongst two generations of British-Somali women. In both cases, the women 
concerned demonstrate a positive attitude towards cultural difference. However, how they articulate their own specific cosmopolitan visions and practices is shaped by their particular generation-specific experiences, expectations, and aspirations. The desire of the secondgeneration British-Somali women in my study to find and perform their own unique and ideal identities in the multicultural city demonstrates an explicitly cosmopolitan vision. In this context, social media platforms support the process of articulating their diasporic selves by allowing them to engage with youth-oriented cultural sites and contexts. These sites depict their peers, who simultaneously articulate multiple aspects of their identity, such as being black, Muslim, and Somali-aspects that have always caused a sense of ambiguity about their positionality within the city. Thus, for my participants, these online sites reveal how they do not have to move between different performances of identity. Rather, they can simultaneously negotiate them, collectively finding their own voice and place. Despite their material realities and experiences, the city indeed frames the collective efforts of secondgeneration British-Somali women by allowing them to (re-)think (imagine) the self through an urban cosmopolitan imaginary.

Therefore, the discussion in this section demonstrates how social media allows the establishment of a dynamic and creative cultural terrain for identity construction, representation, and even moments of resistance with a youth-oriented perspective and style. The extensive range of issues and themes produced and consumed on social media platforms is indicative of how my participants are challenging intersectional marginalisation and negotiating different (yet intertwined) aspects of their British-Somali identity and womanhood in search of social and cultural mobility. In this section, I have primarily focused on the categories (and the intersections) of religion and race, unpacking how these are negotiated in tandem with gendered and generational experiences. As illustrated by the visualisations in figures 7 and 8, different themes and categories such as gender, youth, and clanship operate together in processes of diasporic identity production against the intersectional power structures imposed upon them in the city. In this regard, British-Somali as a hybrid cultural identity is shaped in relation to the shared experiences, cultural references, and meaningful discussions of these young women as they try to pull different strands of their identity together.

According to Bhabha (2015, xiii), "for hybridity, empowerment is about the achievement of agency and authority, rather than the 'authenticity' of identity-however mixed, however 'multi', however intersective or intercultural'. As Bhabha's work suggests, for second-generation British-Somali women, hybrid identities are not about arriving at 
concrete definitions about what should constitute an authentic British-Somali identity. Rather, it is a performative strategy via which to gain agency and authority in the representation of who they are (and who they are not), or who they envision themselves able to become. Hence, their articulation of hybridity is not about negotiating two original cultures-British and Somali. On the contrary, as Bhabha suggests, it is a complex process informed by a "third space" that allows other positions and new possibilities to emerge. Drawing heavily on social media, they reflexively negotiate and interpret their unique narratives in translocal contexts and within an intersectional framework. These narratives encourage them to reclaim their identity and perform their diasporic selves in the city in a manner that challenges gendered, racialised, and religious divides with a collective cosmopolitan vision.

\subsection{Conclusion}

I started this chapter by exploring how female members of the Somali diasporic community in London mediate their diasporic selves with generation-specific performances of identity. In this context, I have illustrated how urban and transnational influences mutually crystallise British-Somali identity within a social context that continuously demands negotiation between the past and the present. In this context, "roots" and "routes" are "intertwined" rather than mutually exclusive (Clifford 1997, 4), mutually constituting the processual character of gendered British-Somali identity and culture. In order to explain what the generation-specific account I presented in this chapter contributes to our understanding of diasporic gendered cultural identities, I would like to return to the questions posed in the introduction.

Do these two generations of British-Somali women mediate their diasporic identities and cultures differently? In my discussion of first-generation Somali women, I explored how these women use the messaging app WhatsApp to engage with transnational online spaces that aim to collect money and carry out projects for rebuilding war-torn Somalia. Nonetheless, an in-depth investigation of my participants' practices around these online groups demonstrates how their diasporic group consciousness is largely shaped by kin values and obligations, rather than their ethnic and/or national ties. In this context, their diasporic identity mediations, as part of the global diaspora, should be seen through a cultural lens rather than in the context of nationality and/or ethnicity. In the case of the second-generation participants, social media platforms provide sites expressing diasporic Somali youth culture. 
In these digitally mediated youth-oriented spaces, we can observe the second generation's efforts to connect with their peers across the world and collectively articulate their own narratives of Somalia and Somali identity. Significantly, my examination of these mediated cultural sites in the context of my participants' reflections demonstrates how secondgeneration British-Somali women digitally revive Somali cultural traditions of sharing information, memories, and experiences. These cultural traditions and practices, now flourishing on the internet, yield the possibility to envision Somalia and Somali culture differently to previous generations. In doing so, generation-specific modes of performing diasporic identities and belonging emerge from a more positive and empowered perspective. This is a reminder of how gendered British-Somali identity is a processual cultural formation that is negotiated and performed with different influences, imaginaries, and intensities across generations. This point provides a consistent theme running throughout the chapter, demonstrating how an intergenerational approach holds the possibility of unearthing changing socio-cultural dynamics, as well as how these impact fluid and temporal notions of diasporic cultural identity.

In what ways do first- and second-generation British-Somali women's experiences and lifestyles differ in London? The fourth section of the chapter addressed this question by highlighting the generation-specific identities and experiences of young Somali women in the city and how these lead to intersectional marginalisation. By focusing primarily on the social categories of race and religion, I have illustrated that social media platforms enable these young women to encounter alternative diasporic identity performances and rearticulate their multi-layered identities within a cosmopolitan ethos. In this context, my analysis also proves how a translocal lens allows one to operationalise intersectionality in tandem with the sociotemporal factors and power relations embedded within specific locations. It does so by explaining how young second-generation Somali women engage with transnational youthoriented digital sites in a manner that helps them to articulate their own specific identifications along the lines of gender, generation, race, and religion in the city. More precisely, these young women's specific experiences within London's urban social context (and the power structures it contains) lead them to negotiate blackness and Muslim identity differently from previous generations. In this context, I argue that their interpretations and performances of racial and religious discourses and practices are part of a broader endeavour to re-imagine British-Somali identity, and to perform their unique urban identities in line with their own gendered and generational experiences and aspirations. 
What role do digital media play in the articulations of gendered and generational identities and experiences? My discussion in this chapter demonstrates how digital media facilitate diasporic identity mediation for both generations of women in a way that is not confined to a "home nation - host nation" nexus. British-Somali women actively contribute to the construction of digitally mediated spaces that open up new avenues via which to imagine and perform the self in line with their sense of urban and transnational belonging. In this context, we can also trace and observe how their performances of diasporic identity aim to challenge workings of power on urban and transnational levels in the hybrid spaces of materiality and digitality. Therefore, my analysis of the British Somali diaspora confirms the main theme of my thesis - namely how, by taking "the local" as a point of departure, we can unearth the ways in which digital media connect urban, national, and transnational communities and contexts in the everyday lives of migrants. Significantly, the way in which "translocality" operates for British-Somali women differs from the Turkish community discussed in the previous chapter. For British-Somali women, the importance of "the local" lies beyond the realm of a simple connection with the "home" nation, but rather traverses transnational sites that connect the members of a wider diasporic community scattered across the globe. In the light of such evidence, I argue that the digital mediation of diasporic identity enacted by British-Somali women challenges the taken-for-granted relationship between diaspora and homeland, as well as the assumed local-global dichotomy. In this context, translocality constitutes an important analytical tool that captures the complex realities that are situated in "the local", whilst also expanding its borders for British-Somali women who unite urban and transnational belonging in different, complex, and non-linear ways across generations. 


\section{Chapter 5: Social Class and Digital Acts of Citizenship: The Case of the Romanian}

\section{Community}

\section{Introduction}

In April 2018, a group of young Romanians invited me to an exhibition called "Post-Soviet Visions: Image and Identity in New Eastern Europe" at Calvert 22 Foundation in Shoreditch, East London. The exhibition consisted of photographs of people and urban landscapes from post-Soviet European cities. We took a few selfies in front of the photograph of Jedrzej Franek, whose work focuses on urban architecture. The image in Figure 10, which breathtakingly depicts Polish tower blocks, started a conversation within the group regarding some of the cultural differences that exist between Eastern and Western European countries and how these contribute to the misrepresentation of Eastern Europeans.

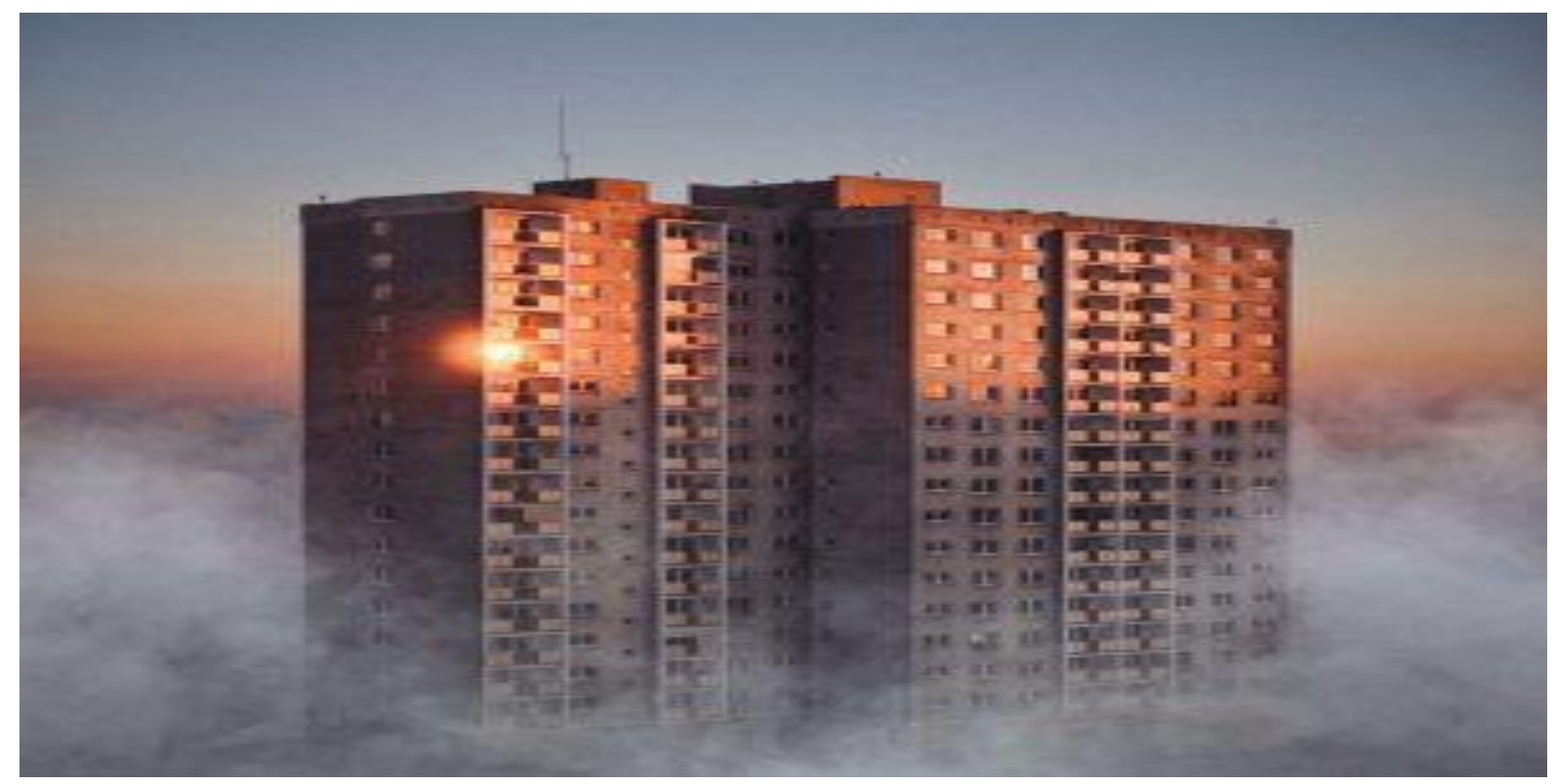

Figure 10.

Photographer: Jedrzej Franek

Courtesy: https://www.worldartfoundations.com/ 
It was interesting how a photograph of Polish urban landscapes — which, for my participants, depicts the traces of communism and the separation of Eastern Europe from the West-led to a conversation about how Western Europeans see peoples and cultures from post-Soviet Eastern European countries as profoundly different from, and even inferior to, themselves. During the conversation, Alexandra (24) raised an important point, namely how these socalled differences between Eastern and Western Europe are manifested, not only in urban architecture, but also in ideas, behaviours, and lifestyles. Describing how certain cultural traits of Romanians impact the ways in which people treat them in London, she continued:

You see the impact communism made on Romania when you see these buildings or how people dress or behave. When they hear you're Romanian, their faces change. People are all over from the world here, they say it's what makes it so special. But people see the changes in the (urban) landscape and judge you for being different. But even the ones [migrants] that came before us judge you. It is a multicultural city, you see it everywhere-so it should be accepting, but they can judge you because you're Romanian.

This powerful quotation from Alexandra demonstrates the extent to which the Romanian migrant women in my study feel that they do not belong to the city and the country in which they study, work, and live. Despite varying social backgrounds and trajectories, they all moved to London to escape increasing unemployment and corrupt politics in Romania. However, now, in a country where the dominant political discourse demonises immigrants for the flaws of the economy and the decline of liberal democracy, Romanian immigrants are portrayed by right-wing politicians and the media as "beggars" and "criminals" who come to steal British jobs and exploit the social welfare system (Briggs and Dobre 2014, 2). I have chosen to start this chapter with Alexandra's statement because it reveals the strong sense of otherness felt by the Romanian women in my study in their new home - a place to which they moved in search of a better life, and yet now leaves them yearning for recognition and acceptance.

During my fieldwork, I became gradually more aware of how these women use digital media to vigorously challenge the discursive practices and material realities that marginalise and exploit them. My participants expressed how the internet and social media platforms constitute important elements in their efforts to resist the structural racialisation and discrimination they experience in their daily lives. Indeed, the digital media practices of Romanian migrant women form part of their broader endeavour to be heard and recognised as 
equal citizens in a country where they are socially and politically denied equal status and recognition. These narratives reveal the important underlying dynamics at work between digital media and diasporic identity production that form the basis for this analysis. In this context, I structure my empirical analysis of Romanian migrant women's digital practices in the light of several primary research questions specific to the case of Romanian migrant women, namely: How does London's urban dynamic and culture marginalise and discriminate against Romanian migrant women? What kinds of digital practices do Romanian migrant women adopt in order to represent and mobilise themselves in their endeavours to challenge hegemonic workings of power? Lastly, how do these digital practices, which aim to achieve recognition and equality, co-constitute their cultural identities and sense of belonging?

Addressing these questions, in this chapter I present an account of my participants' digital media practices and their aim to achieve representation, recognition, and equality. I argue that such practices should be seen as digitally mediated "acts of citizenship" (Isin 2008a) through which they articulate and perform different — albeit intertwined — identities and categories of whiteness, Britishness, Europeanness, and cosmopolitanism in order to claim their rights and belonging as equal subjects in London (and, in a wider context, the United Kingdom). I draw upon the plea of the critical citizenship studies scholar Engin Isin $(2008 \mathrm{~b}, 16,17)$ to think of citizenship as more than simply a legal status of membership to a nation-state. Isin argues that citizenship is constituted through the social, political, cultural, and symbolic acts of individuals and groups whose claims and subjectivities are articulated from below. He theorises that such claim-making practices, which are not necessarily embedded in law or immediately considered as political "acts of citizenship", create (new) sites and scales of struggle between the self and others (Isin 2008b, 18-39).

In the previous chapter, drawing upon Ash Amin's $(2013,4,5)$ argument of recognising "the darker aspect of everyday encounters of difference", I discussed how British-Somali women encounter racism and discrimination in their multicultural urban lives. Similarly, the members of the Romanian diasporic community reflexively interpret and narrate vernacular experiences of hostility and discrimination that shape their everyday lives in London. However, in contrast to the other two communities in my study, the Romanian case requires me to shift my focus to the particularities of Eastern European migration experiences. We can see from Alexandra's statement how urban, national, and supra-national scales intertwine in constructions of identity and community that marginalise Romanians within the context of the city. Whilst she refers to London's image as a "melting pot of 
cultures", she states how people — even other migrants — in reference to Romania's communist past and the status of Romanian migrants as post-socialist subjects, can still “judge for you being Romanian". In this sense, Alexandra's statement reminds us how urban spaces that are imagined as cosmopolitan may in reality comprise social boundaries acting as symbolic gateways that do not welcome everyone. What this and other similar statements to which I refer in this chapter reflect, is the heightened awareness my participants share of their positionality in urban, national, and European socio-political hierarchies that mutually generate vernacular experiences of marginalisation and a profound sense of otherness. Therefore, I examine citizenship within a translocational framework that understands and contextualises how acts of citizenship, which materialise in London, coalesce with national and European spaces of belonging.

In this context, "acts of citizenship" provides a useful concept via which to analyse and discuss the Romanian case, since it allows me to foreground the manner in which Romanian migrant women develop and employ micro-scale practices in order to challenge the hegemonic discourses and structures that other them in their daily lives and routines. From a media and communications perspective and as a counter-narrative to populist rightwing media discourse, my investigation allows us to understand how Romanian migrants themselves make use of media technologies "to act and be heard as citizens" (Slade 2014, 99). As Isin and Ruppert (2015) argue, today digital media technology and the internet are tools through which political subjectivities are also articulated. Indeed, they propose the concept of "digital citizens" to refer to individuals and groups whose digital practices (such as liking, coding, and blocking) and digital claims (about access, privacy, and freedom) constitute online claims to citizenship (Isin and Ruppert 2015). Such acts of citizenship are creative and innovative uses of digital infrastructures across digitally embedded sites (Isin and Ruppert 2015, 8-10).

However, in my investigation of the dynamic relationships between digital media and citizenship I take a different approach to Isin and Ruppert. My focus is on how the everyday use of the internet and mobile technologies becomes integrated into formations of individual and collective identities in an online-offline continuum. In this sense, my analysis differs from Isin and Ruppert's (2015) notion of “digital citizens", which is chiefly concerned with digital-specific rights and claims of citizenship. Rather, I examine how Romanian migrant women mediate their rights and claims to "enact themselves as citizens" (Slade 2014, 16) as embedded in their "everydayness". In this context, I examine the ways in which they use digital media to form networks of support and representation, performing the self at the 
intersection of entangled power modalities. Therefore, I draw upon Isin's (2008b, 18-39) "acts of citizenship" with the explicit aim of taking a "bottom-up" perspective, recognising how digital media become part of my participants' agencies and actions - how they achieve representation, communication, and equality. Whilst these acts may not at first sight seem overtly political in nature, my in-depth investigation reveals how they become a meaningful vehicle for social struggle, challenging broader political and socio-economic power structures that otherwise discriminate and marginalise migrant women.

Yet, as much as digital acts of citizenship are important shared experiences for women in the Romanian community, their diasporic subjectivities, everyday lives, and digital practices are shaped by differing migratory trajectories and socio-economic realities. The existing research on the Romanian diaspora in the United Kingdom indicates the importance of classed differences that exist in the community. Taking class as its main empirical focus, this body of research focuses either on working-class people (e.g., Briggs and Dobre 2014; Datta 2009; Moraşanu 2013a), or on the middle- and upper middle-class members of the community (e.g., Andreouli and Howarth 2019, Moraşanu 2013b). However, in the light of the theories of diaspora that inform our knowledge of how intersectional power structures shape politics of diasporic identity articulation (Anthias 2009a; Brah 2005; Clifford 1994), I go beyond this empirical divide. In this context, I contribute to this existing body of literature by employing a class-specific analysis that encompasses and compares Romanian women across three different social class configurations. Furthermore, I also unpack how social class is entangled with other axes - those of ethnicity, nationality, race, and generation-in order to fully uncover the implications of the intersectional power modalities in which these women are embedded.

In this context, my aim is to demonstrate how female members of the Romanian community, as a heterogeneous migrant group, use digital media to perform multi-layered cultural identities and to establish varying political alliances in their claim-making practices of citizenship. In doing so, the account I present in this chapter uncovers the ways in which migrant Romanian migrant women move between different sites of belonging in relation to their shifting socio-political positionalities at local (London), national (the United Kingdom), and supra-national (European) scales. I start by introducing the community itself. I then embark upon a class-based analysis of the empirical material from my fieldwork in three sections $(3.2,3.3$, and 3.4) that discuss the digital acts of citizenship performed by working-, low-middle-, and middle-class participants respectively. 


\subsection{Who Are "The People"?}

Although Romanian migration to the United Kingdom started (albeit sporadically) in the 1940s, mass migration is a much more recent phenomenon. Following Romania's membership of the European Union in 2007, Romanian citizens obtained the right to free movement across EU member states. However, Romanian (and Bulgarian) citizens were subject to transitional limitations on their access to the UK labour market until 1 January 2014 (Office for National Statistics [ONS] 2019, 6). According to the ONS $(2017,2018)$, although Poland is the most common country of birth and citizenship amongst migrants in the United Kingdom, in recent years the largest increase in population has been seen in those who were either born in Romania or those with Romanian nationality. At the time of writing, the latest statistical bulletin from the ONS states that "the Romanian-born population more than doubled between 2014 and 2018, from 170,000 to 392,000, and a similar pattern was seen also for Romanian nationals" (ONS 2019).

Romanian migrants are often referred to as "New Europeans"- a term used for the citizens of member states that joined the EU in 2004 and 2007. Within the UK national context, "New European" also refers to those who did not move as part of "managed migration" schemes that allocated jobs to migrants according to the national economy's needs, but those who moved informally through the EU's open border policy (McDowell 2009, 19-21). In this context, compared to migration from Turkey and Somalia, the migratory trajectory of Romanians coming to the United Kingdom can be considered as relatively less organised in the sense that Romanians migrated neither through an organised labour migration scheme, nor as asylum seekers or refugees. The number of organisations catering specifically to the needs of Romanians in the United Kingdom is considerably less than those of Turkish, Kurdish, and Somali communities. ${ }^{34}$ Whilst this is in part due to the fact that large-scale Romanian migration to the United Kingdom is relatively recent, some community organisations indicated that they felt there was a lack of financial and organisational support from the state and local councils. The institutional lack of support makes it harder for Romanians to claim their legal rights—as clearly illustrated by the limited financial resources of the organisations, which restrain their ability to assist and represent Romanian migrants in the United Kingdom. This makes the Romanian case an interesting one

\footnotetext{
${ }^{34}$ A list of Romanian organisations in the United Kingdom can be found via: $<$ https://londra.mae.ro/en/node/854>.
} 
to study, since it allows us to see the impact of the post-Brexit "crisis of multiculturalism" (Abbasov 2015) on communities who suffer from declining multicultural policies in the United Kingdom. ${ }^{35}$ The lack of centralised assistance and exclusionary public discourses and practices towards minorities have had a major impact on the experiences of Romanian migrants who struggle to survive and improve their socio-economic situation in the face of limited access to state resources and assistance. In this context, Romanian migrant women's experiences in my study are largely shaped by the contemporary UK national economic structure, which promotes neoliberal values and practices, and holds individuals responsible for their own lives and success. Thus, my analysis of the Romanian community in London yields important insights about how contemporary British class relations impact minority communities. More precisely, it reveals how migrants try to achieve social and economic mobility against the backdrop of an economic liberalism that promotes neoliberal values of "self-improvement", "individual responsibility", and "personal investment", and has dominated Britain's economic policies since 1980s (Biressi and Nunn 2013, 8, emphasis in original).

As Skeggs (1997) argues, access, resources, and legitimation are all important elements that contribute to class formations in the United Kingdom (cited in Biressi and Nunn 2013, 16). Romanian migrants, who are largely deprived of all three by the state, are forced into relying on their own individual conduct in order to succeed financially and gain recognition socially. Within a socio-political and economic context that sees the legitimacy of individuals and particularly migrants through the lens of their own "ability" to "adapt" and "succeed", Romanian migrant women's experiences are unsurprisingly shaped by class politics and positioning. As I have stated earlier, Romanian migration, which has not taken place in a formally organised manner, led to the movement of people from diverse social backgrounds, material resources, and socio-cultural capital despite their common ethnic, religious, and national ties. ${ }^{36}$ Writing about Romanians in London, Moraşanu (2013a, 2013b) highlights the importance of social class in understanding the dynamics and particularities of the Romanian diasporic community. In this regard, she draws attention to the fact that, whilst working-class migration (by those who largely migrate to work in domestic services or

\footnotetext{
${ }^{35}$ For a historical overview of multicultural policies and the political debate around "crisis of multiculturalism" in the United Kingdom, see Abbasov (2015).

${ }^{36}$ My study does not incorporate ethnic minority groups of Romania (such as Roma people or Moldavians) who migrated to London from Romania. I say the participants have common ethnic, religious, and national ties, since they all self-identify as Romanian Christian Orthodox passport holders of Romania.
} 
construction sites) is fairly commonplace, downward social mobility is also common for many Romanians whose diplomas are not accepted as "equivalent" to those in the United Kingdom and so do not guarantee matching jobs. She also adds that the United Kingdom, particularly London, is a highly popular European destination for education and job opportunities amongst middle-class and highly educated Romanians (Moraşanu 2013a, 2165, 2175). In this context, my empirical investigation complements Moraşanu's argument, since the participants' different class positionings tension their everyday experiences and realities, and negotiate their identities and sense of belonging. Such differences call for a class-specific analysis, embracing this further axis of identity alongside those of ethnicity, race, and generation.

In order to explain how I categorise my participants and analyse my findings from a class-specific perspective, it is first necessary to clarify how I approach the subject of "class" itself. I am inspired by Elsayed's (2011) research project on young people in Cairo. By drawing upon Bourdieu's (1984) notion of "class habitus", Elsayed formulates a class-based categorisation of her participants according to a combination of their economic and cultural capital. Therefore, "class" is not only constituted through economic resources, but also through socio-cultural indicators such as education, occupation, and lifestyle. Specifically, in my contextualisation of my participants' daily lives in London, I use her explanation of "lifestyle", not only as "a materialistic category articulated purely through the acquisition of certain essential objects such as a fridge or car", but one that also needs to be "supplanted by an understanding of 'lifestyle' as an everyday cultural performance, centred around particular lifestyles and consumer practices" (Elsayed 2011, 49). Here, analysing lifestyle as an everyday cultural performance also resonates with Butler's (2003) influential notion of "performativity". Butler argues that gender identities are socially constructed via the acts and speeches we perform rather than representing something we are in the face of broader power structures and normative expectations. The notion of performativity is applied to my analysis in combination with Bourdieu's concept of "class habitus", according to which individuals adhere to certain lifestyles and consumer practices in their performances of "middle classness". In this context, I see my participants' classed identities not solely in terms of their material resources, but as their cultural identity performances and lifestyles, executed both online and offline.

At this point, I must emphasise that I do not consider social class to be a fixed social grouping, nor do I aim to represent my participants as a homogenous people strictly bounded by class. Rather, as Biressi and Nunn $(2013,1)$ argue, I see social class as a continuous 
process that informs the way in which certain cultural classifications and labels attributed to individuals are formulated throughout their lifetime trajectories. In this context, I aim to understand how my participants perceive class dynamics by understanding their long-term embodied experiences and feelings in London. In this context, drawing upon in-depth interviews, my empirical discussion explores the self-evaluations migrant women make about their own class positioning in relation to other markers of their multi-layered identities since their arrival in the United Kingdom, specifically, London.

Over the course of my fieldwork, I carried out in-depth interviews with twenty Romanian women belonging to three different social groups: working class, lower middle class, and middle class. My seven working-class participants, whose ages ranged between 39 and 55, carried out jobs that can be classified as "blue collar". Five of my participants, whose ages ranged between 31 and 48, experienced downward social mobility despite possessing university diplomas and/or professional experience in various sectors, such as accounting, teaching, and management. I refer to this group as lower-middle class, since these women in time acquired new institutional qualifications or gained employment experience and managed to get better-paid jobs than those previously held when they initially moved to London. Furthermore, the fact that they had higher education degrees and a good command of English sets them apart from the working-class group, since education not only carries an economic, but also a socio-economic and symbolic value (Elsayed 2011, 50). Despite this apparent advantage, my conversations with this group also suggested that they faced ongoing financial hardships, even though they no longer performed manual "blue-collar" roles. Here, it is important to note that ten of the twelve women making up these two groups had children, meaning that a significant portion of their income was spent supporting their families.

The remaining eight interviewees, whose ages ranged between 24 and 29, had all been educated in the United Kingdom (either undergraduate or postgraduate, or both) and worked in UK or multinational corporations as highly-skilled professionals. Thus, my discussion of the middle-class group exclusively focuses on young migrant women whose migratory experiences are shaped by greater financial resources than they possessed, either in Romania itself or by virtue of Romania's membership of the EU, which allowed them to obtain EU student loans to study in the United Kingdom. Significantly, none of these young women had children and some still received financial support from their parents. As Bourdieu (1984) argues, class and class distinctions are not static economic and socio-cultural formations, but are always changing in relation to trends of consumerism, public discourses, and practices. The fact that these young women have more disposable income (due to less familial 
responsibilities) than the working- and lower middle-class women means that they can afford certain goods and lead (perform) a lifestyle that is associated with urban middle-class tastes and preferences. More precisely, this grants them an important level of freedom and flexibility in locating themselves in a middle-class "habitus" (Bourdieu 1984), performing as middle-class urbanites more easily. The fact that the majority of my young participants were from this particular social group was unintentional, however, it does allow me to unpack classed divisions in tandem with generation-specific lifestyles and digital practices.

\subsection{The Working Class: Cosmopolitanism and Britishness}

I met Daniela (48) at noon in London's bustling Oxford Street. Although I had made it clear that I could go to Edmonton Green where she lives, she wanted to meet by Oxford Street Tube Station. As soon as we met, she suggested we should go to a café nearby where they made "good coffee like Italians". My research assistant Veronica, who works as a teacher of English language for Romanians, also accompanied us. Daniela seemed to be comfortable that Veronica was also there, since her English was limited. Yet she also made it clear that she did not want Veronica to translate unless she really could not manage to express herself. I then understood that Daniela had been encouraged to meet me by Veronica, since our interview could be an opportunity for her to practise English. In addition, I also discovered that Daniela was serious about the quality of her coffee and preferred Italian coffee, as she has lived in Italy for a considerable time before moving to London to join her daughter and granddaughter. She managed to learn Italian quickly, in contrast to English, with which she still struggled even after living in London for two years. She explained that Italian was easy for her, partly because, being both of Latin origin, Romanian and Italian were similar. Another factor was that she was forced to speak Italian daily at work with her employers and colleagues. This led me to think (wrongly, as it transpired) that Daniela did not work in London or, at the very least, that she only worked with Romanians, and our interview was an opportunity for her to speak in English with a non-Romanian. However, Daniela worked fulltime for the perfume store Arabian Oud at its branches located in Oxford Street and Westfield Stratford City. As a matter of fact, her colleagues were not Romanians, so she only spoke Romanian with her family on a day-to-day basis. My question about how she communicates with her colleagues led to an interesting conversation: 
Daniela: "They are also not English like me. They also speak not so good, but we understand, we're okay. I learn English because you learn English then [you have a] better job and you meet English people. You need it."

Melis: "Do you like the people at work?"

Daniela: "They are nice. They are all different, but I like it. But you need to speak English good. In Italy I could speak good... find job good and live good.”

Melis: "How did you find out about English courses? Did you know about Veronica before?" Daniela: "I use the internet for the legislation, for courses, for everything.

Melis: "You search about the legislations online?"

Daniela: "Yes."

Melis: "What about Romanian school? English course?"

Daniela: "On the internet. I wrote English class and found and called Veronica. [There are] many things for Romanians [online] so I learn from there. You need English but you also find information online for Romanians."

This exchange with Daniela reveals two important recurring topics in my conversations with the working-class Romanian women: On the one hand, their jobs expose them to culturally diverse contexts and lead them to develop the skills needed to socialise and work with people from different ethnic backgrounds. Some of my participants even lived in shared houses with people from work when they first moved to London. Most referred to this as a positive experience and became good friends with their housemates in time. Therefore, their work contexts and home contexts lead them to form social ties with people around them beyond shared ethnic and national origins. In this sense, the everyday encounters and socialisations of these women provide a fertile ground for the emergence of "working-class cosmopolitanism" (Werbner 1999), demonstrating how vernacular cosmopolitanism in the form of "social relations of inclusiveness and openness to the world" (Schiller, Darieva, and Gruner-Domic 2011, 402) develops in non-elite forms amongst the working class.

However, it is also important not to over-romanticise working-class cosmopolitanism, which develops through "a strategic engagement with others through coerced choices in order to survive in new environments" (Datta 2009, 353). Evidence from my research suggests that established structural inequalities and material realities render cosmopolitanism more of a "temporal necessity" than an explicit cultural orientation. As the exchange above illustrates, Daniela is insistent that she must improve her English language skills, since it would help her to network with English people who can be potential employers for better jobs. In this 
context, whilst Daniela seems to enjoy the multicultural social context her work provides, her priority is to connect with the white majority of the nation.

Daniela's pursuit of a better job is understandable when one considers that many working-class migrants hold precarious positions and have limited opportunities to improve their social and economic situation. As Moraşanu (2013a, 2176) observes in her study on Romanian working-class migrants in London, "while being beneficial in multiple ways, Romanians' cosmopolitan bridging ties remained confined to the migrant sphere and had limited powers to enhance their integration and social mobility". This concurs with my own findings on working-class Romanian women whose work context provides a fertile ground for vernacular cosmopolitanism to flourish through non-ethnic, class-based identities, although they tend to believe that social relationships with other migrants are not helpful in finding better-paid jobs.

As Daniela mentions, acquiring a good level of English is essential for migrants, however, it is common for newcomers, particularly those from underprivileged social positions, to lack adequate language skills (and other forms of cultural capital) as well as financial resources. For example, in their ethnographic investigation of Romanian migrant workers in London, Briggs and Dobre (2014, 43-60) document how their participants are often given conflicting advice on receiving papers to legitimately work and reside in the United Kingdom. In this context, the working-class women in my study turn to the internet and social media to establish social networks to access information and support from other Romanian migrants when dealing with bureaucratic and legal issues. These networks constitute a mediated diasporic space via which migrants attempt to navigate the political system of a nation-state that fails to offer them the help they need to live and work in Britain as rightful citizens. Thus, they produce and consume diasporic media with the specific aim to enact themselves as citizens by learning, claiming, and practicing their rights despite the nation-state's exclusionary discourse and practices (Trimikliniotis, Parsanoglou, and Tsianos 2015). This digitally mediated diasporic space, which appears to be fundamental to the survival of the working class, demonstrates the struggle Romanian migrant workers face in a national context where their entitlement to equal rights and recognition is severely questioned and even denied by the top-down policies of the state. In this context, I would like to focus on my participants' engagements with these specifically Romanian-run diasporic media spaces and demonstrate how they constitute at least some of their digital acts of citizenship - to claim their legal rights as migrant workers and residents in the United Kingdom. 
In its broadest sense, diasporic media can be understood as the media produced and consumed by ethnic and cultural groups, both for information and/or entertainment purposes. Contemporary theorisations of diasporic media suggest that these groups are neither represented, nor are their needs met by the mainstream media (Siapera 2010, 94). There is a substantial amount of scholarly research that demonstrates the variety of media content, its purpose, and target audience, revealing the broad heterogeneity of diasporic media outlets. ${ }^{37}$ My study with Romanian migrant women reveals the extent to which the digital domain plays a key role in the formation of a diasporic media space for information and connectivity-a space used largely (though not exclusively) by the working class. Daniela's case is representative of the members of this social group, who rely on online research through Google and Facebook to find such diasporic spaces of information sharing in the absence of any institutional help and support from the state. Therefore, these online spaces demonstrate how the typical characteristics of traditional diasporic media forms such as newspapers, radio broadcasts, and television channels that formerly provided help and advice are, in the age of digital media, transformed into websites and Facebook groups. In this context, my interviews, both with the producers and the consumers of Romanian diasporic media content, demonstrate how the working class relies on the internet to learn and claim their rights and to develop their diasporic subjectivities as citizens in their new homes.

In her study on London Greek Radio, Georgiou (2005, cited in Siapera 2010, 107) draws attention to how diasporic media operate at the nexus of universalism and particularism, "translating the universal into the language of particular". For example, a radio programme on social security services "translates" the universalistic framework of citizenship to address the particular needs and characteristics of the Greek diasporic community. Similarly, in my study, the forum website Romani in UK demonstrates how online sites are used as an intermediary between the particular and the universal. ${ }^{38}$ The website has different sections, entitled (amongst others): News; Announcements; Guide UK; Events; and Community Forum. The sections "Guide UK" and "Community Forum" in particular, reveal how recently arrived migrants turn to non-governmental and informal social networks to learn about their obligations and entitlements, as well as the way of life in the United Kingdom.

\footnotetext{
${ }^{37}$ Iranian television in Los Angeles by Naficy [2003]; Greek Cypriot radio in London by Georgiou [2006]; migrant websites by Diminescu and Loveluck [2014], to name but a few.

$38<$ http://www.romani.co.uk/>.
} 
My interview with Christina Irimie (35), director of the recruitment consultancy BritRo and the editor of Ghidul Romanului in UK (The Romanian's Guide to the UK), shows how some community members take the lead in helping migrant workers to challenge the inequalities and injustices they face by establishing online networks of information and sociality. Having migrated to the United Kingdom long before Romania's succession to the EU, Christina witnessed the daily struggles of many Romanians who had been deprived of their rights as illegal migrant workers. Her experiences led her to describe Romanians "as second-class citizens" in "Britain, a democratic flag-bearer" in an article she wrote for The Guardian in 2006. In 2007, she edited Ghidul Romanului in UK-a guide available through the website Romani in $U K$ (which requires website visitors to create a free account for access) — which specifically addresses the needs of Romanian migrant workers. This document not only provides useful guidance regarding the rights and obligations of migrant workers, but also talks about a variety of topics, including (but not limited to) education, health care, churches, and restaurants. In addition, Christina told me how, through the Brit-Ro Consultancy, she frequently encounters cases such as the denial of education, health care, or insurance-related applications by the state and private employers who do not recognise the entitlements Romanians possess as EU (migrant) citizens. Importantly, the guide is soon to be edited in accordance with the changing legal requirements and entitlements in a post-Brexit United Kingdom. In this regard, the website Romani in UK exemplifies how migrants' claims to social rights should be seen as "a process-oriented social struggle" that is shaped by "particular historical and place-bound factors" (Isin, Juteau, and Stasiulus 2008, 11). This requires prominent figures like Christina to take the lead in helping the community to continuously revise the mediums through which they communicate information, translating the changing requirements of citizenship in a way that specifically addresses the community's particular needs in the absence of any formal guidance from the state.

Furthermore, the Romanian digital diasporic media space is an arena in which we can directly observe how acts of citizenship should not only be perceived as socioeconomic struggles. In both working and non-working contexts, the dominant political rhetoric that stigmatises and marginalises Romanian migrant workers encroaches upon their everyday lives and how others perceive and treat them. Nancy Fraser (1995) argues that, although they are taken as two different analytical paradigms, redistribution of resources (of the welfare state) and recognition (patterns of cultural representation and communication) are two intertwined dimensions of social justice that mutually constitute and explain social struggles. In this regard, it is important to acknowledge how some of my working-class participants 
expressed that they felt as if they are seen as easy to exploit by their employers and colleagues, who think that they can work for little money and endure harsh working conditions just because they are Romanian. Drawing upon Fraser's compelling argument, we can see the links between redistribution and recognition: For Romanian migrant workers, achieving socio-economic mobility requires a multicultural understanding of citizenship that would recognise them as equal citizens, rather than as a subordinate ethnic minority group.

However, my participants' own narratives about how they benefit from digitally mediated diasporic spaces indicate that the political struggle for recognition of the working class is largely articulated within a paradigm of "integration" that embraces Britishness rather than a multicultural understanding of citizenship. For example, it is interesting how some of my participants told me that the Ghidul Romanului in $U K$ edited by Christina is much more useful than the official guides published by either the Romanian or UK governments due to inadequate information on social and cultural life in the United Kingdom such as daily life, social norms, and customs. The forum section on the website Romani in UK was also frequently mentioned as a highly informative space, since there were numerous discussions on British social life and cultural values. Similarly, some Facebook groups, such as Romanians in UK or smaller (mothers') groups, were cited as important spaces where they learn about contemporary social issues and dominant cultural values of the United Kingdom. ${ }^{39}$ Existing scholarship examining discussion forums and social networking site usage amongst migrants demonstrates how they serve as important mediated public spheres in which communities are built and national, ethnic, and racial identities and ideologies are re-configured in diasporic contexts (e.g., Byrne 2008; Galasińska 2010). In my study, the participants' perception of such sites - their capacity to build a sense of both identity and community — suggests that they regard them as "evidence" of the effort Romanian migrants make to "integrate" into British society. In other words, the participants consider the purpose of these informative online sites to teach Romanians about British social and cultural values with the express aim of being more able to practice and perform them.

What integration really entails as a social process should be understood in relation to the nation-state's ideological framework and socio-political context (Trimikliniotis et al. $2015,31)$. In this context, of note is the way in which they narrated what they meant by “integration". This concurs with contemporary right-wing British political discourse, which largely demands political and cultural assimilation from migrants if they want to be

$39<$ https://www.facebook.com/RomaniInUK/>. 
recognised as equal subjects in society. In other words, echoing the contemporary right-wing political and economic discourses of the UK political elite, my participants consider how "successful" and "worthy" they are as citizens through the lens of how well they can embody the majority's social and cultural values. This becomes most apparent when they express how they consider Britishness to be "a must" when raising their children. Raising children the "British way" is generally thought the best way to guarantee both socio-cultural recognition and the equal redistribution of resources for the next generation of Romanians in the United Kingdom. Thus, in contrast to my participants from the Turkish and Somali communities, for Romanian women, "British" is not only a civic category, but also a cultural identity encompassing the values and practices of the English establishment—something that must be "successfully" embodied through the culturally reproductive work of mothering. This understanding of Britishness amongst my participants undoubtedly reflects the political and social dynamics of contemporary Britain, where the best way to "deal with" difference has come to be understood in terms of "civic assimilation" and/or "cohesion" (Meer and Madood 2005, 2).

Furthermore, my study shows how, in a context in which the nation-state is dominated by neoliberal logics, the paradigm of integration not only is about civic assimilation or social cohesion, but is also about cultural assimilation. This confirms Isin's $(2008 \mathrm{~b}, 16,17)$ argument that citizenship should not only be seen as a legal status of membership, but also as a form of social and cultural recognition as equal citizens in a given nation-state. My participants see performing the so-called "British way of life" as the only way to achieve social and cultural recognition as equal citizens in the United Kingdom, even if they possess legal citizenship. This underlying paradigm of cultural assimilation, so often narrated by my participants, reveals the inherent difficulty faced by minorities when attempting to build a multicultural understanding of citizenship from the bottom up - a difficulty particularly for those from underprivileged backgrounds, who are left with no other choice but to "integrate" by adopting and performing the discourses and practices dictated by the majority and the nation-state.

As I stated in the beginning of this section, the everyday lives of working-class women in London - particularly in the context of employment - expose them to cultural difference and diversity, allowing them to develop social relationships with other minority groups based on class-based identities and experiences. As such, the everyday urban settings in which they become embedded lead them to develop "cosmopolitanism from below" (Bhabha 2000; Hall 2008) with an underlying strategic engagement and implicit positive 
orientation towards cultural difference. As such, these attitudes towards, and social interactions with, other minority groups, both in the context of employment and the home, demonstrate the relationship between class-based subjectivities and cosmopolitanism in the city. As Datta $(2009,356)$ writes, "it is possible to reconceptualise cosmopolitanism as spatial where forms and degrees of openness to others are shaped by localised spatial contexts where encounters with 'others' take place". For my participants, the city in which they work and live, makes it impossible not to be immersed in social contexts in which they interact with other migrant and minority groups for their survival. This dynamic renders cosmopolitan identity performances an inseparable aspect of urban life. Yet when precisely focused on their digital media practices, through which they mediate their claims and rights as citizens, I did not encounter any kind of incentive to connect with members of other minority groups. Hence, the cosmopolitan cultural capital they accumulate remains completely hidden, since it is not considered a valuable asset that will help them to achieve social mobility in a wider diasporic context.

At the same time, their main mediated information networks, which create an essentially Romanian diasporic space, reveal how their ethnic ties are indeed vital to their survival in the United Kingdom. However, I argue that this should not be taken as evidence of a collective response by the ethnic community to the political system that abuses and discriminates them. Conversely, the ways in which my participants perceive these diasporic mediated spaces show that they mostly serve specific purposes, such as learning English or handling legal administrative work that will help them to work and live in the United Kingdom. As Isin, Juteau, and Stasiulus $(2008,11)$ argue, citizenship is not only a political and legal status, but it is also a social category in which individuals are defined as "fit" candidates - recognised and entitled to particular place-bound rights through performative dimensions and identities. Their digital acts of citizenship reveal that they hope to challenge the hegemonic power structures imposed upon them by performing social and cultural dimensions of dominant understandings of Britishness in their everyday identity performances, merely reflecting the nation-state's contemporary political discourses and practices. In this perspective, it becomes apparent that the criteria through which my participants believe that they can be validated as citizens is, in the long run, embedded in the perceived requirement of cultural assimilation-i.e., performing so-called British social and cultural values - in order to achieve social mobility as migrant citizens. 


\subsection{The Lower-middle Class: Neoliberal Cosmopolitanism and Whiteness}

In the beginning of my fieldwork, my interviews and personal observations with lower middle-class Romanian women often led to contradictory insights. Being fully aware of the unequal power structures that deprive them of certain rights and recognition, the members of this group also expressed a felt necessity to fully "integrate" into British society in order to be seen as "rightful" citizens. However, whilst the working and lower-middle classes could be categorised as a unified group based on their social, cultural, and economic capital, unlike the working class, there initially seemed to be no consistency in the ways that the lower-middle class develop common ways or shared spaces of claiming presence and recognition. This was partly because they were ambiguous about their own positioning in British society, which led to a lack of unity, or shared diasporic group consciousness. The following conversation with Ana (36) and Ioana (31) about their sense of cultural identity clearly demonstrates this:

Ana: "I am Romanian, but also I am European. I mean even we are Eastern Europeans and have to catch up with the rest."

Ioana: "Europe will press the Romanian government to come to the Enlightenment."

Melis: "What do you think about Brexit then? The fact that the UK will not be part of the EU."

Ana: "I am a British citizen, so it won't affect me. They can't take everyone in. I am here, but I work and pay my taxes. When you come here and just claim benefits, it's bad for everyone, for economy."

Ioana: “There are many immigrants here already who don't work or who don't try to fit in. I mean, don't misunderstand me. I like some of them and I work with them and everything, but so many people who don't do any good for the economy."

The sentiments expressed by Ana and Ioana were not exceptional amongst the middle-class Romanian women in my study, who themselves had benefited from the EU's open borders policy. By moving to the United Kingdom as EU citizen migrants, they not only see themselves as Europeans, but also think that it will be the EU that will eventually fix the political and economic problems of Romania. Despite this heightened level of attachment to Europe, it is intriguing that both women offer statements that justify Brexit on the ground that it will help the United Kingdom to curb free movement and prevent "bad" immigrants from 
damaging the economy. As Ioana's final statement suggests, as in the case of the working class, the lower-middle class also have social relationships and interactions with people from different ethnic and cultural backgrounds as a requirement of their work context. However, their understanding of citizenship largely draws upon nation-centric, neoliberal discourse that ranks minorities and decides whether they "deserve" to belong according to their individual financial success and contribution to the UK economy (Biressi and Nunn 2013, 189).

Such contradictions made it harder for me to give meaning to their digital media practices collectively as a group, which had been at the core of my ethnographic endeavour thus far. Nevertheless, gradually, during the course of my fieldwork, I came to realise that what I perceived as inconsistent patterns indeed reflect how each of these women individually (albeit with divergent motivations) develop and navigate a complex web of cultural sites via which they perform their sense of belonging to British society and claim their rights as equal citizens. In other words, I realised that I had to understand their claimmaking practices as citizens in relation to the specific conditions and requirements that shape each woman's life, rather than trying to find a collective endeavour facilitated through the digital. By doing so, I was able to understand how seemingly contradictory narratives of selfidentification and belonging are indicative of how these women continuously traverse multiple cultural scales to claim belonging and recognition in shifting ways.

Considering the changing economic structure and class relations of contemporary Britain, Standing (2011) refers to a new "precariat" class that is "in the making" in the face of neoliberalism (cited in Biressi and Nunn 2013, 11). Standing argues that the precariat is a new class formation in contemporary British society. It is defined by new, flexible, and inherently insecure patterns of waged labour, which generates a sense of vulnerability in the lives and identities of those it embraces (cited in Biressi and Nunn 2013, 11). In my study, the social impacts of instability and vulnerability manifest themselves in the ways in which lower middle-class women perceive the co-existence of different ethnic and cultural groups in the city, and how that impacts their own sense of social position. For example, Olga (38) described how she and her husband had to start from scratch when they married in London, struggling financially for a long period of time. However, things began to improve once her husband established a construction firm and, more recently, partnered with a Cypriot to expand the business. Her husband and the new business partner initially got into contact via Facebook through their shared friendship networks. According to Olga, this demonstrates how social media provides a useful means via which to connect with "entrepreneurial people" outside of one's own ethnic community, giving access to London's dynamic 
economy. Like her husband, Olga, who recently started her career in insurance, also uses Facebook (amongst other business networking sites and apps) as a freelancer. Thus, the internet and mobile applications enable her to work with a flexible schedule and to network with many people beyond her ethnic community.

Therefore, it seems that Olga does not necessarily think that she needs to connect with white and non-migrant British people in order to improve her financial situation in contrast to the working-class women whom I introduced in the previous section. Furthermore, given her advanced level of English and professional qualifications, digital media allow her to connect and move between multicultural mediated spaces. These non-ethnic social networks also materialise by socially interacting with people outside of her ethnic community for work in offline contexts. However, when we started to talk about Brexit, she told me that although she regards herself as a European and wants the United Kingdom to remain in the EU, she still thinks that there are a lot of immigrants who exploit the welfare state and claim benefits instead of simply working harder. It may well be that she was particularly sensitive about the fact that these benefits should be allocated to people who really need them following her experience of two years of being unable to work and earn money due to illness. Yet, for Olga, it was of the utmost importance that the United Kingdom remained a financially strong economy since she and her family will have to leave the country and resettle somewhere else if "something happens, like an economic crisis and things don't go well". With the imposed fear upon her that the economy will suffer because of the exploitation of the system by immigrants, the dominant hegemonic rhetoric leads her to firmly believe that immigrants are indeed responsible for the flaws of the UK economy. In this context, it is important to acknowledge how her assertion reflects the contemporary public discourse that citizens should "make do" and "accept the rolling back of state provision" in the era of austerity (Biressi and Nunn 2013, 21).

At the same time, she still perceives London's multiculturalism to be of economic value, illustrating how alterity becomes an individualised neoliberal asset—essential for achieving economic development. What we see here is how cultural plurality becomes a financial asset within a nation-centric and neoliberal framework for immigrants who are forced to prioritise their own individual development in the interests of survival, rather than developing a politics of solidarity based on their class-based communalities. This indeed leads pro-EU participants such as Olga not only to categorise immigrants as "good" and "bad" based on their economic value, but also to justify that borders should be policed based on this distinction by being essentially closed to immigrants who will not benefit or might 
even harm the economy. As Baban $(2016,374)$ writes, "the borders of Europe are relatively open to those who are economically productive, hence desirable, as opposed to those who are framed as a mere economic burden". Hence, it is interesting to see how Olga, as an immigrant herself, supports a discourse and a practice that is used to police the borders of Europe with a (liberal) cosmopolitan imaginary that aims to satisfy the labour demand of the powerful nation-states without any real (normative) cosmopolitan solidarity and commitment (Baban 2016, 377-86). Thus, Olga's case is reflective of how citizenship can also be understood by migrants themselves in relation to the duties of the citizen within a framework of economic liberalism that puts the burden of "success" and "improvement" on the shoulders of immigrants. As I stated in the introduction, Isin (2008b, 18-39) theorises acts of citizenship in order to recognise how individuals create new sites and struggles between themselves and others. In this perspective, the neoliberal logics that determine who should be allowed to cross the borders of Europe also inform how some lower middle-class participants such as Olga define relations of "self" and "other", and position themselves as rightful citizens in the United Kingdom.

Furthermore, the economic instability and the sense of ambiguity felt by this class certainly intensified with the results of the Brexit referendum. When I was carrying out my empirical investigation with the community two years after the referendum, there was still no certainty on the details of the Brexit deal ${ }^{40}$. It was the midst of the three-year-long political chaos that dominated the country and there was a growing fear that the United Kingdom would eventually leave the union without a deal. The ongoing uncertainty about the legal status of EU migrants residing in the country unsurprisingly increased the sense of vulnerability and instability of Romanian migrants. Furthermore, the pro-Brexit camp continued their propaganda - that the "New Europeans", particularly those from Eastern Europe, do not belong in the country and should be denied the right of settlement after leaving the EU. My participants expressed their profound feelings of bitterness towards the situation, directly challenging right-wing propaganda by claiming their right to "belong" in Britain on the grounds of their whiteness. Through a discourse of "white Europeanism", whilst they do not explicitly deny the distinction between "British" and "European", they perceive their whiteness to be a quality that should entitle them, relatively speaking, to a higher status and treatment than "non-white" and "non-European" others. In this context, whiteness and Europeanness become racial, political, and cultural categories within a

\footnotetext{
${ }^{40}$ The UK and the EU agreed a deal on 24 December 2020.
} 
framework of identity politics that migrants themselves use as discursive tools of othering. Lulle, Moraşanu, and King's (2018) thesis, in which they discuss how "whiteness" can become a "micro-tactic of belonging" for EU citizen migrants, can help here to understand how a discourse of white Europeanism becomes a counter-argument used by Romanian women who wish to remain in the United Kingdom. For my participants, whiteness becomes a tactic of belonging that operates "in relation to a racialized self-identification and social hierarchies through which some Europeans are seen as more 'valuable' or entitled to privilege" (Lulle et al. 2018, 3).

In this context, an analysis of such digital acts of citizenship allows us to see some of the ways in which Romanians put discourses of self-identification and self-racialisation-as white Europeans - into practice through their digitally mediated identity performances. Furthermore, it reveals how for such EU citizen migrants who are forced to justify their belonging to the UK, Europeanness becomes the "best viable option" for self-identification, rendering (the struggle for) citizenship a translocal phenomenon. The experiences of one of my participants, Dora (38), vividly illustrates this point. Dora initially moved to the United Kingdom illegally eleven years ago, using a forged Lithuanian passport. She had to fake her identity when she was working at a hotel as a cleaner, despite the fact that the managers of the hotel knew that she was there illegally (like many other cleaners, she was seen as cheap labour and thus a "blind eye" was turned to her immigration status). Whilst Dora's claims about the hotel managers remain unsubstantiated, it is not hard to believe that she lived in fear of arrest should her true identity be revealed. With reference to her first day when she took the bus to her work in the early morning, Dora says: "I got on the bus and I was the only white person!" Dora's experience as an illegal migrant worker in London has led her to realise how race is not only a black and white category marked by one's skin colour, but also constructed historically, politically, and culturally to racialise and "rank" minorities against one another (McDowell 2009, 28). In other words, she came to realise that "there are distinct shades of white" (McDowell 2009, 34) and these are constructed at the intersections of ethnicity, nationality, and social class. Her years of work as a cleaner not only allowed Dora to get to know people from different racial and ethnic backgrounds, but also to develop a sense of group identity and belonging on the basis of shared class-based status and experiences. With Romania's joining of the EU in 2007 and the transitional ban ending in 2014, Dora's life changed considerably. She was no longer an illegal immigrant and found a better-paid job. However, Dora says she was annoyed by the Facebook posts of some English acquaintances during the Brexit campaigning period, who blamed immigrants for destroying 
the British economy and culture. This has led Dora to engage in heated debates online and to distance herself from these people in real life, since they do not know how "life is hard for the ones who come here with nothing". Such digitally mediated antagonisms demonstrate Dora's frustration with right-wing sentiments as well as her self-identification with other minority groups on the basis of their common status and identity as migrants.

At the same time, another digital media practice used by Dora is to frequently use Facebook to represent Romania and Romanians from a "positive perspective". For example, she regularly posts pictures of landscapes from Romania or shares anecdotes and information about Romanian history and culture on Facebook for her "mixed friends-like English, French and Indians". Dora believes that such actions help to show how Romania is not as different from other Western European countries as many think, since the country had been part of Europe before communism forced it to cut its ties with "European civilisation and its people" in its many years of isolation. Therefore, it seems that Dora's online identity construction and performativity can be understood via her own representations of Romania. Dora's case demonstrates how she strives to locate herself as a white Western member of the European community rather than an immigrant, regardless of the strength of her non-ethnic social ties and explicit cosmopolitan orientation. In this way, Dora's case provides a compelling example of how hegemonic constructions of Europeanness are exercised by some underprivileged EU migrants who believe the most viable way to improve their positionality within the dominant racialised hierarchies of Western Europe is to embrace and perform whiteness itself.

The strategic use of diasporic identity representation and performativity online was also evident amongst those participants who explicitly desired to be part of the Romanian community in London, but feared that this would lead others, especially the British, to perceive them negatively. I became aware of this trend through some of my conversations with mothers whom I met at the Romanian Saturday School located in Hendon, North West London. These mothers bring their children to the school every Saturday so that they can learn the Romanian language, the country's history, and its traditions. The mothers found out about the school via the internet and some use Facebook to keep up to date and access information about the school, its events, and several other Romanian community organisations. In this context, whilst their digital media use certainly indicates their desire to be members of the Romanian community in London, some, although not all, expressed how they prefer not to share or post much about Romania on their social media platforms. For example, a participant expressed how she fears to do so might trigger antagonism on her 
profile, as there may be "anti-Romanian people" amongst her Facebook friends who could feel emboldened to be openly racist towards her. Similarly, another participant expressed how, although she uses Facebook to keep updated about Romanian politics, she prefers to restrict her profile to her hobbies and leisure activities rather than sharing content about Romania. According to her, these represent "who she really is" towards her international friends online, rather than giving the impression that she is a "typical immigrant who does not integrate". As Marwick and boyd $(2011,114)$ argue, social media users have an "imagined audience" to which they develop their digital communicative acts accordingly. In this context, they articulate their identity representations by using the affordances of social media platforms in a manner that allows them to conceal some subjects and advance others in order to achieve authenticity online (Marwick and boyd 2011, 114, 115). Therefore, for the inhabitants of the multicultural city, my participants' online "imagined audience" reflects the urban demographics of London, demonstrating how social media platforms allow them to connect with communities and individuals from different ethnic and socio-cultural backgrounds. However, this form of "mediated multiculturalism" generates the fear of antagonism and racism. I see these tactical identity performances online as digital acts of citizenship by these women as they strategically perform their diasporic identity, even downplaying their Romanian national and ethnic subjectivities online in order to avoid being subject to discrimination and marginalisation.

Thus, in a socio-political context dominated by neoliberal and racialised policies, lower middle-class Romanian women, most of whom have experienced downward social mobility, actively seek to improve their living conditions and social status by becoming established members of the middle class. In this section, I have demonstrated how their "precariat" social class, coupled with their higher level of social and cultural capital than the working class, leads them to form and adopt various digital acts of citizenship in line with their own specific purposes and motivations without feeling permanently bound to a particular group or a cultural space. Despite the divergent narratives and practices that exist within the group, it is apparent that each participant uses the digital domain to represent and perform those diasporic identities and forms of belonging that are deemed to allow them to be recognised as equal citizens and to improve their socio-economic positioning in Britain. In this context, the cultural plurality of the city becomes either an economic asset from which they aspire to benefit, or a racialised social hierarchy in which they must strategically locate themselves. Such trends reveal how migrants must try to survive and cope with the 
contemporary political climate and neoliberal economic realities of twenty-first-century Britain.

In this context, I argue that the online identity representations and performances outlined in this section should be seen as digital acts of citizenship that aim to improve the economic capital and recognition of "successful migrants" - at least in the eyes of the neoliberal nation-state. At the same time, the Romanian women in my study use digital media to strategically perform certain social, cultural, and symbolic acts of citizenship that are also deemed to allow them to pass as white Europeans. This demonstrates how they claim their right to belong to the city and the nation on the grounds of their shared sense of supranational identity, culture, and community with the white majority. Thus, it becomes clear that lower middle-class Romanian women engage with identity politics via social media platforms and web applications, enabling them to strategically mediate certain identity traits and social relations at the intersection of urban, national, and supra-national scales, depending on the perceived "best way" to be seen as rightful citizens in the diasporic context of the individual concerned. In this regard, I argue that this social group reveals how bottom-up claims of citizenship are indeed mediated through strategic individualised identity performances. These identity performances should be seen as "micro-political actions" (Leurs 2015, 27) through which we can observe how migrants use their performative power to claim recognition, equality, and belonging. I now proceed to the final section of the chapter, in which I discuss the acts of digital citizenship of middle-class Romanian migrant women.

\subsection{The Middle Class: Occidental Cosmopolitanism and Europeanness}

So, one thing that really made me think about culture, like in, that will be relevant to you, is when I moved to the student house like, in the house we were like one. I was Romanian, we had an Indian guy, okay, two British people, one German, three Italians, someone from Singapore, and we were from all over the place. But, you know, Ifelt that this was so much people that I would describe as from the same culture as me, a lot more than the Romanian construction workers. Yeah, it just showed me how much people are more divided by education than by nationality. Yeah. I just felt that there was this huge cultural gap between me and the working-class people. We just could not get along. Yeah. It was a little bit shocking for them that I, as a woman without a man, was you know, just coming to the UK and studying and doing things that they did not quite understand.

-Denisa (28) 
Denisa's statement, in which she compares herself with working-class Romanians, is representative of how young middle-class women in my study generally relate to class differences within the Romanian community. Through my conversations with the members of this group, I became aware of how people's personal reflections — on one's own social dispositions and cultural capital — are seen to be indicative of their positioning within the community. Yet I believe it is also necessary to explain the context in which Denisa made such an assertion, as it represents the majority of my young middle-class participants' classbased experiences and lifestyles in London.

Denisa moved to London from Romania six and a half years ago to study for her master's degree. As in the case of many other migrants, she sought to find accommodation through her personal networks. A driver at the company where her aunt worked as a legal advisor in Romania used his connections in London to help her. She found a room in a house with Romanian construction workers, where she lived for a few months. When I asked Denisa about her use of digital media, she enthusiastically spoke of her passion for cooking and how through the internet, she finds recipes for the dishes from many different cuisines. For Denisa, cooking allows her "to experience multiculturalism". This is when Denisa mentioned the time she spent sharing a house with Romanian construction workers, who did not understand and appreciate her passion for "multi-ethnic cooking". When she finally moved into accommodation with an international group of students, she began to understand culture more in terms of education and lifestyle than nationality.

Today Denisa works part-time for a small charity that offers consultancy services on employability and workers' rights to Eastern European migrants - a subject about which she seemed genuinely enthusiastic. At the same time, her self-evaluation-her relationship and interactions with her former housemates - shows how she thinks that a middle-class habitus is articulated in relation to specific tastes, preferences, and lifestyle which, according to Denisa, working-class Romanians lack. As Bourdieu (1984) suggests, class is as much about social, cultural, and symbolic capital as economic capital. In this context, as she said a couple of times during our interview, Denisa values "openness", "tolerance", and "multiculturalism" ideologically and considers these as forms of social and cultural capital that the working class does not (or perhaps cannot) have. Denisa practices these values by living a "cosmopolitan lifestyle"-experiencing multi-ethnic cooking or living in an international household. In this regard, her explicit cosmopolitan orientation (both as a discourse and a practice) leads her to 
distance herself from the working class and to feel as if she is part of the young urban middle class.

The reason why I opened this section with Denisa, is because her statement is indicative of how the young middle-class women in my study tend to determine whether a person is cosmopolitan or not based on their explicit cultural performances. Such cultural performances may encompass their choices in terms of food, fashion, or leisure activities which, according to them, show one's "openness towards different cultures" and are inextricably linked to education and social class. Similarly, I was frequently told how they were interested in different cultures and valued the friendships and professional networks they have managed to establish beyond their ethnic community in London. Therefore, these young women's cosmopolitanism is not only about a subjective understanding of (or position in) the world, but also constituted through certain embodied cultural performances that have a visible presence (Elsayed 2011, 205) specific to the members of the urban, cosmopolitan middle class. Thus, cosmopolitanism, as an embodied cultural performance, is embraced by young educated middle-class participants since it constitutes a public marker of social distinction (Bourdieu 1984) within an urban middle-class habitus. In this context, it is important to acknowledge how such performances are asserted through a framework of class politics that result in the othering of Romanian migrants of working-class backgrounds who cannot afford a similar lifestyle. For example, when I asked about her perception of the Romanian community in London, another participant, Irina (26) mentioned the importance of lifestyle and how working-class migrants do not "integrate" because they do not mix with other ethnic/cultural communities in the city:

Because they don't have the same lifestyle. I don't think they integrate that easily and they stick to Romanians a lot. And I pity them sometimes because I'm just thinking it must be really hard because they're obliged by circumstances to be here. Whereas I'm not obliged, I'm here because I want to be here, so it's quite different. And I don't look at them in any bad way or shameful, I think it's wrong to look at them like this. They just want to do work and gain more than they would in Romania. And again, for them it's harder than it's for me. So, I wouldn't ever blame them, ever. What I sometimes don't like is when I see like bad antisocial behaviour. In the tube or on the streets from Romanians, I really dislike that and that's when Ifeel shame, ashamed that I'm Romanian. 
These classed patterns also apply to some of the digital practices that mediate my participants' everyday cosmopolitan cultural performance on social media platforms. I see these online identity performances as micro-scale digital acts of citizenship that aim to enunciate their urban belonging and locate themselves as part of an urban middle-class habitus. This becomes most apparent in the ways in which they distinguish their middle-class preferences and practices from those of lower socio-economic backgrounds who cannot understand and/or adapt to the way of life in London. The shift from communism to a neoliberal economy has been associated with the generation of a culture that values the "material display of goods and all the trinkets of the good life" amongst Romanians who have become subjected to increasing consumerism and economic individualisation (Briggs and Dobre 2014, 96). One of my participants, for example, gave this as a reason why she could never move back to Romania and also did not feel she belonged to the Romanian community in London: "It has become an overly consumerist culture with people who like to show off rather than to invest in their education and career and become a better version of themselves." However, through my digital ethnographic observations, I noticed how friends, offices, leisure activities, and certain goods and services were frequently displayed. In contrast to other Romanians who "show off" their material acquisitions, the young participants' media accounts documented professional achievements, multi-ethnic friend groups, exhibitions, and vacations. In this context, my interviews with these women, whose social media accounts extensively portray cosmopolitan cultural performances and an urban lifestyle, allowed me to understand how they perceive such self-representational practices as acts that position them as citizens of multicultural London. For these young women, the city provides a framework within which they can be recognised and accepted differently in terms of identity, belonging, and community, beyond the realm of ethnic and cultural homogeneity (Isin, Juteau, and Stasiulus 2008).

In this context, considering how cosmopolitanism is largely seen as an embodied practice and public performance of social distinction (Bourdieu 1984), such mediated cosmopolitan cultural performances are also deliberately displayed with the aim of distancing themselves from Romanians of lower socio-economic backgrounds, representing instead their specifically middle-class urban diasporic identities. However, as in the case of the luxurious material goods "typical" Romanians like to "show off" online, the exhibitions, vacations, and exclusive office jobs these young women like to depict online also represent cultural and economic commodities that are marked as "valuable" by neoliberal consumerist trends. This reveals how, whilst the shift from the Romanian context to the UK context may have led to 
the envisioning of different commodities as desirable, the culture of consumerism and individualisation still plays an important role in the identity performativity of these young women. Therefore, it shows how certain practices and preferences, which signify the embodiment of the "cosmopolitan" lifestyle, are indeed shaped by urban and global consumer cultures, generating neoliberal cosmopolitan subjectivities.

I'm not nationalistic at all. I think if you're gonna gather people together, gather them together because they have the same interests, they like the same artists, they like the same band, they, you know, like to do certain things like climb up walls or whatever... And again, I feel like, and I condemn people that are from my country and probably any other country that come to London, come to England or whatever, leave their homes and that they go into a different country and they don't make any effort to integrate themselves in that society, to integrate themselves in that culture.

Elena's (29) words quoted above demonstrate her anti-nationalist sentiment and how, rather than nationality, she perceives shared interests and practices as traits that unite people. However, these words can also be seen to reveal how anti-nationalism becomes a performed class identity by those who associate nationalism (or nationalist politics) with the working class. In this context, "nationalism" and "cosmopolitanism" are seen as opposing characteristics associated with the working class and the middle class respectively, shaping the class politics within the community. Furthermore, it is intriguing how such statements, common amongst the middle class, often suggest that migrants cannot "integrate" in a "host" country's culture because of their nationalism and lack of willingness, merely reflecting the populist right-wing discourse against immigrants. Thus, it is apparent that, as in the case of previous class groups, these young middle-class women also employ a neoliberal discourse in a diasporic context, which puts the emphasis on the individual's own conduct and "ability" to attain economic, social, and cultural success.

Unsurprisingly, Elena's social media profiles on Facebook and Instagram — where she displays, as she puts it, her "active lifestyle" and "London-specific" experiences with her British boyfriend and international group of friends - perfectly illustrate her thinking. As in the case of the majority of my young middle-class participants, social media plays a key role, allowing Elena to display important facets of her life, keep in touch with her international friends and acquaintances, and learn about places and events in the city. Whilst she is also digitally connected to a number of Romanians, these are largely her family members or close 
friends - her own personal networks. Despite the fact that social media, particularly Facebook, was occasionally mentioned as a tool to connect with other Romanians, this connectivity was generally confined to smaller, specific groups (such as Romanian student societies or expats groups), which were seen as neither particularly useful, nor exciting. Thus, in contrast to the working class, it would appear that members of this group do not see the need to become part of a well-connected Romanian diasporic community for information and support, and they certainly do not seek to become part of a digital diasporic media space.

This lack of any desire to be digitally connected with the wider migrant community leads to a further acknowledgement of the fundamental differences between the young members of the three communities that I investigate in my study. For example, in my previous chapter, I argued for the centrality of the local urban context to the shaping of migrant identity and the creation of a sense of belonging for young British-Somali women. Although the city and urban imaginary also play a central role in the self-representation of Romanians, I believe that it is important to acknowledge how the young middle-class Romanian women in my study do not particularly aspire to position themselves within a collective urban social order - at least for the time being. Whilst I do not want to make a claim about the underlying reasons without a focused and comparative in-depth examination, it is evident that migratory trajectories and the everyday social contexts of young members of the two communities are considerably different. Unlike my second-generation British-Somali participants, who have been raised with a more collectivistic sense of identity in large families and Somali-influenced neighbourhoods, the movement of young middle-class Romanian women to London occurs largely on an individual basis-either for education and/or career-oriented reasons. As they frequently attested, their motivation for moving to London was as much about the opportunity to learn and experience different cultures as it was for the education and employment the city has to offer. In this context, cosmopolitanism offers a worldview and a lifestyle that can be achieved individually without necessarily providing a framework for constructing and performing a collective Romanian youth identity and culture.

At the same time - and despite her explicit cosmopolitan sentiment, in which multiculturalism is seen as an attractive urban characteristic-Elena's words above demonstrate that there is still an emphasis on the need for integration amongst the members of this group. Thus, like working-class and lower middle-class women, it appears that the middle-class participants also think that there is a need to embrace specific socio-cultural values and adopt a certain lifestyle in order to feel part of the majority culture. Interestingly, 
unlike the working class, they do not actively seek to connect with English people or perform Britishness in order to obtain equal rights and status in London. This leads one to question into which majority culture these women think migrants should "integrate", if indeed they see London as a cosmopolitan city in which people can embrace and perform many different cultures. More precisely, if they do not assert their political and economic rights within a nation-oriented framework, which group do these women seek to join and be recognised as being part of?

In my previous chapters, I discussed how the multicultural city acts as a vessel for a specifically cosmopolitan imagination and allows migrant women to negotiate their identities and positionalities in a diasporic context. By doing so, I demonstrated the centrality of the urban context and locally embedded experiences in developing various cosmopolitan visions and practices, and the ways in which the digital domain allows these women to perform these in varying forms and styles. The Romanian case, however, requires an extended focus beyond locally bounded contexts and a recognition of the way in which cosmopolitanism and Europeanness coalesce in the ways young middle-class Romanian participants assert their right to belong. In their study on young Romanians in Britain, Andreouli and Howarth (2019, 280) argue that the everyday cosmopolitanism of young Romanians indicates an "Occidental cosmopolitan" orientation that reinforces the idea that the "West is seen as epitomizing European values of modernity and progress, while the East is seen as backward and traditional". The narratives of many of the middle-class Romanian women with whom I spoke concur with Andreouli and Howarth's argument in the sense that they reflect an "Occidental cosmopolitan" discourse in which cosmopolitanism and Europeanness become qualities via which they assert their right to be recognised as equal citizens based on being more "modern" than non-Western migrants. Seemingly an inversion of Said's (1978) "Orientalism", the term Occidentalism refers to the myriad of ways in which non-Western political leaders, intellectuals, artists and general public understand and represent the West (Wang, 2014). In this context, I argue that my participants' cosmopolitan identities reflect Occidentalist dispositions that perceive Western European identity and modernity, in Venn's words $(2000,19)$, a "universalizing and totalizing ambition" induced by the fact of colonialism and of capitalism. As Bozatzis $(2016,48)$ writes Occidentalist self-positioning "often unfolds in tandem with waves of representational practices aiming at culturally othering populations, nations, or social classes”. Occasionally, I even felt as though young middle-class Romanians intentionally distance themselves from Romania and claim a cosmopolitan and European identity in order to overcome a sense of inferiority and nihilism. 
For instance, when I met with Andreea (25), first and foremost, we talked about London and how we learnt so much about the world by living in such a culturally diverse city. When I asked her about how she perceives her identity after living in London for six years, her answer reflected the opinion of the majority of the women in this group: "Identity, it's definitely a mix. If you ask me, I'd say European. European. If there is something I claim with pride, it's more like European, to be honest." When I asked her opinion on Brexit and the representation of Romanians by the pro-Brexit camp, Andreea suggested that the media are no longer interested in Romanian migrants:

Yes, people from Eastern Europe maybe come here for work and so on. But they're not the typical population from which you would expect to have a bomb, you know. Therefore, they are not interesting anymore, they're not the scapegoat anymore.

Later in our conversation, Andreea also referred to the need for "integration", adding:

I agree with people who want more community integration in terms of people who come from another country. I understand that. But also, Romanians are not immigrants so to speak. Or Polish people are not immigrants in the UK. We are in the European Union. The countries have opened their borders to do business and to exchange of people. So, we are just, you know, moving. I never felt like I was immigrating, never, never.

When taken together, these quotations from Andreea capture an important contradiction that characterises young middle-class Romanian women's cosmopolitanism. On the one hand, Andreea gives the impression that she perfectly embraces the cosmopolitan lifestyle London has to offer. Yet, on the other hand, she makes a clear distinction between the East and the West, claiming the right to belong in the United Kingdom (and even rejecting being categorised as an immigrant) on the grounds of her European identity and EU citizenship. This is strongly reflected in her statements echoing dominant media representations of Muslims as a "typical population which you would expect to have a bomb". In this context, she perceives her legitimacy and recognition within the national context through, to borrow Anderson's (1983) term, a supra-national “imagined community”. This indeed reveals how Europe is articulated through the lens of cosmopolitanism - both as a worldview and a political project - by uniting the people and communities it encompasses. However, such intersections of cosmopolitanism and Europeanism fail to generate a sense of political 
solidarity and unity with "non-Western" ethnic and cultural groups outside of Europe. Therefore, it hints at how Europeanness, as a form of self-identification and citizenship, does not guarantee the development of "a cosmopolitan consciousness" towards cultural difference and diversity (Rumford 2005, 7). In this regard, it resonates with the postcolonial critique of Europe that draws attention to how the cosmopolitan vision of Europe sustains exclusive worldviews, discourses, and practices, fundamentally "othering" peoples and places not considered to be part of the West (Ponzanesi 2018).

In this context, we can also observe in some of the digital practices of the members of this group how they articulate and represent their European political identities and citizenship by engaging with various "European public spaces" (Slade 2014, 732). In contrast to their mediated cosmopolitan cultural performances, which display an acquisition of certain experiences and lifestyles, they use social media platforms to actively engage with a wide range of spaces in which they learn and debate the news and policies of the EU. Hence, it is unsurprising that all of my participants from this group express profoundly negative feelings towards Brexit, and most are members of various pro-EU Facebook groups (such as We are the 48 Percent $^{4 l}$ ). According these participants, during the exhausting Brexit campaigning period, such groups and similar online communities allowed them to feel empowered since they knew that there were many people who disapproved of the stigmatisation and injustice they faced as Romanian immigrants. Through my long-term digital ethnography, I observed how they consistently shared news and issues related to Europe as well as many pro-EU articles and opinion pieces on Facebook. Whilst showing me her latest post on "Tories' lies about European migration", Irina (26) explained to me how Facebook is an important space for her to "educate people about Europe" and show that she is "a true European". She continued:

It is sometimes tiring to get involved or protest or argue with people who may have something stupid to say on something you share, your opinion [on Facebook]. But it's necessary to show that we stand by the EU and believe in Europe. It has its negatives, but it has managed to keep the peace and order in Europe for so long. I always say I am European, even before I am Romanian.

\footnotetext{
${ }^{41}<$ https://www.facebook.com/wearethe48percent>
} 
Even now, writing this chapter more than three years after the Brexit referendum, I frequently encounter how Irina and some other participants still get into heated online debates on the issue of Brexit. This indeed vividly illustrates the role played by social media - in particular, Facebook - in allowing my participants to engage with public performances of European political identity and solidarity. Yet, we also see how cosmopolitan visions and practices do not translate into active politics of solidarity and mobilisation with "non-Western" communities that are marked as the others of Europe - to challenge the nation-state's exclusionary politics of alterity. Rather, they remain limited to strategic and individualised everyday cultural performances of identity.

Therefore, in the light of the discussion presented in this section, it seems that constructions of cosmopolitanism and Europeanism simultaneously articulate the claimmaking practices of young middle-class Romanian women. Through a closer examination of their discursive and digital practices, I discussed how cosmopolitanism primarily operates on a cultural level, whilst Europeanism largely operates on a political level for the members of this group. On the one hand, young middle-class women's online cultural performances reflect how they mediate their right to be recognised as equal citizens by depicting their neoliberal cosmopolitan urban identities and lifestyles in the multicultural city. Yet, the construction and performativity of cosmopolitanism is strongly related to class politics by these educated young women who seek to distance themselves from the working class by gaining a sense of recognition and belonging as members of the urban middle class. On the other hand, their mediated political engagements show that they claim political and legal recognition and equality through Europeanness within the national context. However, as in the case of their Occidental cosmopolitan dispositions, their construction of Europeanism is also selective, since it fails to encompass and create solidarity with those who are seen as the others of Europe. In this context, cosmopolitanism and Europeanism, as two dimensions of their mediated diasporic subjectivities, coalesce in marking some migrants as more entitled to belong to the city and the nation than others. This indeed reveals how the normative and inclusive ideal of a truly "cosmopolitan Europe" is far from being the reality for the migrants themselves, who struggle to ascend the social hierarchies of citizenship. In this context, I argue that social media allows middle-class Romanian women to claim recognition and equality on political and cultural levels through public diasporic identity performances that indeed reinforce classed and racialised migrant hierarchies within a neoliberal and Western European-centric framework. 


\subsection{Conclusion}

I began this chapter by looking at the way in which Romanian migrant women in London use digital media technologies to claim their political and economic rights, and to achieve social recognition as equal citizens in London. I did this by operationalising Isin's (2008b) concept of "acts of citizenship" within a translocal framework, focusing on the social, political, cultural, and symbolic acts through which they articulate, represent, and perform their identities online as equal citizens at the intersections of urban, national and supra-national belongings and power structures. By drawing upon a wealth of empirical material, I have demonstrated how the neoliberal practices of the state, coupled with its racialised discourses, marginalise Romanian migrant women — regardless of their social class positioning — in London. Thus, the strength of the account I present here rests in the manner in which it proves that the nation-state's ethno-centric modes of citizenship materialise in London-one of the most multi-ethnic and multicultural cities in the world. In this context, the notion of acts of citizenship is of profound relevance to gaining an understanding of the digital practices and online identity performances of Romanian migrants who must rely on selfreliance and resilience in order to survive the harsh realities of an increasingly more nationalist and neoliberal country.

The Romanian case, compared to the other two groups in my study, exemplifies the extent to which members of a new migrant community in London must develop a range of symbolic identity performances and alliances if they are to claim recognition and equal rights - those denied by national political and legal bodies. In other words, my analysis illustrates how, for migrants and minorities, citizenship is not only about legal and political rights, but also about navigating social and cultural hierarchies through performative acts of identity that are deemed to permit them to be heard and recognised as equal subjects. In this context, the Romanian migrant women in my study adopt multiple digital practices in order to perform shifting alliances and to engage with different sites of belonging in their endeavours to challenge power geometries at the intersections of their varying social locations of social class, ethnicity, generation, and race. In this context, this chapter demonstrates how the internet and social media platforms become important tools via which these women mediate their varying political, social, and cultural claims to citizenship through shifting performances of identity and belonging. In this mode of mediating their identity and belonging, my participants simultaneously articulate and perform Britishness, Europeanism, 
whiteness, and cosmopolitanism with the purpose of locating themselves as equal and recognised subjects within society.

Yet, the class-specific account I have presented here shows how digital acts of citizenship are far from being collective and unitary for the Romanian migrant community in London. Operating in a hegemonic neoliberal system that puts emphasis on individuals' own "merit of success", my participants aim to achieve social mobility and recognition within a paradigm of "integration" that creates a culture of othering along the lines of social class, ethnicity, and race. As Goldberg $(2013,18)$ writes, "postraciality" is merely an illusion in contemporary American and European contexts in the face of nation-states' neoliberal logics. For Romanian women, Britishness, whiteness, Europeanism, and cosmopolitanism all become discourses and practices of self-production through which they seek to increase or maintain their own social status individually, rather than forming an effective politics of solidarity within and beyond their ethnic community. In this context, the performative and self-representative online practices of Romanian migrant women, along the lines of these varying social constructions, even of cosmopolitanism, aim to align the self with the white majority of Britain and Europe at the dawn of a profound "neoliberalisation of the state and the subsequent individualisation of the social" (Goldberg 2013, 8).

To conclude, my analysis in this chapter demonstrates that there is no uniform manner in which the Romanian migrant women in my study digitally mediate their cultural identities and sense of belonging since their class-specific experiences and material realities in London lead them to position themselves across urban, national, and supra-national social hierarchies in complex, shifting ways. The only common thread is the manner in which, given that their everyday lives in the city shape their own class-biased feelings and experiences, all of them indeed actively articulate their subjectivities through broader national and transnational understandings of identity and community. In this context, the role of digital media should be understood via its ability to allow them to entangle urban, national, and European scales in their performances of translocal diasporic identities with the hope of becoming legitimate members of London, Britain, and Europe. 


\section{Conclusions}

The overarching research question that this thesis set out to answer was how diasporic migrant women living in London mediate their cultural identities at the crossroads of urban and digital spaces. Employing a bottom-up qualitative research approach centered on the subjects' experiences and narratives, the thesis examined the power of digital media in order to establish how it might create the possibility for migrant women to narrate their identities through varying forms, styles, and motivations. Whilst writing this thesis, I often wondered in what ways the contemporary political, economic, and social context of London-a city that is home to hundreds of different cultures - may change in post-Brexit United Kingdom.

On 31 January 2020, the United Kingdom formally left the European Union, entering into a period of transition. This period, in which the United Kingdom can negotiate the details of its future relationship with the rest of the European Union, ended when both sites finally reached an agreement on 24 December 2020. In the 2019 general elections, the Conservative Party made significant gains in historically Labour-held heartlands, indicating how the political map of Britain had changed drastically. The results of the general elections were interpreted by many as a sign of how the public was drawn to the Conservative Party's slogan "Get Brexit Done", with the hope of moving on and gaining some certainty about Britain's future as a non-EU country. ${ }^{42}$ Rather like the Brexit campaign, the issue of immigration was also at the heart of the political campaigns for the general elections in 2019. The election results demonstrate that the Right wing's hardline stance on reducing the number of immigrants and focusing on "integration" policies to restore social cohesion resonated with an important section of the society. Dominant media narratives and populist representations played a significant role in this process by narrowly depicting migration as a political crisis and reducing the identities and experiences of migrants to racialised stereotypes. These political developments often made me feel as if the country in which I chose to pursue my higher education - its multicultural society and civil freedoms - seemed to wane in the midst of deep social divisions, political polarisation, and intolerance. As I am writing these lines now in January 2021, the freedom of movement between the United Kingdom and the European Union has come to an end, and it is not clear how the United Kingdom will weather the political, social, and economic challenges ahead.

\footnotetext{
${ }^{42}<$ https://www.bbc.com/news/world-europe-50746464 >
} 
Nonetheless, I believe that the stories of the migrant women whom I had the opportunity to get to know and whose experiences this thesis documents, shed light upon how the subjects of such hegemonic discourses of alterity experience this particular time in British and European history. Regardless of their different trajectories, ideas, and lifestyles, what unites these women is the desire for equality, recognition, and self-representation in a country where they are now increasingly seen as threatening the foundations of nationhood (Appadurai 2006). Despite the gloomy political atmosphere, in the spirit of the stories of the women who have driven this thesis, I do not want to end on a negative tone. As I have hoped to show in this thesis, these women all keep fighting to counter the hegemonic power structures in which they live and they prove how the politics of identity is part of the contemporary social struggles, woven into the micro-politics of everyday life.

In this concluding part of my thesis, I would like to start my discussion by addressing the sub-research questions and recapping the empirical findings of my study. Then, turning once more to the overarching research question, I introduce the notion of translocal modes of belonging to understand how mediations of diasporic cultural identity can be understood via situated and mobile modes of belonging at intersections of the city and digital media. Finally, I reflect on how this study can generate further developments in the field of diaspora, migration, and digital media by proposing some directions for further research.

\section{Addressing Sub-research Questions}

This section returns to the sub-research questions and addresses them by referring to the empirical findings from chapters 3,4, and 5. The sub-research questions aimed to address the role of the city and digital media in the constitution of everyday lives and cultures. In doing so, they allowed me to operationalise a translocational framework that locates the production of diasporic identity within a multi-spatial framework. This was achieved by delving into the intertwined spatio-temporal contexts of urban, national, and transnational belonging.

\section{Ethnographic Return in the Field of Diaspora, Migration, and Digital Media}

How do migrant women themselves recognise the role of digital media technologies in their everyday lives and cultures? 
In posing this first sub-question, I aimed to understand how migrant women attribute meaning and purpose to digital media technologies within the context of their everyday lives and cultures. My interest in digital media has been informed by a non-media-centric, ethnographic approach that suggests investigating online and offline practices and dynamics together within wider socio-cultural environments. This approach has led me to thematically analyse and to contextualise my empirical discussions in two dimensions that together helped me to present a vivid account of how digital media practices should be seen as integral to the daily experiences and social struggles of migrant women: First, I utilised concepts specific to the internet and digital technologies in my analysis, such as "affordances-in-practice" (Costa 2018) and "scalable sociality" (Miller at al. 2016) ). These concepts allowed me to discuss the participants' digital media practices in relation to the infrastructural characteristics of social media platforms and web applications in a manner that recognises the meaning-making processes that the participants attach to them.

Second, I situated my discussions thematically in line with wider theories from different disciplines of the social sciences and humanities. Each empirical chapter drew upon specific theories, namely: "tactics" (De Certeau 1984) for Turkish migrant women (chapter 3); "performativity" (Butler 2003) for Somali migrant women (chapter 4); and "acts of citizenship" (Isin 2008a) for Romanian migrant women (chapter 5). These theoretical frameworks allowed me to illustrate how digital media practices should be understood in line with specific characteristics, conditions, and processes that lead migrant women to use digital media in forming strategic interventions, cultural performances, and socio-political claimmaking practices respectively.

Furthermore, the "multi-sited" approach I employed allowed me to move back and forth between online and offline spaces revealing the diverse motivations and meaningmaking processes of migrant women in their engagements with websites, social media platforms, and mobile applications used for connectivity, sociality, and self-representation. In this context, I have demonstrated how digital media are integral parts of everyday sociocultural practices through which migrant women establish socio-symbolic connections and boundaries, networks of communication and information, and embody and perform their diasporic selves. As explained in chapter 1, Hall's $(1990,222)$ notion of positions of enunciation refer to the processes through which diasporic identities are constituted by continuously constructing and (re-)imagining histories, cultures, and experiences through cinematic representations. My study reveals how digital practices that serve diverse purposes - from interpersonal communication, to self-representation and political activism- 
allow migrant women to articulate positions of enunciation through which they not only construct, but also live, practice, and experience their diasporic cultural identities. Whilst such practices may be fashioned towards representing and performing a specifically urban diasporic identity, they may also aim to locate diasporic selfhood within the context of national and transnational communities.

Most of the digital practices I have discussed in this thesis would not have been captured had I limited my examination to the "online" domain and focused on hyperlinks, websites, or social media platforms without also conducting complimentary "offline" fieldwork. For example, I could only see how mobile phones become embodied tools via which to claim presence and recognition in the city by spending time with Turkish migrant women in North London and observing their common practice of setting the ezan as a ringtone. Furthermore, I could only unpack the relationship between this particular digital practice and their religious identities and cosmopolitan imaginaries by talking with them and understanding their thoughts, experiences, and feelings regarding both Islam and London (chapter 3). These women do not have a Facebook page, website, or any kind of visible online public presence as a group. Yet digital media are an important component — albeit not one that is publicly visible on the internet at first sight — of how they live their diasporic urban identities through different modes of embodiment and connectivity in a collective manner. In this regard, my study highlights the need to focus on how the digital is also incorporated in the formation of diasporic communities and cultures in the specific localities in which everyday lives are situated.

Furthermore, my approach to view the online and the offline as existing on a continuum demonstrates how researchers may easily fail to see how digital diasporas come into being, often in ways that are not easily visible if they only focus on the digital realm. This happens because digital-centric methodologies tend to focus on public and datatraceable online spaces such as websites, Facebook groups, and Twitter conversations, thus neglecting those spaces that are private and/or smaller in both scope and size. These private and smaller digital spaces are not easily visible to a researcher unless they speak with people about their digital media use, and observe their daily lives and routines. For example, my interviews with first-generation British Somali women uncovered how private WhatsApp groups digitally mediate global diasporic communities. The participants use WhatsApp groups to connect with Somalis across different parts of the world and raise donations to rebuild infrastructure and help people in Somalia. These WhatsApp groups allow firstgeneration British Somali women to feel part of the global Somali diaspora by creating 
transnational networks of connectivity and socialisation based on shared humanitarian incentives (chapter 4).

My empirical discussions also highlight the need to examine the gendered dimension of digitally mediated diasporic formations at the intersection of women's social roles, for example as mothers, workers, friends, and neighbours, and the social categories in which they find themselves, such as generation, religion, and social class. The digital-centric approach that currently dominates the field (Candidatu, Leurs and Ponzanesi 2019; Ponzanesi 2020) overemphasises that which is visible online and, in the case of this research, would have obscured the voices and experiences of migrant women whose digital media practices may be more subtle due to gendered social norms and responsibilities. Thus, if we aim to understand the lives and experiences of migrant women (or any other marginalised social group), we need to acknowledge that the digital is incorporated into the formation of diasporic lives and cultures beyond that which is immediately visible and explicit online.

In her detailed analysis of the history of the media audience, Livingstone (2003) draws attention to how audiences - once seen as passive receivers of the media contenthave, in a contemporary context, through the use of ethnography and the contextualisation of their relationship with the media in socio-culturally situated settings, come to be seen as both active interpreters and users. With the introduction of digital media technologies, she describes how the term "users" has come to mean individuals

who are clicking on hypertext links in order to create a sequential flow of images on the world wide web, typing in order to co-construct the messages of the chat room, externalizing their conception of interface design and genre when producing their website, and manipulating their game character in order to keep the game going.

(Livingstone 2003, 26)

Existing digital-centric research on diaspora, migration, and digital media treats members of digital diasporas solely as users who are only visible as long as they are data-traceable (in the form of hyperlinks, likes, shares, comments, etc.) whilst neglecting their socio-cultural interpretations and meaning-making processes. However, as demonstrated in the rich ethnographic account presented in this thesis, people are not solely "users" detached from their material environments. On the contrary, they are active actors who develop varying modes via which to engage with the internet and digital technologies, and create a dialectic relationship between the digital and the material in their everyday lives and cultures. In this 
context, I argue that we also need an ethnographic "return" in our field, perhaps one similar to that which occurred in audience reception studies. In this way, we might be better able to contextualise digitally mediated sociality and connectivity, and recognise the emotional and socio-cultural significance of the digital domain to individuals without essentialising them as disembodied "users" behind computer and smartphone screens.

\section{Cosmopolitanism, Identity, and Belonging in the City}

What role does London, as migrant women's main site of everyday life, play in the articulation of the relations of the self and others, and different cosmopolitan visions and practices?

In posing the second sub-question, I was interested to learn how London, as the site of everyday life and culture for its inhabitants, impacts upon the ways in which migrant women articulate their relations - both to themselves and others. More precisely, drawing upon Gilroy's (2006) notion of the "everyday conviviality of multiculture" and Bhabha's (2000) notion of "vernacular cosmopolitanism", I aimed to understand how they negotiate cultural difference and diversity in the city whilst giving shape to their diasporic cultural identities.

Diasporic migrant identity in political and public policy circles, as well as in academic literature, has been often discussed in relation to the cultural "integration" of migrants, suggesting that they will eventually adopt the identity of the "host" nation (Fong, Verkuyten and Choi 2016, 559). In this context, this sub-research question has led to one of the most important findings of my thesis, which is that most participants produce and perform their diasporic selves in relation to other ethnic and cultural minorities in the city, rather than the white majority. In the light of such a premise, which recognises how diasporic identities are urban and cosmopolitan, the role of the multicultural city indeed demands that detailed attention be paid to understanding how gendered diasporic subjectivities are not necessarily torn between essentialisms of majority and minority culture.

In my empirical discussions, I analysed how migrant women negotiate the "everyday conviviality" of the city and reveal how a "vernacular cosmopolitan" ethos, and the practices that accompany it, are tied up with their gender-specific everyday realities and routines. The discussion here demonstrates that the way in which migrant women develop their vernacular cosmopolitan ethos and practices should always be examined from an intersectional perspective that accounts for different social categories, such as ethnicity, race, generation, 
religion, and social class. For example, young migrant women from all three communities assert their diasporic urban identities with cosmopolitan performances that depict how they hybridise different cultures in their everyday practices and lifestyles in ways that are inherently tied up with generation-specific cultural references and modes of living. Similarly, religious migrant women from Turkey develop a subtle cosmopolitan ethos and practice that needs to be contextualised within the multicultural context of the migrant neighbourhoods in which they carry out their gendered routines and responsibilities. Although they do not mix with other ethnic and cultural groups, my interviews demonstrate how my religious participants in North London attain positive attitudes towards cultural diversity and develop practices that indicate their sense of belonging in the multicultural urban space as hybrid, diasporic subjects. In this context, whilst these women maintain their particular identities, they see themselves as cosmopolitan subjects and claim to belong in the city via the establishment of Islamic spaces, rituals, and symbols in their neighbourhoods (chapter 3).

As Fenster $(2005,244)$ writes, belonging to the city is "based on the ritualised use of space" and "has a clear gendered dimension". Such claims and appropriation of space(s) in the city are usually "informal" and articulated through performative actions that indicate a form of belonging, expressed via certain practices and repetitions in everyday life (Fenster 2005, 248). The manner in which migrant women express belonging in informal, mundane ways is interwoven with the cosmopolitan ethos and practices outlined above. In this sense, cosmopolitanism is considered to be an "appropriate" performance of the self(Bourdieu 1984 cited in Fenster 2005, 246) in the urban context of London. Thus, cosmopolitanism, as it emerges in my study, is not solely the aspiration to become a "world-citizen". Rather, it is (also) a performative subjectivity that allows women to negotiate different strands of their identity and publicly represent their "difference" — an experience that most do not consider to be possible in any place other than London in white majority Britain. For example, for second-generation British-Somali women, other diasporic youth groups in the city, such as East Asians or Arabs, are inspirational for the way in which they establish their own mediated cultural sites and create instructions and boundaries from the bottom up when constructing and imagining the self. In this context, the urban context and culture of London lead them to relate to other diasporic youth groups as exemplary cultural references and encourage them to also represent and perform their own unique hybrid, diasporic selves by pulling together different strands of their identity, such as race and religion (chapter 4).

Moreover, cosmopolitanism can also be a temporal and contextual orientation for many women who embrace it as a performative cultural identity in the city rather than 
translating their cosmopolitan ethos into political mobilisation and class-based solidarities between different ethnic and cultural minority groups. In this context, cosmopolitanism as a performative identity also serves as a warning, demonstrating how, for many migrant women, it can only be a contextual and temporal cultural orientation, rather than a political identity that translates into social struggles, advocating a more inclusive and multicultural understanding of citizenship in the United Kingdom. This is often the case for those who find themselves in the position to improve their political and socio-economic standing within the contemporary national context via a paradigm of "integration" that implicitly promotes a dominant logic of cultural assimilation. This signals the need to acknowledge how sociopolitical realities play into differently nuanced embodied and mediated performances of cosmopolitanism (Ong 2009). This became most apparent in my empirical discussion of the working-class Romanian migrant women who build non-ethnic social ties and cosmopolitan orientations in London, but still perceive explicit identity performances of Britishness (or Englishness, to be more precise) as the most viable way to be recognised as equal citizens in Britain.

In this context, whilst the city should be recognised for its role in the constitution of cosmopolitan visions and practices, we should also be aware of the ways in which contemporary political alterity in Britain plays into differently nuanced constructions of identity and belonging for migrants and minorities in the wider context of the nation (chapter 5). As Ong $(2009,460)$ argues, critically engaging with cosmopolitanism via an empirical and contextualised approach enables one to capture the tensions implicated in the fabric of everyday life and avoid taking hybridity for granted as a fundamental component of diasporic identities. In this context, in our examination of the city and its cultural diversity, we need to understand how broader national and global workings of power are also interwoven with diasporic identity constructions, rendering cosmopolitanism a contextual identity that we weave in and out of reconciling difference (both our own and that of others) at varying times and in varying contexts (Ong 2009, 452).

\section{Identity, Agency, and Digital Media in the City}

How (if at all) do digital media technologies facilitate the everyday actions and agencies of migrant women in the city? 
This third sub-question was addressed in two ways. First, I examined the ways in which migrant women with different social positions use digital media technologies to create, represent, and embody their subjectivities in the city. Second, I examined how their digital media practices are integral to their daily socio-cultural practices that create networks, alliances, and boundaries in the city. Of course, these two dimensions, rather than being separate, need to be seen as inextricably linked if we are to gain an understanding of how complex maps of identity and belonging are actively drawn by migrant women themselves. The account I have presented in this thesis illustrates how migrant women navigate different points of identification and sites of belonging in the context of shifting social positionings. These navigational strategies highlight the importance of the digital domain in facilitating "actions of emplacement and mobility" (Grossberg 1996, 102) within complex sites of belonging through individualised and collective modes of embodiment, representation, and communication.

As Mack-Canty (2004) highlights, focusing on "everydayness" allows us to see how women claim agency and act in places and contexts that were previously seen as apolitical. Although the migrant groups in my study are positioned differently to one another within the power geometries that emerge at the intersections of varying social categories, each claim their own agency by challenging gendered, ethnicised, religious, generational, and classed marginalisation. For example, as discussed in chapter 3, a number of young Turkish participants use affordances of social media platforms in order to locate themselves as cosmopolitan subjects in the city whilst avoiding political censorship and surveillance. In this context, their digital identity mediations do not reject their national or ethnic belongings, but rather allow them to select which aspects (and to what extent) of these specific identities to express. Similarly, second-generation British-Somali women also position themselves as cosmopolitan subjects in London, albeit for different reasons, in order to challenge racialised and gendered stereotypes imposed upon them (chapter 4). Although these practices may not always be overtly political, they are aimed towards enabling a greater ability to locate themselves and move amongst different points of identification and spaces of belonging. Here, self-emplacement and mobility become resources of agency deployed to increase social status and gain recognition within urban hierarchies. They also become resources via which to articulate subjectivities in a contextual manner, rather than being fixed to the particular social locations imposed upon them by political elites and powerful media institutions. I argue that a productive framework that delves into the "everyday" does not neglect such structural relations, recognising instead how actions are formed within complex power 
geometries that materialise in daily urban life. In this context, digital technologies surely do not overcome the workings of power on their own, but rather become crucial resources of agency and action that facilitate the emergence of contextually defined subjectivities amongst different sites of belonging.

On a general note, if we are to examine the relations between agency, digital media, and the city from a culture-oriented perspective, I argue for the need to establish new theoretical and methodological frameworks. In this regard, the notions of "identity" and "belonging" can help us to grasp how digital media practices are integrated into processes through which self-identifications and networks of alliances become resources of agency in daily urban life. The relationship between identity and agency is an area of great interest to scholars in cultural studies, who see agency as expressions and "possibilities of actions" through which individuals create subjectivities for enacting particular sites of activity, access, and belonging in their social struggles (Grossberg 1996, 99). In this context, legitimising identities, claiming belongingness, and constituting alliances all become actions of agency for those who are located at the bottom of hierarchical structures of subjectivity and seek to counter marginalisation and gain power (Grossberg 1996, 99). In this context, my thesis highlights how the city and digital media can be incorporated within the same theoretical and empirical framework, aimed towards an examination of bottom-up practices and agencies in ongoing processes of identity formation. It does so by employing an analysis of everyday life in the city, enabling us to examine the ways in which identity claims and ways of belonging become actions of agency expressed by migrant women in London.

\section{Intersectionality and Shifting Sites of Belonging}

To what extent does gender, in tandem with the issues of ethnicity, race, social class, generation, and religion, influence how migrant women use digital media technologies and mediate their cultural identities?

The fourth sub-question aimed to analyse the digital mediation of gendered diasporic identity in a manner that takes into account the intertwined spatio-temporal contexts and social locations that shape modalities of power (Anthias 2020). In my empirical chapters, an intersectional approach led me to focus upon various axes of identity and difference, such as social class, gender, religion, generation, and race. These themes were chosen with the aim of illustrating how different political, social, and economic factors render various social 
locations significant in the social struggles that define collective identities and boundaries of difference. Thus, the account I have presented does not see these themes as distinct from each other. On the contrary, it uncovers how different socially constructed axes of identity raise a range of issues in the context of social struggle, and account for specific spatial and temporal factors that play into differently nuanced claims of identity and belonging.

My thesis demonstrates that we cannot come to simplistic conclusions about whether digital media technologies empower migrant women in all spheres of life. As Shaw (2014, 274) writes in relation to embracing intersectionality in our research on the internet and digital technologies, "feminist analysis does not assume tools are inherently bad or good, and always examines technologies in the context of their production and consumption". In this context, the answer to this research question is significant and complex, since the intersections of different social categories not only generate similarities, but also differences in the digital media practices of migrant women.

Anthias' (2002) discussion of collective identity and belonging - in which she invokes the notion of "positionality"- proves helpful here in understanding how the use of an intersectional framework allowed me to understand the relationship between digital media and diasporic cultural formation. Anthias defines positionality both as an identification and an action that describes the "performativity" and agency of subjects who are located at the intersections of different power geometries and develop relations of exclusion and inclusion accordingly (Anthias 2002, 501, 502). In this regard, migrants construct and practice varying collective identities and spheres of belonging in different contexts in order to enunciate their situated locations, alliances, and claims (Anthias 2002, 502). Here, Anthias' theoretical framework provides a useful way to explain how the interplay of a range of social locations - such as gender, race, generation, religion, and class - shape the ways in which migrant women use digital media to construct and practice shifting collective identities and belonging. For example, in chapter 5, I discussed how social class shapes the way in which Romanian migrant women engage with the internet to claim legal rights and social recognition as equal citizens. In this context, social media platforms are used as a means via which to establish non-ethnic social ties and perform cosmopolitan identities in order to selfposition as urban dwellers in the multicultural city. However, their digitally mediated political subjectivities indicate how they also aim to locate themselves as "white" and "European", merely reflecting the hegemonic discourses around race, identity, and culture in Britain and Europe. In this context, their digital media practices are tailored towards moving between shifting sites of belonging, where they form varying relations of we-ness and 
otherness (and inclusion and exclusion) in relation to their positionality amongst different (yet intertwined) political, economic, and cultural power geometries. Here, we see how intersections of social class, race, and ethnicity generate complex social positionalities for migrant women and co-constitute the ways in which how they locate themselves differently on urban, national, and transnational scales. In this context, the digital plays an important role in allowing women to mediate multi-layered diasporic identities by facilitating selfemplacement and mobility across these different sites of belonging.

Furthermore, I see the contribution my thesis makes in its employment of “intersectionality" (Collins 2000; Crenshaw 1989; Davis 1981), highlighting the significance of generation as a social category in the use of the internet and social media platforms. In each empirical chapter of the thesis, I discussed young migrant women as a separate social group by virtue of the greater level of social and cultural flexibility they experience in the types of media and mediated spaces with which they engage in their daily lives and routines (Georgiou 2006, 77). Yet here it is also important to note that I do not want to see young migrant women as a homogenous social group. My empirical chapters clearly demonstrate how young migrant women's subjectivities and experiences operate within broader power structures that position them differently in relation to their specific ethnic, racial, and classed affiliations. Yet I argue that there are important similarities in the ways in which young migrant women from all three communities engage with the internet in their production and consumption of urban and global popular cultures. Cultural spaces open up novel avenues for the construction of youth-oriented social imaginaries and cosmopolitan identities. This becomes most obvious in the way diasporic youth identity is negotiated — with explicit cosmopolitan identity performances and urban aesthetics becoming common themes for young women from all three migrant communities. Both Turkish and Romanian migrant women (who migrated to London as young adults) and second-generation Somali women (who were born and/or raised in London as descendants of Somali refugees) see both London and the digital as "vessels" that allow them to fashion hybrid, diasporic identities in their own unique ways and styles.

\section{Identity and Translocal Modes of Belonging}

As Brickell and Datta (2011) suggest, a translocational lens allows us to see that whilst migrants are embedded in multiple scales - the home, neighbourhood, city, national, and transnational - their social positionalities at each scale varies because of shifting, complex 
power geometries. Whilst some forms of subjectivity, capital, or practices may render migrants "successful" at one scale (such as the city), they might be marginalised at other scales, such as the national or the transnational. Thus, migrants need reflexive identities and different resources to "play the "rules of the game"" in different socio-spatial scales (Brickell and Datta 2011,22). This point is also articulated (albeit slightly differently) by Anthias' (2018) notion of "translocational positionalities", in which she emphasises the roles of urbanity and digitality in shaping shifting social locations of migrants. She argues that "translocational positionalities" are determined by "translocal and transnational dimensions of context and time, including the realities of multicultural and cosmopolitan spaces and digitalised communities, relating to virtual space and time and post coloniality" (Anthias 2018, 13).

My thesis demonstrates how diasporic migrant women in London use digital media to locate themselves and move between different spheres of belonging in relation to their varying social locations and the complex power structures embedded in multi-scalar geographies. More precisely, their diasporic identities are digitally mediated as simultaneously urban, national, and transnational in a social context in which they invoke particular alliances, aesthetics, and performances in each socio-spatial layer. I demonstrate how (self-)emplacement and mobility across different sites of belonging become resources through which migrant women aim to locate their diasporic selves as members of multiple communities and achieve socio-cultural mobility across urban, national, and transnational scales simultaneously.

In chapter 3, I illustrated how the female members of the politicised migrant community from Turkey navigate tense intra-community dynamics. Here, digital technology becomes an important tool for maintaining their established identities, since it facilitates the creation of homogenous and scattered networks of sociality in the city. Thus, their mediated networks articulate particular alliances in relation to their competing political affiliations and the national imaginaries embedded in the modern history of their "home" nation Turkey. They connect London and Turkey, creating a translocational sense of belonging through which relations of "sameness" and "difference" are constructed. Here, we see how translocality as a framework allows us to capture how the digitally mediated connections that migrants produce, create relations that connect the local/urban (London) and the national (Turkey). This offers an alternative perspective to that of transnational social fields, which is chiefly concerned with the presumed prominence of the links between nation-states in the 
construction of migrants' social relations and cultural practices (Porst and Sakdapolrak 2017, 112).

In chapter 4, I discussed how similar patterns emerge, albeit under different social and spatio-temporal dynamics, for the female members of the Somali diaspora in London. In this case, my discussion shows how British-Somali women perform their cultural identity in a manner that permits them to digitally mediate themselves as members of the multicultural city and transnational diasporic community simultaneously. Their diasporic identities are urban, and they claim, on a cultural and social level, to belong in the city. At the same time, their diasporic identities are transnational, and they claim to belong to the (imaginary) global Somali diaspora on an ideational level. In this context, they use the digital realm to perform particularistic aesthetics and attributions that allow them to claim belonging on the level of both the urban and the transnational simultaneously. What we see here is how a translocational framework bypasses the local-global dichotomy and reveals how migrant women's everyday digital media practices connect these two socio-spatial layers by facilitating emplacement and mobility across multiple social and cultural groups.

In chapter 5, in which I discussed the case of Romanian migrant women, I illustrated how broader scales of the national and the regional, and the narrower scale of the urban, become entwined in shaping claim-making practices of citizenship. Romanian migrant women move between different cultural and political sites of belonging in relation to their shifting socio-political positionalities in the context of London, Britain, and Europe. More precisely, whilst their cosmopolitan identity performances aim to position them as legitimate members of the multicultural city, their political alliances and representations reflect the hegemonic racialised discourses of the United Kingdom and Europe, which are deemed to grant higher long-term socio-political status and economic benefits.

In the light of my empirical findings, I see identity and belonging as mutually constituting an entwined map of subjectivity through which migrant women create, move across, and locate themselves in a reflexive manner. By doing so, migrant women use digital media technologies to weave in and out of different spheres of belonging and manage to live their diasporic selves as urban, national, and transnational dwellers simultaneously. Migrant women use digital technologies to create varying alliances, dialogues, and aesthetics in the production of diasporic cultural identity. Thus, their digitally mediated diasporic identity facilitates self-emplacement and mobility across their varying social locations and sociospatial spaces of belonging. Yet these actions of (self-)emplacement and mobility should be 
understood and contextualised in relation to the micro-politics of everyday life that materialise in the city.

In the light of the above, I suggest that diasporic migrant women's mediation of cultural identities can be understood through the notion of translocal modes of belonging. This can be thought of as recognising how different alliances, aesthetics, and performances are digitally evoked to position the diasporic self within a multi-spatial framework. Migrant women use digital media to form alliances with different political groups and utilise gendered, racial, generational and classed aesthetics in varying social and cultural contexts. These alliances and aesthetics not only allow them to connect, socialise and mobilise, but also become part of their diasporic identity performances in urban and digital spaces. Thus, their digitally mediated identities should be understood as modes via which they assert urban, national and transnational belongings and challenge power geometries from the "ground up". In this context, the notion of translocal modes of belonging suggests a recognition of the agency of migrant women in negotiating (and challenging) the implications of different social locations (such as gender, race, religion, class, generation, ethnicity, and nationality) and spaces of belonging (on urban, national, and transnational levels). It recognises that, whilst gendered diasporic cultural identities are formed within intersectional systems of power, the politics of inclusion and exclusion that materialise in the city are always stretched and/or transformed by the national and transnational sense of belonging of the women concerned.

\section{Suggestions for Further Research}

As explained at length in the chapter dealing with methodology, I utilised both qualitative ethnographic, and quantitative data-driven research methods, following the methodological approaches of "digital ethnography" (Pink et al. 2016) and "mixed-methods" (Alinejad et al. 2019; Leurs 2015). These approaches suggest utilising a combination of different perspectives and methodologies in a flexible, unbounded manner depending on research objectives. Driven by my research objective of examining "the everyday", I developed a methodological approach in which I pushed the boundaries between ethnography and digital methods in a manner that utilised digital data for the purpose of supplementing and deepening my ethnographic findings. In this context, I carried out two small-scale sub-projects that utilised digital methods and interpreted these by drawing parallels between my ethnographic insights and the online data gathered. A possible line of further inquiry could be the sharing of digital data with the participants (for example via visual illustrations, as presented in 
Figures 3, 4, 7 and 8) and encouraging them to present their perspectives regarding their interpretation of that data. This research perspective was implemented in the ConnectingEurope project as a methodology shared by the research team (Alinejad et al. 2019). We interviewed a key actor on the issue under investigation - a blood cell donation campaign — and asked his opinion regarding the interpretation of the digital data collected. Not only did this enhance our understanding of how the campaign was disseminated online, but it also achieved a more ethnical stance by including his voice and consent in our knowledge production process (Alinejad et al. 2019, 35).

As a final note, I strongly argue that translocality as a concept and a research perspective that delves into the relations between diaspora, migration, digital media, and the city as a productive and important area for further research. A substantial challenge in my research was the establishment of a framework that encompassed both the situatedness in the city on one hand, and the mobility across different time-space contexts facilitated by digital media on the other. As Smith $(2005,237)$ argues with his theorical synthesis Transnational Urbanism, a translocalised urban research enables the researcher to capture "a sense of distanciated yet situated possibilities for constituting and reconstituting social relations" in a manner that permits one to recognise the social actor's agency as well as structured workings of power. There has been a tendency in the field of media and communications to see space either as too abstract, or even as an insignificant layer of analysis - unworthy of consideration in the age of intense digitally mediated sociality, connectivity and solidarity (Christensen and Jansson 2015, 12). Using a translocational lens, I have embraced the task of theorising the role of the urban and the digital in the articulation of such "distanciated yet situated" social relations. In this context, to borrow Harvey's (2005) term, my thesis is a gesture of recognising space as inherently "relational", and unpacking the agency of migrant women as they challenge "from the ground up" the multi-spatial power structures they encounter. 


\section{Bibliography}

A

Abbasov, N. 2015. The Crisis of Multiculturalism in the UK: Has it Failed? Caucasus International 5(1) (Spring 2015), pp. 85-97.

Abidin, C. 2015. Communicative $\bigcirc$ Intimacies: Influencers and Perceived Interconnectedness. Ada: A Journal of Gender, New Media, and Technology, no. 8. doi:10.7264/N3MW2FFG. [Accessed on 22 August 2019].

Adorno, T. and Horkheimer, M. 1947/1997. The Dialectic of the Enlightenment, trans. J. Cumming. London: Verso.

African Culture Blog. 2016. Mapping London's Somali Community (2016): Discourses, Dilemmas \& Demographics. [Online]. Available at: < https://africanculture.blog/2016/07/22/mapping-londons-somali-community-2016-discoursesdilemmas-demographics/> [Accessed on 28 September 2019].

Ahmed, S. 2000. Strange Encounters: Embodied Others in Post-coloniality. London: Routledge.

Aksoy, A. 2006. Transnational Virtues and Cool Loyalties: Responses of Turkish-Speaking Migrants in London to September 11. Journal of Ethnic and Migration Studies 32 (6), pp. 923-46.

Aksoy, A. and Robins, K. 2000. Thinking Across Spaces: Transnational Television from Turkey. European Journal of Cultural Studies 3(3), pp. 343-65.

Aksoy, A. and Robins, K. 2003. The Enlargement of Meaning: Social Demand in a Transnational Context. Gazette 65(4-5), pp. 365-88.

Alemdar, Z. and Corbacioglu, R. B. 2012. Alevis and the Turkish State. Turkish Politics Quarterly 10(4), pp. 117-24.

Ali, H. 2017. The Story of Us. [e-book]. Available at: < https://marketfiftyfour.com/products/the-story-of-us-e-book-2> [Accessed on 2 July 2019]. Alinejad, D. 2017. The Internet and Formations of Iranian American-ness: Next Generation Diaspora. (e-book). Palgrave Macmillan. Accessed at: < https://link-springercom.proxy.library.uu.nl/book/10.1007\%2F978-3-319-47626-1> [ Accessed on 13 January 2020].

Alinejad, D. 2019. Careful Co-presence: The Transnational Mediation of Emotional Intimacy. Social Media + Society 5(2), pp. 1-11. 
Alinejad, D., Candidatu, L., M. Mevsimler, Minchilli, C., Ponzanesi, S. and Van der Vlist, F. N. 2019. Diaspora and Mapping Methodologies: Tracing Transnational Digital Connections with "Mattering Maps". Global Networks 19(1), pp. 21-43.

Alinejad, D. and Ponzanesi, S. 2020. Migrancy and Digital Mediations of Emotion.

International Journal of Cultural Studies, 23(5), pp. 621-638.

Alonso, A. and Qiarzabal, P. 2010. Diasporas in the New Media Age: Identity, Politics, and Community. Neveda: University of Neveda Press.

Amin, A. 2012. The Land of Strangers. Cambridge, UK: Polity Press.

Amin, A. 2013. Land of strangers. Identities 20(1), pp. 1-8.

Anderson, B. 1983. Imagined Communities: Reflections on the Origin and Spread of Nationalism. London: Verso.

Anderson, B. 1992. Long-distance Nationalism: World Capitalism and the Rise of Identity Politics. Available at: < http://www.mariteslmendoza.com/english242dfiles/WL Anderson.pdf $>$ [Accessed on 30 April 2019].

Andreouli, E. and Howarth, C. 2019. Everyday Cosmopolitanism in Representations of Europe among Romanians in Britain. Sociology 53(2), pp. 280-96.

Ang, I. 2003. 'Together-in-difference: Beyond Diaspora, into Hybridity'. Asian Studies Review 27(2), pp. 141-54.

Anthias, F. 2002.Where do I belong? Narrating Collective Identity and Translocational Positionality. Ethnicities 2(4), pp. 491-514.

Anthias, F. 2009a. Translocational Belonging, Identity and Generation: Questions and Problems in Migration and Ethnic Studies. Finnish Journal of Ethnicity and Migration 4(1), pp. 6-15.

Anthias, F. 2009b. Thinking Through the Lens of Translocational Positionality: An Intersectionality Frame for Understanding Identity and Belonging. Translocations: Migration and Social Change 4(1), pp. 5-20.

Anthias, F. 2018. Identity and Belonging: Conceptualizations and Reframings through a Translocational Lens. In K. Davis, H. Ghorashi, and P. Smets (Eds.), Contested Belonging: Spaces, Practices, Biographies. Emerald Publishing Limited, pp. 137-57. doi:10.1108/978-178743-206-220181007.

Anthias, F. 2020. Translocational Belongings: Intersectional Dilemmas and Social Inequalities. London: Routledge. 
Anthias, F. and Yuval-Davis, N. in association with Harriet Cain. 2005. Racialized Boundaries: Race, Nation, Gender, Colour and Class and the Anti-racist Struggle. London: Routledge.

Appadurai, A. 1995. The Production of Locality. In F. Richard, Counterworks: Managing the Diversity of Knowledge (Ed.). London: Routledge, pp. 204-25.

Appadurai, A. 1996. Modernity at Large: Cultural Dimensions of Globalization: The Human Consequences. Cambridge: Polity Press.

Appadurai, A. 2006. Fear of Small Numbers: An Essay on the Geography of Anger. Durham, CA: Duke University Press.

Arab, P. T. 2015. “A Minaret of Light”: Transducing the Islamic Call to Prayer? Material Religion 11(2), pp. 136-63.

Atay, T. 2010. Ethnicity within Ethnicity among the Turkish-Speaking Immigrants in London. Insight Turkey 12(1), pp. 123-38.

Atkinson, R., Burrows, R., and Rhodes, D. 2016. Capital City? London's Housing Markets and the "Super-rich." In I. Hay and J. Beaverstock (Eds.), International Handbook of Wealth and the Super-rich. London: Edward Elgar, pp. 225-43.

Aurigi, A. 2016. Making the Digital City: The Early Shaping of Urban Internet. London: Routledge.

Azak, U. 2008. Secularism in Turkey as a Nationalist Search for Vernacular Islam: The Ban on the Call to Prayer in Arabic (1932-1950). Revue des mondes musulmans et de la Méditerrané (November 2008), pp. 161-79.

\section{B}

Baban, F. 2016. Cosmopolitanism from the Margins: Redefining the idea of Europe through Postcoloniality. In S. Ponzanesi and D. Colpani (Eds.), Postcolonial in Europe: Contexts, Practices and Politics. London: Rowman \& Littlefield International, pp. 371-391.

Bachmann-Medick, D. and Kugele, J. 2018. Migration: Changing Concepts, Critical Approaches. Berlin: Walter de Gruyter.

Back, L. 1993. Race, Identity and Nation within an Adolescent Community in South London. New Community 19(2), pp. 217-33.

Balibar, E. 2005. Difference, Otherness, Exclusion. Parallax 11(1), pp. 19-34. doi.org/10.1080/1353464052000321074.

Barbero, M. 1993. Communication, Culture and Hegemony: From the Media to Mediations. London: SAGE Publications. 
Basch, L., Schiller, N. G., and Blanc, C. S. 1994. Nations Unbound: Transnational Projects, Postcolonial Predicaments, and Deterritorialized Nation-states. London: Routledge.

Bauman, Z. 2000. Liquid Modernity. Cambridge: Polity Press.

Bhabha, H. 2000. The Vernacular Cosmopolitan. In F. Dennis and N. Khan (Eds.), Voices of the Crossing: The Impact of Britain on Writers from Asia, the Caribbean, and Africa.

Serpent's Tail: London, pp. 133-42.

Bhabha, H. 2015. Foreword. In P. Werbner, T. Madood, and H. Bhabha (Eds.), Debating Cultural Hybridity: Multicultural Identities and the Politics of Anti-Racism. London: Zed Books, pp. ix-xii.

Biressi, A. and Nunn, H. 2013. Crisis and Contemporary British Culture. Basingstoke: Palgrave Macmillan.

Birmingham City Council. 2011. Census 2011 Population and Migration Profile for Wards and Constituencies in Birmingham. Available at:

<https://www.birmingham.gov.uk/downloads/file/4616/census_2011_population_profile_for _small_areas_in_birminghamxls> [Accessed on 12 June 2019].

Boellstorff, T., B., Pearce, N.C. and Taylor, T.L. 2014. Ethnography and Virtual Worlds: A Handbook of Method. Princeton NJ: Princeton University Press.

Bolter, J. D. and Grusin, R. 2000. Remediation: Understanding New Media. Cambridge MA: MIT Press.

Borgerson, J. and Miller, D. 2015. Scalable Sociality and "How the World Changed Social Media": Conversation with Daniel Miller. Available at: < https://discovery.ucl.ac.uk/id/eprint/1549225/1/Miller CMC-Daniel'15-SubmitJb.pdf> [Accessed on 23 September 2019].

Bourdieu, P. 1984. Distinction: A Social Critique of the Judgement of Taste, trans. Richard Nice. London: Routledge \& Kegan Paul.

boyd, D. 2014. It's Complicated: The Social Lives of Networked Teens. New Haven NH : Yale University Press.

Boyd, M. and Grieco, E. 2003. Women and Migration: Incorporating Gender into International Migration Theory. The Online Journal of Migration Policy Institute. [Online]. Available at: < https://www.migrationpolicy.org/article/women-and-migration-incorporatinggender-international-migration-theory> [Accessed on 10 March 2020].

Bozatzis, N. 2016. Cultural Othering, Banal Occidentalism, and the Discursive Construction of the 'Greek Crisis' in Global Media: A Case Study. Suomen Antropologi, 41 (2), pp. 47- 71. 
Bozdağ, Ç. 2019. Bottom-up Nationalism and Discrimination on Social Media: An Analysis of the Citizenship Debate About Refugees in Turkey. European Journal of Cultural Studies, pp. 1-19. doi/10.1177/1367549419869354.

Brah, A. 2005. Cartographies of Diaspora: Contesting Identities. Second edition. New York: Routledge.

Braziel, E. and Mannur, A. 2003. Theorizing Diaspora: A Reader. Malden, MA: WileyBlackwell.

Brennen, B. S. 2017. Qualitative Research Methods for Media Studies. New York: Routledge.

Brickell, K. and Datta, A. 2011. Introduction: Translocal Geographies. In K. Brickell and A. Datta (Eds.), Translocal Geographies Spaces, Places, Connections. Farnham: Ashgate, pp. $3-20$.

Briggs, D. and Dobre, D. 2014. Culture and Immigration in Context: An Ethnography of Romanian Migrants Workers in London. London: Palgrave Macmillan.

Brinkerhoff, J. M. 2009. Digital Diasporas: Identity and Transnational Engagement. New York: Cambridge University Press.

Bryant, R. 2010. The State of Cypriot Silences. The Cyprus Review 22(2) (Fall 2010), pp. $113-22$.

Bucerius, S. M. 2013. Becoming a "Trusted Outsider" : Gender, Ethnicity, and Inequality in Ethnographic Research. Journal of Contemporary Ethnography 42(6), pp. 690-72.

Buikema, R. 2018. The Arena of Imaginings: Sarah Bartmann and the Ethnics of Representation. In R. Buikema, L. Plate and K. Thiele, Doing Gender in Media, Art and Culture: A Comprehensive to Gender Studies. Oxon: Routledge, pp. 81-94.

Butler, J. 2003. Performative Acts and Gender Constitution. In A. Jones (Ed.), Visual Culture Reader. London: Routledge, pp. 392-402.

Byrne, D. N. 2008. The Future of (the) "Race": Identity, Discourse, and the Rise of Computer-mediated Public Spheres. In A. Everett (Ed.), Learning Race and Ethnicity: Youth and Digital Media. Cambridge, MA: MIT Press, pp. 15-38.

C

Candidatu, L., Leurs, K. and Ponzanesi, S. 2019. Digital Diasporas: Beyond the Buzzword: Toward a Relational Understanding of Mobility and Connectivity. In J. Retis and R. Tsagarousianous (Eds.), The Handbook of Diasporas, Media, and Culture. Medford, MA: John Wiley \& Sons, pp. 31-47. 
Carpentier, N. 2007. Translocalism, Community Media and the City. CeMoSo. Working Papers 7. Available at: < http://nicocarpentier.net/workpap/cemeso-07-translocalism.pdf> [Accessed on 1 April 2019].

Christensen, M. 2012. Online Mediations in Transnational Spaces: Cosmopolitan (Re)formations of Belonging and Identity in the Turkish Diaspora. Ethnic and Racial Studies 35(5), pp. 888-905.

Christensen, M. and Jansson, A. 2015. Cosmopolitanism and the Media: Cartographies of Change. London: Palgrave Macmillan.

Christou, F. and Sofos, S. 2019. Physical and Virtual Spaces Among the Palestinian Diaspora in Malmö. In J. Retis and R. Tsagarousianou (Eds.), The Handbook of Diasporas, Media, and Culture. Medford, MA: Wiley Blackwell. Available at:

<https://onlinelibrary.wiley.com/doi/book/10.1002/9781119236771> [Accessed 12 April 2019].

Cicchelli V. and Octobre S. 2018. Aesthetico-cultural Cosmopolitanism and French Youth. Consumption and Public Life: The Taste of the World. Cham: Palgrave Macmillan.

Clifford, J. 1994. Diasporas. Cultural Anthropology 9(3), pp. 302-38.

Clifford, J. 1997. Routes: Travel and Translation in the Late Twentieth Century. Cambridge: Harvard University Press.

Cohen, R. 1996. Diasporas and the State: From Victims to Challengers. International Affairs 72(3) (July 1996), pp. 507-20.

Cohen, R. 2003. "Diaspora": Beyond the Jewish Experience. Public Lecture for the Jacob Gitlin Library, Cape Town 8001, South Africa, 18 September 2003. Available at: < https://s3.amazonaws.com/academia.edu.> [Accessed on 15 March 2020].

Cohen, R. 2008. Global Diasporas: An Introduction. Second edition. London: UCL Press.

Cooke, M. 2007. The Muslimwoman. Contemporary Islam 1, pp. 139-15. DOI 10.1007/s11562-007-0013-z.

Costa, E. 2016. Social Media in Southeast Turkey: Love, Kinship and Politics. E-book. UCL Press. Available at: < https://www-jstor-org.proxy.library.uu.nl/stable/j.ctt1g69z14> [Accessed on 23 March 2019].

Costa, E. 2018. Affordances-in-practice: An Ethnographic Critique of Social Media Logic and Context Collapse. New Media \& Society 20(10), pp. 3641-56.

Collins, P. H. 2000. Black Feminist Thought: Knowledge, Consciousness and the Politics of Empowerment. New York: Routledge.

Couldry, N. 2003a. Media Rituals: A Critical Approach. Routledge: London. 
Couldry. N. 2003b. Passing Ethnographies: Rethinking the Sites of Agency and Reflexivity in a Mediated World. In P. D. Murphy and M. M. Kraidy, Global Media Studies:

Ethnographic Perspectives. New York: Routledge, pp. 40-57.

Couldry, N. 2004. Theorizing Media as Practice. Social Semiotics 14(2), pp. 115-32. DOI:

$10.1080 / 1035033042000238295$.

Couldry, N. 2008. Mediatization or Mediation? Alternative Understandings of the Emergent Space of Digital Storytelling. New Media and Society 10(3), pp. 373-91.

Couldry, N. 2012. Media, Society, World: Social Theory and Digital Media Practice.

Cambridge: Polity Press.

Crenshaw, K. 1989. Demarginalizing the Intersection of Race and Sex: A Black Feminist

Critique of Antidiscrimination Doctrine, Feminist Theory, and Antiracist Politics. University of Chicago Legal Forum, pp. 139-67.

Cruz, E. G. and E. Ardèvol,. 2013. Ethnography and the Field in Media(Ted) Studies: A Practice Theory Approach. Westminster Papers 9(3), pp. 28-45. Available at:

<iEld_iN_MEdiatEd_studiEs-_a_practicE_thEory_approach.pdf?response-contentdisposition=inline $\% 3 \mathrm{~B} \% 20$ filename\%3DEthnography_and_the_Field_in_Media_ted_s.pdf\& X-Amz-Algorithm=AWS4-HMAC-SHA256\&X-Amz-

Credential=AKIAIWOWYYGZ2Y53UL3A\%2F20200206\%2Fus-east-

1\%2Fs3\%2Faws4_request $\& X-A m z-D a t e=20200206$ T152359Z\&X-Amz-Expires=3600\&XAmz-SignedHeaders=host \&X-Amz-

Signature $=613 \mathrm{~b} 5 \mathrm{efb} 4 \mathrm{~b} 9 \mathrm{e} 711559 \mathrm{f} 3 \mathrm{db} 3 \mathrm{~d} 84 \mathrm{~d} 9 \mathrm{~b} 41 \mathrm{f0c} 9719 \mathrm{a} 5480 \mathrm{c} 70 \mathrm{cb} 5 \mathrm{~d} 9118616 \mathrm{a} 146195>$ [Accessed on 6 February 2020].

Ç

Çağlar, A. and Glick Schiller, N. 2018. Migrants and City-making: Dispossession, Displacement, and Urban Regeneration. Durham, CA: Duke University Press.

Çelik, A. B., Bilali R. and Iqbal, Y. 2017. Patterns of "Othering” in Turkey: A Study of Ethnic, Ideological, and Sectarian Polarisation. South European Society and Politics 22(2), pp. 217-38.

D

Datta, A. 2009. Places of Everyday Cosmopolitanisms: East-European Construction Workers in London. Environment and Planning A 41(2), pp. 353-70.

Davis, A. 1981. Women, Race and Class. New York: Random House. 
De Certeau, M. 1984: The Practice of Everyday Life. Berkeley: University of California Press.

Dernie, F., Lewis, K. and McLean, C. 2008. Raising Achievement of Somali Pupils: Good Practice in London Schools. Accessed at: <

https://www.lambeth.gov.uk/rsu/sites/lambeth.gov.uk.rsu/files/Raising Achievement of So mali_Pupils_Good_Practice_in_London_Schools_2008.pdf> [Accessed on 11 August 2019]. Diminescu, D. 2008. The Connected Migrant: An Epistemological Manifesto. Social Science Information 47(4), pp. 565-79.

Diminescu, D. 2012. E-diasporas: The Concept. Available at: < http://www.e-diasporas.fr/>. [Accessed on 5 February 2020].

Diminescu, D. and B. Loveluck. 2015. Traces of Dispersion: Online Media and Diasporic Identities. Crossings: Journal of Migration Culture 5(1), 23-39. DOI: 10.1386/ cjmc.5.1.23. van Doorn, N. 2011. Digital Spaces, Material Traces: How Matter Comes to Matter in Online Performances of Gender, Sexuality and Embodiment. Media, Culture \& Society 33(4), pp. $531-47$.

Dwyer, C. 1998. Contested Identities: Challenging Dominant Representations of Young British Muslim Women. In T. Skelton and G. Valentine (Eds.), Cool Places. London: Routledge, pp. 50-66.

$\mathbf{E}$

Eade, J. 1996. Nationalism, Community, and the Islamization of Space in London. In B. D. Metcalf (Ed.), Making Muslim Space in North America and Europe. Berkeley: University of California Press, pp. 217-234.

Eade, J. 1997. Living the Global City: Globalization as a local process. London: Routledge. Eade, J. and Eckardt, F. 2011. The Ethnically Diverse City. Berlin: BERLINER WISSENSCHAFTS-VERLAG.

Ebin, V. 1996. Making Room versus Creating Space: The Construction of Spatial Categories by Itinerant Mouride Trades. In B. D. Metcalf (Ed.), Making Muslim Space in North America and Europe. Berkeley: University of California Press, pp. 92-110.

Edwards, R. and Mathner, M. 2002. Ethics and Feminist Research: Theory and Practice. Available at: < https://pdfs.semanticscholar.org/f7f8/11c132bd722fbb9b3913f0f46ac72cbd9747.pdf> [Accessed on 16 January 2020]. 
Einashe, I. and Kennard, M. 2018. In the Valley of Death: Somaliland's Forgotten Genocide. [Online]. Available at: < https://pulitzercenter.org/reporting/valley-death-somalilandsforgotten-genocide> [Accessed on 6 August 2019].

Elsayed, H. 2011. A Tale of Three Cities? Mediated Imagination, Class and the Many Young Cosmopolitans of Cairo. $\mathrm{PhD}$ dissertation, LSE. Available at: < http://etheses.1se.ac.uk/407/1/Elsayed_A\%20Tale\%20of\%20Three\%20Cities.pdf> [Accessed on 1 February, 2020].

Elsayed, H. 2016. A Divine Cosmopolitanism? Religion, Media and Imagination in a Socially Divided Cairo. Media, Culture \& Society 38(1), pp. 48-63.

Elshtain, J. B. 2017. Cosmopolitanism and the Claims of Religious Identity. In B. Robbins, and P. L. Horta, Cosmopolitanisms. New York: New York University Press, pp. 127-135. England, K. V. L. 1994. Getting Personal: Reflexivity, Positionality, and Feminist Research. The Professional Geographer 46(1), pp. 80-89.

Everett, A. 2009. Digital Diaspora: A Race for Cyberspace. Albany, NY: State University of New York Press.

$\mathbf{F}$

Fenster, T. 2005. Gender and the City: The Different Formations of Belonging. In L. Nelson and J. Seager (Eds.), A Companion to Feminist Geography. Oxford: Blackwell, pp. 242-57. Flick, U. 2009. An Introduction to Qualitative Research. London: Sage.

Fong, E., Verkuyten, M. and Choi, S. Y. P. 2016. Migration and Identity: Perspectives from Asia, Europe, and North America. American Behavioural Scientist 60(5-6), pp. 559-64.

Fraser, N. 1995. From Redistribution to Recognition? Dilemmas of Justice in a "PostSocialist” Age. New Left Review. Available at: <http://bibliopreta.com.br/wpcontent/uploads/2018/01/Fraser-Redistribution-Recognition-Dilema-1.pdf> [Accessed on 2 November 2020].

$\mathbf{G}$

Galasińska, A. 2010. Leavers and Stayers Discuss Returning Home: Internet Discourses on Migration in the Context of Post-Communist Transformation. Social Identities: Journal for the Study of Race, Nation and Culture 16(3), pp. 309-24.

Georgiou, M. 2005. Diasporic Media Across Europe: Multicultural Societies and the Universalism-Particularism Continuum. Journal of Ethnic and Migration Studies 31(3), pp. 481-98. ISSN 1469-9451. 
Georgiou, M. 2006. Diaspora, Identity and the Media: Diasporic Transnationalism and Mediated Spatialities. Cresskill, NJ: Hampton Press.

Georgiou, M. 2010. Identity, Space and the Media: Thinking through Diaspora. Les médias des minorités ethniques 26(1), pp. 17-35.

Georgiou, M. 2012. Introduction: Gender, Migration and the Media. Ethnic and Racial Studies 35(5), pp. 791-99. ISSN 0141-9870.

Georgiou, M. 2013. Media and the City: Cosmopolitanism and Difference. Cambridge. Polity Press.

Georgiou, M. 2017. Is London Open? Mediating and Ordering Cosmopolitanism in Crisis. International Communication Gazette 79(6-7), pp. 636-655..

Giddens, A. 1991. Modernity and Self-identity: Self and Society in the Late Modern Age. Cambridge: Polity Press.

Giglou, R. I., d'Haenens, L. and Ogan, C. 2018. Social Media Responses of the Turkish Diaspora to Protests in Turkey: The Impact of Gezi on Attitude and Behavioural Change. In K. H. Karim and A. Al-Rawi. 2018. Diaspora and Media in Europe: Migration, Identity, and Integration. E-book. Palgrave Macmillan, Cham pp. 97-125. Available at: < https://linkspringer-com.proxy.library.uu.nl/book/10.1007\%2F978-3-319-65448-5> [Accessed on 22 March 2019].

Gilroy, P. 1993. The Black Atlantic: Modernity and Double Consciousness. Cambridge, MA: Harvard University Press.

Gilroy, P. 2006. Postcolonial Melancholia. New York: Columbia University Press. Goldberg, D. T. 2013. The Postracial Contemporary. In N. Kapoor, V. S. Kalra, and J. (Eds.), The State of Race. Basingstoke: Palgrave Macmillan, pp. 15-30.

Gole, N. 2011. The Public Visibility of Islam and European Politics of Resentment: The Minarets-Mosques Debate. Philosophy and Social Criticism 37(4), pp. 383-92.

Greiner, C. and Sakdapolrak, P. 2013. Translocality: Concepts, Applications and Emerging Research Perspectives. Geography Compass 7(5), pp. 373-84.

Grigoriadis, I. N. 2007. Turk of Turkiyeli? The Reform of Turkey's Minority Legislation and the Rediscover of Ottomanism. Middle Eastern Studies 43(3), pp. 423-38.

Grossberg, L. 1996. Identity and Cultural Studies: Is that All There Is? In S. Hall and P. Du Gay (Eds.), Questions of Cultural Identity. London: Sage Publications, pp. 87-107.

Guerin, P., Elmi, F. H. and Guerin, B. 2006. Weddings and Parties: Cultural Healing in One Community of Somali Women. Australian e-Journal for the Advancement of Mental Health (AeJAMH) 5(2), pp. 105-12. 
Gundel, J. 2009. Clans in Somalia. Available at: <

https://www.refworld.org/pdfid/4b29f5e82.pdf> [Accessed on 1 August 2019].

Gustafson, P. 2001. Roots and Routes: Exploring the Relationship between Place Attachment and Mobility. Environment and Behavior 33(5), pp. 667-86.

\section{$\mathbf{H}$}

Hall, S. 1990. Cultural Identity and Diaspora. In J. Rutherford, Identity: Community, Culture, Difference. London: Lawrence \& Wishart, pp. 222-37.

Hall, S. 1996. Who Needs "Identity"? In S. Hall and P. du Gay, Questions of Cultural Identity. London: Sage Publications, pp. 1-17.

Hall, S. 2000. The Multicultural Question. The Political Economy Research Center Annual Lecture. 4 May 2000. Available at: < https://red.pucp.edu.pe/wpcontent/uploads/biblioteca/Stuart_Hall_The_multicultural_question.pdf> [Accessed on 21 May 2020].

Hall, S. 2008. Cosmopolitanism, Globalisation and Diaspora. In P. Werbner (Eds.), Anthropology and the New Cosmopolitanism. Oxford: Berg, pp. 345-361.

Hammond, L. 2007. Obliged to Give: Remittances and the Maintenance of Transnational Networks Between Somalis at Home and Abroad. Bildhaan: International Journal of Somali Studies 10, pp. 125-51.

Haraway, D. 1988. Situated Knowledges: The Science Question in Feminism and the Privilege of Partial Perspective. Feminist Studies 14(3) (Autumn 1988), pp. 575-99. Harvey, D. 2005. Cosmopolitanism and the Geographies of Freedom. New York: Columbia University Press.

van Hear, N. 1998. New Diasporas: The Mass Exodus, Dispersal and Regrouping of Migrant Communities. London: UCL Press.

van Hear, N. 2009. The Rise of Refugee Diasporas. Current History 108(717), pp. 180-85. Hegde, R. S. 2016. Mediating Migration. Cambridge: Polity Press.

Herman, E. S., and Chomsky, N. 1988. Manufacturing Consent: The Political Economy of the Mass Media. New York: Pantheon.

Higgins, P., Campanera, N. and Nobajas, A. 2014. Quality of Life and Spatial Inequality in London. European Urban and Regional Studies 21(1), pp. 42-59. DOI: 10.1177/0969776412439201.

Hill, M. 2010. No Redress. Somalia's Forgotten Minorities: Report by Minority Rights Group International. Available at: < https://minorityrights.org/wp-content/uploads/old-site- 
downloads/download-912-Click-here-to-download-full-report.pdf> [Accessed on 3

September 2019].

Hine, C. 2008. Ethnographies of Online Communities: Modes, Varieties, Affordances. In N.

Fielding, M. L Raymond, and G. Blank (Eds.), The SAGE Handbook of Online Research

Methods. London: SAGE, pp. 402-413.

Hine, C. 2015. Ethnography for the Internet: Embedded, Embodied and Everyday. London:

Bloomsbury.

Hopkins, G. 2010. A Changing Sense of Somaliness: Somali Women in London and Toronto. Gender, Place \& Culture 17(4), pp. 519-38.

Horst, C. 2008. The Transnational Political Engagements of Refugees: Remittance Sending Practices Amongst Somalis in Norway. Conflict, Security \& Development 8(3), pp. 317-39.

Horst, C. 2013. The Depoliticisation of Diasporas from the Horn of Africa: From Refugees to Transnational Aid Workers. African Studies 72(2), 228-45.

Hutchby, I. 2001. Technologies, Texts and Affordances. Sociology 35(2), pp. 441-56. doi:10.1177/S0038038501000219.

I

Isin, E. (Ed.) 2008a. Recasting the Social in Citizenship. Toronto: University of Toronto Press.

Isin, E. 2008b. Theorizing Acts of Citizenship. In E. F. Isin and G. M. Nielsen (Eds.), Acts of Citizenship. London: Palgrave Macmillan, pp. 15-43.

Isin, E., Brodie, J, Juteau, D. and Stasiulus, D. 2008. Recasting the Social in Citizenship. In

E. Isin (Ed.), Recasting the Social in Citizenship. Toronto: University of Toronto Press, pp.320 .

Isin, E. and Ruppert, E. 2015. Being Digital Citizens. London: Rowman \& Littlefield International.

Irimie, C. 2006. Second-class Citizens. The Guardian. 26 October 2016. Available at: <https://www.theguardian.com/commentisfree/2006/oct/26/comment.politics $>$. [Accessed 12 September 2018].

\section{$\mathbf{J}$}

Jassal, S. T. 2014. The Sohbet: Talking Islam in Turkey. Sociology of Islam 1(3-4). (Online). Available at: 〈https://brill.com/view/journals/soi/1/3-4/article-p188 5.xml?lang=en> [Accessed on 3 March 2019]. 
Jensen, O. B. 2019. On the Move: On Mobile Agoras, Networked Selves, and the Contemporary City. In Z. Krajina and D. Stevenson. 2019. The Routledge Companion to Urban Media and Communication. New York: Routledge, pp. 96-106.

Joppke, C. 1996. Multiculturalism and Immigration: A Comparison of the United States, Germany, and Great Britain. Theory and Society 25(4), pp. 449-500.

$\mathbf{K}$

Kaula, F. 2009. Homi Bhabha's Third Space and African identity. Journal of African Cultural Studies 21(1), pp. 23-32.

Keith, M. 2005. After the Cosmopolitan? Multicultural Cities and the Future of Racism. London: Routledge.

Keles, J. Y. 2015. The Politics of Religious and Ethnic Identity among Kurdish Alevis in the Homeland and in Diaspora. In K. Omarkhali (Ed.), Religious Minorities in Kurdistan: Beyond the Mainstream. Series: Studies in Oriental Religions 68, pp. 173-24. Available at: $<$ https://www.researchgate.net/publication/275658965_The_Politics_of_Religious_and_Ethn ic Identity among Kurdish Alevis in the Homeland and in Diaspora> [accessed on 8 April 2019].

King, A. D. 2007. Boundaries, Networks and Cities. In A. Cinar and T. Bender (Eds.), Urban Imaginaries: Locating the Modern City. Minneapolis: University of Minnesota Press, pp. 114.

Kok, S. and Rogers, R. 2016. Rethinking Migration in the Digital Age: Transglocalization and the Somali Diaspora. Global Networks 17(1), pp. 23-46. DOI: 10.1111/glob.12127. Kozinets, R. V. 2009. Netnography: Doing Ethnographic Research Online. London: SAGE. Krajina, Z., Moores, S., and Morley, D. 2014. Non-media-centric Media Studies: A Crossgenerational Conversation. European Journal of Cultural Studies 17(6), pp. 682-700. Krajina, Z. and Stevenson, D. 2019. On the Move: On Mobile Agoras, Networked Selves, and the Contemporary City. In Z. Krajina and D. Stevenson, In Routledge Companion to Urban Media and Communication. New York: Routledge, pp. 96-106.

$\mathbf{L}$

Lacroix, T. and Fiddian-Qasmiyeh, E. 2013. Refugee and Diaspora Memories: The Politics of Remembering and Forgetting. Journal of Intercultural Studies 34(6), pp. 684-69.

Lane, J. 2016. The Digital Street: An Ethnographic Study of Networked Street Life in Harlem. American Behavioral Scientist 60(1), pp. 43-58. 
Lane, J. 2018. The Digital Street. New York: Oxford University Press.

Lefebvre, H. 1991. The Production of Space, trans. Donald Nicholson-Smith. Oxford:

Blackwell.

Leurs, K. 2015. Digital Passages: Migrant Youth 2.0. Diaspora, Gender and Youth Cultural Intersections. Amsterdam: Amsterdam University Press.

Leurs, K. and Georgiou, M. 2016. Digital Makings of the Cosmopolitan City: Young

People's Urban Imaginaries of London. International Journal of Communication 10, pp. 3689-709.

Leurs, K., Georgiou, M., McQuire, S., Vuolteenaho, J, and Sumiala, J. 2015. The Politics and Praxis of Media-City Research: A Duo Interview with Myria Georgiou and Scott McQuire. Observatorio. 9, pp. 193-208.

Levitt, P., and Schiller, N. G. 2006. Conceptualizing Simultaneity: A Transnational Social Field Perspective on Society. International Migration Review 38, pp. 1002-39. doi:10.1111/j.1747-7379.2004.tb00227.x.

Liberatore, G. 2013. Transforming the Self: An Ethnography of Ethical Change Amongst Young Somali Muslim Women in London. PhD thesis, The London School of Economics and Political Science (LSE). Available at: < http://etheses.lse.ac.uk/743/> [Accessed on 10 August 2019].

van Liempt, I. 2011. “And Then One Day They All Moved to Leicester": The Relocation of Somalis from the Netherlands to the UK Explained. Population, Space and Place 17, pp. 254-66.

Lindley, A. 2010. The Early Morning Phone call: Somali Refugees' Remittances. Oxford: Berghahn Books.

Lister, M., Dovey, J., Giddins, S., Grant, I. and Kelly, K. 2009. New Media: A Critical Introduction. Second Edition. Oxon: Routledge.

Livingstone, S. 2000. On the Cutting Edge, or Otherwise, of Media and Communication Research. Nordicom Review 21(2), pp. 7-13.

Livingstone, S. 2003. The Changing Nature of Audiences: From the Mass Audience to Interactive Media User. In A. N. Valdivia (Ed.), A Companion to Media Studies. Oxford: Wiley-Blackwell, pp.337-359.

London Datastore. 2011. 2011 Census Diversity. Available at: <https://data.london.gov.uk/dataset> [Accessed on 26 June 2019].

Loveluck, M. 2017. "My Coming Out Story": Lesbian, Gay and Bisexual Youth Identities on YouTube. International Journal of Cultural Studies 22(1), pp. 70-80. 
Lulle, A., Moraşanu, L. and King, R. 2018. And Then Came Brexit: Experiences and Future Plans of Young EU Migrants in the London Region. Population, Space and Place 24(1), pp. 1-11. https://doi.org/10.1002/psp.2122.

\section{M}

Mack-Canty, C. 2004. Third-wave Feminism and the Need to Reweave the Nature/Culture Duality. NWSA Journal 16(3) (Autumn 2004), pp. 154-79.

MacLeod, G. 2018. The Grenfell Tower Atrocity. City 22(4), pp. 460-89.

Madianou, M. 2005. Mediating the Nation. London: UCL Press.

Madianou, M. and Miller, D. 2012. Migration and New Media: Transnational Families and Polymedia. London: Routledge.

Marchetti, S. and Salih, R. 2017. Policing Gender Mobilities: Interrogating the "Feminisation of Migration" to Europe. International Review of Sociology 27(1), pp. 6-24.

Marwick, A. E., and boyd, d. 2011. I Tweet Honestly, I Tweet Passionately: Twitter Users, Context Collapse, and the Imagined Audience. New Media \& Society 13(1), pp. 114-33. https://doi.org/10.1177/1461444810365313.

Massey, D. 2007. World City. Cambridge: Polity Press.

Massicard, E. 2005. Alevi Hareketinin Siyasallasmasi. Istanbul: Iletisim Yayinlari.

Mathieu, F. 2017. The Failure of State Multiculturalism in the UK? An Analysis of the UK's Multicultural Policy for 2000-2015. Ethnicities 18(1), pp. 43-69.

McDowell, L. 2009. Old and New European Economic Migrants: Whiteness and Managed Migration Policies. Journal of Ethnic and Migration Studies 35(1), pp. 19-36.

McGown, R. B. 1999. Muslims in the Diaspora: The Somali communities of London and Toronto. Toronto: University of Toronto Press.

McLuhan, M. 1964. Understanding Media: The Extensions of Man. London: McGraw-Hill. McMichael, C. 2002. "Everywhere is Allah's Place:” Islam and the Everyday Life of Somali Women in Melbourne, Australia. Journal of Refugee Studies 15(2), pp. 171-88.

McQuire, S. 2008. The Media City: Media, Architecture and Urban Space. London: Sage Publication.

McQuire, S. 2016. Geomedia: Networked Cities and the Future of the Public Space.

Cambridge: Polity Press.

Mehri, M. n.d. Our Father, Who art in Hendon. (Online). Available at: < https://nationalpoetryday.co.uk/poem/our-father-who-art-in-hendon/> [Accessed on 7 December 2020]. 
Meer, N. and Madood, T. 2005. Public and Political Debates on Multicultural Crisis in Britain. < http://www.eliamep.gr/wp-

content/uploads/en/2008/05/uk report multicultural discourses final.pdf> [Accessed on 18 May 2020].

Merriam, S., Ntseane, G., Lee, M., Kee, Y. Johnson-Bailey, J. and Muhamad, M. 2000.

Power and Positionality: Negotiating Insider/Outsider Status in Multicultural and Cross-

Cultural Research. Adult Education Research Conference. (Online). Available at:

<https://newprairiepress.org/aerc/2000/ symposia/3 > [Accessed on 19 March 2020].

Metcalf, B. D. (Ed.) 1996. Making Muslim Space in North America and Europe. Berkeley:

University of California Press.

Meyer, B. 2009. Aesthetic Formations: Media, Religion, and the Senses. New York:

Palgrave.

Miller, D. and Slater, D. 2000. The Internet: An Ethnographic Approach. New York: Berg Press.

Miller, Daniel, Costa, E., Haynes, N., McDonald, T., Nicolescu, R., Sinanan, J. Spyer, J., Venkatraman, S. and Wang, X. 2016. "What Is Social Media?" In How the World Changed Social Media, London: UCL Press, pp. 1-8. Available at: < http://www.jstor.org/stable/j.ctt1g69z35.8.> [Accessed on 17 October 2020].

Moncrieffe, J. 2007. "Labelling, Power and Accountability: How and Why Our Categories Matter”. In J. Moncrieffe and R. Eyben (Eds.), Power of Labelling: How People Are Categorised and Why It Matters. London: Earthscan, pp. 1-16.

Moores, S. 2006. Media Uses and Everyday Environmental Experiences: A Positive Critique of Phenomenological Geography. Participations: Journal of Audience \& Reception Studies 3(2). Available at: <www.participations.org/volume\%203/issue \%202\%20-\%20special/3_02 moores.htm> [Accessed 2 March 2019].

Moraşanu, L. 2013a. "We All Eat the Same Bread": The Roots and Limits of Cosmopolitan Bridging Ties Developed by Romanians in London. Ethnic and Racial Studies 36(12), pp. 2160-81.

Moraşanu, L. 2013b. Between Fragmented Ties and "Soul Friendships": The Cross-border Social Connections of Young Romanians in London. Journal of Ethnic and Migration Studies 39(3), pp. 353-72.

Morley, D. 1991. Where the Global Meets the Local: Notes from the Sitting Room. Screen 32(1), pp. 1-15.

Morley D. 2000. Home Territories: Media, Mobility and Identity. London: Routledge. 
Morley D. 2010. Television as a Means of Transport: Digital Teletechnologies and Transmodal Systems. In J. Gripsrud (Ed.), Relocating Television: Television in the Digital Context. London: Routledge, pp. 257-70.

Morley, D and Robins, K. 1995. Spaces of Identity: Global Media, Electronic Landscapes and Cultural Boundaries. London: Routledge.

Murphy, P. D. 2011. Locating Media Ethnography. In V. Nightingale (Ed.), The Handbook of Media Audiences. Chichester: Blackwell, pp. 380-403.

Murphy, P. D. and Kraidy, M. M. 2003. Media Ethnography: Local, Global, or Translocal? In P. D. Murphy and M. M. Kraidy (Eds.), Global Media Studies: An Ethnographic Perspective. New York: Routledge, pp. 299-308.

Murray, L. 2014. "Diaspora". Britannica. (Online). Available at: < https://www.britannica.com/topic/diaspora-social-science> [Accessed on 30 October 2020].

$\mathbf{N}$

Naficy, H. 2003. Narrowcasting in Diaspora: Middle Eastern Television in Los Angeles. In K. Karim (Ed.), The Media of Diaspora. London: Routledge, pp. 51-62.

Natale, S. 2016. There Are No Old Media. Journal of Communication 66 (4), pp. 585-603. doi: $10.1111 /$ jcom.12235.

Nava, M. 2002. Cosmopolitan Modernity: Everyday Imaginaries and the Register of Difference, Theory Culture Society 19(1-2), pp. 81-99.

Nedelcu, M. 2012. Migrants' New Transnational Habitus: Rethinking Migration Through a Cosmopolitan Lens in the Digital Age. Journal of Ethnic and Migration Studies 38(9), pp. $1339-56$.

\section{$\mathbf{O}$}

Oakley, K., Laurison, D., O’Brien, D. and Friedman, S. 2017. Cultural Capital: Arts Graduates, Spatial Inequality, and London's Impact on Cultural Labour Markets. American Behavioural Scientist 61(12), pp. 1510-31.

Office for National Statistics. 2017. Population of the UK by Country of Birth and Nationality: 2017 (Online). Available at:< https://www.ons.gov.uk/peoplepopulationandcommunity/populationandmigration/internation almigration/datasets/populationoftheunitedkingdombycountryofbirthandnationality> [Accessed 3 October 2019]. 
Office for National Statistics. 2018. Population of the UK by Country of Birth and Nationality: 2018. Available at:<

https://www.ons.gov.uk/peoplepopulationandcommunity/populationandmigration/internation almigration/datasets/populationoftheunitedkingdombycountryofbirthandnationality > [Accessed 1 October 2019].

Office for National Statistics. 2019. Migration Statistics Quarterly Report: August 2019. Available at: < https://www.ons.gov.uk/peoplepopulationandcommunity/populationandmigration/internation almigration/datasets/populationoftheunitedkingdombycountryofbirthandnationality> [Accessed 1 October 2019].

Olden, A. 1999. Somali Refugees in London: Oral Culture in a Western Information Environment. Libri-Copenhagen 40, pp. 212-24. Available at: <http://harep.org/ifaapr/19994pp212-224.pdf> [Accessed 13 July 2010].

Ong, J.C. 2009. Cosmopolitanism. Media, Culture \& Society 31(3), pp. 449-66.

Ong, J. 2019. Toward an Ordinary Ethics of Mediated Humanitarianism: An Agenda for Ethnography. International Journal of Cultural Studies 22(4), pp. 481-98.

Open Society Foundations. 2013. Somalis in London: Somalis in European Cities. Available at: < https://www.opensocietyfoundations.org/uploads/cfbed57a-9d85-454f-9e8dd65b3aeaf1b9/somalis-london-20141010.pdf> [Accessed on 30 September 2019]. Open Society Foundations. 2015. Somalis in European Cities: Overview. Available at: <https://www.opensocietyfoundations.org/uploads/0c066f1c-9980-4b5c-a66d10ebed919d24/somalis-europe-overview-20150803.pdf> [Accessed on 10 January 2021]. Osman, I. 2017. Media, Diaspora and the Somali Conflict. London: Palgrave Macmillan.

\section{$\mathbf{P}$}

Palmary, I., Burman, E., Chantler, K. and Kiguwa, P. 2013. Gender and Migration: Feminist Interventions. London: Zed Books.

Parreñas, R. S. 2015. Servants of Globalization: Migration and Domestic Work: Second edition. Stanford, CA: Stanford University Press.

Pink, S., Horst, H., Postill, J., Hjorth, L., Lewis, T. and Tacchi, J. 2016. Digital Ethnography: Principles and Practice. London: Sage.

Pink, S. and Morgan, J. 2013. Short-term Ethnography: Intense Routes to Knowing. Symbolic Interaction 36(3), pp. 351-61. 
Pollock, S., Bhabha, H., Breckenrigde, C. A. and Chakrabarty, D. 2002. Cosmopolitanisms. In Breckenrigde, C.A, Pollock, S., Bhabha, H. and Chakrabarty, D. 2002. Cosmopolitanism [Kindle e-reader]. pp. 1-13.

Ponzanesi, S. 2018. Cosmopolitan Europe: Postcolonial Interventions and Global Transitions. In G. Delanty (Ed.), Routledge International Handbook of Cosmopolitan Studies. London: Routledge, pp. 564-57. Available at: 〈http://ebookcentral.proquest.com>. [Accessed on 12 December 2019].

Ponzanesi, S. 2020. Digital Diasporas: Postcoloniality, Media and Affect. Interventions. 22(8), pp. 977-993. DOI: 10.1080/1369801X.2020.1718537.

Porst, L. and Sakdapolrak. P. 2017. How Scale Matters in Translocality: Uses and Potentials of Scale in Translocal Research. Erdunke 71(2), pp. 111-26.

Preissle, J. 2006. Feminist Research Ethics. Available at: < http://citeseerx.ist.psu.edu/viewdoc/download?doi=10.1.1.463.2877\&rep=rep1\&type=pdf $>$ [Accessed on 2 January 2020].

\section{$\mathbf{R}$}

Ran, N.H. n.d. Optimism. (online). Available at:< https://www.hurriyetdailynews.com/turkeys-poet-of-hope-nazim-hikmet-155280>. [ Accessed 25 December 2020].

Retis, J. and Tsagaraousianous, R. 2019. Diasporas, Media, and Culture: Exploring Dimensions of Human Mobility and Connectivity in the Era of Global Interdependency. In J. Retis and R. Tsagarousianous (Eds.), The Handbook of Diasporas, Media, and Culture. Medford, MA: John Wiley \& Sons, pp. 1-20.

Rieder, B. 2013. Studying Facebook via data extraction: the Netvizz application. WebSci '13: Proceedings of the 5th Annual ACM Web Science Conference, pp. 346-355. Available at:< https://dl.acm.org/doi/10.1145/2464464.2464475>. [Accessed 06 January 2021].

Rigoni, I. 2002. Turkish and Kurdish Media Production in Europe: A Comprehensive Overview. EMTEL project report. Available at: < www.lse.ac.uk/collections/EMTEL/Minorities/.papers/turkishkurdimedia.pdf> [Accessed on 22 April 2019].

Rogers, R. 2013. Digital Methods. Cambridge: MA: MIT Press.

Rose, N. 1996. Identity, Genealogy, History. In S. Hall and P. du Gay (eds), Questions of Cultural Identity. London: Sage Publications, pp. 128-151. 
Rumford, C. 2005. Cosmopolitanism and Europe. Innovation: The European Journal of Social Science Research (18)1, pp. 1-9.

\section{$\mathbf{S}$}

Safran, W. 1991. Diasporas in Modern Societies: Myths of Homeland and Return. Diaspora: A Journal of Transnational Studies 1(1), pp. 83-99.

Said, E. 1978. Orientalism. New York: Random House, Vintage Books.

Samatar, A. 1992. Destruction of State and Society in Somalia: Beyond the Tribal

Convention. The Journal of Modern African Studies 30(4), pp. 625-41.

Samatar, A. 2016. Somalia: The Forgotten Story. [Online]. Available at: < https://www.youtube.com/watch?v=-io RfLBpgc\&t=1023s > [Accessed on 1 June 2019]. Saner, G. and Dedeoğlu, S. 2017. Turkish/Kurdish Women's Migrant Steps in London: Public Walks/Personal Returns. In G. E. Lelandais and Y. Şentürk (Eds.), Identity, Justice and Resistance in the Neoliberal City. London: Palgrave, pp. 171-96.

Sassen, S. 1991. The Global City: New York, London, Tokyo. Oxford: Princeton University Press.

Schiller, G. N. and Çağlar, A. 2013. Locating Migrant Pathways of Economic Emplacement: Thinking Beyond the Ethnic Lens. Ethnicities 13(4), pp. 1-30.

Schiller, G. N., Darieva, T. and Gruner-Domic, S. 2011. Defining Cosmopolitan Sociability in a Transnational Age. An introduction Ethnic and Racial Studies 34(3), pp. 399-418.

Scott, K. 2016. The Digital City and Mediated Urban Ecologies. E-book: Palgrave Macmillan:

Sehlikoglu, S. 2016. The Daring Mahrem: Changing Dynamics of Public Sexuality in Turkey. In G. Ozyegin (ed), Gender and Sexuality in Muslim Culture. London: Ashgate, pp. 235-52.

Shahi, A. 2010. The Failure of British Multiculturalism and the Virtue of Reciprocity. (Online). Available at: < https://www.opendemocracy.net/en/opendemocracyuk/failure-ofbritish-multiculturalism-and-virtue-of-reciprocity/> [Accessed on 31 August 2020].

Shaw, A. 2014. The Internet is Full of Jerks, Because the World is Full of Jerks: What Feminist Theory Teaches Us About the Internet. Communication and Critical/Cultural Studies 11(3), pp. 273-77. DOI:10.1080/14791420.2014.926245.

Shaw, A. 2017. Encoding and Decoding Affordances: Stuart Hall and Interactive Media Technologies. Media, Culture \& Society 37(4), pp. 592-602. 
Shire, W. n.d. Home. Available at: < https://www.theguardian.com/books/2015/sep/16/poetsspeak-out-for-refugees-> [Accessed on 14 October 2020].

Siapera, E. 2010. Cultural Diversity and Global Media: The Mediation of Difference. Oxford: Blackwell.

Silverstone, R. 2005. The Sociology of Mediation and Communication. In C. Calhoun, C.

Rojek, and B. Turner (Eds.), The Sage Handbook of Sociology. London: Sage, pp. 188-207.

Sirkeci, I. 2003. Migration, Ethnicity and Conflict: The Environment of Insecurity and Turkish Kurdish International Migration. PhD thesis, University of Sheffield.

Sirkeci, I. 2006. The Environment of Insecurity in Turkey and the Emigration of Turkish Kurds to Germany. Lewiston NY: The Edwin Mellen Press.

Sirkeci, I. 2009. Transnational Mobility and Conflict. Migration Letters 6(1), pp. 3-14.

Sirkeci, I., Bilecen, T., Costu, Y, Dedeoğlu, S., Kesici, M. R., Seker, B.D, Tilbe, F. and Unutulmaz, O. 2016. Little Turkey in Great Britain. London: Transnational Press London. Sirkeci, I. and Cohen, J. H. 2016. Cultures of Migration and Conflict in Contemporary Human Mobility in Turkey. European Review 24(3), pp. 381-96.

Sirkeci, I. and Esipova, N. 2013. Turkish Migration in Europe and Desire to Migrate to and from Turkey. Border Crossing (1), pp. 1-13.

Slade, C. 2014. Watching Arab Television in Europe: From Diaspora to Hybrid Citizens. Basingstoke: Palgrave Macmillan.

Smets, K. 2016. Ethnic Media, Conflict, and the Nation-state: Kurdish Broadcasting in Turkey and Europe and Mediated Nationhood. Media, Culture and Society 38(5), pp. 738-54. Smith, M. P. 2005. Transnational Urbanism Revisited. Journal of Ethnic and Migration Studies 31(2), pp. 235-44.

\section{$\mathbf{T}$}

Talle, A. 2008. Precarious Identities: Somali Women in Exile. Finnish Journal of Ethnicity and Migration 3(2), pp. 64-73.

Taylor, C. 2002. Modern Social Imaginaries. Public Culture 14(1), pp. 91-124.

Tiilikainen, M. 2003. Somali Women and Daily Islam in the Diaspora. Social Compass 50(1), pp. 59-69.

Tiilikainen, M. 2011. Failed Diaspora: Experiences of Dhaqan Celis and Mentally Ill Returnees in Somaliland. Nordic Journal of African Studies 20(1), pp. 71-89.

Timms, E. and Goksu, S. 1999. Romantic Communist: The Life and Work of Nazim Hikmet. London: Hurst Publishers. 
Tölölyan, K. 1996. Rethinking Diaspora(s): Stateless Power in the Transnational Moment. Diaspora: A Journal of Transnational Studies 5, pp. 3-36. doi:10.1353/ dsp.1996.0000.

Tölölyan, K. 2007. The Contemporary Discourse of Diaspora Studies. Comparative Studies of South Asia, Africa and the Middle East 27(3), pp. 641-55.

Trandafoiu, R. 2013. Diaspora Online: Identity Politics and Romanian Migrants. New York: Berghahn.

Trimikliniotis, N., Parsanoglou, D. and Tsianos, V. S. 2015. Mobile Commons, Migrant Digitalities and the Right to the City. Basingstoke: Palgrave Macmillan.

Tüleylioğlu, O. 2013. Kahramanmaras Katliami. Ugur Mumcu Arastirmaci Gazetecilik Vakfi.

\section{$\mathbf{Y}$}

Yeğen, M. 2007.Turkish nationalism and the Kurdish question. Ethnic and Racial Studies, 30:1, pp. 119-151.

Yukleyen, A. 2009. State Policies and Islam in Europe: Milli Görüş in Germany and the Netherlands. Journal of Ethnic and Migration Studies 36(3), pp. 445-463.

Yuval-Davis, N., Wemyss, G. and Cassidy, K. 2019. Bordering. Cambridge: Polity Press.

$\mathbf{U}$

UNHCR. 2008. Global Trends: Refugees, Asylum-seekers, Returnees, Internally Displaced and Stateless Persons. Available at: < https://www.unhcr.org/4852366f2.pdf > [Accessed on 26 October 2020].

Unutulmaz, K. O. 2014. Football and Immigrant Communities: Transnational Diaspora Politics, Identities, and Integration in Turkish-speaking Ethnic Football in London. PhD thesis, University of Oxford.

\section{V}

Venn, C. 2000. Occidentalism: Modernity and Subjectivity. London: Sage Publications. Vertovec, S. 2001. Transnationalism and Identity. Journal of Ethnic and Migration Studies 27(4), pp. 573-82. DOI: 10.1080/13691830120090386.

W 
Wang, M. 2014. The West as the Other: A Genealogy of Chinese Occidentalism. Hong Kong: Chinese University Press.

Werbner, P. 1999. Global Pathways: Working Class Cosmopolitans and the Creation of Transnational Ethnic Worlds. Social Anthropology 7(1), pp. 17-35.

Werbner, P. 2006. Understanding Vernacular Cosmopolitanism. Anthropology News. May 2006. Available at:

〈https://pdfs.semanticscholar.org/6ca3/93065daeec557037cc98b9ab33bd056f6059.pdf>

[Accessed on 4 February 2019].

Werbner, P. 2009. Revisiting the UK Muslim Diasporic Public Sphere at a Time of Terror:

From Local (Benign) Invisible Spaces to Seditious Conspiratorial Spaces and the "Failure of Multiculturalism” Discourse. South Asian Diaspora 1(1), pp. 19-45.

Werbner, P. 2015. Introduction: The Dialectics of Cultural hybridity. In P. Werbner, T. Madood, and H. Bhabha (Eds.), Debating Cultural Hybridity: Multicultural Identities and the Politics of Anti-racism. London: Zed Books, pp. 1-26.

Wimmer, A. and Schiller, N. G. 2002. Methodological Nationalism and Beyond: Nation-state Building, Migration and the Social Sciences. Global Networks 2(4), pp. 301-34. DOI: 10.1111/ 1471-0374.00043.

Wimmer, A. and Schiller, N. G. 2003. Methodological Nationalism, the Social Sciences, and the Study of Migration: An Essay in Historical Epistemology. International Migration Review 37(3), pp. 576-561. 


\section{Appendices}

Appendix 1. Interviewees' Information (with Pseudonyms)

\section{Turkish Community}

\begin{tabular}{|l|l|}
\hline Name & Age \\
\hline Beren & 40 \\
\hline Buse & 26 \\
\hline Ceren & 23 \\
\hline Ceyda & 44 \\
\hline Clara & 21 \\
\hline Duygu & 31 \\
\hline Hatice & 41 \\
\hline Kader & 19 \\
\hline Merve & 48 \\
\hline Nur & 38 \\
\hline Nuriye & 47 \\
\hline Özen & 25 \\
\hline Sema & 35 \\
\hline Seran & 25 \\
\hline Serra & 33 \\
\hline Sertap & 40 \\
\hline Sevgi & 27 \\
\hline Sevil & 26 \\
\hline Zehra & 37 \\
\hline Zerrin & 46 \\
\hline
\end{tabular}

Somali Community

\begin{tabular}{|l|l|}
\hline Name & Age \\
\hline Aliya & 27 \\
\hline Rada & 42 \\
\hline
\end{tabular}




\begin{tabular}{|l|l|}
\hline Asha & 22 \\
\hline Ashakayf & 25 \\
\hline Asia & 46 \\
\hline Faduma & 46 \\
\hline Hamada & 27 \\
\hline Hawa & 40 \\
\hline Hayat & 40 \\
\hline Hibaq & 48 \\
\hline Idil & 25 \\
\hline Ifrah & 48 \\
\hline Isra & 23 \\
\hline Khadra & 49 \\
\hline Ladan & 56 \\
\hline Roukiya & 28 \\
\hline Sagal & 20 \\
\hline Sahra & 26 \\
\hline Sulekha & 40 \\
\hline Zainab & 24 \\
\hline
\end{tabular}

\section{Romanian Community}

\begin{tabular}{|l|l|}
\hline Name & Age \\
\hline Alina & 39 \\
\hline Alexandra & 24 \\
\hline Ana & 36 \\
\hline Andreea & 25 \\
\hline Andriana & 29 \\
\hline Christina & 35 \\
\hline Daniela & 48 \\
\hline Daniella & 37 \\
\hline Denisa & 28 \\
\hline Denisa & 25 \\
\hline
\end{tabular}




\begin{tabular}{|l|l|}
\hline Domnica & 31 \\
\hline Dora & 38 \\
\hline Elena & 29 \\
\hline Ioana & 31 \\
\hline Irina & 26 \\
\hline Larisa & 46 \\
\hline Lilliana & 55 \\
\hline Maria & 36 \\
\hline Olga & 38 \\
\hline Veronica & 48 \\
\hline
\end{tabular}




\section{Appendix 2. Consent Form}

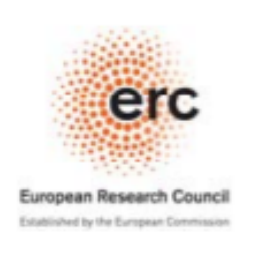

Utrecht University

\section{CONSENT FORM}

We request your participation in an international study which focuses on the use of internet and transnational connections. The study called CONNECTINGEUROPE is carried out by Prof. Sandra Ponzanesi, a scholar from the Netherlands and her team. This study is part of an international research project funded by the European Union with an ERC consolidator grant, granted for the period 2016-2021. I am working on this project at Utrecht University in the Netherlands, with a team composed of $3 \mathrm{PhDs}$, a postdoc and a Principal Investigator, who do research in different countries (Netherlands, UK, Italy, Somalia, Turkey, and Romania).

- The overall topics of the interview(s) will cover your use of digital communications technologies and your everyday life experiences with relation to migration and the city in which you live. If this interview is recorded, this will be agreed with you before beginning the recording.

- If at any point during the interview you prefer not to answer any of the questions for any reason, or you prefer to stop the recording or the interview, please indicate this.

- If you feel the need to amend some of your interview responses after the interview, you are welcome to contact the interviewer about this.

- A selection of your responses may be used by the researcher and the project team for various academic publications.

- Access to the data will be limited to the research team only.

— With your agreement, we would welcome discussing your online postings and/or phone apps with you.

- If we find any of the material you post online useful for our research, we will make follow-up agreements with you about collecting and using it in the future. None of this material will be used for publication without your consent. 
- Your personal identity will be kept confidential unless you specifically request to have your real name associated with your responses.

We estimate that the interview will take approximately 1 hour. If you have any complaints, you can contact Professor Sandra Ponzanesi, email: $\underline{\text { S.Ponzanesi@uu.nl }}$

Sign if you give consent:

Name

Signature

Researcher:

Name

Signature 


\section{Appendix 3. Individual Semi-structured Interview Topic Guide}

\section{Topics to be covered}

-Relation to, and experience with, migration

-Experience of living in London

-Kinds of digital media and internet usage practices

-Other kinds of everyday media practices

-Experiences with gender roles

-Imaginations, ideas, and experiences with life in Britain

-Imaginations, ideas, and experiences with life in Europe

-Opinions on cultural identity

-Relationships with people and places in country they migrated from

\section{Introduction}

-Self-introduction and explaining the research project and aims

-Answering any questions about the researcher or the research project

-Consent

\section{$\underline{\text { Kinds of questions to be covered }}$}

-Warm-up questions:

E.g., Why did you migrate to London? How would you describe the experience of settling in London? Do you foresee yourself living in London or anywhere in the UK in the future?

-City-related questions:

E.g., What is the most pleasant/difficult thing about living in London? What are the most important places in the city for you, and why? How would you describe a typical day of yours in London? Can you tell me how you feel about living in your neighborhood?

-Media-related questions:

E.g., What is your usual way of staying in touch with loved ones abroad? What is a website or an app you typically visit/ use in daily life? Could you draw up a map of the 
apps/websites you use/visit on daily basis? Why are they important to you? What kind of things do you like to share/post/engage with online? What is the most memorable moment in which you used a website or an app?

-Terminology questions:

E.g., How would you define your (cultural) identity? What kind of words you would use to define cultural identity? Tell me about a moment/context when you felt the need to claim your cultural or national identity. Do you ever talk about Brexit with people close to you? How would you describe being British and/or European? What does the category of British/European mean to you? Have you ever encountered a moment/experience that made you claim your identity as a woman?

\section{Closing}

-Is there anything would you like to add to our interview?

-Do you have any further questions for me?

-Acknowledgements and presenting a voucher as a token of appreciation. 


\section{Appendix 4. Organisations that Helped with Participant Recruitment and Observation}

\begin{tabular}{|l|}
\hline Romanian Women UK \\
\hline Brit-Ru Consultancy \\
\hline HAYA Community Centre \\
\hline London Alevi Cultural Centre \\
\hline Milli Görüş \\
\hline Women's Platform UK \\
\hline
\end{tabular}

\section{Short biography}

Melis Mevsimler was born in Nicosia, Cyprus, on 29 March 1992. In 2014, she obtained her BSc degree in Politics and International Relations from University of Bath, the United Kingdom. In 2015, she obtained her MSc degree in Media, Communication and Development from London School of Economics and Political Science (LSE), the United Kingdom. In 2016, she was appointed to carry out her doctoral research project as part of ERC Project Digital Crossings in Europe: Gender, Diaspora and Belonging (ConnectingEurope) based at the Media and Cultural Studies Department of Utrecht University, the Netherlands. Melis was supervised by the principal investigator of the project, Prof. Sandra Ponzanesi (Utrecht University, the Netherlands), Prof. Myria Georgiou (LSE, the United Kingdom), and Dr Koen Leurs (Utrecht University, the Netherlands). During her PhD, she was the young scholars' representative of the Diaspora, Migration and the Media (DMM) section of the European Communication Research and Education Association (ECREA). As part of her role as the young scholars' representative, she organised two workshops for $\mathrm{PhD}$ candidates of the DDM section in Bilbao, Basque Country, Spain, in 2017, and Belgium, Brussels, in 2019. She also attended the doctoral research programme of the LSE's Media and Communications Department for one academic term between September 2017 and January 2018, as a visiting student.

Alinejad, D., Candidatu, L. I., Mevsimler, M., Minchilli, C., Ponzanesi, S. and van der Vlist, F. N. 2019. Diaspora and Mapping Methodologies: Tracing Transnational Digital Connections with "Mattering Maps". Global Networks 19(1), pp. 21-43. 
Leurs, K. H. A., Smets, K., Agirreazkuenaga, I. and Mevsimler, M. 2020. The Politics and Poetics of Migrant Narratives. European Journal of Cultural Studies, 23 (5). pp. 1-19.

Mevsimler, M. and Ponzanesi, S. 2017. Mediating Migration. Feminist Media Studies 17(4), pp. 695-97. 